(C) 2018. This manuscript version is made available under the CC-BY-NC-ND 4.0 license http:// creativecommons.org/licenses/by-nc-nd/4.0/

\title{
The low-temperature thermo-tectonic evolution of the western Tian
}

\section{Shan, Uzbekistan}

\author{
Gilby Jepson*1, Stijn Glorie ${ }^{1}$, Dmitry Konopelko ${ }^{2,3}$, Rustam Mirkamalov ${ }^{4}$, Martin Danišík ${ }^{5}$, \\ and Alan S. Collins ${ }^{1}$ \\ ${ }^{1}$ Centre for Tectonics, Resources, and Exploration (TRaX, Department of Earth Sciences, The University of \\ Adelaide, 5005, Australia. \\ ${ }^{2}$ Saint Petersburg State University, 7/9 University Embankment, SPb 199034, Russia. \\ ${ }^{3}$ Novosibirsk State University, 2 Pirogova St., Novosibirsk, 630090, Russia. \\ ${ }^{4}$ State Committee of the Republic of Uzbekistan on Geology and Mineral Resources, Tashkent, Uzbekistan. \\ ${ }^{5}$ John de Laeter Centre, TIGeR, School of Earth and Planetary Sciences, Curtin University, Perth, 6846, \\ Australia.
}

Accepted on: August 24, 2018

\section{Key Points}

The Uzbek western Tian Shan underwent three discrete periods of exhumation in the MesozoicCenozoic.

In the Cretaceous, rapid exhumation is focused only in the core of relict suture zones or major faults.

The Cretaceous Uzbek Tian Shan landscape developed as a series of parallel linear mountain belts.

\begin{abstract}
The Kyzylkum-Nurata region represents a key area in understanding the tectonic evolution of the western Tian Shan. In this study, we present new thermochronological data (apatite fission track

*corresponding author (gilby.jepson@adelaide.edu.au)
\end{abstract}


and apatite (U-Th-Sm)/He) and associated thermal history models for 45 igneous samples from the Kyzylkum-Nurata Segment of South Tian Shan on the territory of Uzbekistan and Tajikistan. Our data show that the Kyzylkum-Nurata Segment experienced a multi-phase Mesozoic thermal history that differs from previously studied segments of the Tian Shan. A Triassic ( 220-200 Ma) cooling signal is widespread throughout the Tian Shan and is interpreted as being associated with exhumation following the closure of the Palaeo-Asian Ocean. Following this period of fast cooling, the Kyzylkum-Nurata Segment experienced a period of slow cooling and erosion in the Early Jurassic ( 190-160 Ma). However, in contrast to other parts of the Tian Shan, our study area preserves evidence for rapid cooling during the Late Jurassic-Early Cretaceous ( 160-120). Given that this rapid cooling signal was only recorded for samples in association with major structures (e.g., relic suture-shear zones), we interpret this event as a period of fault reactivation related with tectonic processes at the Eurasian margin of the Tethys Ocean. Subsequently, the Late Cretaceous-early Palaeogene ( 100-50 Ma) is characterised by slow cooling and erosion. Since the late Palaeogene, the basement of the Tian Shan experienced cooling related to the India-Eurasia collision. The thermal signal of this collision has been extensively recorded in the high-altitude Kyrgyz Tian Shan. Within the low-relief Kyzylkum-Nurata Segment, this Cenozoic overprint is not recorded, allowing for a detailed assessment of the Mesozoic thermal and landscape evolution of the western Tian Shan. Our study demonstrates that the Cretaceous Uzbek Tian Shan was characterised by a series of parallel, linear mountain belts that formed along suture zones during fault reactivation.

\section{Introduction}

Central Asia hosts one of the world's largest active orogen, the intracontinental mountain range of the Tian Shan. The Tian Shan provides an excellent natural laboratory for investigating the impact of marginal tectonic processes on the continental interior. The Tian Shan is situated to the north of the active Cenozoic continental margin collisional orogenic belts of the Himalaya, Pamir, and Tibet, and south of the Palaeozoic orogens of Kazakhstan and Mongolia (Brookfield 2000, Alexeiev et al. 2009). The ancestral Tian Shan orogen formed during the Palaeozoic due to the accretion of several microcontinents and island arcs to the southern margin of Palaeo-Kazakhstan (Windley et al. 2007, Biske \& Seltmann 2010, Xiao et al. 2013, Burtman 2015, Konopelko et al. 2017a). Throughout the Mesozoic and Cenozoic, progressive ocean closure along the southern margin of Eurasia generated regional deformation and the reactivation of existing structures (Bullen et al. 2001, 2003, De Grave et al. 2007, Glorie et al. 2010, 2011, Jepson et al. 2018). As a result, these intracontinental structures in the Tian Shan have been the focus of many geo- and thermochronological studies in order to generate 
a model for the formation of the Tian Shan intracontinental orogenic system (e.g. Sobel \& Dumitru 1997, Dumitru et al. 2001, Bullen et al. 2001, De Grave et al. 2007)

Previous thermochronological studies of the Tian Shan have identified several major periods of Mesozoic exhumation-related basement cooling, which have been interpreted to be related to exhumation in response to the collision of Cimmerian blocks with the southern Eurasian continental margin (e.g. Sobel et al. 2006b, Glorie et al. 2011, De Grave et al. 2013, Macaulay et al. 2014, Glorie \& De Grave 2016). In addition, thermochronometers have been successful in identifying the widespread presence of Cenozoic cooling, which has been interpreted as exhumation due to the ongoing India-Eurasia collision (e.g. Sobel et al. 2006a, De Grave et al. 2012, Bande et al. 2017b, Käßner et al. 2017b, Nachtergaele et al. 2017, Jepson et al. 2018). The majority of previous thermochronological studies have focused on high relief areas within the core of the Tian Shan. However, there has been little work done on the eastern and western extremities of this vast mountain range. In this study we specifically target the westernmost extremity of the Tian Shan in Uzbekistan in order to provide constraints on the thermo-tectonic and landscape evolution of this largely unstudied, low relief segment of the Tian Shan. Filling this gap in the thermochronology allows for a more accurately constrained model on the tectonic evolution of the Tian Shan intracontinental system as a whole. In this study, we present new apatite fission track $(\mathrm{AFT})$ and apatite $(\mathrm{U}-\mathrm{Th}-\mathrm{Sm}) / \mathrm{He}(\mathrm{AHe})$ ages from the westernmost extent of the Tian Shan, termed the Kyzylkum-Nurata Segment of the South Tian Shan (Figure 1), specifically targeting the Gissar, Zeravshan, and South Tian Shan (STS) sutures in western Uzbekistan (Figure 3, Burtman 2015, Dolgopolova et al. 2017, Konopelko et al. 2017a).

\section{Geological Background}

The Uzbek western Tian Shan formed during the Palaeozoic, due to the collision between Precambrian microcontinents and island-arcs in the south with the Palaeozoic Kazakhstan continent to the north, as a response to the progressive closure of the Palaeo-Asian Ocean (Windley et al. 2007, Biske \& Seltmann 2010, Xiao et al. 2013, Dolgopolova et al. 2017). The Tian Shan can be subdivided into three terranes: (1) the Northern Tian Shan (NTS), representing the deformed margin of the Palaeo-Kazakhstan microcontinent; (2) the Middle Tian Shan (MTS), comprised of Precambrian microcontinental slivers, such as the Karakum, and superimposed island-arcs, such as the Chatkal-Kurama; and (3) the Southern 


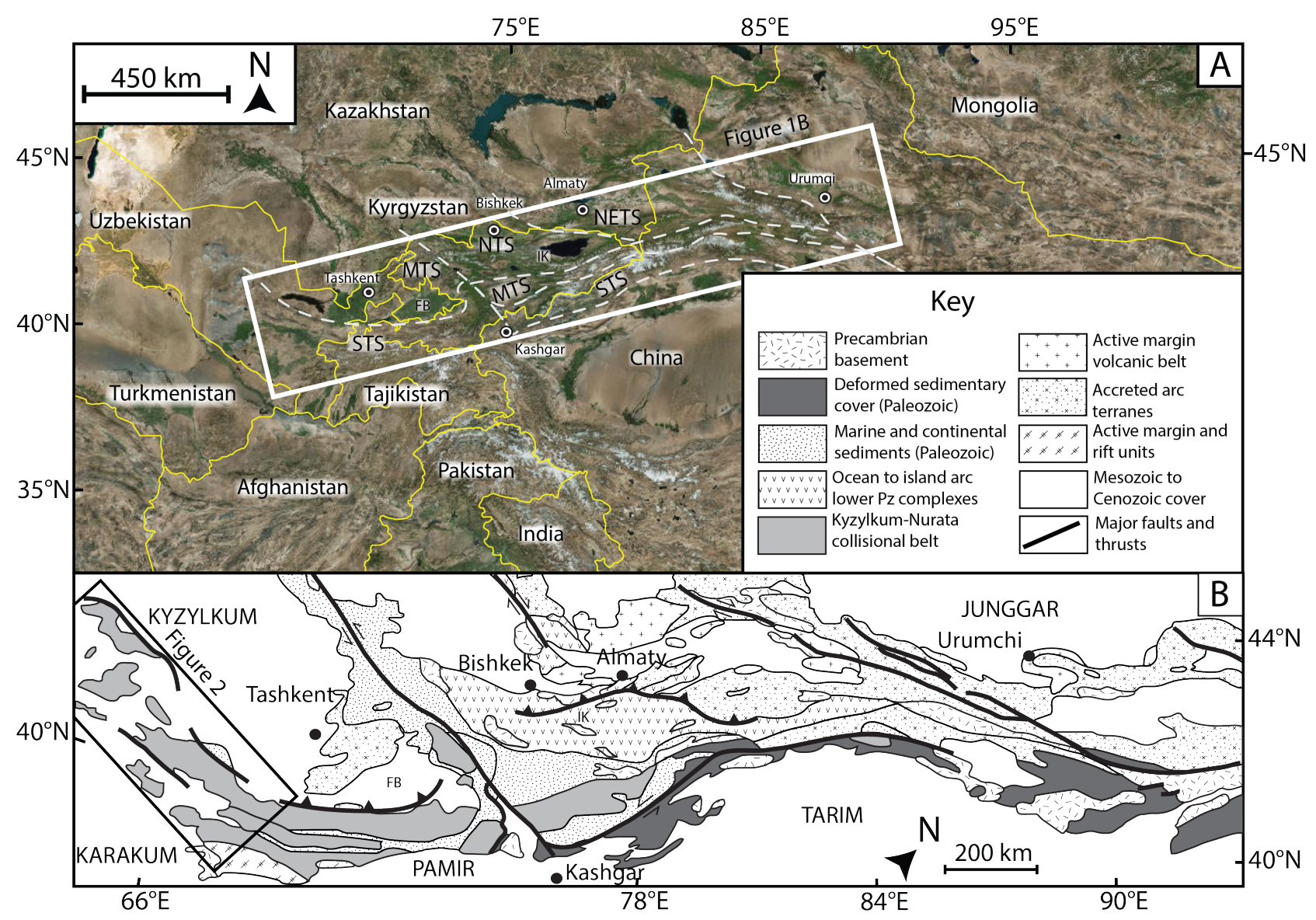

Figure 1: (a) Location map of the Tian Shan split into its main components; NETS is the north-eastern Tian Shan, NTS is the North Tian Shan, MTS is the Middle Tian Shan, and STS is the South Tian Shan (after Glorie et al. 2011). FB is the Fergana Basin, and IK is lake Issyk-Kul. (b) Simplified map of the Palaeozoic Tian Shan outlining study area (after Biske \& Seltmann 2010). 
Tian Shan (STS), a late Palaeozoic fold-and-thrust belt (Figure 1, Biske \& Seltmann 2010, Burtman 2015, Konopelko et al. 2017a).

The STS is traditionally subdivided into four segments from west to east; the Kyzylkum-Nurata Segment, the Gissar Segment, the Alai Segment, and the Kokshaal Segment. Our study area, the Kyzylkum-Nurata Segment (Dolgopolova et al. 2017), is located in the westernmost extent of the South Tian Shan (STS, Figure 1). The Kyzylkum-Nurata Segment formed due to the closure of the PaleoAsian Ocean in the Late Carboniferous, accreting the Kyzylkum-Alai terranes onto the Middle Tian Shan, generating the South Tian Shan fold belt (Burtman 2015, Konopelko et al. 2017a, Dolgopolova et al. 2017). Prior to the closure of the Paleo-Asian Ocean, the Kyzylkum-Alai terrane developed as the southern passive margin of the Paleo-Asian Ocean since the Neoproterozoic (Konopelko et al. 2015, Kempe et al. 2016, Dolgopolova et al. 2017). The Turkestan ocean closed in the CarboniferousPermian, accreting the Kyzylkum-Alai terrane to the margin of the Middle Tian Shan which formed the South Tian Shan Suture, this accretion initiated the broadly synchronous closure of the Vashan and Gissar Basins, which had formed due to rifting in the Karakum continent further south (Figure 2). The closure of the Vashan Basin formed the Zeravshan suture (Figure 3, Dolgopolova et al. 2017), while the short-lived Gissar Basin was associated with rift and subduction related mamatism during the Carboniferous, and its closure resulted in the final amalgamation of the Gissar Segment to the South Tian Shan (Figure 2, Burtman 1975, Biske \& Seltmann 2010, Seltmann et al. 2011, Konopelko et al. 2017a, 2018). The synchronous closure of the Vashan, Gissar, and Turkestan oceanic basins led to the emplacement of voluminous post-collisional granitoid magmatism (Figure 2, Biske \& Seltmann 2010, Seltmann et al. 2011, Käßner et al. 2017a). The Late Palaeozoic ocean closure and collision resulted in the southward thrusting of carbonate platforms, forming a large nappe system (Dolgopolova et al. 2017). This oceanic closure was subsequently followed by a period of post-collisional granitoid magmatism throughout the Kyzylkum-Nurata Segment and the greater South Tian Shan during the early Permian (Konopelko et al. 2011, 2015, Kempe et al. 2016, Konopelko et al. 2017a, Dolgopolova et al. 2017). During the Late Permian-Early Triassic, the western Tian Shan experienced uplift and erosion resulting in a notable absence of Triassic sediments over such an extensive area (Figure 2, McCann 2016b).

During the Mesozoic, the South Tian Shan experienced punctuated episodes of deformation and reactivation (e.g. De Grave et al. 2007, Jolivet et al. 2010, 2013, De Grave et al. 2013). The closure of the Palaeo-Tethys Ocean during the Mesozoic initiated the accretion of Cimmerian continental 


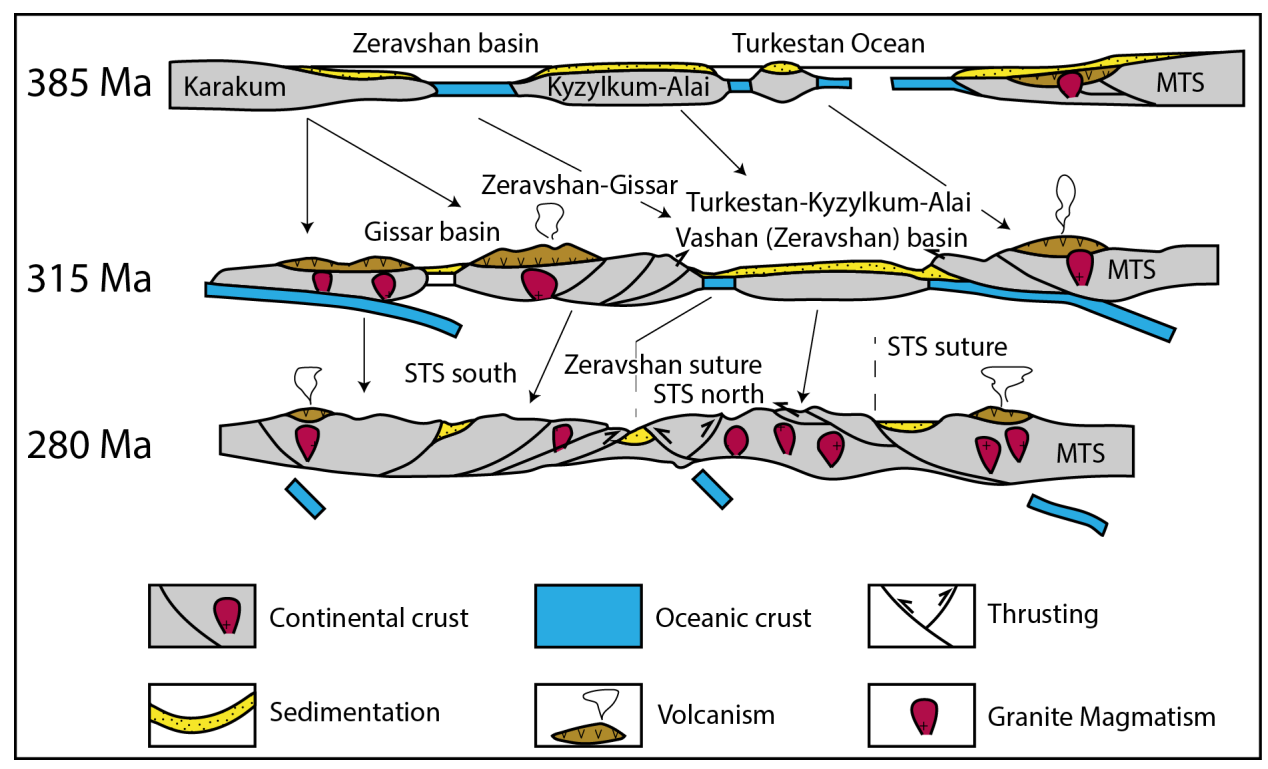

Figure 2: A schematic geodynamic model of the Palaeozoic western Tian Shan, modified after Dolgopolova et al. (2017)

fragments with the southern margin of Laurasia, causing widespread deformation (e.g. De Grave et al. 2007, Jolivet et al. 2010, Glorie et al. 2011, Xiao et al. 2013). Known collectively as the Cimmerian Orogeny, these events include the collisions of the Qiangtang block during the Late Triassic-Early Jurassic, the Lhasa block during the Late Jurassic-Early Cretaceous, and the Kohistan-Ladakh arc during the Late Cretaceous (e.g Yin \& Harrison 2000, Angiolini et al. 2013, De Grave et al. 2013, Jolivet et al. 2013, Glorie \& De Grave 2016, Käßner et al. 2017a). The series of collisions and other tectonic processes at the Tethyan margin are thought to have caused exhumation induced basement cooling within the Tian Shan and have been recorded using multi-chronometric methods (Glorie et al. 2010, Jolivet et al. 2010, De Grave et al. 2013, Jolivet et al. 2013, Gillespie et al. 2017). More specifically, the Tian Shan has been shown to have experienced two main deformation events in the Mesozoic. A rapid Triassic-Early Jurassic ( 230-200 Ma) thermo-tectonic cooling that is recorded regionally throughout the Tian Shan and is thought to be related with the final closure of the Palaeo-Asian Ocean at $\sim 250$ Ma (Xiao et al. 2013) and/or the Qiangtang collision at 180 Ma (e.g. Ratschbacher et al. 2003, Robinson 2015). Followed by a period of rapid cooling in the Cretaceous, recorded by samples taken in the vicinity to relic suture-shear zones that dissect the Tian Shan (Figure 3, e.g. Glorie et al. 2010, De Grave et al. 2013, De Pelsmaeker et al. 2015, Nachtergaele et al. 2017). In contrast, away from the suture-shear zones, the Tian Shan as a whole experienced slow cooling and peneplanation during the Cretaceous period (Jolivet et al. 2010, Macaulay et al. 2014). The extent of this period of Cretaceous fault reactivation is particularly not well understood for the western Tian Shan and is the main target 
of this study.

The ongoing closure of the Neo-Tethys Ocean culminated in the collision of the continent of India with the southern margin of Eurasia during the Cenozoic (e.g. Beck et al. 1995, Aitchison et al. 2007, Najman et al. 2010, van Hinsbergen et al. 2011). The India-Eurasia collision caused widespread deformation and rapid exhumation in the Tian Shan (e.g. Sobel et al. 2006a, De Grave et al. 2007, Jolivet et al. 2010, Macaulay et al. 2014, Bande et al. 2017b). In the South Tian Shan, previous studies have identified initiation of exhumation at $\sim 30-20$ Ma and accelerating of exhumation since $\sim 15-10 \mathrm{Ma}$, which correlates with periods of Pamir convergence (e.g. De Grave et al. 2012, De Pelsmaeker et al. 2015, Käßner et al. 2017b, Rutte et al. 2017, Nachtergaele et al. 2017, Jepson et al. 2018).

\section{Methodology}

In this study, new thermochronological data for 45 granitoid rock samples from the western extent of the South Tian Shan are presented (Figure 3). Two different thermochronological methods were applied; (1) apatite fission track (partial annealing zone $\sim 120-60^{\circ} \mathrm{C}$, Green et al. 1986), and (2) apatite (U-Th-Sm)/He dating (partial retention zone $\sim 80-40^{\circ} \mathrm{C}$, Zeitler et al. 1987).

\subsection{Apatite Fission Track}

The apatite fission track method (AFT) is based on the temperature dependent annealing of mineral lattice damage features, known as 'fission tracks', which are created by the spontaneous fission decay of ${ }^{238} \mathrm{U}$ (e.g. Fleischer et al. 1975, Wagner \& Van den haute 1992, Gleadow et al. 2015). Fission tracks record the thermal history of a rock sample through the apatite partial annealing zone (APAZ) of $\sim 120-60^{\circ} \mathrm{C}$ (Green et al. 1986). Apatite grains were picked and mounted in epoxy resin, then polished to expose internal sections, and were subsequently chemically etched in a $5 \mathrm{M} \mathrm{HNO}_{3}$ solution for $20 \mathrm{~s}$ at $20^{\circ} \mathrm{C}$ to reveal the natural spontaneous fission tracks (Gleadow et al. 2002). Fission track analysis was performed at The University of Adelaide using an Autoscan system. The concentration of uranium $\left({ }^{238} \mathrm{U}\right)$ and chlorine $\left({ }^{35} \mathrm{Cl}\right)$ of each apatite grain was measured using Laser Ablation-Inductively Coupled Plasma-Mass Spectrometry. Data reduction was performed in Iolite using the Trace Elements DRS (data reduction scheme, Paton et al. 2011). Instrumental drift correction was carried out using NIST610 as an external standard, and elemental concentrations were calculated using ${ }^{43} \mathrm{Ca}$ as the internal standard (Pearce et al. 1997, Vermeesch 2017). Age calculation was carried out as described 


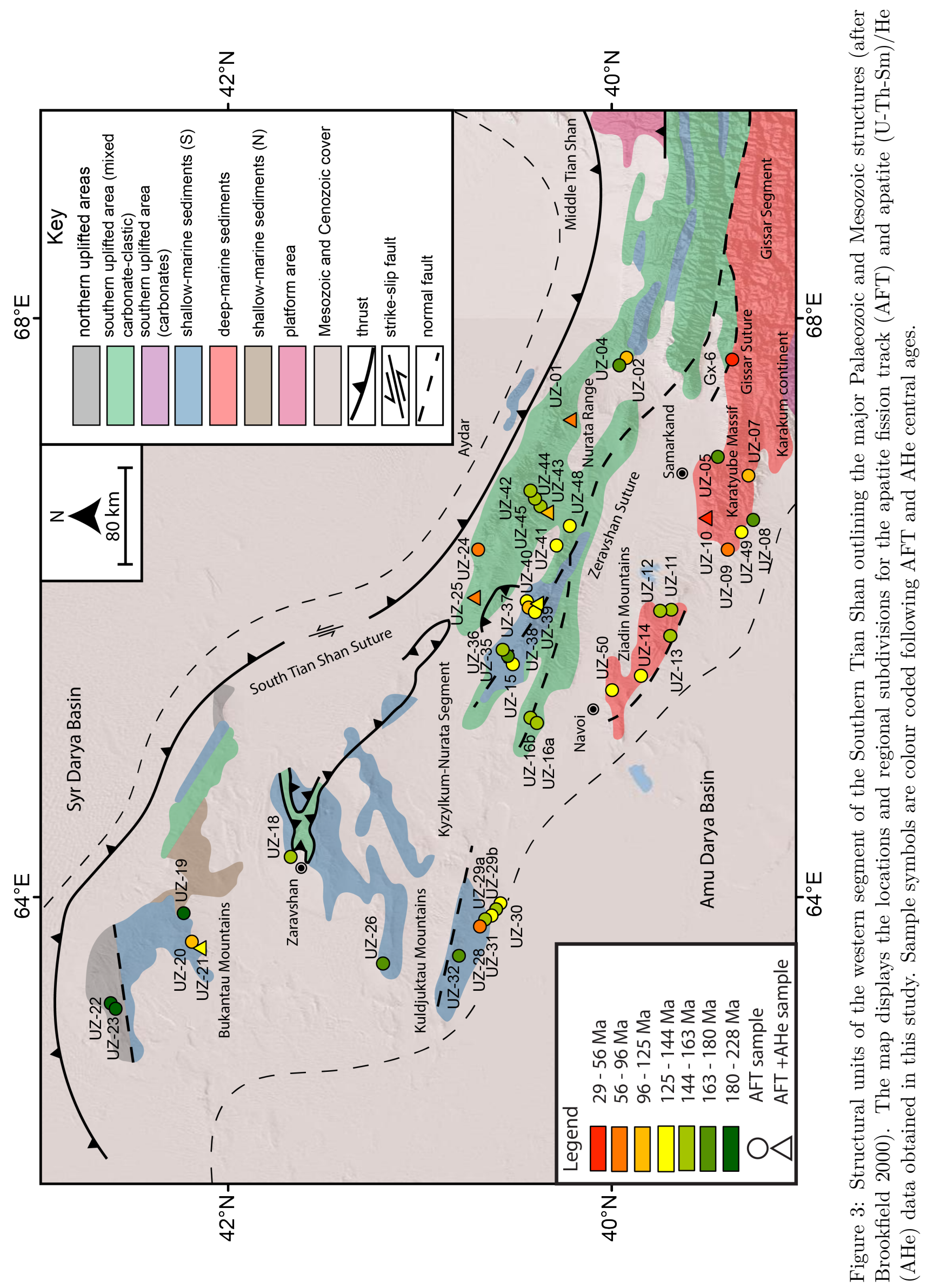


in Hasebe et al. (2004) and De Grave et al. (2012), using the Durango apatite (McDowell et al. 2005) to perform a zeta calibration (Vermeesch 2017). For a detailed methodology see Glorie et al. (2017) and Gillespie et al. (2017).

\subsection{Apatite (U-Th-Sm)/He}

The (U-Th-Sm)/He thermochronometer is based on the accumulation and thermal diffusivity of radiogenic ${ }^{4} \mathrm{He}$. Partial retention of $\mathrm{He}$ in apatite occurs between $\sim 80-40^{\circ} \mathrm{C}$ making it valuable for constraining the most recent basement cooling event (Zeitler et al. 1987, Farley 2002). The apatite (UTh-Sm)/He analyses for this study were undertaken at the John de Laeter Centre, Curtin University and followed the protocols described in Danišík et al. (2012).

Apatite crystals were hand-picked following the recommendations of Farley (2002), photographed and measured for physical dimensions, before being loaded in Pt microtubes. Helium $\left({ }^{4} \mathrm{He}\right)$ was extracted for apatite at $\sim 900^{\circ} \mathrm{C}$, under ultra-high vacuum using a diode laser and measured by isotope dilution on a Pfeiffer Prisma QMS-200 mass spectrometer. A "re-extract" was run after each sample to verify complete outgassing of the crystals. Helium gas results were corrected for blank, determined by heating empty microtubes using the same procedure. After the ${ }^{4} \mathrm{He}$ measurements, tubes containing the crystals were retrieved from the laser cell, spiked with ${ }^{235} \mathrm{U}$ and ${ }^{230} \mathrm{Th}$ and dissolved. Sample, blank, and spiked standard solutions were analysed by isotope dilution for ${ }^{238} \mathrm{U}$ and ${ }^{232} \mathrm{Th}$, and by external calibration for ${ }^{147} \mathrm{Sm}$ on an Agilent 7500 ICP-MS. The total analytical uncertainty (TAU) was calculated as a square root of sum of squares of uncertainty on He and weighted uncertainties on U, Th, Sm and He measurements, and is typically $<5 \%(1 \sigma)$. The raw (U-Th-Sm)/He ages were corrected for alpha ejection (Ft correction) after Farley et al. (1996), whereby a homogenous distribution of U, Th and Sm was assumed for the crystals. Replicate analyses of internal standard Durango apatite $(\mathrm{n}=$ 10) measured over the period of this study, yielded mean $(\mathrm{U}-\mathrm{Th}-\mathrm{Sm}) / \mathrm{He}$ ages of $31.9 \pm 1.9 \mathrm{Ma}(1 \sigma)$, consistent with the reference Durango (U-Th-Sm)/He age of $31.02 \pm 1.01 \mathrm{Ma}$ (McDowell et al. 2005).

\subsection{Thermal History Modelling}

Thermal history models were produced for samples using their mean track length (MTL), AFT ages, AHe ages, and confined track length distributions. The QTQt software (version 5.6.0) was applied, which uses Bayesian trans-dimensional Markov Chain Monte Carlo statistics to determine models for 
the cooling pathway of the sample (Gallagher 2012). An initial unconstrained run is performed to explore the statistical space, followed by adjustments to the search parameters or the addition of geological constraints where necessary. This approach follows the Bayesian philosophy of the software, which seeks to minimize the complexity of the model by statistical means. Many iterations $(>>10,000)$ are run to generate a range of models that create a probability distribution, from which individual models can be selected, including the maximum likelihood and "expected" (weighted mean) paths. The range of the general prior was set as $t=\mathrm{AFT}$ central age \pm AFT central age, temperature $=70$ $\pm 70^{\circ} \mathrm{C}$. Acceptance rates for models were between 0.2 and 0.6 and birthdeath ratio was $\sim 1$. Spherical geometry and the radiation damage model of Gautheron et al. (2009) were used for modeling AHe data. The annealing model from Ketcham et al. (2007) was used for fission track data with $\mathrm{D}_{\text {par }}$ as the kinetic parameter. More details on the modelling approach can be found in Gallagher (2012) and Gillespie et al. (2017).

\section{Results}

The Kyzylkum-Nurata Segment hosts several relict suture zones, the South Tian Shan Suture, the Zeravshan suture, and the Gissar suture (Figure 3, Burtman 1975, Biske \& Seltmann 2010, Seltmann et al. 2011, Dolgopolova et al. 2017). In this study, forty-five granitoid samples were analysed from outcropping rocks along, and away from, the suture zones. The samples yielded a range of ages from Triassic to Palaeogene, from both AFT and AHe methods (Figure 3). For a more thorough description, samples have been subdivided into six geographical clusters of samples based on regional proximity to each other. The groups are named after the ranges or nearby features that they were sourced from: (1) the Bukantau Mountains, (2) the Kuldjuktau Mountains, (3) the Nurata Range, (4) Aydar, (5) the Ziadin Mountains, and (6) the Karatyube Massif (Figure 3). Mean track lengths are referred to their relative length following the outline established in Figure 5, with samples that produce MTLs 12.9-13.5 $\mu \mathrm{m}$ refered to as "long", MTLs of 12.6-12.8 $\mu \mathrm{m}$ are "moderate", and MTLs of 11.4-12.5 $\mu \mathrm{m}$ are refered to as "short". Tables 4.1 and 4.2 summarise the AFT and AHe data. Detailed tables and figures for all single-grain AFT, mean track length (MTL) data, individual thermal history models, and modelling parameters are available in Supplementary files (Supplementary files 1, 2, 3, and 4). 
Table 1: Apatite fission track data: $\mathrm{n}$ is the number of grains analysed per sample and \# of lengths is the number of confined track lengths identified in each sample. Age is the central age calculated for each sample, and P Age is the pooled age of each sample. Samples in italics represent samples with fewer than 40 confined tracks, and a represented as dashed lines in the thermal history modelling.

\begin{tabular}{|c|c|c|c|c|c|c|c|c|c|}
\hline Sample & Lat & Long & Elev & $n$ & Age $\pm 1 \sigma$ & $\mathrm{P}$ Age $\pm 1 \sigma$ & $\#$ & MTL & $\pm 1 \sigma$ \\
\hline \multicolumn{10}{|c|}{ Bukantau Mountains } \\
\hline$U Z-18$ & 41.676 & 64.278 & 370 & 5 & $154.0 \pm 12.0$ & $151.4 \pm 13.0$ & 8 & 12.8 & 0.9 \\
\hline UZ-19 & 42.227 & 63.889 & 242 & 30 & $220.9 \pm 9.0$ & $214.1 \pm 17.0$ & 72 & 13.1 & 1.0 \\
\hline$U Z-20$ & 42.184 & 63.691 & 256 & 29 & $127.8 \pm 6.7$ & $111.8 \pm 9.6$ & 33 & 12.5 & 0.9 \\
\hline UZ-21 & 42.181 & 63.686 & 250 & 36 & $130.4 \pm 3.5$ & $126.0 \pm 10.0$ & 93 & 12.8 & 1.2 \\
\hline$U Z-22$ & 42.599 & 63.264 & 405 & 40 & $209.7 \pm 7.9$ & $202.3 \pm 18.4$ & 20 & 12.8 & 1.0 \\
\hline UZ-23 & 42.599 & 63.264 & 405 & 40 & $228.0 \pm 9.9$ & $221.1 \pm 19.9$ & 50 & 13.4 & 1.1 \\
\hline
\end{tabular}

Kuldjuktau Mountains

\begin{tabular}{|c|c|c|c|c|c|c|c|c|c|}
\hline UZ-26 & 41.200 & 63.540 & 484 & 27 & $178.0 \pm 11.0$ & $181.5 \pm 16.2$ & 49 & 11.6 & 1.2 \\
UZ-28 & 40.666 & 63.825 & 310 & 13 & $92.0 \pm 12.0$ & $98.1 \pm 9.0$ & 37 & 11.9 & 1.1 \\
UZ-29a & 40.640 & 63.887 & 310 & 37 & $125.0 \pm 3.9$ & $129.4 \pm 11.8$ & 53 & 12.9 & 1.3 \\
UZ-29b & 40.640 & 63.887 & 310 & 38 & $150.9 \pm 4.9$ & $155.1 \pm 13.8$ & 80 & 12.7 & 0.9 \\
UZ-30 & 40.642 & 63.878 & 312 & 38 & $136.6 \pm 3.9$ & $138.9 \pm 12.5$ & 48 & 12.3 & 1.3 \\
UZ-31 & 40.665 & 63.846 & 322 & 35 & $153.8 \pm 7.6$ & $152.3 \pm 10.2$ & 31 & 12.5 & 1.1 \\
UZ-32 & 40.802 & 63.594 & 409 & 28 & $180.0 \pm 9.5$ & $178.4 \pm 17.8$ & 33 & 12.2 & 1.0 \\
\hline
\end{tabular}

Aydar

\begin{tabular}{|c|c|c|c|c|c|c|c|c|c|}
\hline UZ-01 & 40.214 & 67.334 & 1092 & 33 & $83.2 \pm 6.0$ & $84.7 \pm 6.9$ & 46 & 12.4 & 1.8 \\
UZ-24 & 40.701 & 66.402 & 418 & 39 & $92.0 \pm 4.8$ & $85.1 \pm 7.5$ & 35 & 12.5 & 1.2 \\
UZ-25 & 40.724 & 66.099 & 455 & 35 & $92.6 \pm 3.8$ & $93.4 \pm 8.3$ & 94 & 12.6 & 1.1 \\
\hline
\end{tabular}

Nurata Range

\begin{tabular}{|c|c|c|c|c|c|c|c|c|c|}
\hline UZ-02 & 39.921 & 67.728 & 1012 & 28 & $114.5 \pm 9.2$ & $133.1 \pm 12.6$ & 35 & 13.5 & 1.3 \\
UZ-04 & 39.959 & 67.677 & 820 & 26 & $176.1 \pm 7.0$ & $162.8 \pm 8.8$ & 94 & 12.5 & 1.1 \\
UZ-42 & 40.400 & 66.765 & 1019 & 31 & $151.7 \pm 8.5$ & $148.8 \pm 14.1$ & 82 & 12.6 & 1.2 \\
UZ-43 & 40.357 & 66.686 & 1050 & 34 & $112.1 \pm 4.6$ & $107.6 \pm 6.9$ & 37 & 13.1 & 1.1 \\
UZ-44 & 40.366 & 66.684 & 1095 & 42 & $152.0 \pm 8.4$ & $136.0 \pm 19.5$ & 46 & 13.0 & 1.1 \\
UZ-45 & 40.390 & 66.725 & 1291 & 43 & $149.0 \pm 7.4$ & $140.6 \pm 13.4$ & 22 & 13.0 & 1.2
\end{tabular}




\begin{tabular}{|c|c|c|c|c|c|c|c|c|c|} 
UZ-15 & 40.530 & 65.628 & 578 & 40 & $139.7 \pm 6.9$ & $131.4 \pm 11.2$ & 35 & 13.0 & 1.3 \\
UZ-16a & 40.428 & 65.239 & 572 & 39 & $152.0 \pm 9.6$ & $141.6 \pm 12.3$ & 66 & 12.8 & 1.1 \\
UZ-16b & 40.428 & 65.239 & 572 & 37 & $163.3 \pm 8.0$ & $156.3 \pm 13.6$ & 35 & 12.4 & 1.0 \\
UZ-35 & 40.539 & 65.641 & 585 & 36 & $177.0 \pm 12.0$ & $166.7 \pm 16.3$ & 89 & 12.5 & 1.1 \\
UZ-36 & 40.560 & 65.669 & 506 & 38 & $160.0 \pm 10.0$ & $152.7 \pm 13.6$ & 38 & 13.0 & 1.3 \\
UZ-37 & 40.433 & 66.025 & 805 & 29 & $143.9 \pm 7.3$ & $142.3 \pm 13.2$ & 70 & 12.6 & 1.4 \\
UZ-38 & 40.404 & 65.970 & 1498 & 35 & $138.6 \pm 9.2$ & $132.6 \pm 12.4$ & 26 & 12.8 & 1.0 \\
UZ-39 & 40.401 & 66.005 & 1240 & 35 & $115.6 \pm 7.8$ & $94.8 \pm 7.8$ & 104 & 12.9 & 1.2 \\
UZ-40 & 40.417 & 66.005 & 1023 & 39 & $109.8 \pm 5.2$ & $110.2 \pm 9.8$ & 26 & 13.0 & 1.1 \\
UZ-41 & 40.291 & 66.430 & 1125 & 42 & $131.1 \pm 5.4$ & $133.8 \pm 12.0$ & 35 & 12.9 & 1.0 \\
UZ-48 & 40.220 & 66.565 & 1009 & 33 & $134.1 \pm 9.6$ & $140.0 \pm 9.4$ & 44 & 12.9 & 1.1 \\
\hline
\end{tabular}

Ziadin Mountains

\begin{tabular}{|c|c|c|c|c|c|c|c|c|c|}
\hline UZ-11 & 39.683 & 65.988 & 559 & 38 & $156.0 \pm 7.7$ & $139.1 \pm 12.5$ & 95 & 13 & 0.9 \\
UZ-12 & 39.742 & 65.978 & 708 & 41 & $154.2 \pm 6.3$ & $150.3 \pm 12.8$ & 55 & 13.2 & 1.1 \\
UZ-13 & 39.689 & 65.807 & 572 & 29 & $150.9 \pm 6.6$ & $139.1 \pm 8.4$ & 44 & 12.3 & 1.0 \\
UZ-14 & 39.845 & 65.528 & 472 & 32 & $132.8 \pm 6.1$ & $127.5 \pm 10.6$ & 16 & 12.9 & 0.9 \\
UZ-50 & 39.997 & 65.431 & 615 & 27 & $141.4 \pm 6.6$ & $129.1 \pm 11.0$ & 144 & 13.2 & 1.0 \\
\hline
\end{tabular}

Karatyube Massif

\begin{tabular}{|c|c|c|c|c|c|c|c|c|c|}
\hline UZ-05 & 39.435 & 67.043 & 923 & 31 & $177.0 \pm 11.0$ & $167.5 \pm 10.4$ & 37 & 12.7 & 1.0 \\
UZ-07 & 39.271 & 66.914 & 1206 & 41 & $124.2 \pm 3.4$ & $121.6 \pm 6.1$ & 71 & 12.5 & 1.2 \\
UZ-08 & 39.247 & 66.608 & 724 & 37 & $177.0 \pm 11.0$ & $159.8 \pm 11.9$ & 33 & 12.1 & 1.1 \\
UZ-09 & 39.382 & 66.401 & 682 & 11 & $96.6 \pm 7.8$ & $84.5 \pm 8.4$ & 18 & 12.2 & 1.5 \\
UZ-10 & 39.499 & 66.628 & 911 & 29 & $56.1 \pm 4.0$ & $52.8 \pm 5.9$ & 93 & 12 & 1.5 \\
UZ-49 & 39.309 & 66.524 & 890 & 36 & $130.3 \pm 4.4$ & $126.4 \pm 7.5$ & 66 & 12.4 & 1.4 \\
GX-6 & 39.360 & 67.717 & 1752 & 36 & $29.5 \pm 1.8$ & $30.0 \pm 2.4$ & - & - & - \\
\hline
\end{tabular}




\subsection{Apatite Fission Track}

\subsubsection{Bukantau Mountains}

The Bukantau Mountains is the northern-most extent of the Kyzylkum-Nurata Segment and lies directly on the margin of the Syr-Darya Block, and hosts the Teskuduk ophiolite complex of the South Tien Shan (Figure 3, Brookfield 2000, Dolgopolova et al. 2017). The Bukantau Mountains yielded the oldest AFT ages of all samples of the Kyzylkum-Nurata Segment, with the north-eastern samples UZ-19, UZ-22, and UZ-23 producing AFT central ages of $221 \pm 9 \mathrm{Ma}, 210 \pm 8 \mathrm{Ma}$, and 228 $\pm 10 \mathrm{Ma}$, respectively. The samples of Triassic AFT age corresponded with long to moderate MTLs of $13.1 \pm 1.0 \mu \mathrm{m}, 12.8 \pm 1.0 \mu \mathrm{m}, 13.4 \pm 1.1 \mu \mathrm{m}$, respectively. In the south-west of the Bukantau Mountains, samples UZ-18, UZ-20, and UZ-21 yield Jurassic and Cretaceous AFT ages of $154 \pm 12$ Ma, $124 \pm 7 \mathrm{Ma}$, and $130 \pm 4 \mathrm{Ma}$, and moderate MTLs of $12.8 \pm 0.9 \mu \mathrm{m}, 12.5 \pm 0.9 \mu \mathrm{m}$, and $12.8 \pm$ $1.2 \mu \mathrm{m}$, respectively (Figure 3, 5, and Table 1).

\subsubsection{Kuldjuktau Mountains}

The Kuldjuktau Mountains is the south-western most extent of both the Gissar and Zeravshan sutures, and represents the last set of outcrops of the South Tian Shan North of the Amu Darya Basin (Figure 3, Burtman 2000, McCann 2016a). Samples from the Kuldjuktau Mountains yielded Jurassic and Cretaceous AFT central ages. North of the Kuldjuktau Mountains, in the southern Tamdy mountains, sample UZ-26 yielded a Jurassic AFT central age of $178 \pm 11$ Ma, with a MTL of $11.6 \pm 1.2 \mu \mathrm{m}$. The remaining samples formed a transect across several minor faults (Figure 5). Samples UZ-29b, UZ-31, UZ-32 yielded Jurassic AFT central ages of $151 \pm 5 \mathrm{Ma}, 154 \pm 8 \mathrm{Ma}$, and $180 \pm 10 \mathrm{Ma}$, respectively. The samples of Jurassic AFT age produced moderate to short MTLs of $12.7 \pm 0.9 \mu \mathrm{m}, 12.5 \pm 1.1 \mu \mathrm{m}$, and $12.2 \pm 1.0 \mu \mathrm{m}$, respectively. Samples UZ-28, UZ-29a, and UZ-30 yielded Cretaceous AFT central ages of $92 \pm 12 \mathrm{Ma}, 125 \pm 4 \mathrm{Ma}$, and $137 \pm 4 \mathrm{Ma}$, respectively. The Cretaceous-aged samples yielded both long and short MTLs of $11.9 \pm 1.1 \mu \mathrm{m}, 12.9 \pm 1.3 \mu \mathrm{m}$, and $12.3 \pm 1.3 \mu \mathrm{m}$, respectively Figure 3, 5 and Table 1).

\subsubsection{Nurata Range}

The Nurata Range is the main segment of the South Tian Shan Suture that crops out within Uzbekistan, which extends to the Turkistan-Alai Suture in Kyrgyzstan (De Grave et al. 2012, Dolgopolova 
et al. 2017). The Nurata Range can be further divided into two subsets, the northern Nurata Range and the southern Nurata Range (Figure 3). In this study, four samples were taken along a transect in the core of the northern Nurata Range, and two samples from its extent into the Nurata-Turkestan-Alai region (Figure 1). The northern Nurata Range transect strikes from north-east (UZ-42) to south-west (UZ-43). Samples UZ-42, UZ-45, and UZ-44 yielded Jurassic AFT central ages of $152 \pm 9$ Ma, $155 \pm$ $7 \mathrm{Ma}, 152 \pm 8 \mathrm{Ma}$, receptively. From the same transect, UZ-43 yielded a Cretaceous central age of $112 \pm 5$ Ma. The transect yielded long to moderate MTLs of $12.6 \pm 1.2 \mu \mathrm{m}, 13.0 \pm 1.2 \mu \mathrm{m}$, and 13.0 $\pm 1.1 \mu \mathrm{m}$, respectively for the Jurassic samples, and $13.1 \pm 1.1 \mu \mathrm{m}$ for the Cretaceous samples. In the Turkestan-Alai segment, sample UZ-04 yielded a Jurassic AFT central age of $176 \pm 7$ Ma, and sample UZ-02 yielded a Cretaceous AFT central age of $115 \pm 9$ Ma, with MTLs of $13.5 \pm 1.3 \mu \mathrm{m}$ and $12.5 \pm$ $1.1 \mu \mathrm{m}$, respectively (Figure 3, 5 and Table 1).

The southern section of the Nurata Range represents the inferred western extent of the Zeravshan suture, which formed due to the closure of the Vashan basin in the late Palaeozoic (Dolgopolova et al. 2017). Three samples were taken along the north-western extent, two samples were taken from the south-western extent, two samples were taken from the eastern extent, and one vertical profile of four samples were obtained from the core of the southern Nurata Range (Figure 3). Across the northwestern extent, sample UZ-36, UZ-35, and UZ-15 produced AFT central ages of $160 \pm 10 \mathrm{Ma}, 177 \pm$ $12 \mathrm{Ma}$, and $140 \pm 7 \mathrm{Ma}$, with long to moderate MTLs of $13.0 \pm 1.3 \mu \mathrm{m}, 12.5 \pm 1.1 \mu \mathrm{m}$, and $13.0 \pm$ $1.3 \mu \mathrm{m}$, respectively. The two samples, UZ-16a and UZ-16b, from the south-western extent, yielded indistinguishable Jurassic AFT central ages of $152 \pm 10 \mathrm{Ma}$ and $163 \pm 8 \mathrm{Ma}$, respectively. Samples UZ-16a and UZ-16b produced MTLs of $12.8 \pm 1.1 \mu \mathrm{m}$ and $12.4 \pm 1.0 \mu \mathrm{m}$, respectively. The vertical profile in the core of the southern Nurata Range consists of four samples, from $\sim 800 \mathrm{~m}$ to $\sim 1500 \mathrm{~m}$ with a 200m sample interval, with all samples returning Cretaceous AFT central ages and relatively long MTLs. At the base of the profile, sample UZ-37 (840m) yielded an age of $144 \pm 7 \mathrm{Ma}$, sample UZ-40 $(1010 \mathrm{~m})$ yielded an age of $140 \pm 7 \mathrm{Ma}$, sample UZ-39 $(1235 \mathrm{~m})$ yielded a major age peak of $116 \pm 8$ Ma, and sample UZ-38 (1520m) yielded an age of $139 \pm 9$ Ma. All four samples along the vertical profile returned similar long to moderate MTLs of $12.6 \pm 1.4 \mu \mathrm{m}, 13.0 \pm 1.1 \mu \mathrm{m}, 12.9 \pm 1.2 \mu \mathrm{m}$, and $12.8 \pm 1.0 \mu \mathrm{m}$, respectively. To the east of the southern Nurata Range, both UZ-41 and UZ-48 yielded Cretaceous AFT central ages of $131 \pm 5 \mathrm{Ma}$ and $134 \pm 10 \mathrm{Ma}$, respectively, with these samples producing MTLs of $12.9 \pm 1.0 \mu \mathrm{m}$ and $12.9 \pm 1.1 \mu \mathrm{m}$, respectively (Figure 3, 5 and Table 1). 


\subsubsection{Aydar}

Samples from along the northern margin of the Nurata Range and the southern margin of the Aydar lake yield markedly different AFT ages compared to the rest of the Nurata Range (Figure 3). Three samples were collected from the boundary between the Nurata Range and the Aydar lake, samples UZ-25, UZ-24, and UZ-01. Samples UZ-25 and UZ-24 produced Cretaceous AFT central ages of $92 \pm$ $5 \mathrm{Ma}$ and $93 \pm 4 \mathrm{Ma}$ and moderate to short MTLs of $12.5 \pm 1.2 \mu \mathrm{m}$ and $12.6 \pm 1.1 \mu \mathrm{m}$, respectively. To the east, sample UZ- 01 yielded a Cretaceous AFT central age of $83 \pm 6$ Ma and a MTL of $12.4 \pm$ $1.8 \mu \mathrm{m}$ (Figure 3, 5 and Table 1).

\subsubsection{Ziadin Mountains}

The Ziadin Mountains is the inferred western continuation of the Gissar suture outcropping in Uzbekistan, between the Kuldjuktau Mountains to the north-west and the Karatyube Massif to the south-east (Dolgopolova et al. 2017). Five samples were taken from the Ziadin Mountains along the Gissar suture. The three eastern samples, UZ-11, UZ-12, and UZ-13, all yielded similar Jurassic AFT central ages of $156 \pm 8 \mathrm{Ma}, 154 \pm 6 \mathrm{Ma}$, and $151 \pm 7 \mathrm{Ma}$, respectively. The samples of Jurassic age produced MTLs of $13.0 \pm 0.9 \mu \mathrm{m}$, MTL of $13.2 \pm 1.1 \mu \mathrm{m}$, and $12.3 \pm 1.0 \mu \mathrm{m}$, respectively. The two western samples UZ-14 and UZ-50 both yielded Cretaceous AFT central ages of $133 \pm 6 \mathrm{Ma}$, and $141 \pm 7$ Ma and long MTLs of $12.9 \pm 0.9 \mu \mathrm{m}$ and $13.2 \pm 1.0 \mu \mathrm{m}$, respectively (Figure 3, 5 and Table 1 ).

\subsubsection{Karatyube Massif}

The large Karatybe Massif is located on the western termination of the Gissar range mountain range that largely crops out in Tajikistan (Konopelko et al. 2017a). The seven samples from the Karatyube Massif yielded a range of ages over the Mesozoic and Cenozoic, two produced Jurassic AFT central ages, three produced Cretaceous AFT central ages, and two produced Palaeogene AFT central ages. Samples UZ-05 and UZ-08 yielded identical ages of $177 \pm 11 \mathrm{Ma}$, and both samples produced moderate to short MTLs of $12.7 \pm 1.0 \mu \mathrm{m}$ and $12.1 \pm 1.1 \mu \mathrm{m}$, respectively. Three samples yielded a Cretaceous AFT central age; UZ-07, UZ-09, and UZ-49 yielded ages of $124 \pm 3 \mathrm{Ma}, 97 \pm 8 \mathrm{Ma}$, and $130 \pm 4 \mathrm{Ma}$, respectively. The Cretaceous ages were associated with short MTLs of $12.5 \pm 1.2 \mu \mathrm{m}, 12.2 \pm 1.5 \mu \mathrm{m}$, and $12.4 \pm 1.4 \mu \mathrm{m}$, respectively. The two Palaeogene AFT central ages identified in the Karatyube Massif are the youngest basement AFT ages for the entire Kyzylkum-Nurata Segment. Sample UZ-10 
yielded an AFT central age of $56 \pm 4 \mathrm{Ma}$, and sample Gx-6 yielded an age of $30 \pm 2$ Ma. Sample UZ-10 displayed a short MTL of $12.0 \pm 1.5 \mu \mathrm{m}$. Sample Gx-6, despite being irradiated with ${ }^{252} \mathrm{Cf}$ to increase the number of confined tracks, did not produce enough tracks to produce a reliable MTL and length distribution (Figure 3, 5 and Table 1).

\subsection{Apatite (U-Th-Sm)/He}




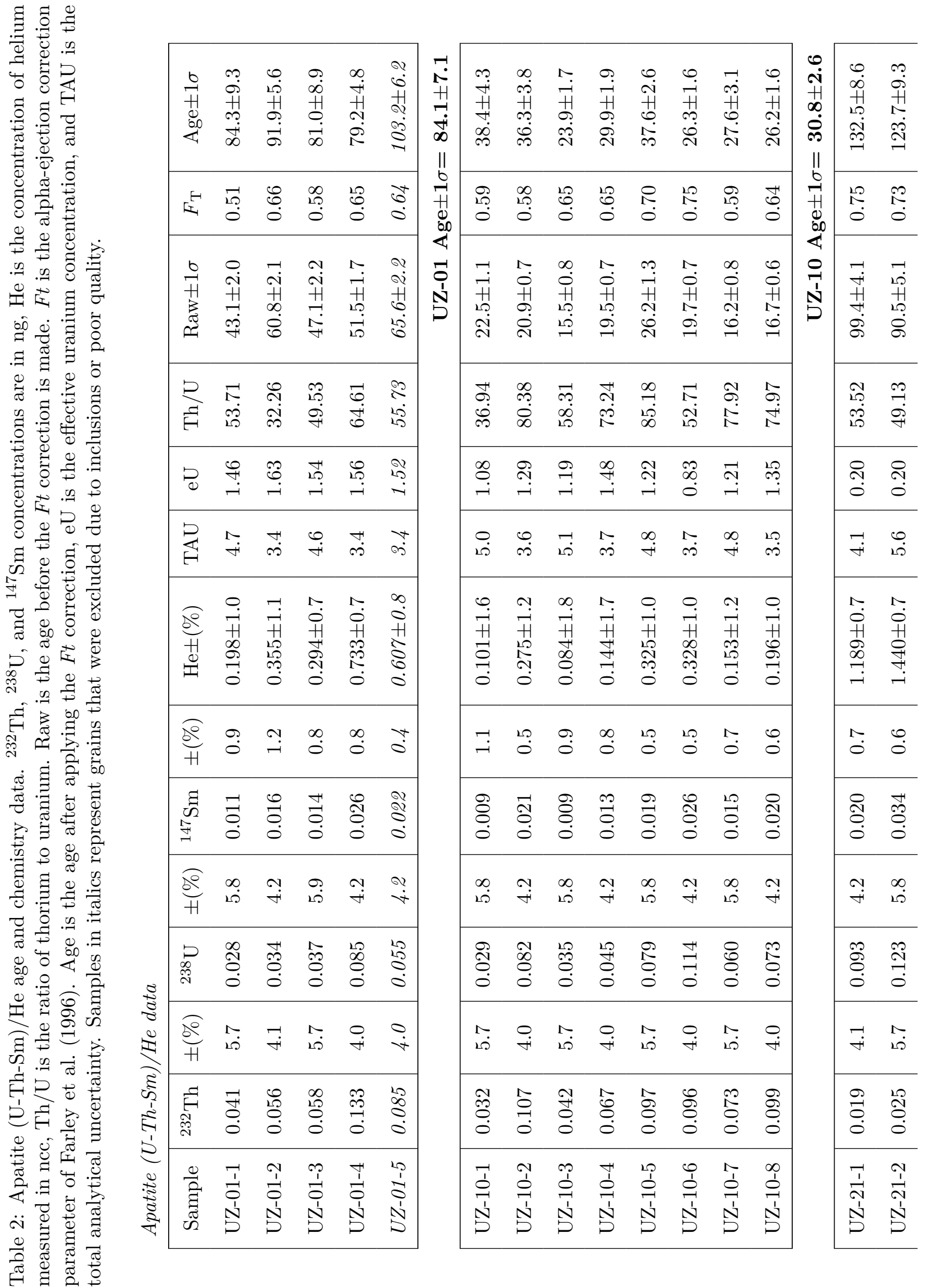




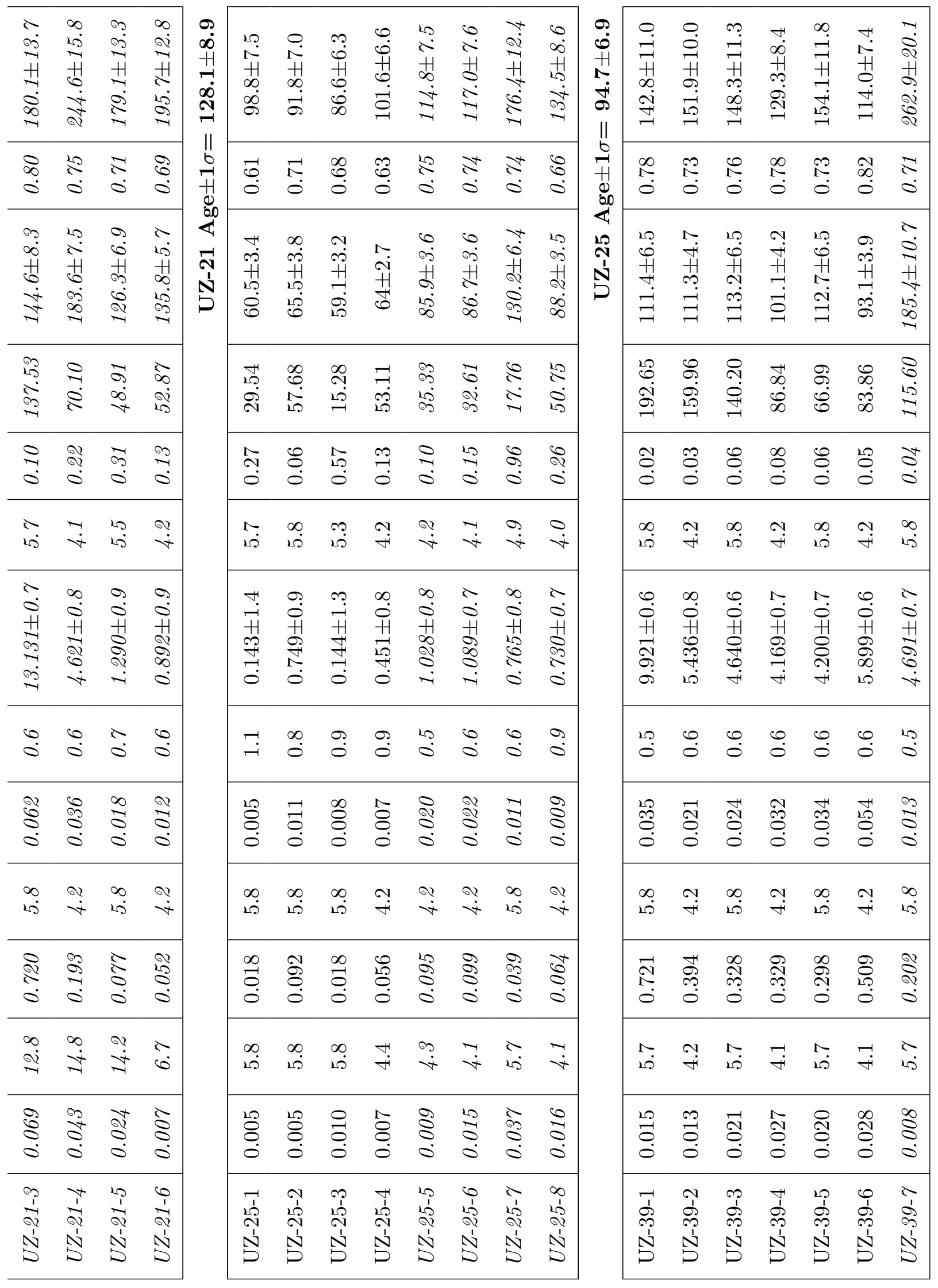




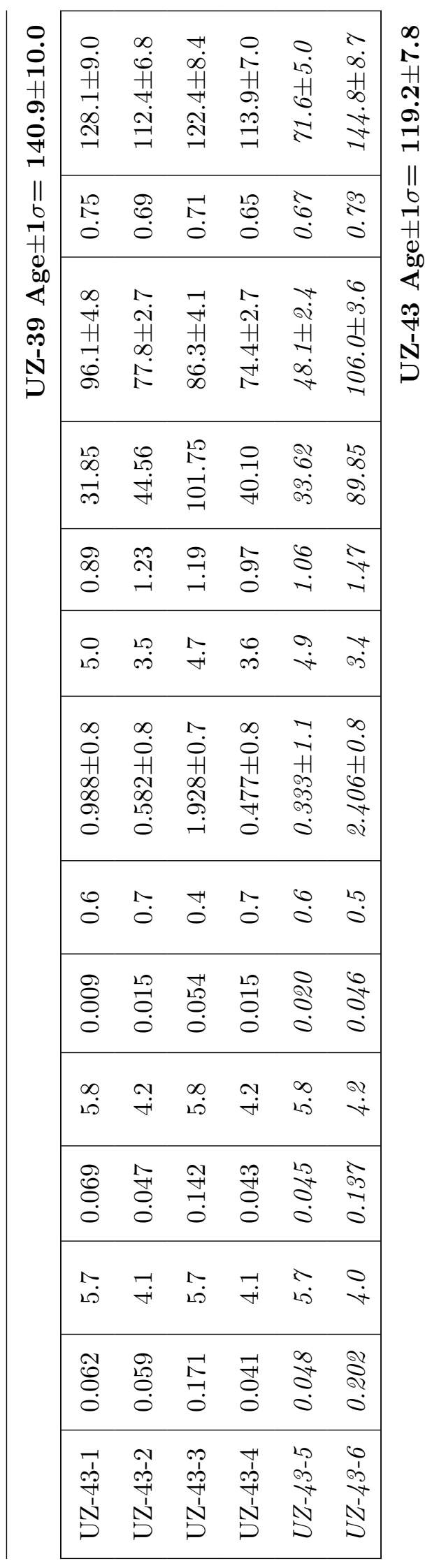


Six samples were selected for AHe analysis (Table 2). Samples that produced young AFT ages and relatively long MTLs were prioritised in order to better constrain the Cretaceous-Cenozoic phase of cooling experienced by the Kyzylkum-Nurata Segment. In the Bukantau Mountains, sample UZ-21 yielded a Cretaceous AHe age of $128 \pm 9 \mathrm{Ma}$, which overlaps with the AFT central age from sample UZ-21 of $130 \pm 4 \mathrm{Ma}$ (Table 1 and 2). For the Nurata Range, one sample was selected from the northern area and one sample was selected from the southern area. Sample UZ-43 yielded an AHe age of $119 \pm 8 \mathrm{Ma}$, which is within error with its respective AFT age (AFT central age of $112 \pm$ 5 Ma, Table 1 and 2). In the southern Nurata Range, sample UZ-39 produced an AHe age of 141 \pm 10 Ma with significant single-grain age scatter. Compared to the AFT age for this sample ( 99 Ma central age, 116 Ma oldest age peak), the AHe age is significantly older. This discrepancy may be explained by the anomalously high eU (effective uranium, Table 2). However, the AHe age is in excellent agreement with the other samples in the vertical profile (AFT age range $140-110$ Ma, Table 1 and 4.2, Supplementary File 1). Two samples from the Aydar - Nurata Range margin were selected for AHe analysis; UZ-01 (AFT central age of $83 \pm 6 \mathrm{Ma}$ ) yielded an AHe age of $84 \pm 7$ and UZ-25 (AFT central age of $93 \pm 4 \mathrm{Ma}$ ) yielded an AHe age of $95 \pm 7 \mathrm{Ma}$. Both AHe ages from the Aydar area were thus, in excellent agreement with their respective AFT age (Table 1 and 2). Sample UZ-10 (AFT central age of $56 \pm 4 \mathrm{Ma}$ ) from the Karatyube Massif yielded an AHe age of $31 \pm 3$ Ma (Table 1). Although, the ages produced by the AFT and AHe thermochronometers do not overlap, the presence of a young $\sim 30 \mathrm{Ma}$ AHe age combined with the regionally proximal $\sim 30 \mathrm{Ma}$ AFT central age for sample Gx-6, does suggest the presence of a Eocene-Oligocene cooling signal in the south-eastern end of the Kyzylkum-Nurata Segment (Figure 3 and Table 2).

\subsection{Thermal History Modelling}

Thermal history modelling was conducted for thirty-nine samples. Models that are based on less than 40 confined tracks are thought to be less accurate and are, therefore, drawn as dashed lines in the thermal history modelling figures (Figure 4 and Table 1). All models were constrained to start at temperatures greater than the $\mathrm{APAZ}\left(>120^{\circ} \mathrm{C} \pm 20^{\circ} \mathrm{C}\right)$. For all samples the AFT annealing model Ketcham et al. (2007) was used. In addition, apatite helium data were integrated into relevant thermal models, using the He radiation damage model of Gautheron et al. (2009). Individual models, confined track distributions, and modelling parameters are available in Figure 4 and Supplementary Files 3, and 4 (following Flowers et al. 2015). 
The thermal models produced two distinct Mesozoic and Cenozoic thermal histories. The six regions identified in the results can, therefore, be further subdivided into two tectonic groups with discrete thermal evolutions. The first group can be identified by samples that were taken in close proximity to relict suture zones, comprising of the the Nurata Range and the Ziadin Mountains. The second group is identified by samples that were taken from regions that were distal to the main suture zones, the Kuldjuktau Mountains, the Bukantau Mountains, the Aydar area, and the Karatyube Massif (Figure $4)$.

\subsubsection{Tectonic Group One: Near Major Structures}

For the Nurata Range, sixteen samples were modelled (five from the northern and eleven from the southern range). Samples UZ-43 and UZ-39 were constrained using additional AHe data (Table 2). The models show rapid cooling in the Late Triassic-Early Jurassic ( 210-180 Ma), slower cooling in the Jurassic ( 180-150 Ma), faster cooling in the Late Jurassic-Early Cretaceous ( 150-120 Ma), and slow cooling in the middle to Late Cretaceous ( 120-100 Ma, Figure 4a). Five thermal history models were obtained from the Ziadin Mountains in southern Uzbekistan. No additional constraints were placed on any of the five thermal history models. All five thermal history models identified relatively rapid cooling during the Late Jurassic-Early Cretaceous ( 160-130 Ma). The thermal evolution for the regions that comprise Tectonic Group One preserve two pulses of relatively rapid cooling during (1) the Late Triassic-Early Jurassic ( 210-180 Ma) and (2) the Late Jurassic-Early Cretaceous ( 160-130 Ma, Figure 4).

\subsubsection{Tectonic Group Two}

Thermal history modelling was performed on seven samples from the Kuldjuktau Mountains. There were no AHe or additional data, all seven models were allowed to run unconstrained. The Kuldjuktau Mountains displays a broad range of thermal histories dominated by slow cooling throughout the Mesozoic from $\sim 220$ Ma to 110 Ma. However, one sample displays a variation from the theme of slow cooling, UZ-29b, which shows rapid cooling at 170 Ma (Figure 4c).

For the Aydar region, thermal history models were produced for all three samples. Two of the three samples had corresponding AHe data which was used by each respective model (Table 2 and Supplementary File 3 and 4). All three samples produced Late Cretaceous AFT ages, with two samples 
modelling relatively fast cooling through the APAZ at 110-90 Ma. In contrast, sample UZ-01 displays protracted cooling throughout the Late Cretaceous (Figure 4d).

Thermal history modelling was performed on five samples from the Karatyube Massif, with one sample modelled with its respective AHe data. The four thermal history models without AHe constraints all produced slow cooling thermal histories, entering the upper APAZ in the Early Jurassic and cooling to below the APAZ in the mid-Cretaceous. Two samples which produced thermal histories with an extended residence in the APAZ during the Late Jurassic-Early Cretaceous (Figure 4e). The Palaeogene sample, UZ-10, demonstrates a relatively rapid rate of cooling at 50 Ma. After exiting the APAZ, sample UZ-10 shows a deviation in its thermal history model, constrained by the AHe data obtained for that sample at $\sim 30 \mathrm{Ma}$, before cooling to surface temperatures at $~ 15 \mathrm{Ma}$ (Figure 4e and 5, and Supplementary File 3).

Five samples from the Bukantau Mountains were suitable for modelling. Four of the five thermal history models were run without additional AHe constraints, with one sample constrained by Cretaceous AHe data (UZ-21). The thermal history models for the Bukantau Mountains record a dominant rapid Triassic cooling signal ( 220-200 Ma) while also displaying a period of rapid cooling in the Late Jurassic $(\sim 140 \mathrm{Ma})$, and a period of relatively slow cooling in the Late Cretaceous ( 110 Ma, Figure 4f).

The thermal evolution for the regions that comprise Tectonic Group Two is generally defined by slow cooling throughout the Jurassic and Cretaceous-early Palaeogene, excluding a few samples which demonstrate faster cooling. In addition, the thermal model for one sample (UZ-10), shows evidence for renewed cooling in the late Palaeogene (Figure 4c, 4d, 4e, and 4f).

\section{Interpretation and Discussion}

The results of this study reveal that the Kyzylkum-Nurata Segment, and the relict suture zones that it hosts, underwent a multi-phase cooling history during the Mesozoic and Cenozoic.

\subsection{Mesozoic and Cenozoic Thermal History and Control of the Suture Zones}

The Kyzylkum-Nurata Segment is dominated by three relict suture zones, the South Tian Shan Suture in the north, the Zeravshan suture in the centre, and the Gissar suture to the south (Figure 5, Burtman 

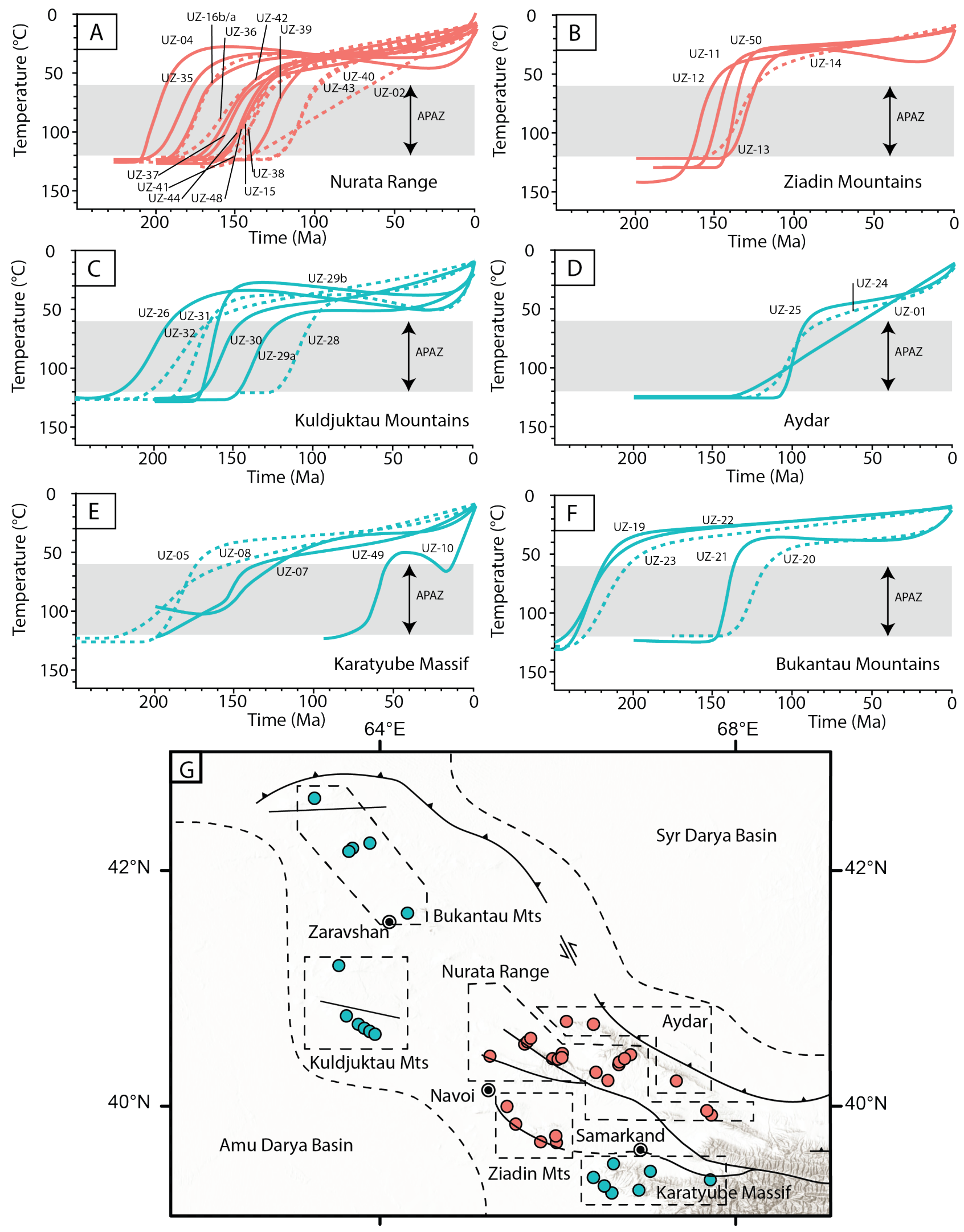

Figure 4: Caption next page 
Figure 4: Plots displaying the modelled temperature-time paths for all samples within the KyzylkumNurata Segment that yielded sufficient confined track data for modelling purposes $(>40)$. Modelling was performed using QTQt Gallagher (2012), with the bold and dashed lines representing the expected temperature-time pathway modelled. Apatite $(\mathrm{U}-\mathrm{Th}-\mathrm{Sm}) / \mathrm{He}$ data was used to refine the thermal models where appropriate (see thermal model section). The thermal history models are grouped in their corresponding region; with associated sample location inset (g). Bold lines represent thermal history models from samples which contained at least 40 confined tracks, with dashed lines representing thermal history models from samples which contained between 40 and 25 confined tracks. The grey bar represents the apatite partial annealing zone (APAZ) between $120^{\circ} \mathrm{C}$ and $60^{\circ} \mathrm{C}$. For detailed individual thermal history models and modelling parameters see Supplementary File 3 and 4 )

1975, Konopelko et al. 2017a). These three sutures are the dominant control on the current topography of the Kyzylkum-Nurata Segment, as most of the ranges and outcropping rocks either lie on, or along strike of, each of the suture zones (Figure 5, Dolgopolova et al. 2017). In order to evaluate the control of these suture zones on the Mesozoic topography, Figure 5 was produced to plot the geospatial location of the confined track MTL for each analysed samples. Longer MTL values correspond to faster cooling (as shown in the thermal history models of Figure 4) and show a close relationship with the samples in close vicinity to the sutures (Figure 5).

The Nurata Range strikes along the Zeravshan suture and is dominated by long MTLs and fast cooling during the Late Jurassic-Early Cretaceous. In contrast, the Kuldjuktau Mountains, which is located to the south of the western extent of the Zeravshan suture, is characterised by mostly slow cooling during the Late Jurassic-Early Cretaceous and exhibits associated short MTLs (Figures 4.4 and 4.5). This pattern suggests that the Nurata Range was exhumed in the Early Cretaceous, controlled by the reactivation of the Zeravshan suture. At the northern slopes of the Nurata Range, in the Aydar region, the thermal history models show a mixture between relatively fast, Late Cretaceous cooling, and slow, protracted cooling (Figure 4d). Here, the AFT ages are younger (Late Cretaceous) and the associated MTLs are shorter on average and show broad distributions (Figures 4.3 and 4.5). This suggests that the AFT ages of the Aydar region may represent mixing ages between two thermal events that are not clearly identified by the thermal history modelling. The Aydar samples are in relatively close vicinity to the South Tian Shan Suture, which has been reactivated in the Cenozoic (e.g. Glorie et al. 2011, Käßner et al. 2017b), and therefore, the AFT ages may have been affected by this reactivation event.

The Bukantau Mountains preserve Early Triassic rapid cooling in the north-east and rapid Early Cretaceous cooling the south-west, suggesting that the Cretaceous fault reactivation seen in the Nurata Range also affected the Bukantau Mountains (Figures 4.3, 4.4, and 4.5). However, given that Early 
Triassic AFT cooling ages are preserved in the region, the oldest preserved cooling signal identified in the Kyzylkum-Nurata Segment, the area would have not been extensively affected by the Cretaceous deformation and exhumation.

In the south of the Kyzylkum-Nurata Segment, along the Gissar suture, there is a section displaying fast cooling (Ziadin Mountains), and a section displaying slow cooling (Karatyube Massif, Figure 5). In more detail, samples taken from along a granitoid pluton to the south of the Gissar suture (UZ-08, UZ-09, and UZ-49) display a mixed series of ages from Jurassic to Late Cretaceous along with slow cooling models and relatively short MTLs (Figures 4.3, 4.4, and 4.5). In contrast, samples taken to the north of the Gissar suture, within the Ziadin Mountains, display fast cooling during the Early Cretaceous and associated with long MTLs (Figures 4.4 and 4.5). The differential record of cooling ages on either side of the suture suggests that the suture was reactivated in the Early Cretaceous, leading to the rapidly cooled AFT ages and long MTLs observed in the Ziadin Mountains. Within the suture and particularly in the high relief areas of the Karatyube Massif, Palaeogene AFT and AHe ages, and fast cooling models were obtained, suggesting that the eastern extent of the suture was reactivated during the Cenozoic (Figure 5).

In summary, the Kyzylkum-Nurata Segment records a clear spatial relationship between MTLs and their associated thermal history models, and proximity to a major suture zone. Samples that were taken from ranges and outcrops that lie directly along the suture zones display a different thermal history from samples that were taken from the suture zone peripheries (Figure 4). This implies that the main NW-SE striking suture zones were reactivated during the Early Cretaceous. Therefore, the Early Cretaceous topography was likely characterised by a series of linear NW-SE striking ridges that built on the reactivated fault zones.

\subsection{AFT Age-Confined Track Length Plot}

In order to further distinguish periods of tectonic reactivation and exhumation (fast cooling) from periods of erosion and peneplanation (slow cooling), the mean track length for each sample was plotted against its respective age (Figure 6). Called a "boomerang plot", this plot demonstrates the relationship between AFT ages and MTL for a set of samples from a region which has likely experienced a multiple thermo-tectonic events (Green 1986, Gallagher \& Brown 1997, Gallagher et al. 1998). In such a plot for the Kyzylkum-Nurata Segment, a characteristic "boomerang" trend can be identified, the descending segment defined by comprise Tectonic Group Two samples with Triassic-Early Jurassic AFT ages and 


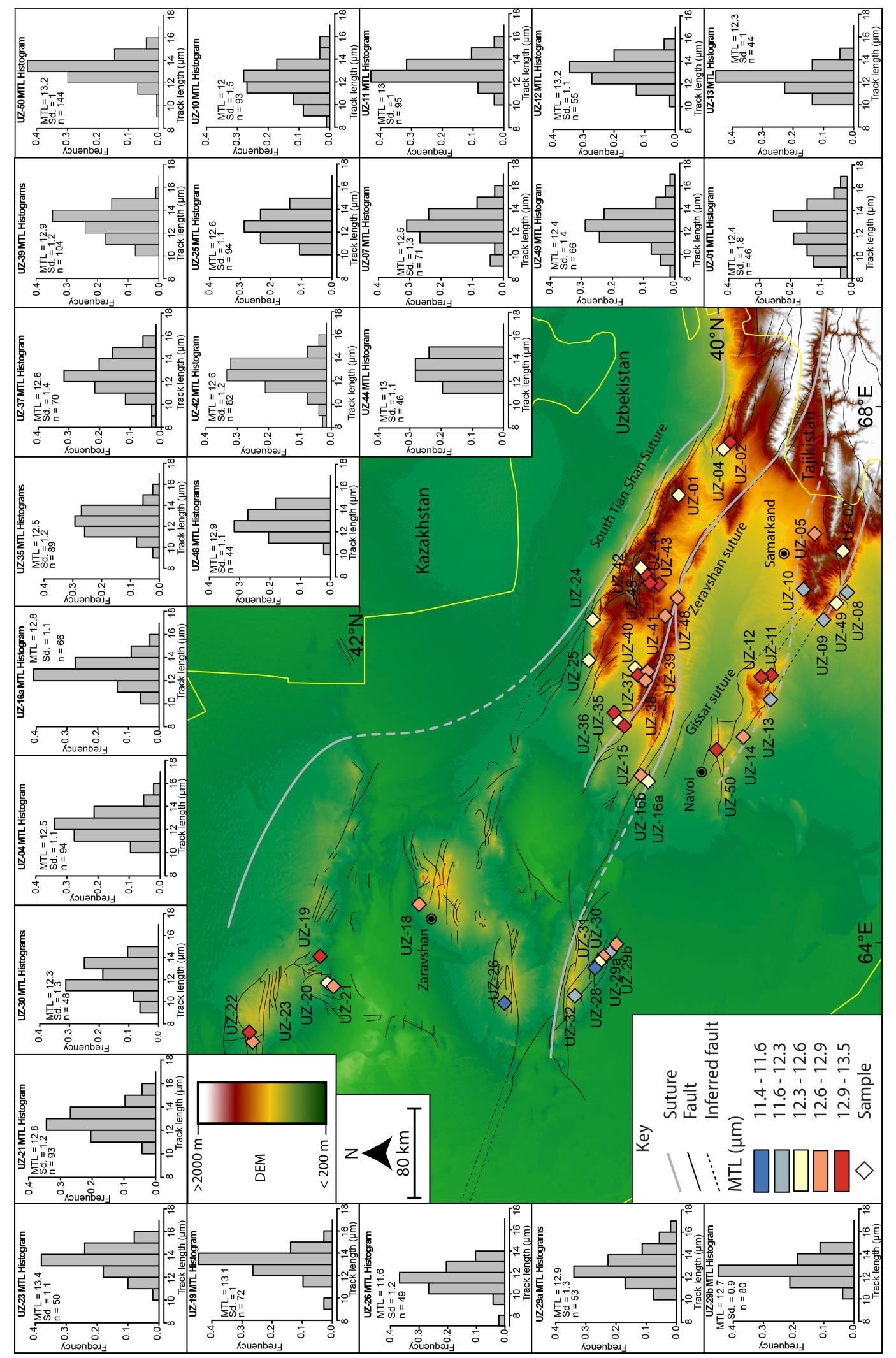

党自要

쿄원

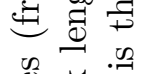

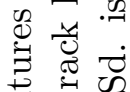

क ज क

.-

छ

票高

䨔 $\frac{0}{2}$

苂

.

घ $\Sigma$

专

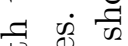

용.

20 శ్

寻总

ठ 尊

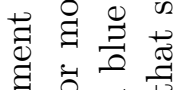

कृ

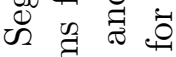

कृष की

额当

索范

\& $\infty 0$

들 으

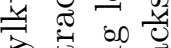

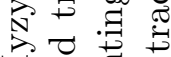

㲅

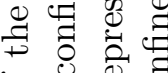

पै 0 is

छे

空高要

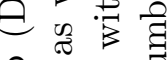

웜의

증

ซี

䒕 क्ष

己े छ

\%

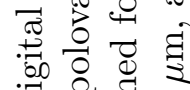

मे ô.

เ

施 
the ascending segment defined by published data from the proximal, high elevation $(>2 \mathrm{~km})$ region of the Gissar Range (Käßner et al. 2017b).

In more detail, Tectonic Group Two demonstrates that the Kyzylkum-Nurata Segment experienced a partial 'boomerang' in the Mesozoic, beginning with fast cooling in the Late Triassic-Early Jurassic ( 220-180 Ma), followed by a protracted period of thermal stability, defined by short MTLs, from the Early Jurassic to the Late Cretaceous ( 200-50 Ma, blue symbols in Figure 6). Within this period of thermal stability, the data is rather scattered by may hint to a gentle increase of MTLs and cooling rate during the Early Cretaceous. The fast-cooling Cenozoic AFT data from the Gissar Range, identified by Käßner et al. (2017b), compliments the Mesozoic data obtained in this study, defining the Cenozoic segment to complete the Mesozoic-Cenozoic MTL boomerang ( 50-5 Ma, black symbols in Figure 6).

In contrast to the complete boomerang recorded by Tectonic Group Two and the published data (Käßner et al. 2017b), samples from Tectonic Group One record a distinct period of rapid cooling during the Late Jurassic-Early Cretaceous ( 160-130 Ma, red symbols in Figure 6). The samples that comprise Tectonic Group One were sampled either directly or proximal to the major structures of the South Tian Shan and Zeravshan sutures, further highlighting that these suture zones were affected by a secondary phase of exhumation that is only slightly recorded further away from these structures (Figure 5 and 6).

The interpretation of two discrete thermo-tectonic histories for the Kyzylkum-Nurata Segment can also be identified when comparing the sample elevation to its relative AFT age (Figure 7). The ageelevation plot reveals a clear trend of increasing AFT ages with increasing elevation (Figure 7). The oldest samples (Triassic) in the Kyzylkum-Nurata Segment are found at the lowest elevation $(\sim 200 \mathrm{~m})$. The relationship between age and elevation for Group One and Two diverge in the Jurassic-Cretaceous. In this time period, samples from Group Two (away from the sutures) show significant scatter and a large variation in AFT age at a given elevation, implying slow cooling and thus, a prolonged residence in the APAZ. In contrast, samples from Group One show a strong linear trend of increasing age with elevation during the Late Jurassic-Early Cretaceous.

Combined, both Tectonic Group One and Two chart the thermal evolution of the Kyzylkum-Nurata Segment (Figure 6). Although classified as Tectonic Group One, the Bukantau Mountains along the Southern Tian Shan Suture displays a similarity to both Tectonic Group One and Two. The Bukantau Mountains hosts low relief and old ages, synonymous with the regions that define Tectonic Group 


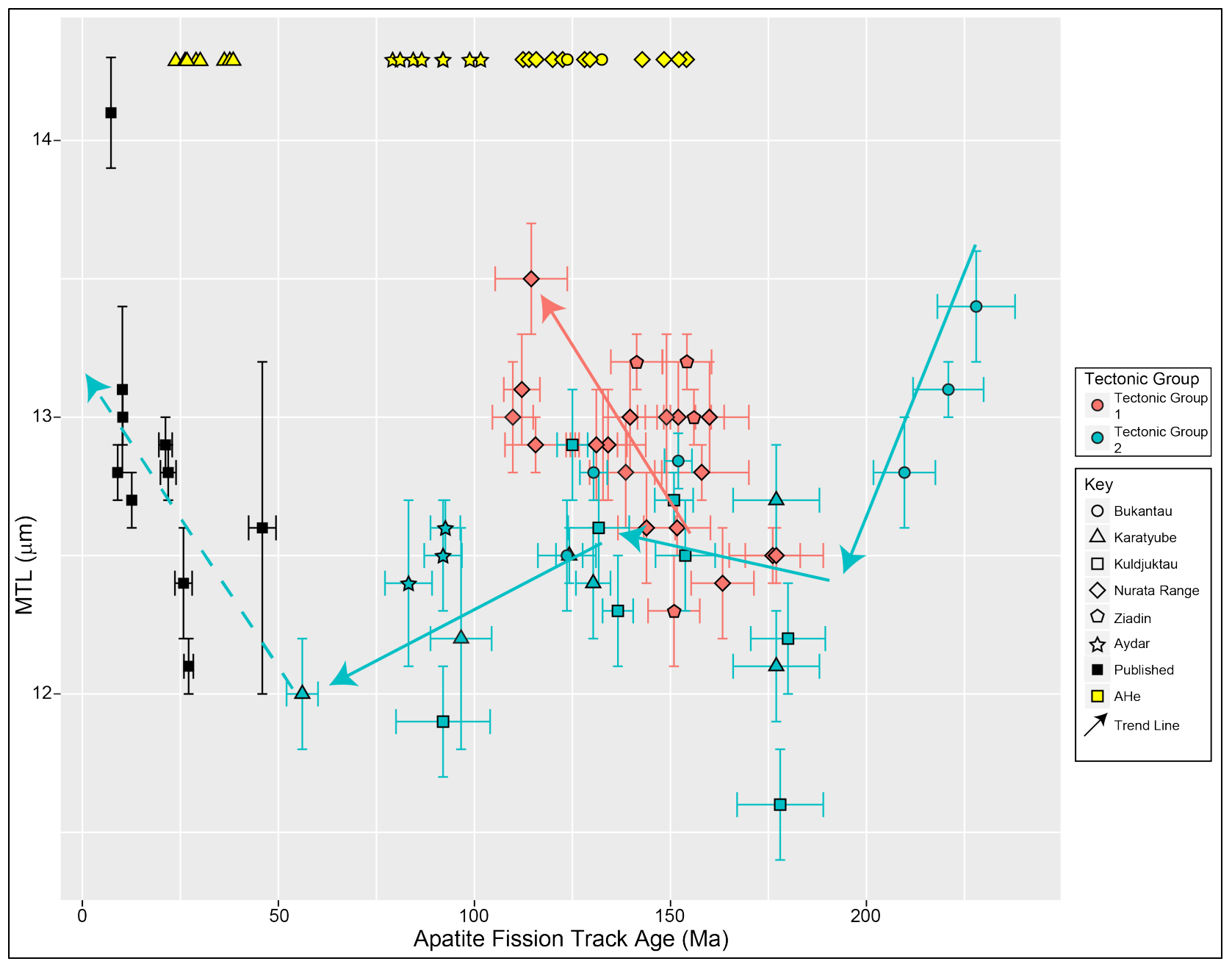

Figure 6: A 'boomerang' plot displaying apatite fission track (AFT) central age, and apatite (U-Th$\mathrm{Sm}) / \mathrm{He}(\mathrm{AHe})$ ages against mean track lengths (MTL, Table 1 and 2). Red filled symbols represent samples that correspond to Tectonic Group One and blue filled symbols represent samples that correspond to Tectonic Group Two. Black filled samples are AFT and MTL data obtained from the nearby Gissar Range (Käßner et al. 2017b). The solid arrows outline the thermal pathways defined in this study, and the dashed arrows outline a thermal pathway inferred from this study and the data from Käßner et al. (2017b). 
Two. However, it also hosts fast, suture zone cooling that is characteristic of the regions that comprise Tectonic Group One. As this region shows similarities of both groups, it is reasonable to suggest that the Bukantau Mountains hosts the thermo-tectonic relic of the ancestral Tian Shan which the modern Tian Shan is built upon. Away from the main suture zones, in low-relief areas, the Kyzylkum-Nurata Segment records slow cooling and erosion throughout the Mesozoic, since the Late Triassic ( 220 Ma). In the main suture zone, a second phase of rapid uplift and fast cooling has been identified in the Early Cretaceous, overprinting the ancestral Tian Shan thermal history of regional slow cooling (Figure 4 and 5, De Grave et al. 2012). Finally, the Karatyube Massif and Aydar regions of the Kyzylkum-Nurata Segment host samples that document the transition between the Jurassic-Cretaceous thermal history, and the rapid Cenozoic deformation identified elsewhere in the South Tian Shan (Figure 6).

\subsection{Thermotectonic evolution of the Kyzylkum-Nurata Region}

\subsubsection{Triassic Exhumation}

The Kyzylkum-Nurata Segment, hosts three samples which produced a Triassic AFT central age. All three are located in the north-western region of the Bukantau Mountains on the margin of the Syr Darya Basin (Figure 3). The three samples yielded central ages of $\sim 230-210 \mathrm{Ma}$, and were associated with relatively long MTLs and thermal history models showing fast cooling (Figure 4). A recent study by Dolgopolova et al. (2017) into the emplacement age and origin of the Kyzylkum-Nurata Segment magmatism, found that all granitoid samples (including a sample from the same region in the Bukantau Mountains) exhibited Permian ages of $\sim 293-273$ Ma. The difference in the zircon uraniumlead $(\mathrm{ZrUPb})$ age and the fast cooling, Triassic AFT central ages, suggest that following emplacement, the Kyzylkum-Nurata Segment experienced steady, post-emplacement magmatic cooling. A similar relationship between the Triassic Tian Shan thermochronology and the Syr Darya block has also been found in the Chatkal-Kurama range in the western Tian Shan, with fast cooling Triassic AFT ages identified on the Chatkal-Kurama-Syr Darya margin.

Previous thermchonological studies in the Tian Shan ascribe Triassic-Early Jurassic AFT ages to the closure of the Turkestan Ocean in the Permian and the subsequent collision of the Qiangtang Block with the Eurasian margin (e.g. Xiao et al. 2009, Glorie et al. 2010, De Grave et al. 2011, Macaulay et al. 2014, Glorie \& De Grave 2016). During this period, samples from along the north-western margin of the Kyzylkum-Nurata Segment were rapidly cooled to surface temperatures (Figure 4c). Thus, we 
interpret the Triassic fast cooling signal in our data to be related with exhumation associated with the closure of the Turkestan Ocean and/or the Qiangtang convergence in the Triassic-Early Jurassic.

\subsubsection{Jurassic-Cretaceous Regional Tectonic Stability and Peneplanation}

The Jurassic-Cretaceous thermo-tectonic evolution of the Kyzylkum-Nurata Segment is defined by two discrete trends outlined by the "boomerang plot" (Figure 6); one profile demonstrating thermo-tectonic stability, and one profile demonstrating an increased basement cooling via exhumation. The samples that comprise Tectonic Group Two record a regional trend of tectonic stability and pleneplanation. A series of samples from across the Kyzylkum-Nurata Segment yielded Early to Middle Jurassic AFT central ages (Figure 2). The Early to Middle Jurassic AFT ages were largely associated with low MTLs, and the associated thermal history models showing slow cooling (Figures 4.4 and 4.5). These data are indicative of protracted residence in the APAZ, suggesting a period of steady, slow denudation and tectonic quiescence at that time. A recent study into the lowest part of the Mesozoic cover of the Kyzylkum-Nurata Segment by McCann (2016b) identified the presence of Lower Jurassic alluvial-fan, river valley, lagoonal, and shallow marine sedimentation (distinct absence of Triassic sedimentation). The source of the sedimentation is assessed as derived from the weathering and erosion of the recently uplifted Kyzylkum-Nurata Segment (McCann 2016b). This conclusion fits with the Triassic exhumation identified in this study, indicating that the Triassic exhumation provided the source that underwent subsequent erosion and sedimentary deposition in the Kyzylkum-Nurata Segment during the Jurassic.

During the Jurassic, the greater western Tian Shan experienced periodic marine incursions by the Paratethys Sea into the Amu Darya, Tajik, Fergana, and Tarim basins (Bosboom et al. 2011, 2014, Bande et al. 2017b, De Pelsmaeker et al. 2018). The series of marine incursions by the Paratethys Sea to the western Tian Shan indicates that there was a period of tectonic stability, erosion, and sedimentation experienced by the Kyzylkum-Nurata Segment during the Jurassic (Figure 7).

\subsubsection{Localised Late Jurassic to Early Cretaceous Exhumation}

In contrast to the regional tectonic stability, defined by samples from Tectonic Group Two, samples taken in vicinity of the faults (Tectonic Group One) record rapid basement cooling and exhumation during the Late Jurassic-Early Cretaceous. During the Late Jurassic-Early Cretaceous, the sutures of the Kyzylkum-Nurata Segment underwent a period of exhumation, deformation, and mountain building. 


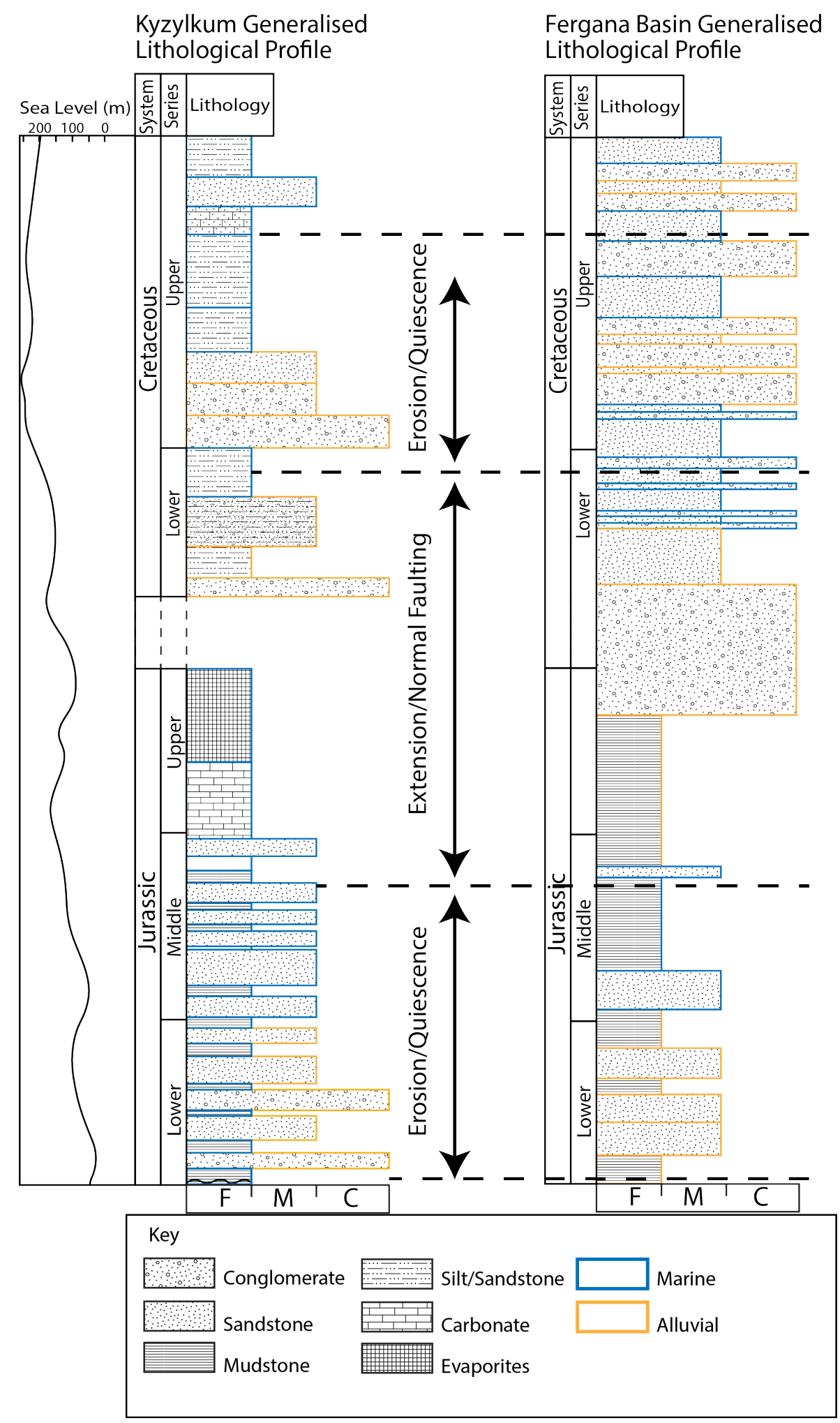

Figure 7: Generalised lithological profiles for both the Kyzylkum (McCann 2016a,b), and the nearby Fergana Basin (De Pelsmaeker et al. 2018), as well as the global eustasy for the Jurassic and Cretaceous (Haq et al. 1987). Compared against the relationship between the apatite fission track (AFT) age and mean track length (MTL) of samples from the Kyzylkum-Nurata Segment in order to identify periods of uplift, erosion, and tectonic stability. Sediment grain size is defined by fine (F), medium (M), or coarse $(\mathrm{C})$. 
This period of deformation and reactivation is evidenced by samples with overlapping closure temperatures, long MTLs, and rapid cooling thermal history models (Figure 6). Recent thermochronological studies on the basement of the proximal Gissar Range by Käßner et al. (2017b) and Käßner et al. (2017a) also identified the presence of a Late Jurassic-Early Cretaceous cooling signal, however, this signal was largely obscured due to a prolific Cenozoic thermal overprint (e.g. Bande et al. 2017b, Käßner et al. 2017b,a, Jepson et al. 2018). The basement outcrops in the Kyzylkum-Nurata Segment preserve this Cretaceous cooling event, as the faults and ranges have been sheltered from the major impacts of subsequent Mesozoic-Cenozoic collisions, further evidenced work by De Pelsmaeker et al. (2018) indicating that Talas-Fergana Fault (Figure 1) acted as a barrier to the strain that was being experienced by the Tian Shan east of the Talas-Fergana Fault.

The Mesozoic sedimentary record in the Kyzylkum desert identified by McCann (2016a,b) and simplified in Figure 7, shows a period of marine incursion depositing a carbonate layer, transitioning into a salt dominated layer, before a distinct hiatus and subsequent coarse clastic sedimentation at the start of the Early Cretaceous. The marine sediment transition and unconformity could represent a response to exhumation along the Kyzylkum-Nurata Segment, leading to a lack of sedimentation during the Early Cretaceous. At the same time, in the Fergana Basin, thick packages of coarse alluvial sediments were being deposited, indicating that some of the coarse sediment preserved in the Fergana Basin could have been sourced from the exhumed Kyzylkum-Nurata Segment (Figure 7).

To the east of the Kyzylkum-Nurata Segment, in the Kyrgyz Tian Shan, other geo- and thermochronological studies have identified Late Jurassic-Early Cretaceous exhumation. Nachtergaele et al. (2017) and De Pelsmaeker et al. (2018) found that the areas to the east of the Talas-Fergana fault underwent rapid Early Cretaceous basement cooling, and that the fault acted as a structural divide between the Cretaceous exhumed Tian Shan to the east and the Paratethys Ocean to the west. The Late Jurassic-Early Cretaceous thermochronological signal has previously been interpreted as a relic of the Cimmearan collisions that drove much of the deformation in the Middle Tian Shan (De Grave et al. 2007, Glorie \& De Grave 2016, Käßner et al. 2017a, Nachtergaele et al. 2017). Given that the exhumation at the time was solely focused on suture zones within the Kyzylkum-Nurata Segment, it may be more likely that the suture zones were reactivated by an extensional tectonic event. Stockli et al. (2002) demonstrated that extension and associated rapid footwall exhumation can result in (tilted) sections where samples record rapid localised cooling, without the need for voluminous denudation. 
Recent geodynamic models by Hall (2012) and Zahirovic et al. (2016) have suggested that the southern Eurasia margin was undergoing slab rollback related extension during the mid-Cretaceous ( $155 \mathrm{Ma})$, which could have been a possible mechanism for footwall exhumation and basement cooling identified in the sampled suture zones. Therefore, we envisage the Cretaceous Tian Shan landscape and deformation style to be comparable to the present-day Basin and Range province in the south-western USA.

\subsubsection{Late Cretaceous to Early Palaeogene Tectonic Stability and Denudation}

From the mid Cretaceous to the early Palaeogene, the low-temperature thermochronology of the Kyzylkum-Nurata Segment shows a decline in fast cooling and exhumation, and thus, transitioning into a period of slow cooling and erosion, with distinct absence of thermochronology data from $\sim 80-50$ Ma (Figure 6). Similarly, in the Gissar Range, Käßner et al. (2017b) also identifies a period of Late Jurassic to Oligocene quiescence from $\sim 150$ to 25 Ma.

McCann (2016a) identified the presence of Cretaceous sedimentation from the Albian to the Maastrichian in fluvial and shallow marine environments indicative of a coastal-marine transitional zone. During the Late Cretaceous the Kyzylkum-Nurata Segment experienced coastline change due to major marine incursions, with much of the material for sedimentation coming from the Late Jurassic-Early Cretaceous exhumed regions in the Kyzylkum-Nurata Segment (Figure 7). The sedimentary evidence, in conjunction with the thermochronological data provided in this paper, suggest that the KyzylkumNurata Segment experienced a period of erosion and denudation causing sedimentation during the Late Cretaceous-early Palaeogene (McCann 2016a).

The Late Cretaceous stability is contrasted by samples of the Aydar region, close to the South Tian Shan suture, which display over-lapping AFT and AHe thermochronometers (Figure 5 and 6, Tables 1 and 2). McCann (2016a) found that the northern and southern extents experienced a phase of terrestrial sedimentation during the Upper Cretaceous. The terrestrial sedimentation and over-lapping thermochronometers implies that the margins of the Northern Nurata Range experienced some degree of exhumation during the Late Cretaceous. Although, it is likely that the Cretaceous AFT and AHe ages represent mixing ages between the Early Cretaceous and late Palaeogene thermal events. 


\subsubsection{Palaeogene Reactivation}

During the Palaeogene, the Eurasian continent was redeformed as a result of the collision of India with Eurasia (e.g. Beck et al. 1995, Aitchison et al. 2007, Najman et al. 2010, van Hinsbergen et al. 2011). In the Kyzylkum-Nurata Segment we identify only a minor thermochronological response to this collision in the Karatyube Massif, proximal to the high elevation Gissar Range (Figure 3). In addition, it is possible that the presence of mixing ages in the Aydar region may also be an indicator of Palaeogene thermal activity, as explained above. Given the lack of relief within the Kyzylkum-Nurata Segment, the thermo-tectonic response to the India-Eurasia collision has not been exhumed to the surface yet.

In the South Tian Shan, numerous thermochronological studies report Palaeogene and Neogene ages that correspond with the collision and ongoing indenture of the Indian continent with Eurasia (Sobel et al. 2006a, De Grave et al. 2012, Bande et al. 2017b, Käßner et al. 2017b, Nachtergaele et al. 2017, Jepson et al. 2018). Since only a slight Palaeogene thermochronological signal can be identified in the Kyzylkum-Nurata Segment, it is likely that much of the exhuming strain and deformation produced by the India-Eurasia collision is partitioned away from the western margin of the South Tian Shan and into the core of the Tian Shan.

\subsection{Conclusion}

In this study we presented low-temperature apatite thermochronological analysis of forty-five samples from the western segment of the Southern Tian Shan, the Kyzylkum-Nurata Segment, in order to track its thermo-tectonic evolution through the Mesozoic-Cenozoic. The Kyzylkum-Nurata Segment experienced a phase of fast basement cooling and exhumation in the Triassic that is interpreted as a response to the closure of the Palaeo-Asian Ocean. During the Jurassic and Cretaceous, the study area experienced regional slow cooling. However, the major suture zones that dissect the Kyzylkum-Nurata Segment record rapid cooling during the Late Jurassic-Early Cretaceous, coincident with increased sedimentation in the Kyzylkum and Fergana Basins. We interpret this event of fault reactivation to be related with footwall exhumation as a response to extensional tectonics in the Tethys Ocean. In the Late Cretaceous, the Kyzylkum-Nurata Segment experienced a second phase of marine incursion, erosion, and slow cooling until the early Palaeogene. Finally, in the Palaeogene, the Kyzylkum-Nurata Segment records minor evidence for cooling and exhumation due to the collision of India with the Eurasian margin. 
This study has revealed that the western segment of the South Tian Shan has experienced a different thermo-tectonic evolution when compared to its core, where thermo-tectonic evolution of the South Tian Shan has been overprinted via rapid Cenozoic exhumation. The western segment preserves a detailed archive of the Mesozoic tectonic activity that Eurasia experienced prior to the India-Eurasia collision.

\subsection{Acknowledgements}

We are grateful to Farid Divaev, Vladimir Chirikin, and Yunus Mamadjanov, who were responsible for logistics and transportation in the field. This study was supported by an Australian Research Council Discovery grant (DP150101730). D. Konopelko was supported by the Ministry of Education and Science of the Russian Federation (project No 14.Y26.31.0018) and by travel grant (mer. 6-2018) from Saint Petersburg State University. Ben Wade and Sarah Gilbert are thanked for assistance with the LA-ICP-MS facility at the University of Adelaide. This paper forms TRaX record 407.

\section{References}

Aitchison, J. C., Ali, J. R. \& Davis, A. M. (2007), 'When and where did India and Asia collide?', Journal of Geophysical Research: Solid Earth 112(B5).

URL: https://agupubs.onlinelibrary.wiley.com/doi/abs/10.1029/2006JB004706

Alexeiev, D. V., Cook, H. E., Burtyshkin, V. M. \& Golub, L. Y. (2009), 'Structural evolution of the Ural-Tian Shan junction: A view from Karatau ridge, South Kazakhstan', Comptes Rendus Geoscience 341(2), 287 - 297. Mécanique de l'orogénie varisque : Une vision moderne de le recherche dans le domaine de l'orogénie.

URL: http://www.sciencedirect.com/science/article/pii/S163107130800285X

Angiolini, L., Andrea, Z., Stefano, Z., Alda, N. \& Giovanni, V. (2013), 'The Cimmerian geopuzzle: new data from South Pamir', Terra Nova 25(5), 352-360.

URL: https://onlinelibrary.wiley.com/doi/abs/10.1111/ter.12042

Bande, A., Sobel, E. R., Mikolaichuk, A. \& Torres, A. V. (2017b), 'Talas-Fergana Fault Cenozoic timing of deformation and its relation to Pamir indentation', Geological Society, London, Special 
Publications 427(1), 295-311.

URL: http://sp.lyellcollection.org/content/427/1/295

Beck, R. A., Burbank, D. W., Sercombe, W. J., Riley, G. W., Barndt, J. K., Berry, J. R., Afzal, J., Khan, A. M., Jurgen, H., Metje, J., Cheema, A., Shafique, N. A., Lawrence, R. D. \& Khan, M. A. (1995), 'Stratigraphic evidence for an early collision between northwest India and Asia', Nature $\mathbf{3 7 3}(6509), 55$.

Biske, Y. \& Seltmann, R. (2010), 'Paleozoic Tian-Shan as a transitional region between the Rheic and Urals-Turkestan oceans', Gondwana Research 17(2), 602 - 613. The Rheic Ocean: Palaeozoic Evolution from Gondwana and Laurussia to Pangaea.

URL: http://www.sciencedirect.com/science/article/pii/S1342937X09002160

Bosboom, R., Dupont-Nivet, G., Grothe, A., Brinkhuis, H., Villa, G., Mandic, O., Stoica, M., Kouwenhoven, T., Huang, W., Yang, W. \& Guo, Z. (2014), 'Timing, cause and impact of the late eocene stepwise sea retreat from the tarim basin (west china)', Palaeogeography, Palaeoclimatology, Palaeoecology 403, $101-118$.

URL: http://www.sciencedirect.com/science/article/pii/S0031018214001709

Bosboom, R. E., Dupont-Nivet, G., Houben, A., Brinkhuis, H., Villa, G., Mandic, O., Stoica, M., Zachariasse, W. J., Guo, Z., Li, C. \& Krijgsman, W. (2011), 'Late eocene sea retreat from the tarim basin (west china) and concomitant asian paleoenvironmental change', Palaeogeography, Palaeoclimatology, Palaeoecology 299(3), 385 - 398.

URL: http://www.sciencedirect.com/science/article/pii/S0031018210006954

Brookfield, M. (2000), 'Geological development and Phanerozoic crustal accretion in the western segment of the southern Tien Shan (Kyrgyzstan, Uzbekistan and Tajikistan)', Tectonophysics 328(12), 1-14.

Bullen, M., Burbank, D., Garver, J. \& Abdrakhmatov, K. (2001), 'Late Cenozoic tectonic evolution of the northwestern Tien Shan: New age estimates for the initiation of mountain building', GSA Bulletin 113(12), 1544.

URL: http://dx.doi.org/10.1130/0016-7606(2001)113<1544:LCTEOT>2.0.CO;2

Bullen, M. E., Burbank, D. W. \& Garver, J. I. (2003), 'Building the Northern Tien Shan: Integrated 
Thermal, Structural, and Topographic Constraints', The Journal of Geology 111(2), 149-165.

URL: https://doi.org/10.1086/345840

Burtman, V. (2000), 'Cenozoic crustal shortening between the Pamir and Tien Shan and a reconstruction of the Pamir-Tien Shan transition zone for the Cretaceous and Palaeogene', Tectonophysics 319(2), $69-92$.

URL: http://www.sciencedirect.com/science/article/pii/S0040195100000226

Burtman, V. S. (1975), 'Structural geology of variscan Tien Shan, USSR', Am. J. Sci 275, 157-186.

Burtman, V. S. (2015), 'Tectonics and geodynamics of the Tian Shan in the Middle and Late Paleozoic', Geotectonics 49(4), 302-319.

URL: https://doi.org/10.1134/S0016852115040020

Danišík, M., Štěpančíková, P. \& Evans, N. J. (2012), 'Constraining long-term denudation and faulting history in intraplate regions by multisystem thermochronology: An example of the Sudetic Marginal Fault (Bohemian Massif, central Europe)', Tectonics 31(2).

URL: https://agupubs.onlinelibrary.wiley.com/doi/abs/10.1029/2011TC003012

De Grave, J., Buslov, M. M. \& Van den haute, P. (2007), 'Distant effects of India-Eurasia convergence and Mesozoic intracontinental deformation in Central Asia: Constraints from apatite fissiontrack thermochronology', Journal of Asian Earth Sciences 29(2), 188 - 204. The 19th HimalayaKarakoram-Tibet Workshop (HKT19) held at Niseko, Hokkaido, Japan, 10-13 July 2004.

URL: http://www.sciencedirect.com/science/article/pii/S136791200600071X

De Grave, J., Glorie, S., Buslov, M. M., Izmer, A., Fournier-Carrie, A., Batalev, V. Y., Vanhaecke, F., Elburg, M. \& Van den haute, P. (2011), 'The thermo-tectonic history of the Song-Kul plateau, Kyrgyz Tien Shan: Constraints by apatite and titanite thermochronometry and zircon U/Pb dating', Gondwana Research 20(4), $745-763$.

URL: http://www.sciencedirect.com/science/article/pii/S1342937X11001201

De Grave, J., Glorie, S., Buslov, M. M., Stockli, D. F., McWilliams, M. O., Batalev, V. Y. \& Van den haute, P. (2013), 'Thermo-tectonic history of the Issyk-Kul basement (Kyrgyz Northern Tien Shan, Central Asia)', Gondwana Research 23(3), 998 - 1020. Ultrahigh-pressure and high-pressure metamorphic terranes in orogenic belts: reactions, fluids and geological processes.

URL: http://www.sciencedirect.com/science/article/pii/S1342937X12002377 
De Grave, J., Glorie, S., Ryabinin, A., Zhimulev, F., Buslov, M., Izmer, A., Elburg, M., Vanhaecke, F. \& Van den haute, P. (2012), 'Late Palaeozoic and Meso-Cenozoic tectonic evolution of the southern Kyrgyz Tien Shan: Constraints from multi-method thermochronology in the Trans-Alai, TurkestanAlai segment and the southeastern Ferghana Basin', Journal of Asian Earth Sciences 44, 149 - 168. Asian Climate and Tectonics.

URL: http://www.sciencedirect.com/science/article/pii/S1367912011001866

De Pelsmaeker, E., Glorie, S., Buslov, M. M., Zhimulev, F. I., Poujol, M., Korobkin, V. V., Vanhaecke, F., Vetrov, E. V. \& De Grave, J. (2015), 'Late-Paleozoic emplacement and Meso-Cenozoic reactivation of the southern Kazakhstan granitoid basement', Tectonophysics 662, 416 - 433. Special issue on Comparative tectonic and dynamic analysis of cratons, orogens, basins, and metallogeny:

URL: https://www.sciencedirect.com/science/article/pii/S0040195115003091

De Pelsmaeker, E., Jolivet, M., Laborde, A., Poujol, M., Robin, C., Zhimulev, F. I., Nachtergaele, S., Glorie, S., Clercq, S. D., Batalev, V. Y. \& Grave, J. D. (2018), 'Source-to-sink dynamics in the Kyrgyz Tien Shan from the Jurassic to the Paleogene: Insights from sedimentological and detrital zircon U-Pb analyses', Gondwana Research 54, 180 - 204.

URL: http://www.sciencedirect.com/science/article/pii/S1342937X17300679

Dolgopolova, A., Seltmann, R., Konopelko, D., Biske, Y. S., Shatov, V., Armstrong, R., Belousova, E., Pankhurst, R., Koneev, R. \& Divaev, F. (2017), 'Geodynamic evolution of the western tien shan, uzbekistan: Insights from u-pb shrimp geochronology and sr-nd-pb-hf isotope mapping of granitoids', Gondwana Research 47, 76 - 109. Continental construction in Central Asia and actualistic comparisons with western Pacific.

URL: http://www.sciencedirect.com/science/article/pii/S1342937X16304324

Dumitru, T. A., Zhou, D., Chang, E. Z., Graham, S. A., Hendrix, M. S., Sobel, E. R. \& Carroll, A. R. (2001), 'Uplift, exhumation, and deformation in the Chinese Tian Shan', Memoirs-Geological Society of America pp. 71-100.

Farley, K. A. (2002), '(U-Th)/He Dating: Techniques, Calibrations, and Applications', Reviews in Mineralogy and Geochemistry $\mathbf{4 7}(1), 819$.

URL: http://dx.doi.org/10.2138/rmg.2002.47.18

Farley, K., Wolf, R. \& Silver, L. (1996), 'The effects of long alpha-stopping distances on (U-Th)/He 
ages', Geochimica et Cosmochimica Acta 60(21), 4223 - 4229.

URL: http://www.sciencedirect.com/science/article/pii/S0016703796001937

Fleischer, R. L., Price, P. B., Walker, R. M. \& W., R. M. (1975), Nuclear tracks in solids: principles and applications, Univ of California Press.

Flowers, R. M., Farley, K. A. \& Ketcham, R. A. (2015), 'A reporting protocol for thermochronologic modeling illustrated with data from the Grand Canyon', Earth and Planetary Science Letters 432, $425-435$.

URL: http://www.sciencedirect.com/science/article/pii/S0012821X15006317

Gallagher, K. (2012), 'Transdimensional inverse thermal history modeling for quantitative thermochronology', Journal of Geophysical Research: Solid Earth 117(B2).

URL: https://agupubs.onlinelibrary.wiley.com/doi/abs/10.1029/2011JB008825

Gallagher, K. \& Brown, R. (1997), 'The onshore record of passive margin evolution', Journal of the Geological Society 154(3), 451-457.

URL: http://jgs.lyellcollection.org/content/154/3/451

Gallagher, K., Brown, R. \& Johnson, C. (1998), 'Fission track analysis and its applications to geological problems', Annual Review of Earth and Planetary Sciences 26(1), 519-572.

URL: https://doi.org/10.1146/annurev.earth.26.1.519

Gautheron, C., Tassan-Got, L., Barbarand, J. \& Pagel, M. (2009), 'Effect of alpha-damage annealing on apatite (U-Th)/He thermochronology', Chemical Geology 266(3), 157 - 170.

URL: http://www.sciencedirect.com/science/article/pii/S0009254109002630

Gillespie, J., Glorie, S., Jepson, G., Zhang, Z. Y., Xiao, W. J., Danišík, M. \& Collins, A. S. (2017), 'Differential Exhumation and Crustal Tilting in the Easternmost Tianshan (Xinjiang, China), Revealed by Low-Temperature Thermochronology', Tectonics 36(10), 2142-2158.

URL: https://agupubs.onlinelibrary.wiley.com/doi/abs/10.1002/2017TC004574

Gleadow, A., Harrison, M., Kohn, B., Lugo-Zazueta, R. \& Phillips, D. (2015), 'The fish canyon tuff: A new look at an old low-temperature thermochronology standard', Earth and Planetary Science Letters 424, 95 - 108.

URL: http://www.sciencedirect.com/science/article/pii/S0012821X15002927 
Gleadow, A. J., Belton, D. X., Kohn, B. P. \& Brown, R. W. (2002), 'Fission Track Dating of Phosphate Minerals and the Thermochronology of Apatite', Reviews in Mineralogy and Geochemistry 48(1), 579. URL: + http://dx.doi.org/10.2138/rmg.2002.48.16

Glorie, S., Alexandrov, I., Nixon, A., Jepson, G., Gillespie, J. \& Jahn, B.-M. (2017), 'Thermal and exhumation history of Sakhalin Island (Russia) constrained by apatite U-Pb and fission track thermochronology', Journal of Asian Earth Sciences 143, 326 - 342.

URL: http://www.sciencedirect.com/science/article/pii/S1367912017302262

Glorie, S. \& De Grave, J. (2016), 'Exhuming the Meso-Cenozoic Kyrgyz Tianshan and Siberian AltaiSayan: A review based on low-temperature thermochronology', Geoscience Frontiers 7(2), 155 170. Special Issue: Exhuming Asia.

URL: https://www.sciencedirect.com/science/article/pii/S1674987115000468

Glorie, S., De Grave, J., Buslov, M., Elburg, M., Stockli, D., Gerdes, A. \& Van den haute, P. (2010), 'Multi-method chronometric constraints on the evolution of the Northern Kyrgyz Tien Shan granitoids (Central Asian Orogenic Belt): From emplacement to exhumation', Journal of Asian Earth Sciences 38(3), $131-146$.

URL: http://www.sciencedirect.com/science/article/pii/S1367912009002636

Glorie, S., Grave, J. D., Buslov, M. M., Zhimulev, F. I., Stockli, D. F., Batalev, V. Y., Izmer, A., Van den haute, P., Vanhaecke, F. \& Elburg, M. A. (2011), 'Tectonic history of the Kyrgyz South Tien Shan (Atbashi-Inylchek) suture zone: The role of inherited structures during deformation-propagation', Tectonics 30(6).

URL: https://agupubs.onlinelibrary.wiley.com/doi/abs/10.1029/2011TC002949

Green, P., Duddy, I., Gleadow, A., Tingate, P. \& Laslett, G. (1986), 'Thermal annealing of fission tracks in apatite: 1. A qualitative description', Chemical Geology: Isotope Geoscience section 59, 237 253. Calibration of the Phanerozoic Time Scale.

URL: http://www.sciencedirect.com/science/article/pii/0168962286900746

Green, P. F. (1986), 'On the thermo-tectonic evolution of Northern England: evidence from fission track analysis', Geological Magazine 123(5), 493-506.

Hall, R. (2012), 'Late Jurassic-Cenozoic reconstructions of the Indonesian region and the Indian 
Ocean', Tectonophysics 570-571, 1-41.

URL: http://www.sciencedirect.com/science/article/pii/S0040195112002533

Haq, B. U., Hardenbol, J. \& Vail, P. R. (1987), 'Chronology of Fluctuating Sea Levels Since the Triassic', Science 235(4793), 1156-1167.

URL: http://science.sciencemag.org/content/235/4793/1156

Hasebe, N., Barbarand, J., Jarvis, K., Carter, A. \& Hurford, A. J. (2004), 'Apatite fission-track chronometry using laser ablation ICP-MS', Chemical Geology 207(3), 135 - 145.

URL: http://www.sciencedirect.com/science/article/pii/S0009254104000427

Jepson, G., Glorie, S., Konopelko, D., Gillespie, J., Danišík, M., Evans, N. J., Mamadjanov, Y. \& Collins, A. S. (2018), 'Thermochronological insights into the structural contact between the Tian Shan and Pamirs, Tajikistan', Terra Nova 30(2), 95-104.

URL: https://onlinelibrary.wiley.com/doi/abs/10.1111/ter.12313

Jolivet, M., Dominguez, S., Charreau, J., Chen, Y., Li, Y. \& Wang, Q. (2010), 'Mesozoic and Cenozoic tectonic history of the central Chinese Tian Shan: Reactivated tectonic structures and active deformation', Tectonics 29(6). TC6019.

URL: http://dx.doi.org/10.1029/2010TC002712

Jolivet, M., Heilbronn, G., Robin, C., Barrier, L., Bourquin, S., Guo, Z., Jia, Y., Guerit, L., Yang, W. \& Fu, B. (2013), 'Reconstructing the Late Palaeozoic - Mesozoic topographic evolution of the Chinese Tian Shan: available data and remaining uncertainties', Advances in Geosciences 37, 7-18. URL: https://hal-insu.archives-ouvertes.fr/insu-00920043

Kempe, U., Graupner, T., Seltmann, R., de Boorder, H., Dolgopolova, A. \& van Emmichoven, M. Z. (2016), 'The Muruntau gold deposit (Uzbekistan) - A unique ancient hydrothermal system in the southern Tien Shan', Geoscience Frontiers 7(3), 495 - 528. Special Issue: Giant Mineral Deposits. URL: http://www.sciencedirect.com/science/article/pii/S1674987115001139

Ketcham, R. A., Carter, A., Donelick, R. A., Barbarand, J. \& Hurford, A. J. (2007), 'Improved modeling of fission-track annealing in apatite', American Mineralogist 92(5-6), 799.

URL: http://dx.doi.org/10.2138/am.200\%.2281 
Käßner, A., Ratschbacher, L., Jonckheere, R., Enkelmann, E., Khan, J., Sonntag, B., Gloaguen, R., Gadoev, M. \& Oimahmadov, I. (2017b), 'Cenozoic intracontinental deformation and exhumation at the northwestern tip of the India-Asia collision - southwestern Tian Shan, Tajikistan, and Kyrgyzstan', Tectonics 35(9), 2171-2194.

URL: https://agupubs.onlinelibrary.wiley.com/doi/abs/10.1002/2015TC003897

Käßner, A., Ratschbacher, L., Pfänder, J. A., Hacker, B. R., Zack, G., Sonntag, B.-L., Khan, J., Stanek, K. P., Gadoev, M. \& Oimahmadov, I. (2017a), 'Proterozoic-Mesozoic history of the Central Asian orogenic belt in the Tajik and southwestern Kyrgyz Tian Shan: U-Pb, ${ }^{40} \mathrm{Ar} /{ }^{39} \mathrm{Ar}$, and fissiontrack geochronology and geochemistry of granitoids', GSA Bulletin 129(3-4), 281.

URL: http://dx.doi.org/10.1130/B31466.1

Konopelko, D., Klemd, R., Mamadjanov, Y., Hegner, E., Knorsch, M., Fidaev, D., Kern, M. \& Sergeev, S. (2015), 'Permian age of orogenic thickening and crustal melting in the Garm Block, South Tien Shan, Tajikistan', Journal of Asian Earth Sciences 113, 711 - 727. The Making of Asia.

URL: http://www.sciencedirect.com/science/article/pii/S1367912015300845

Konopelko, D. L., Biske, Y. S., Kullerud, K., Seltmann, R. \& Divaev, F. (2011), 'The Koshrabad granite massif in Uzbekistan: petrogenesis, metallogeny, and geodynamic setting', Russian Geology and Geophysics 52(12), 1563-1573. Geodynamics, Tectonics, and Metallogeny of Orogenic Belts.

URL: http://www.sciencedirect.com/science/article/pii/S1068797111002549

Konopelko, D., Seltmann, R., Mamadjanov, Y., Romer, R., Rojas-Agramonte, Y., Jeffries, T., Fidaev, D. \& Niyozov, A. (2017a), 'A geotraverse across two paleo-subduction zones in Tien Shan, Tajikistan', Gondwana Research 47, 110 - 130. Continental construction in Central Asia and actualistic comparisons with western Pacific.

URL: http://www.sciencedirect.com/science/article/pii/S1342937X16302878

Konopelko, D., Wilde, S., Seltmann, R., Romer, R. \& Biske, Y. S. (2018), 'Early Permian intrusions of the Alai range: Understanding tectonic settings of Hercynian post-collisional magmatism in the South Tien Shan, Kyrgyzstan', Lithos 302-303, 405-420.

URL: https://doi.org/10.1016/j.lithos.2018.01.024

Macaulay, E. A., Sobel, E. R., Mikolaichuk, A., Kohn, B. \& Stuart, F. M. (2014), 'Cenozoic deformation 
and exhumation history of the Central Kyrgyz Tien Shan', Tectonics 33(2), 135-165.

URL: https://agupubs.onlinelibrary.wiley.com/doi/abs/10.1002/2013TC003376

McCann, T. (2016a), 'The Cretaceous of the South Kyzylkum and Nuratau Region, Western Tien Shan, Central Uzbekistan', Geological Society, London, Special Publications 427(1), 439-489.

URL: http://sp.lyellcollection.org/content/427/1/439

McCann, T. (2016b), 'The Jurassic of the Western Tien Shan: the Central Kyzylkum Region, Uzbekistan', Geological Society, London, Special Publications 427(1), 411-437.

URL: http://sp.lyellcollection.org/content/427/1/411

McDowell, F. W., McIntosh, W. C. \& Farley, K. A. (2005), 'A precise 40Ar-39Ar reference age for the Durango apatite (U-Th)/He and fission-track dating standard', Chemical Geology 214(3), 249 $-263$.

URL: http://www.sciencedirect.com/science/article/pii/S0009254104004218

Nachtergaele, S., De Pelsmaeker, E., Glorie, S., Zhimulev, F., Jolivet, M., Danišík, M., Buslov, M. M. \& De Grave, J. (2017), 'Meso-Cenozoic tectonic evolution of the Talas-Fergana region of the Kyrgyz Tien Shan revealed by low-temperature basement and detrital thermochronology', Geoscience Frontiers .

URL: http://www.sciencedirect.com/science/article/pii/S1674987117302013

Najman, Y., Appel, E., Boudagher-Fadel, M., Bown, P., Carter, A., Garzanti, E., Godin, L., Han, J., Liebke, U., Oliver, G., Parrish, R. \& Vezzoli, G. (2010), 'Timing of India-Asia collision: Geological, biostratigraphic, and palaeomagnetic constraints', Journal of Geophysical Research: Solid Earth 115(B12). B12416.

URL: http://dx.doi.org/10.1029/2010JB007673

Paton, C., Hellstrom, J., Paul, B., Woodhead, J. \& Hergt, J. (2011), 'Iolite: Freeware for the visualisation and processing of mass spectrometric data', Journal of Analytical Atomic Spectrometry 26(12), 2508-2518.

Pearce, N. J., Perkins, W. T., Westgate, J. A., Gorton, M. P., Jackson, S. E., Neal, C. R. \& Chenery, S. P. (1997), 'A Compilation of New and Published Major and Trace Element Data for NIST SRM 610 and NIST SRM 612 Glass Reference Materials', Geostandards Newsletter 21(1), 115-144.

URL: https://onlinelibrary.wiley.com/doi/abs/10.1111/j.1751-908X.1997.tb00538.x 
Ratschbacher, L., Hacker, B. R., Calvert, A., Webb, L. E., Grimmer, J. C., McWilliams, M. O., Ireland, T., Dong, S. \& Hu, J. (2003), 'Tectonics of the Qinling (Central China): tectonostratigraphy, geochronology, and deformation history', Tectonophysics 366(1), 1 - 53.

URL: http://www.sciencedirect.com/science/article/pii/S0040195103000532

Robinson, A. C. (2015), 'Mesozoic tectonics of the Gondwanan terranes of the Pamir plateau', Journal of Asian Earth Sciences 102, 170 - 179. Special Issue on CIMMERIAN TERRANES.

URL: http://www.sciencedirect.com/science/article/pii/S1367912014004258

Rutte, D., Ratschbacher, L., Khan, J., Stübner, K., Hacker, B. R., Stearns, M. A., Enkelmann, E., Jonckheere, R., Pfänder, J. A., Sperner, B. \& Tichomirowa, M. (2017), 'Building the Pamir-Tibetan Plateau-Crustal stacking, extensional collapse, and lateral extrusion in the Central Pamir: 2. Timing and rates', Tectonics 36(3), 385-419. 2016TC004294.

URL: http://dx.doi.org/10.1002/2016TC004294

Seltmann, R., Konopelko, D., Biske, G., Divaev, F. \& Sergeev, S. (2011), 'Hercynian post-collisional magmatism in the context of Paleozoic magmatic evolution of the Tien Shan orogenic belt', Journal of Asian Earth Sciences 42(5), 821 - 838. Continental accretion and intra-continental deformation of the Central Asian Orogenic Belt.

URL: http://www.sciencedirect.com/science/article/pii/S1367912010002646

Sobel, E. R., Chen, J. \& Heermance, R. V. (2006a), 'Late Oligocene-Early Miocene initiation of shortening in the Southwestern Chinese Tian Shan: Implications for Neogene shortening rate variations', Earth and Planetary Science Letters 247(1), 70 - 81.

URL: http://www.sciencedirect.com/science/article/pii/S0012821X06002834

Sobel, E. R. \& Dumitru, T. A. (1997), 'Thrusting and exhumation around the margins of the western Tarim basin during the India-Asia collision', Journal of Geophysical Research: Solid Earth 102(B3), 5043-5063.

URL: http://dx.doi.org/10.1029/96JB03267

Sobel, E. R., Oskin, M., Burbank, D. \& Mikolaichuk, A. (2006b), 'Exhumation of basement-cored uplifts: Example of the Kyrgyz Range quantified with apatite fission track thermochronology', Tectonics 25(2). TC2008.

URL: http://dx.doi.org/10.1029/2005TC001809 
Stockli, D. F., Surpless, B. E., Dumitru, T. A. \& Farley, K. A. (2002), 'Thermochronological constraints on the timing and magnitude of Miocene and Pliocene extension in the central Wassuk Range, western Nevada', Tectonics 21(4), 10-1-10-19.

URL: https://agupubs.onlinelibrary.wiley.com/doi/abs/10.1029/2001TC001295

Survey, U. G. (2012), 'Geological Map of Uzbekistan', State Geological Information Centre .

van Hinsbergen, D. J. J., Steinberger, B., Doubrovine, P. V. \& Gassmöller, R. (2011), 'Acceleration and deceleration of India-Asia convergence since the Cretaceous: Roles of mantle plumes and continental collision', Journal of Geophysical Research: Solid Earth 116(B6). B06101.

URL: http://dx.doi.org/10.1029/2010JB008051

Vermeesch, P. (2009), 'RadialPlotter: A Java application for fission track, luminescence and other radial plots', Radiation Measurements 44(4), 409-410.

Vermeesch, P. (2017), 'Statistics for LA-ICP-MS based fission track dating', Chemical Geology 456, 19 $-27$.

URL: http://www.sciencedirect.com/science/article/pii/S0009254117301158

Wagner, G. A. \& Van den haute, P. (1992), 'Fission-track dating', Kluwer Academic Publishers p. 285.

Windley, B. F., Alexeiev, D., Xiao, W., Kröner, A. \& Badarch, G. (2007), 'Tectonic models for accretion of the Central Asian Orogenic Belt', Journal of the Geological Society 164(1), 31.

URL: http://dx.doi.org/10.1144/0016-76492006-022

Xiao, W. J., Windley, B. F., Huang, B. C., Han, C. M., Yuan, C., Chen, H. L., Sun, M., Sun, S. \& Li, J. L. (2009), 'End-Permian to mid-Triassic termination of the accretionary processes of the southern Altaids: implications for the geodynamic evolution, Phanerozoic continental growth, and metallogeny of Central Asia', International Journal of Earth Sciences 98(6), 1189-1217.

URL: https://doi.org/10.100\%/s00531-008-040\%-z

Xiao, W., Windley, B. F., Allen, M. B. \& Han, C. (2013), 'Paleozoic multiple accretionary and collisional tectonics of the Chinese Tianshan orogenic collage', Gondwana Research 23(4), 1316 - 1341. URL: http://www.sciencedirect.com/science/article/pii/S1342937X12000469

Yin, A. \& Harrison, T. M. (2000), 'Geologic Evolution of the Himalayan-Tibetan Orogen', Annual 
Review of Earth and Planetary Sciences 28(1), 211-280.

URL: https://doi.org/10.1146/annurev.earth.28.1.211

Zahirovic, S., Matthews, K. J., Flament, N., Müller, R. D., Hill, K. C., Seton, M. \& Gurnis, M. (2016),

'Tectonic evolution and deep mantle structure of the eastern Tethys since the latest Jurassic', Earth-

Science Reviews 162, 293-337.

URL: http://www.sciencedirect.com/science/article/pii/S0012825216302872

Zeitler, P., Herczeg, A., McDougall, I. \& Honda, M. (1987), 'U-Th-He dating of apatite: A potential thermochronometer', Geochimica et Cosmochimica Acta 51(10), 2865 - 2868.

URL: http://www.sciencedirect.com/science/article/pii/0016703787901645

\section{Supplementary Files}

\subsection{Supplementary File 1}

Apatite fission track data and chemical data: $\rho_{\mathrm{s}}$ is the density of spontaneous tracks within the region of interest and is expressed as $10^{5}$ tracks $/ \mathrm{cm}^{2} . N_{\mathrm{s}}$ is the total number of counted spontaneous tracks per sample. ${ }^{238} \mathrm{U}$ is the average concentration in ppm of uranium 238 measured in each grain. ${ }^{35} \mathrm{Cl}$ is the average concentration in ppm of chlorine 35 measured in each grain; concentrations were obtained using laser ablation-inductively coupled plasma-mass spectrometry (LA-ICP-MS). BLOD is below limits of detection, and thus, could not provide a concentration value and was not used in calculating sample concentration averages. Dpar is the length of spontaneous track etch pits in $\mu \mathrm{m}$. $\mathrm{t}$ is the AFT single grain age for each sample in Ma.

\begin{tabular}{|c|c|c|c|c|c|c|c|c|c|c|}
\hline Sample & $\rho_{\mathrm{s}}$ & $N_{\mathrm{s}}$ & ${ }^{238} \mathrm{U}$ & $\pm 1 \sigma$ & ${ }^{35} \mathrm{Cl}$ & $\pm 1 \sigma$ & Dpar & $\pm 1 \sigma$ & $\mathrm{t}$ & $\pm 1 \sigma$ \\
$\mathrm{UZ}-01-1$ & 13.9 & 40 & 26.9 & 1.5 & 1820 & 110 & 1.7 & 0.5 & 107.5 & 19.6 \\
$\mathrm{UZ}-01-2$ & 3.3 & 10 & 26.1 & 2.3 & 10500 & 5500 & 2.0 & 0.1 & 26.3 & 8.8 \\
$\mathrm{UZ}-01-3$ & 3.5 & 7 & 21.6 & 2.4 & 2270 & 300 & 2.2 & 0.5 & 33.2 & 13.3 \\
$\mathrm{UZ}-01-4$ & 7.6 & 20 & 29.0 & 2.3 & 11900 & 4500 & 2.3 & 0.9 & 54.3 & 13.5 \\
$\mathrm{UZ}-01-5$ & 11.7 & 29 & 23.8 & 2.4 & 2400 & 140 & 2.5 & 1.1 & 102.0 & 22.8 \\
$\mathrm{UZ}-01-6$ & 13.4 & 72 & 30.3 & 1.6 & 29400 & 8800 & 2.1 & 1.0 & 91.9 & 13.6 \\
$\mathrm{UZ}-01-7$ & 13.3 & 50 & 31.9 & 1.8 & 1840 & 140 & 1.9 & 0.3 & 86.4 & 14.6 \\
$\mathrm{UZ}-01-8$ & 12.0 & 23 & 18.9 & 1.0 & 2350 & 140 & 2.4 & 0.2 & 131.5 & 29.8 \\
$\mathrm{UZ}-01-9$ & 3.2 & 10 & 16.8 & 1.3 & 6500 & 1800 & 1.9 & 0.5 & 39.1 & 13.0 \\
$\mathrm{UZ}-01-10$ & 12.2 & 53 & 33.0 & 2.4 & 2250 & 150 & 1.9 & 0.3 & 76.6 & 13.1
\end{tabular}




\begin{tabular}{|c|c|c|c|c|c|c|c|c|c|c|}
\hline UZ-01-11 & 15.1 & 25 & 17.6 & 1.6 & 1740 & 150 & 2.0 & 0.6 & 177.6 & 41.1 \\
\hline UZ-01-12 & 13.2 & 42 & 17.2 & 3.2 & 2310 & 180 & 2.1 & 0.7 & 159.7 & 40.3 \\
\hline UZ-01-13 & 15.5 & 78 & 25.8 & 2.4 & 2240 & 150 & 2.1 & 0.9 & 124.8 & 20.4 \\
\hline UZ-01-14 & 7.7 & 21 & 36.0 & 2.4 & 2690 & 620 & 1.7 & 0.3 & 44.2 & 10.6 \\
\hline UZ-01-15 & 10.3 & 34 & 32.9 & 2.1 & 5600 & 2100 & 1.9 & 0.5 & 64.9 & 12.8 \\
\hline UZ-01-16 & 16.6 & 66 & 29.8 & 1.8 & 2390 & 340 & 1.9 & 0.4 & 115.7 & 17.9 \\
\hline UZ-01-17 & 5.7 & 15 & 23.4 & 1.4 & 15400 & 5100 & 1.7 & 0.6 & 50.4 & 13.8 \\
\hline UZ-01-18 & 12.6 & 37 & 36.0 & 2.9 & 2040 & 130 & 1.8 & 0.3 & 72.3 & 14.2 \\
\hline UZ-01-19 & 4.4 & 21 & 11.8 & 0.7 & 2360 & 130 & 2.1 & 0.7 & 77.4 & 18.3 \\
\hline UZ-01-20 & 6.0 & 15 & 19.3 & 1.2 & 2950 & 220 & 3.0 & 2.0 & 64.0 & 17.6 \\
\hline UZ-01-21 & 28.7 & 54 & 101.3 & 7.6 & 198000 & 29000 & 2.0 & 0.6 & 58.7 & 10.1 \\
\hline UZ-01-22 & 15.1 & 25 & 30.3 & 2.6 & 1890 & 160 & 2.1 & 0.6 & 103.5 & 23.7 \\
\hline UZ-01-23 & 15.2 & 19 & 19.7 & 1.2 & 7200 & 3100 & 2.6 & 1.3 & 159.6 & 39.6 \\
\hline UZ-01-24 & 13.7 & 41 & 37.6 & 3.3 & 5300 & 2100 & 1.6 & 0.3 & 75.7 & 14.6 \\
\hline UZ-01-25 & 12.2 & 70 & 25.6 & 2.4 & 1750 & 110 & 1.6 & 0.3 & 98.7 & 16.6 \\
\hline UZ-01-26 & 14.8 & 44 & 39.9 & 3.7 & 11900 & 5600 & 1.7 & 0.3 & 76.8 & 14.7 \\
\hline UZ-01-27 & 9.0 & 42 & 30.6 & 2.4 & 1560 & 130 & 1.8 & 0.3 & 61.3 & 11.5 \\
\hline UZ-01-28 & 16.5 & 57 & 21.3 & 1.4 & 1910 & 200 & 1.7 & 0.3 & 160.2 & 26.3 \\
\hline UZ-01-29 & 11.3 & 25 & 14.4 & 1.0 & 1910 & 150 & 1.8 & 0.4 & 162.5 & 36.3 \\
\hline UZ-01-30 & 16.3 & 59 & 36.7 & 2.7 & 2940 & 180 & 2.1 & 0.4 & 92.2 & 15.3 \\
\hline UZ-01-31 & 5.9 & 14 & 24.6 & 1.8 & 11400 & 4200 & 2.0 & 0.7 & 49.6 & 14.2 \\
\hline UZ-01-32 & 13.9 & 53 & 38.0 & 2.8 & 3250 & 230 & 2.1 & 0.3 & 75.9 & 13.0 \\
\hline UZ-01-33 & 11.4 & 48 & 33.4 & 2.1 & 2340 & 190 & 1.9 & 0.3 & 70.5 & 12.2 \\
\hline UZ-02-1 & 0.5 & 1 & 1.5 & 0.1 & 1800 & 120 & 3.1 & 0.7 & 68.5 & 68.8 \\
\hline UZ-02-2 & 23.3 & 81 & 38.5 & 2.1 & 970 & 290 & 2.3 & 0.8 & 125.6 & 18.0 \\
\hline UZ-02-3 & 0.6 & 1 & 1.6 & 0.1 & 1740 & 120 & 2.9 & 0.5 & 71.3 & 71.7 \\
\hline UZ-02-4 & 0.6 & 1 & 2.2 & 0.3 & 2660 & 680 & 2.9 & 0.5 & 55.4 & 56.1 \\
\hline UZ-02-5 & 1.4 & 4 & 2.6 & 0.2 & 1340 & 130 & 2.9 & 0.5 & 108.4 & 55.4 \\
\hline UZ-02-6 & 1.4 & 2 & 3.3 & 0.2 & 40100 & 5600 & 1.7 & 0.5 & 89.2 & 63.7 \\
\hline UZ-02-7 & 0.4 & 1 & 2.3 & 0.1 & 2030 & 150 & 4.1 & 0.7 & 36.3 & 36.5 \\
\hline UZ-02-8 & 2.7 & 5 & 2.4 & 0.2 & 3030 & 880 & 5.8 & 0.4 & 234.1 & 107.5 \\
\hline
\end{tabular}




\begin{tabular}{|c|c|c|c|c|c|c|c|c|c|c|}
\hline UZ-02-9 & 0.9 & 3 & 1.7 & 0.1 & 1890 & 120 & 1.9 & 0.6 & 110.7 & 64.6 \\
\hline UZ-02-10 & 0.9 & 4 & 1.9 & 0.1 & 1216 & 98 & 2.5 & 1.1 & 103.4 & 52.5 \\
\hline UZ-02-11 & 1.0 & 2 & 2.0 & 0.1 & 1550 & 170 & 1.9 & 0.6 & 100.5 & 71.7 \\
\hline UZ-02-12 & 0.9 & 2 & 3.7 & 0.3 & 16000 & 11000 & 1.9 & 0.6 & 52.6 & 37.6 \\
\hline UZ-02-13 & 1.0 & 2 & 2.0 & 0.1 & 1810 & 120 & 1.9 & 0.6 & 107.0 & 76.3 \\
\hline UZ-02-14 & 1.0 & 3 & 2.1 & 0.1 & 1520 & 130 & 3.4 & 0.3 & 100.3 & 58.7 \\
\hline UZ-02-15 & 13.5 & 65 & 24.8 & 1.9 & 516 & 93 & 2.5 & 0.5 & 113.1 & 18.4 \\
\hline UZ-02-16 & 2.2 & 4 & 3.0 & 0.2 & 2430 & 270 & 2.9 & 0.2 & 148.5 & 75.9 \\
\hline UZ-02-17 & 19.9 & 81 & 33.8 & 4.2 & 22000 & 16000 & 2.4 & 0.7 & 122.2 & 22.2 \\
\hline UZ-02-18 & 1.0 & 4 & 2.5 & 0.2 & 30900 & 7600 & 1.9 & 0.6 & 87.1 & 44.4 \\
\hline UZ-02-19 & 0.9 & 2 & 2.4 & 0.1 & 1170 & 140 & 2.6 & 0.6 & 82.2 & 58.5 \\
\hline UZ-02-20 & 1.1 & 5 & 1.9 & 0.1 & 1870 & 260 & 3.0 & 0.1 & 123.7 & 56.3 \\
\hline UZ-02-21 & 2.4 & 5 & 2.2 & 0.1 & 1390 & 150 & 2.2 & 0.3 & 231.3 & 105.9 \\
\hline UZ-02-22 & 1.1 & 2 & 1.9 & 0.1 & 2350 & 180 & 3.4 & 0.3 & 116.4 & 83.0 \\
\hline UZ-02-23 & 1.2 & 3 & 2.2 & 0.2 & 1770 & 120 & 3.2 & 0.2 & 115.2 & 67.5 \\
\hline UZ-02-24 & 3.1 & 6 & 2.0 & 0.1 & 3230 & 200 & 2.9 & 0.2 & 329.6 & 138.3 \\
\hline UZ-02-25 & 2.1 & 3 & 3.7 & 0.2 & 18300 & 7200 & 3.0 & 0.8 & 117.6 & 68.7 \\
\hline UZ-02-26 & 18.1 & 28 & 17.6 & 1.3 & 520 & 130 & 2.2 & 0.3 & 212.7 & 45.8 \\
\hline UZ-02-27 & 0.7 & 2 & 2.0 & 0.2 & 1910 & 140 & 2.4 & 0.2 & 77.8 & 55.6 \\
\hline UZ-02-28 & 1.5 & 4 & 2.4 & 0.3 & 9400 & 4900 & 3.4 & 0.3 & 125.6 & 65.6 \\
\hline UZ-02-29 & 3.2 & 5 & 2.5 & 0.1 & 30000 & 11000 & 2.3 & 0.5 & 270.7 & 123.3 \\
\hline UZ-02-30 & 1.3 & 3 & 2.6 & 0.2 & 3080 & 320 & 2.1 & 0.5 & 102.3 & 60.1 \\
\hline UZ-02-31 & 1.2 & 3 & 2.2 & 0.1 & 2730 & 450 & 2.1 & 0.5 & 110.5 & 64.5 \\
\hline UZ-02-32 & 6.6 & 18 & 20.1 & 1.3 & 540 & 130 & 2.8 & 0.2 & 68.3 & 17.4 \\
\hline UZ-04-1 & 24.8 & 100 & 27.2 & 1.2 & 3140 & 290 & 2.0 & 0.3 & 199.4 & 23.7 \\
\hline UZ-04-2 & 38.8 & 105 & 37.6 & 1.7 & 5370 & 460 & 2.0 & 0.3 & 225.6 & 26.4 \\
\hline UZ-04-3 & 26.7 & 97 & 46.2 & 2.1 & 6030 & 410 & 2.0 & 0.3 & 126.5 & 15.3 \\
\hline UZ-04-4 & 32.3 & 170 & 34.6 & 1.6 & 5390 & 430 & 2.0 & 0.3 & 204.1 & 20.6 \\
\hline UZ-04-5 & 4.0 & 16 & 5.9 & 0.4 & 24500 & 3600 & 1.7 & 0.3 & 149.8 & 39.2 \\
\hline UZ-04-6 & 25.1 & 83 & 32.8 & 1.2 & 6260 & 460 & 1.7 & 0.3 & 167.8 & 20.9 \\
\hline UZ-04-7 & 7.0 & 24 & 9.6 & 0.5 & 3410 & 500 & 1.7 & 0.2 & 159.4 & 34.6 \\
\hline
\end{tabular}




\begin{tabular}{|c|c|c|c|c|c|c|c|c|c|c|}
\hline UZ-04-8 & 27.4 & 67 & 35.6 & 1.4 & 5520 & 400 & 1.9 & 0.3 & 168.5 & 23.0 \\
\hline UZ-04-9 & 41.2 & 57 & 46.0 & 2.2 & 8820 & 580 & 1.4 & 0.2 & 196.2 & 29.1 \\
\hline UZ-04-10 & 30.6 & 81 & 28.6 & 1.3 & 4020 & 320 & 1.9 & 0.3 & 234.0 & 30.1 \\
\hline UZ-04-11 & 15.8 & 35 & 35.8 & 2.3 & 25600 & 6600 & 2.2 & 0.3 & 96.5 & 18.0 \\
\hline UZ-04-12 & 29.4 & 70 & 36.0 & 1.5 & 3120 & 330 & 1.8 & 0.3 & 178.5 & 24.1 \\
\hline UZ-04-13 & 44.1 & 95 & 51.4 & 2.1 & 6140 & 380 & 1.8 & 0.2 & 187.8 & 22.5 \\
\hline UZ-04-14 & 27.7 & 58 & 39.7 & 1.9 & 6130 & 500 & 1.8 & 0.4 & 152.6 & 22.5 \\
\hline UZ-04-15 & 18.1 & 34 & 16.3 & 1.2 & 530 & 250 & 1.5 & 0.3 & 243.3 & 46.8 \\
\hline UZ-04-16 & 5.0 & 18 & 9.6 & 0.4 & BLOD & BLOD & 1.3 & 0.4 & 113.0 & 27.6 \\
\hline UZ-04-17 & 28.0 & 76 & 30.7 & 1.3 & 5520 & 390 & 1.9 & 0.2 & 199.3 & 26.1 \\
\hline UZ-04-18 & 28.4 & 74 & 30.7 & 1.4 & 6040 & 440 & 1.8 & 0.3 & 202.3 & 27.0 \\
\hline UZ-04-19 & 30.5 & 49 & 34.0 & 1.6 & 6470 & 490 & 2.1 & 0.3 & 196.1 & 30.9 \\
\hline UZ-04-20 & 34.9 & 100 & 39.2 & 2.3 & 8000 & 540 & 2.1 & 0.3 & 194.7 & 24.3 \\
\hline UZ-04-21 & 27.5 & 102 & 36.4 & 1.6 & 5770 & 460 & 2.0 & 0.2 & 165.6 & 19.5 \\
\hline UZ-04-22 & 23.8 & 39 & 51.2 & 3.1 & 5520 & 920 & 1.7 & 0.1 & 101.7 & 18.1 \\
\hline UZ-04-23 & 42.0 & 79 & 58.2 & 3.3 & 5860 & 500 & 1.9 & 0.3 & 158.0 & 21.2 \\
\hline UZ-04-24 & 29.9 & 126 & 38.0 & 1.6 & 6520 & 380 & 2.1 & 0.2 & 172.2 & 18.8 \\
\hline UZ-04-25 & 19.9 & 73 & 25.4 & 1.2 & 3610 & 360 & 1.8 & 0.3 & 171.7 & 23.1 \\
\hline UZ-04-26 & 31.2 & 143 & 31.9 & 2.1 & 6450 & 500 & 2.2 & 0.3 & 213.8 & 24.8 \\
\hline UZ-05-1 & 10.6 & 28 & 10.6 & 0.6 & BLOD & BLOD & 1.8 & 0.1 & 207.9 & 41.5 \\
\hline UZ-05-2 & 17.3 & 17 & 19.7 & 1.0 & 1510 & 430 & 2.1 & 0.8 & 183.3 & 45.9 \\
\hline UZ-05-3 & 58.3 & 114 & 98.2 & 4.0 & 900 & 340 & 1.8 & 0.4 & 124.0 & 13.5 \\
\hline UZ-05-4 & 22.7 & 61 & 20.9 & 0.8 & 620 & 300 & 1.9 & 0.2 & 226.5 & 31.4 \\
\hline UZ-05-5 & 6.9 & 7 & 11.7 & 0.8 & 19000 & 4100 & 1.6 & 0.0 & 123.5 & 47.7 \\
\hline UZ-05-6 & 27.6 & 60 & 33.3 & 1.6 & 1070 & 330 & 1.7 & 0.4 & 173.5 & 24.8 \\
\hline UZ-05-7 & 14.5 & 49 & 9.3 & 0.4 & 780 & 330 & 1.2 & 0.3 & 326.1 & 50.0 \\
\hline UZ-05-8 & 10.9 & 23 & 22.7 & 2.3 & 2840 & 790 & 1.3 & 0.1 & 100.5 & 23.6 \\
\hline UZ-05-9 & 20.9 & 21 & 18.8 & 1.3 & 1660 & 350 & 1.2 & 0.3 & 232.1 & 53.8 \\
\hline UZ-05-10 & 9.4 & 28 & 6.5 & 0.3 & 840 & 380 & 1.3 & 0.2 & 302.8 & 60.3 \\
\hline UZ-05-11 & 31.1 & 71 & 37.8 & 1.8 & 4700 & 1200 & 1.3 & 0.3 & 171.8 & 22.9 \\
\hline UZ-05-12 & 27.1 & 60 & 44.8 & 1.4 & 1350 & 360 & 1.3 & 0.4 & 126.4 & 17.4 \\
\hline
\end{tabular}




\begin{tabular}{|c|c|c|c|c|c|c|c|c|c|c|}
\hline UZ-05-13 & 14.8 & 37 & 14.3 & 0.9 & 1160 & 320 & 1.3 & 0.5 & 216.2 & 38.9 \\
\hline UZ-05-14 & 4.2 & 12 & 12.0 & 0.4 & 710 & 330 & 1.0 & 0.1 & 73.3 & 21.5 \\
\hline UZ-05-15 & 13.6 & 40 & 21.9 & 1.3 & BLOD & BLOD & 1.1 & 0.2 & 130.1 & 22.5 \\
\hline UZ-05-16 & 25.2 & 40 & 29.7 & 1.4 & BLOD & BLOD & 1.2 & 0.3 & 177.4 & 30.0 \\
\hline UZ-05-17 & 26.4 & 74 & 17.9 & 1.2 & BLOD & BLOD & 1.2 & 0.3 & 308.7 & 43.0 \\
\hline UZ-05-18 & 18.6 & 33 & 14.4 & 0.7 & 970 & 310 & 1.5 & 0.5 & 270.0 & 50.0 \\
\hline UZ-05-19 & 8.9 & 27 & 11.3 & 0.5 & 860 & 300 & 1.2 & 0.2 & 165.4 & 33.2 \\
\hline UZ-05-20 & 9.6 & 35 & 17.3 & 1.2 & 870 & 350 & 2.2 & 0.3 & 116.0 & 21.6 \\
\hline UZ-05-21 & 6.4 & 29 & 7.6 & 0.5 & BLOD & BLOD & 2.2 & 0.6 & 176.7 & 35.1 \\
\hline UZ-05-22 & 3.6 & 15 & 4.5 & 0.3 & BLOD & BLOD & 1.2 & 0.3 & 169.2 & 45.1 \\
\hline UZ-05-23 & 9.5 & 51 & 13.1 & 0.7 & 1090 & 400 & 2.3 & 0.7 & 151.7 & 23.6 \\
\hline UZ-05-24 & 17.2 & 23 & 35.6 & 3.4 & 6500 & 2200 & 2.7 & 0.3 & 100.8 & 23.4 \\
\hline UZ-05-25 & 19.1 & 48 & 18.7 & 1.4 & 990 & 350 & 2.1 & 0.7 & 213.6 & 35.6 \\
\hline UZ-05-26 & 12.4 & 49 & 13.3 & 0.7 & BLOD & BLOD & 1.5 & 0.2 & 194.0 & 30.5 \\
\hline UZ-05-27 & 6.1 & 28 & 10.5 & 0.6 & BLOD & BLOD & 1.6 & 0.3 & 122.0 & 24.4 \\
\hline UZ-05-28 & 19.6 & 48 & 21.4 & 1.8 & BLOD & BLOD & 1.6 & 0.3 & 191.1 & 32.7 \\
\hline UZ-05-29 & 14.7 & 41 & 12.8 & 0.8 & 27400 & 2300 & 1.1 & 0.2 & 238.9 & 41.2 \\
\hline UZ-05-30 & 11.3 & 21 & 14.7 & 0.6 & BLOD & BLOD & 1.8 & 0.6 & 161.4 & 36.4 \\
\hline UZ-05-31 & 17.4 & 32 & 16.1 & 1.2 & 830 & 240 & 1.6 & 0.2 & 226.0 & 44.2 \\
\hline UZ-07-1 & 20.6 & 74 & 40.7 & 1.3 & BLOD & BLOD & 1.2 & 0.3 & 105.6 & 13.3 \\
\hline UZ-07-2 & 23.8 & 63 & 32.4 & 1.1 & 480 & 310 & 1.2 & 0.3 & 153.3 & 20.8 \\
\hline UZ-07-3 & 13.7 & 50 & 33.8 & 1.3 & BLOD & BLOD & 1.1 & 0.2 & 84.5 & 12.8 \\
\hline UZ-07-4 & 18.2 & 73 & 29.5 & 1.5 & BLOD & BLOD & 0.9 & 0.2 & 129.2 & 17.2 \\
\hline UZ-07-5 & 19.7 & 68 & 44.4 & 1.5 & BLOD & BLOD & 0.9 & 0.2 & 92.8 & 12.2 \\
\hline UZ-07-6 & 19.3 & 94 & 30.2 & 1.4 & BLOD & BLOD & 1.1 & 0.2 & 133.7 & 15.9 \\
\hline UZ-07-7 & 27.7 & 61 & 43.7 & 1.8 & 600 & 280 & 1.2 & 0.2 & 132.3 & 18.5 \\
\hline UZ-07-8 & 14.6 & 56 & 32.0 & 1.6 & 850 & 290 & 1.1 & 0.2 & 95.4 & 14.1 \\
\hline UZ-07-9 & 15.1 & 63 & 25.5 & 1.2 & BLOD & BLOD & 1.4 & 0.3 & 123.6 & 17.3 \\
\hline UZ-07-10 & 2.4 & 12 & 2.5 & 0.2 & 9190 & 760 & 1.5 & 0.2 & 199.7 & 60.3 \\
\hline UZ-07-11 & 27.6 & 114 & 38.3 & 1.7 & 550 & 320 & 1.7 & 0.3 & 150.6 & 16.6 \\
\hline UZ-07-12 & 20.0 & 83 & 33.0 & 1.8 & 2260 & 470 & 1.1 & 0.3 & 126.6 & 16.2 \\
\hline
\end{tabular}




\begin{tabular}{|c|c|c|c|c|c|c|c|c|c|c|}
\hline UZ-07-13 & 40.5 & 169 & 61.6 & 2.2 & 4800 & 1600 & 1.4 & 0.3 & 137.5 & 12.7 \\
\hline UZ-07-14 & 11.2 & 53 & 19.2 & 0.8 & BLOD & BLOD & 0.8 & 0.2 & 121.8 & 18.1 \\
\hline UZ-07-15 & 26.7 & 91 & 42.8 & 2.1 & BLOD & BLOD & 1.5 & 0.2 & 130.4 & 15.9 \\
\hline UZ-07-16 & 14.8 & 53 & 17.7 & 0.7 & 830 & 280 & 1.2 & 0.2 & 174.2 & 25.8 \\
\hline UZ-07-17 & 19.1 & 93 & 32.6 & 1.4 & BLOD & BLOD & 1.3 & 0.3 & 122.6 & 14.5 \\
\hline UZ-07-18 & 23.8 & 81 & 39.5 & 1.5 & BLOD & BLOD & 1.1 & 0.3 & 125.7 & 15.5 \\
\hline UZ-07-19 & 24.3 & 100 & 37.8 & 1.4 & 520 & 240 & 1.0 & 0.3 & 134.5 & 15.2 \\
\hline UZ-07-20 & 19.9 & 78 & 31.6 & 1.0 & 690 & 270 & 1.0 & 0.2 & 131.6 & 16.2 \\
\hline UZ-07-21 & 13.4 & 57 & 32.4 & 1.4 & BLOD & BLOD & 0.9 & 0.2 & 86.1 & 12.4 \\
\hline UZ-07-22 & 15.7 & 78 & 21.5 & 0.7 & BLOD & BLOD & 1.2 & 0.3 & 152.9 & 19.0 \\
\hline UZ-07-23 & 3.9 & 19 & 4.5 & 0.2 & 1710 & 340 & 1.2 & 0.2 & 183.5 & 43.4 \\
\hline UZ-07-24 & 24.5 & 126 & 40.7 & 1.6 & 640 & 300 & 1.1 & 0.3 & 125.7 & 13.1 \\
\hline UZ-07-25 & 19.6 & 80 & 24.5 & 1.1 & 640 & 270 & 1.0 & 0.3 & 166.9 & 21.1 \\
\hline UZ-07-26 & 26.6 & 107 & 46.5 & 2.6 & BLOD & BLOD & 1.0 & 0.2 & 119.7 & 14.1 \\
\hline UZ-07-27 & 24.7 & 93 & 50.1 & 3.3 & BLOD & BLOD & 1.2 & 0.2 & 102.9 & 13.2 \\
\hline UZ-07-28 & 22.4 & 81 & 38.2 & 1.7 & BLOD & BLOD & 1.0 & 0.3 & 122.3 & 15.3 \\
\hline UZ-07-29 & 21.5 & 100 & 39.7 & 1.6 & BLOD & BLOD & 1.3 & 0.4 & 113.4 & 12.9 \\
\hline UZ-07-30 & 13.4 & 63 & 28.2 & 1.5 & BLOD & BLOD & 1.3 & 0.3 & 99.3 & 14.1 \\
\hline UZ-07-31 & 15.5 & 74 & 22.9 & 0.9 & BLOD & BLOD & 1.4 & 0.3 & 141.4 & 18.2 \\
\hline UZ-07-32 & 24.1 & 91 & 43.6 & 1.7 & 520 & 250 & 1.2 & 0.3 & 115.5 & 13.6 \\
\hline UZ-07-33 & 25.1 & 106 & 44.0 & 2.2 & BLOD & BLOD & 1.1 & 0.2 & 119.2 & 13.8 \\
\hline UZ-07-34 & 19.5 & 86 & 40.9 & 1.7 & BLOD & BLOD & 1.2 & 0.3 & 99.8 & 12.1 \\
\hline UZ-07-35 & 25.3 & 78 & 49.4 & 2.7 & 540 & 320 & 1.2 & 0.2 & 107.1 & 14.0 \\
\hline UZ-07-36 & 22.5 & 113 & 30.4 & 2.0 & BLOD & BLOD & 1.5 & 0.3 & 154.9 & 18.7 \\
\hline UZ-07-37 & 20.5 & 44 & 38.2 & 2.0 & 1630 & 330 & 1.3 & 0.3 & 112.4 & 18.4 \\
\hline UZ-07-38 & 23.2 & 74 & 49.5 & 2.2 & BLOD & BLOD & 1.1 & 0.6 & 98.0 & 12.7 \\
\hline UZ-07-39 & 21.7 & 97 & 22.9 & 3.4 & 275000 & 39000 & 1.1 & 0.3 & 198.1 & 36.4 \\
\hline UZ-07-40 & 19.9 & 94 & 38.1 & 2.0 & BLOD & BLOD & 1.2 & 0.2 & 109.2 & 13.3 \\
\hline UZ-07-41 & 21.1 & 62 & 32.3 & 1.2 & BLOD & BLOD & 1.2 & 0.2 & 136.6 & 18.8 \\
\hline UZ-08-1 & 6.5 & 20 & 7.8 & 0.3 & 720 & 270 & 0.8 & 0.3 & 174.7 & 40.2 \\
\hline UZ-08-2 & 5.1 & 15 & 4.5 & 0.3 & 670 & 340 & 0.9 & 0.1 & 235.0 & 63.7 \\
\hline
\end{tabular}




\begin{tabular}{|c|c|c|c|c|c|c|c|c|c|c|}
\hline UZ-08-3 & 9.2 & 8 & 10.4 & 0.6 & 2360 & 770 & 0.8 & 0.2 & 185.8 & 66.9 \\
\hline UZ-08-4 & 22.1 & 37 & 46.0 & 2.2 & 1060 & 310 & 1.6 & 0.5 & 100.5 & 17.6 \\
\hline UZ-08-5 & 45.8 & 49 & 79.3 & 4.9 & 1680 & 380 & 1.5 & 0.4 & 120.7 & 19.3 \\
\hline UZ-08-6 & 4.2 & 7 & 4.0 & 0.3 & 970 & 270 & 1.6 & 0.6 & 218.0 & 84.2 \\
\hline UZ-08-7 & 8.7 & 10 & 15.2 & 1.0 & 128000 & 18000 & 1.2 & 0.5 & 119.6 & 38.8 \\
\hline UZ-08-8 & 3.5 & 18 & 2.9 & 0.1 & 610 & 350 & 1.8 & 0.6 & 255.1 & 62.1 \\
\hline UZ-08-9 & 5.4 & 4 & 9.6 & 0.6 & 2530 & 560 & 1.6 & 0.5 & 117.7 & 59.5 \\
\hline UZ-08-10 & 4.8 & 10 & 4.0 & 0.4 & 1110 & 340 & 1.7 & 0.3 & 254.2 & 84.0 \\
\hline UZ-08-11 & 6.8 & 15 & 5.0 & 0.4 & 3300 & 1400 & 1.6 & 0.3 & 283.2 & 76.6 \\
\hline UZ-08-12 & 7.6 & 17 & 6.8 & 0.5 & 41400 & 7500 & 1.6 & 0.1 & 233.7 & 60.0 \\
\hline UZ-08-13 & 3.5 & 14 & 3.3 & 0.2 & 610 & 270 & 1.2 & 0.2 & 223.7 & 61.8 \\
\hline UZ-08-14 & 7.9 & 19 & 12.1 & 0.9 & 83000 & 14000 & 1.2 & 0.4 & 135.7 & 33.2 \\
\hline UZ-08-15 & 4.7 & 12 & 8.6 & 0.7 & 75000 & 15000 & 0.7 & 0.2 & 114.9 & 34.6 \\
\hline UZ-08-16 & 2.8 & 14 & 3.9 & 0.3 & 720 & 250 & 1.4 & 0.3 & 150.7 & 41.9 \\
\hline UZ-08-17 & 8.6 & 20 & 7.1 & 0.4 & 940 & 310 & 1.3 & 0.3 & 252.0 & 59.2 \\
\hline UZ-08-18 & 3.0 & 6 & 5.9 & 0.3 & 4300 & 1700 & 1.4 & 0.3 & 105.7 & 43.6 \\
\hline UZ-08-19 & 6.1 & 8 & 5.6 & 0.3 & 660 & 250 & 1.2 & 0.2 & 229.0 & 82.1 \\
\hline UZ-08-20 & 3.0 & 10 & 3.5 & 0.2 & 600 & 240 & 1.5 & 0.2 & 182.6 & 59.0 \\
\hline UZ-08-21 & 9.6 & 10 & 6.1 & 0.4 & 920 & 280 & 1.5 & 0.2 & 331.9 & 108.4 \\
\hline UZ-08-22 & 12.9 & 32 & 12.3 & 0.8 & BLOD & BLOD & 1.5 & 0.2 & 219.3 & 42.1 \\
\hline UZ-08-23 & 15.5 & 15 & 14.4 & 2.2 & 2390 & 630 & 1.4 & 0.4 & 225.6 & 68.2 \\
\hline UZ-08-24 & 4.0 & 7 & 3.8 & 0.2 & 490 & 250 & 1.2 & 0.1 & 222.7 & 85.2 \\
\hline UZ-08-25 & 7.9 & 11 & 7.4 & 0.5 & 620 & 260 & 1.3 & 0.3 & 222.3 & 69.0 \\
\hline UZ-08-26 & 2.8 & 15 & 4.6 & 0.3 & 660 & 280 & 1.7 & 0.5 & 126.6 & 33.7 \\
\hline UZ-08-27 & 5.8 & 12 & 5.3 & 0.3 & 6100 & 1200 & 1.8 & 0.1 & 228.1 & 67.3 \\
\hline UZ-08-28 & 2.2 & 3 & 11.0 & 0.9 & 1630 & 330 & 1.5 & 0.3 & 41.3 & 24.2 \\
\hline UZ-08-29 & 5.1 & 20 & 5.8 & 0.3 & BLOD & BLOD & 1.7 & 0.5 & 182.3 & 42.1 \\
\hline UZ-08-30 & 6.1 & 21 & 5.3 & 0.2 & BLOD & BLOD & 1.8 & 0.1 & 241.9 & 54.5 \\
\hline UZ-08-31 & 7.9 & 16 & 8.8 & 0.5 & 23000 & 5300 & 1.8 & 0.3 & 188.5 & 48.6 \\
\hline UZ-08-32 & 8.1 & 29 & 8.7 & 0.4 & BLOD & BLOD & 1.4 & 0.3 & 194.4 & 37.6 \\
\hline UZ-08-33 & 5.0 & 8 & 13.3 & 0.8 & 700 & 280 & 1.9 & 0.2 & 77.7 & 28.0 \\
\hline
\end{tabular}




\begin{tabular}{|c|c|c|c|c|c|c|c|c|c|c|}
\hline UZ-08-34 & 2.7 & 4 & 4.0 & 0.3 & 490 & 250 & 1.4 & 0.4 & 137.4 & 69.5 \\
\hline UZ-08-35 & 11.3 & 14 & 7.8 & 0.5 & 590 & 270 & 1.3 & 0.3 & 301.1 & 83.8 \\
\hline UZ-08-36 & 5.7 & 11 & 13.9 & 0.7 & BLOD & BLOD & 1.4 & 0.2 & 85.3 & 26.3 \\
\hline UZ-08-37 & 6.0 & 6 & 12.5 & 1.1 & 950 & 340 & 1.3 & 0.3 & 100.9 & 42.3 \\
\hline UZ-09-1 & 53.2 & 37 & 74.4 & 3.3 & 930 & 240 & 2.2 & 0.5 & 149.4 & 26.0 \\
\hline UZ-09-2 & 31.2 & 39 & 77.8 & 4.1 & BLOD & BLOD & 1.8 & 0.6 & 83.7 & 14.5 \\
\hline UZ-09-3 & 16.5 & 33 & 24.6 & 1.1 & 740 & 260 & 2.0 & 0.3 & 139.8 & 25.7 \\
\hline UZ-09-4 & 17.4 & 28 & 56.9 & 3.5 & 14100 & 8700 & 1.5 & 0.3 & 63.8 & 12.9 \\
\hline UZ-09-5 & 30.5 & 40 & 66.8 & 2.4 & 890 & 290 & 2.7 & 0.7 & 95.6 & 15.9 \\
\hline UZ-09-6 & 47.4 & 37 & 120.8 & 8.8 & 33600 & 7700 & 2.0 & 0.6 & 82.0 & 15.1 \\
\hline UZ-09-7 & 52.3 & 75 & 141.4 & 5.3 & 810 & 280 & 1.3 & 0.4 & 77.4 & 9.8 \\
\hline UZ-09-8 & 40.6 & 49 & 161.0 & 10.0 & BLOD & BLOD & 1.5 & 0.3 & 52.6 & 8.4 \\
\hline UZ-09-9 & 50.3 & 30 & 114.4 & 7.7 & 770 & 390 & 2.6 & 0.5 & 91.9 & 18.2 \\
\hline UZ-09-10 & 33.4 & 29 & 97.7 & 6.1 & 66000 & 19000 & 2.0 & 0.2 & 71.4 & 14.2 \\
\hline UZ-09-11 & 42.3 & 48 & 79.4 & 5.7 & 760 & 290 & 1.8 & 0.6 & 111.3 & 18.4 \\
\hline UZ-09-12 & 5.3 & 32 & 8.1 & 0.4 & 670 & 290 & 1.6 & 0.4 & 136.6 & 25.6 \\
\hline UZ-10-1 & 3.8 & 13 & 21.1 & 1.4 & BLOD & BLOD & 1.0 & 0.2 & 37.4 & 10.7 \\
\hline UZ-10-2 & 3.3 & 11 & 19.1 & 1.2 & 690 & 330 & 1.1 & 0.3 & 35.7 & 11.1 \\
\hline UZ-10-3 & 11.2 & 30 & 26.8 & 1.8 & 560 & 320 & 1.2 & 0.2 & 87.5 & 17.3 \\
\hline UZ-10-4 & 3.2 & 7 & 12.0 & 0.9 & 4540 & 720 & 1.0 & 0.3 & 55.8 & 21.6 \\
\hline UZ-10-5 & 3.3 & 13 & 9.4 & 0.4 & 760 & 270 & 0.9 & 0.2 & 74.4 & 21.1 \\
\hline UZ-10-6 & 5.1 & 13 & 9.6 & 0.4 & BLOD & BLOD & 1.6 & 0.5 & 109.8 & 31.1 \\
\hline UZ-10-7 & 4.7 & 15 & 20.9 & 1.3 & 630 & 320 & 1.2 & 0.3 & 47.0 & 12.6 \\
\hline UZ-10-8 & 3.5 & 9 & 13.8 & 0.8 & BLOD & BLOD & 1.5 & 0.5 & 53.3 & 18.1 \\
\hline UZ-10-9 & 2.0 & 7 & 9.7 & 0.4 & BLOD & BLOD & 0.8 & 0.1 & 43.4 & 16.6 \\
\hline UZ-10-10 & 2.8 & 9 & 10.3 & 0.5 & BLOD & BLOD & 1.1 & 0.2 & 57.4 & 19.5 \\
\hline UZ-10-11 & 4.4 & 14 & 20.6 & 1.4 & 1160 & 330 & 1.4 & 0.4 & 44.9 & 12.5 \\
\hline UZ-10-12 & 3.8 & 12 & 8.2 & 0.4 & 640 & 260 & 1.3 & 0.3 & 96.8 & 28.6 \\
\hline UZ-10-13 & 4.1 & 17 & 9.9 & 0.6 & BLOD & BLOD & 0.9 & 0.3 & 86.2 & 21.8 \\
\hline UZ-10-14 & 6.7 & 11 & 18.1 & 1.6 & 750 & 290 & 0.8 & 0.2 & 77.7 & 24.6 \\
\hline UZ-10-15 & 4.2 & 8 & 18.0 & 1.8 & 1140 & 400 & 1.3 & 0.2 & 48.8 & 18.0 \\
\hline
\end{tabular}




\begin{tabular}{|c|c|c|c|c|c|c|c|c|c|c|}
\hline UZ-10-16 & 1.0 & 2 & 5.1 & 0.3 & 740 & 300 & 0.2 & 0.2 & 40.8 & 28.9 \\
\hline UZ-10-17 & 4.7 & 18 & 17.9 & 2.4 & BLOD & BLOD & 1.3 & 0.3 & 54.7 & 15.0 \\
\hline UZ-10-18 & 1.6 & 8 & 8.6 & 0.5 & BLOD & BLOD & 1.3 & 0.4 & 38.1 & 13.7 \\
\hline UZ-10-19 & 1.6 & 3 & 37.0 & 4.6 & 89000 & 43000 & 1.3 & 0.4 & 8.8 & 5.2 \\
\hline UZ-10-20 & 4.6 & 19 & 13.8 & 0.8 & BLOD & BLOD & 1.7 & 0.5 & 69.3 & 16.7 \\
\hline UZ-10-21 & 3.5 & 18 & 11.2 & 0.7 & 560 & 270 & 1.2 & 0.3 & 65.3 & 16.1 \\
\hline UZ-10-22 & 1.3 & 4 & 10.2 & 0.5 & 950 & 330 & 1.1 & 0.4 & 27.5 & 13.8 \\
\hline UZ-10-23 & 2.2 & 6 & 7.4 & 0.4 & BLOD & BLOD & 1.0 & 0.2 & 61.9 & 25.6 \\
\hline UZ-10-24 & 5.1 & 27 & 17.1 & 0.8 & 560 & 250 & 1.4 & 0.4 & 62.5 & 12.6 \\
\hline UZ-10-25 & 3.7 & 13 & 11.3 & 0.8 & BLOD & BLOD & 1.2 & 0.1 & 67.8 & 19.5 \\
\hline UZ-10-26 & 1.4 & 5 & 10.2 & 0.6 & 460 & 250 & 1.3 & 0.1 & 28.6 & 12.9 \\
\hline UZ-10-27 & 1.7 & 6 & 11.9 & 0.6 & BLOD & BLOD & 1.2 & 0.3 & 29.3 & 12.1 \\
\hline UZ-10-28 & 5.1 & 18 & 15.3 & 1.2 & 770 & 330 & 1.3 & 0.2 & 69.4 & 17.4 \\
\hline UZ-10-29 & 2.9 & 9 & 19.6 & 1.6 & 650 & 300 & 1.4 & 0.1 & 31.2 & 10.8 \\
\hline UZ-11-1 & 10.2 & 24 & 11.1 & 0.6 & BLOD & BLOD & 1.2 & 0.2 & 192.6 & 41.5 \\
\hline UZ-11-2 & 14.8 & 30 & 14.3 & 0.6 & 550 & 300 & 1.0 & 0.2 & 216.6 & 41.5 \\
\hline UZ-11-3 & 8.5 & 26 & 12.9 & 0.7 & 750 & 340 & 1.3 & 0.2 & 136.9 & 28.4 \\
\hline UZ-11-4 & 22.4 & 24 & 47.9 & 9.1 & BLOD & BLOD & 1.0 & 0.2 & 97.7 & 27.5 \\
\hline UZ-11-5 & 13.4 & 44 & 12.1 & 0.5 & BLOD & BLOD & 1.1 & 0.2 & 231.7 & 37.1 \\
\hline UZ-11-6 & 19.1 & 32 & 15.3 & 0.9 & 14300 & 4400 & 1.6 & 0.2 & 261.2 & 49.7 \\
\hline UZ-11-7 & 7.9 & 34 & 11.7 & 0.6 & 660 & 310 & 0.9 & 0.2 & 141.7 & 25.8 \\
\hline UZ-11-8 & 19.1 & 33 & 32.3 & 1.4 & BLOD & BLOD & 1.2 & 0.2 & 123.8 & 22.7 \\
\hline UZ-11-9 & 4.6 & 21 & 5.3 & 0.4 & BLOD & BLOD & 1.1 & 0.2 & 183.7 & 42.8 \\
\hline UZ-11-10 & 28.2 & 50 & 50.2 & 1.7 & 810 & 320 & 1.1 & 0.2 & 117.3 & 17.6 \\
\hline UZ-11-11 & 11.7 & 14 & 13.6 & 0.5 & BLOD & BLOD & 1.3 & 0.1 & 179.6 & 49.0 \\
\hline UZ-11-12 & 7.6 & 14 & 9.5 & 0.5 & BLOD & BLOD & 1.2 & 0.1 & 167.4 & 45.9 \\
\hline UZ-11-13 & 10.8 & 18 & 14.2 & 0.6 & BLOD & BLOD & 0.9 & 0.2 & 159.1 & 38.6 \\
\hline UZ-11-14 & 7.1 & 8 & 22.4 & 2.7 & 930 & 320 & 1.1 & 0.3 & 65.9 & 24.7 \\
\hline UZ-11-15 & 24.7 & 43 & 25.3 & 1.8 & BLOD & BLOD & 1.0 & 0.2 & 204.2 & 35.2 \\
\hline UZ-11-16 & 8.3 & 18 & 16.8 & 1.6 & BLOD & BLOD & 1.1 & 0.2 & 103.3 & 26.6 \\
\hline UZ-11-17 & 66.2 & 105 & 161.3 & 5.4 & 730 & 310 & 1.2 & 0.2 & 85.7 & 9.4 \\
\hline
\end{tabular}




\begin{tabular}{|c|c|c|c|c|c|c|c|c|c|c|}
\hline UZ-11-18 & 13.3 & 55 & 13.4 & 1.0 & BLOD & BLOD & 1.2 & 0.2 & 206.1 & 32.5 \\
\hline UZ-11-19 & 54.2 & 90 & 92.9 & 2.7 & 1300 & 430 & 1.2 & 0.2 & 121.9 & 14.1 \\
\hline UZ-11-20 & 5.1 & 16 & 4.0 & 0.2 & 720 & 360 & 1.2 & 0.3 & 266.5 & 68.5 \\
\hline UZ-11-21 & 14.9 & 33 & 14.0 & 0.7 & BLOD & BLOD & 0.9 & 0.1 & 221.2 & 40.8 \\
\hline UZ-11-22 & 33.1 & 62 & 52.2 & 2.0 & BLOD & BLOD & 1.1 & 0.2 & 132.6 & 18.3 \\
\hline UZ-11-23 & 61.4 & 61 & 95.6 & 3.5 & 610 & 320 & 1.3 & 0.2 & 134.3 & 18.6 \\
\hline UZ-11-24 & 44.2 & 54 & 63.4 & 3.7 & BLOD & BLOD & 1.1 & 0.2 & 145.6 & 22.2 \\
\hline UZ-11-25 & 26.0 & 56 & 42.0 & 1.1 & 850 & 370 & 1.1 & 0.2 & 129.6 & 18.3 \\
\hline UZ-11-26 & 14.0 & 36 & 13.3 & 0.6 & BLOD & BLOD & 1.1 & 0.2 & 220.0 & 38.9 \\
\hline UZ-11-27 & 31.1 & 56 & 42.2 & 2.1 & BLOD & BLOD & 1.1 & 0.2 & 153.9 & 22.7 \\
\hline UZ-11-28 & 37.3 & 50 & 51.7 & 2.1 & BLOD & BLOD & 1.2 & 0.2 & 150.9 & 22.9 \\
\hline UZ-11-29 & 6.6 & 16 & 13.4 & 0.8 & 700 & 360 & 1.2 & 0.2 & 103.4 & 26.9 \\
\hline UZ-11-30 & 25.8 & 60 & 37.5 & 1.8 & BLOD & BLOD & 1.1 & 0.2 & 143.6 & 20.5 \\
\hline UZ-11-31 & 10.1 & 25 & 12.1 & 0.6 & BLOD & BLOD & 1.2 & 0.3 & 173.0 & 36.3 \\
\hline UZ-11-32 & 11.9 & 43 & 22.1 & 1.5 & BLOD & BLOD & 1.0 & 0.2 & 112.9 & 19.3 \\
\hline UZ-11-33 & 15.9 & 38 & 13.4 & 0.5 & 580 & 300 & 1.1 & 0.2 & 248.4 & 42.5 \\
\hline UZ-11-34 & 11.5 & 31 & 13.4 & 0.6 & BLOD & BLOD & 1.0 & 0.3 & 179.6 & 34.0 \\
\hline UZ-11-35 & 2.3 & 5 & 65.9 & 5.5 & BLOD & BLOD & 1.0 & 0.3 & 7.3 & 3.3 \\
\hline UZ-11-36 & 20.2 & 63 & 47.9 & 3.5 & 3700 & 1600 & 1.1 & 0.2 & 88.3 & 13.3 \\
\hline UZ-11-37 & 9.4 & 17 & 11.1 & 0.5 & 850 & 380 & 1.1 & 0.1 & 176.4 & 44.0 \\
\hline UZ-11-38 & 10.7 & 51 & 13.1 & 0.5 & 670 & 340 & 1.3 & 0.3 & 171.4 & 25.8 \\
\hline UZ-11-39 & 12.7 & 18 & 18.6 & 0.8 & BLOD & BLOD & 1.0 & 0.2 & 142.9 & 34.6 \\
\hline UZ-11-40 & 16.0 & 21 & 14.7 & 0.7 & BLOD & BLOD & 1.2 & 0.2 & 227.6 & 51.4 \\
\hline UZ-12-1 & 14.7 & 47 & 15.9 & 0.8 & 410 & 180 & 1.3 & 0.3 & 197.7 & 31.2 \\
\hline UZ-12-2 & 13.9 & 24 & 29.2 & 1.4 & 930 & 240 & 1.7 & 0.2 & 101.6 & 21.6 \\
\hline UZ-12-3 & 11.8 & 35 & 15.6 & 0.8 & BLOD & BLOD & 1.6 & 0.1 & 161.8 & 29.1 \\
\hline UZ-12-4 & 13.9 & 23 & 14.7 & 0.6 & BLOD & BLOD & 1.5 & 0.2 & 201.2 & 43.4 \\
\hline UZ-12-5 & 23.4 & 68 & 30.8 & 1.8 & BLOD & BLOD & 1.5 & 0.3 & 162.7 & 22.7 \\
\hline UZ-12-6 & 23.0 & 53 & 22.6 & 1.1 & 490 & 240 & 1.4 & 0.3 & 217.3 & 32.7 \\
\hline UZ-12-7 & 9.6 & 19 & 15.6 & 0.7 & BLOD & BLOD & 1.3 & 0.2 & 131.7 & 31.2 \\
\hline UZ-12-8 & 15.4 & 22 & 18.7 & 0.6 & 400 & 210 & 1.5 & 0.2 & 175.8 & 38.4 \\
\hline
\end{tabular}




\begin{tabular}{|c|c|c|c|c|c|c|c|c|c|c|}
\hline UZ-12-9 & 8.9 & 26 & 14.8 & 0.7 & BLOD & BLOD & 1.4 & 0.1 & 128.5 & 26.5 \\
\hline UZ-12-10 & 35.2 & 69 & 50.1 & 2.9 & BLOD & BLOD & 1.5 & 0.3 & 150.0 & 20.8 \\
\hline UZ-12-11 & 26.8 & 61 & 51.1 & 2.3 & BLOD & BLOD & 1.4 & 0.2 & 112.0 & 15.8 \\
\hline UZ-12-12 & 15.0 & 32 & 17.2 & 0.8 & BLOD & BLOD & 1.4 & 0.3 & 187.1 & 34.8 \\
\hline UZ-12-13 & 20.2 & 34 & 41.8 & 3.0 & BLOD & BLOD & 1.7 & 0.2 & 103.5 & 19.6 \\
\hline UZ-12-14 & 13.0 & 31 & 12.4 & 0.6 & BLOD & BLOD & 1.6 & 0.2 & 223.6 & 42.2 \\
\hline UZ-12-15 & 13.4 & 28 & 16.0 & 0.8 & 490 & 160 & 1.6 & 0.3 & 179.1 & 35.5 \\
\hline UZ-12-16 & 6.8 & 21 & 9.7 & 0.6 & BLOD & BLOD & 1.4 & 0.4 & 150.6 & 34.7 \\
\hline UZ-12-17 & 28.9 & 61 & 32.5 & 2.5 & 390 & 260 & 1.5 & 0.3 & 190.0 & 29.3 \\
\hline UZ-12-18 & 29.7 & 39 & 47.6 & 2.0 & 620 & 250 & 1.4 & 0.3 & 133.3 & 22.6 \\
\hline UZ-12-19 & 8.9 & 16 & 16.8 & 0.8 & 530 & 180 & 1.6 & 0.2 & 113.1 & 29.0 \\
\hline UZ-12-20 & 8.8 & 17 & 11.1 & 0.6 & BLOD & BLOD & 1.6 & 0.2 & 169.2 & 42.4 \\
\hline UZ-12-21 & 8.0 & 23 & 30.9 & 2.4 & 1050 & 210 & 1.4 & 0.3 & 55.0 & 12.4 \\
\hline UZ-12-22 & 8.0 & 19 & 14.9 & 0.7 & BLOD & BLOD & 1.6 & 0.2 & 114.3 & 27.1 \\
\hline UZ-12-23 & 23.5 & 64 & 21.0 & 1.0 & BLOD & BLOD & 1.2 & 0.3 & 239.0 & 33.0 \\
\hline UZ-12-24 & 13.6 & 53 & 16.5 & 0.7 & BLOD & BLOD & 1.6 & 0.5 & 176.2 & 26.2 \\
\hline UZ-12-25 & 10.4 & 23 & 16.0 & 0.6 & BLOD & BLOD & 1.5 & 0.3 & 138.4 & 29.8 \\
\hline UZ-12-26 & 19.4 & 53 & 35.7 & 1.8 & BLOD & BLOD & 1.7 & 0.3 & 116.0 & 17.5 \\
\hline UZ-12-27 & 8.8 & 16 & 22.7 & 0.8 & BLOD & BLOD & 1.2 & 0.3 & 83.4 & 21.3 \\
\hline UZ-12-28 & 27.3 & 65 & 31.6 & 3.6 & BLOD & BLOD & 1.7 & 0.3 & 184.9 & 31.9 \\
\hline UZ-12-29 & 12.0 & 44 & 17.4 & 1.0 & 540 & 240 & 1.3 & 0.4 & 147.9 & 24.4 \\
\hline UZ-12-30 & 14.7 & 43 & 15.1 & 0.8 & BLOD & BLOD & 1.3 & 0.3 & 207.0 & 34.1 \\
\hline UZ-12-31 & 7.8 & 21 & 15.8 & 1.2 & 680 & 250 & 1.5 & 0.3 & 106.0 & 24.8 \\
\hline UZ-12-32 & 13.6 & 29 & 19.1 & 1.0 & BLOD & BLOD & 1.3 & 0.2 & 152.7 & 30.0 \\
\hline UZ-12-33 & 11.5 & 41 & 24.5 & 1.5 & 450 & 210 & 1.6 & 0.2 & 100.5 & 17.3 \\
\hline UZ-12-34 & 17.0 & 55 & 16.4 & 0.8 & 450 & 310 & 1.5 & 0.2 & 221.8 & 32.8 \\
\hline UZ-12-35 & 7.5 & 21 & 13.3 & 0.6 & 4140 & 400 & 1.5 & 0.2 & 119.4 & 27.0 \\
\hline UZ-12-36 & 27.6 & 66 & 39.2 & 1.8 & BLOD & BLOD & 1.5 & 0.4 & 150.4 & 20.5 \\
\hline UZ-12-37 & 16.3 & 50 & 18.5 & 1.3 & 1750 & 400 & 1.3 & 0.3 & 187.9 & 30.5 \\
\hline UZ-12-38 & 9.6 & 32 & 14.4 & 0.6 & 930 & 230 & 1.4 & 0.5 & 142.0 & 26.3 \\
\hline UZ-12-39 & 24.3 & 61 & 14.7 & 0.5 & BLOD & BLOD & 1.3 & 0.3 & 353.6 & 48.5 \\
\hline
\end{tabular}




\begin{tabular}{|c|c|c|c|c|c|c|c|c|c|c|}
\hline UZ-12-40 & 12.8 & 63 & 19.2 & 0.9 & BLOD & BLOD & 1.4 & 0.3 & 141.7 & 19.7 \\
\hline UZ-12-41 & 10.8 & 30 & 13.1 & 0.5 & BLOD & BLOD & 1.5 & 0.3 & 177.2 & 33.7 \\
\hline UZ-12-42 & 15.7 & 49 & 15.9 & 0.8 & BLOD & BLOD & 1.4 & 0.3 & 211.6 & 32.8 \\
\hline UZ-12-43 & 7.9 & 23 & 17.5 & 1.0 & BLOD & BLOD & 1.6 & 0.4 & 96.6 & 21.2 \\
\hline UZ-13-1 & 13.6 & 32 & 38.6 & 2.0 & BLOD & BLOD & 1.1 & 0.2 & 75.2 & 14.1 \\
\hline UZ-13-2 & 12.4 & 36 & 36.7 & 1.6 & BLOD & BLOD & 1.0 & 0.3 & 72.1 & 12.7 \\
\hline UZ-13-3 & 18.6 & 55 & 26.0 & 1.3 & 640 & 310 & 1.0 & 0.2 & 153.2 & 22.8 \\
\hline UZ-13-4 & 6.7 & 22 & 5.6 & 0.3 & BLOD & BLOD & 1.2 & 0.2 & 256.4 & 57.1 \\
\hline UZ-13-5 & 0.7 & 1 & 0.6 & 0.0 & BLOD & BLOD & 1.5 & 0.5 & 279.2 & 280.2 \\
\hline UZ-13-6 & 22.0 & 67 & 21.8 & 0.7 & BLOD & BLOD & 1.1 & 0.2 & 215.8 & 28.3 \\
\hline UZ-13-7 & 41.2 & 78 & 134.0 & 11.0 & BLOD & BLOD & 1.1 & 0.3 & 65.7 & 9.5 \\
\hline UZ-13-8 & 13.2 & 44 & 19.6 & 1.0 & BLOD & BLOD & 1.1 & 0.2 & 144.1 & 23.5 \\
\hline UZ-13-9 & 11.1 & 11 & 27.2 & 1.1 & 600 & 370 & 1.2 & 0.2 & 87.4 & 26.8 \\
\hline UZ-13-10 & 15.5 & 23 & 32.9 & 1.3 & BLOD & BLOD & 1.1 & 0.2 & 100.9 & 21.7 \\
\hline UZ-13-11 & 12.7 & 24 & 154.0 & 14.0 & BLOD & BLOD & 0.9 & 0.2 & 17.6 & 4.0 \\
\hline UZ-13-12 & 24.6 & 64 & 35.0 & 1.8 & BLOD & BLOD & 1.2 & 0.3 & 150.0 & 21.0 \\
\hline UZ-13-13 & 9.6 & 9 & 32.6 & 1.4 & 580 & 280 & 1.2 & 0.2 & 63.0 & 21.3 \\
\hline UZ-13-14 & 15.8 & 55 & 36.0 & 1.8 & BLOD & BLOD & 1.1 & 0.3 & 94.0 & 14.0 \\
\hline UZ-13-15 & 15.3 & 25 & 30.8 & 1.2 & BLOD & BLOD & 1.5 & 0.6 & 105.9 & 21.9 \\
\hline UZ-13-16 & 27.0 & 58 & 40.3 & 1.6 & 960 & 320 & 1.2 & 0.2 & 143.4 & 20.4 \\
\hline UZ-13-17 & 3.4 & 6 & 3.2 & 0.2 & BLOD & BLOD & 1.0 & 0.2 & 227.1 & 93.8 \\
\hline UZ-13-18 & 31.5 & 64 & 34.3 & 1.4 & 2850 & 370 & 1.2 & 0.4 & 196.3 & 26.8 \\
\hline UZ-13-19 & 18.8 & 22 & 23.0 & 1.4 & BLOD & BLOD & 1.0 & 0.3 & 174.8 & 39.3 \\
\hline UZ-13-20 & 14.9 & 48 & 22.8 & 1.1 & BLOD & BLOD & 0.9 & 0.3 & 139.3 & 21.8 \\
\hline UZ-13-21 & 9.5 & 42 & 12.0 & 0.8 & BLOD & BLOD & 0.9 & 0.2 & 168.6 & 28.9 \\
\hline UZ-13-22 & 5.7 & 9 & 15.2 & 1.4 & BLOD & BLOD & 1.0 & 0.3 & 80.8 & 28.1 \\
\hline UZ-13-23 & 17.9 & 30 & 34.4 & 2.8 & 790 & 320 & 1.2 & 0.3 & 111.4 & 22.6 \\
\hline UZ-13-24 & 24.6 & 49 & 32.7 & 1.9 & BLOD & BLOD & 1.3 & 0.3 & 160.5 & 25.5 \\
\hline UZ-13-25 & 26.4 & 44 & 22.5 & 1.6 & 890 & 420 & 1.1 & 0.3 & 251.2 & 42.9 \\
\hline UZ-13-26 & 30.6 & 48 & 30.8 & 2.2 & BLOD & BLOD & 1.3 & 0.4 & 212.5 & 35.1 \\
\hline UZ-13-27 & 18.9 & 55 & 29.4 & 1.4 & BLOD & BLOD & 1.1 & 0.3 & 137.3 & 20.3 \\
\hline
\end{tabular}




\begin{tabular}{|c|c|c|c|c|c|c|c|c|c|c|}
\hline UZ-13-28 & 11.0 & 26 & 12.5 & 0.6 & BLOD & BLOD & 1.3 & 0.2 & 188.2 & 38.5 \\
\hline UZ-13-29 & 11.2 & 19 & 16.5 & 0.7 & BLOD & BLOD & 1.0 & 0.3 & 145.9 & 34.4 \\
\hline UZ-13-30 & 23.5 & 53 & 28.9 & 1.2 & BLOD & BLOD & 1.2 & 0.2 & 173.7 & 25.8 \\
\hline UZ-13-31 & 18.1 & 36 & 26.8 & 1.1 & BLOD & BLOD & 1.1 & 0.3 & 144.7 & 25.4 \\
\hline UZ-13-32 & 7.5 & 13 & 14.3 & 0.8 & BLOD & BLOD & 1.3 & 0.2 & 111.5 & 31.8 \\
\hline UZ-13-33 & 18.7 & 21 & 33.5 & 1.7 & 1130 & 320 & 0.9 & 0.2 & 119.1 & 27.1 \\
\hline UZ-13-34 & 11.1 & 9 & 20.5 & 1.1 & BLOD & BLOD & 1.7 & 0.2 & 115.3 & 39.2 \\
\hline UZ-13-35 & 15.5 & 47 & 30.3 & 3.2 & BLOD & BLOD & 1.2 & 0.2 & 109.2 & 20.1 \\
\hline UZ-13-36 & 27.2 & 29 & 50.7 & 2.2 & BLOD & BLOD & 1.0 & 0.3 & 114.8 & 22.3 \\
\hline UZ-13-37 & 17.3 & 38 & 28.9 & 1.3 & BLOD & BLOD & 1.3 & 0.2 & 128.3 & 22.1 \\
\hline UZ-13-38 & 29.8 & 41 & 52.5 & 3.2 & BLOD & BLOD & 1.1 & 0.2 & 121.4 & 20.9 \\
\hline UZ-13-39 & 13.5 & 40 & 36.8 & 1.4 & BLOD & BLOD & 1.1 & 0.2 & 78.7 & 13.1 \\
\hline UZ-13-40 & 10.1 & 30 & 12.6 & 0.6 & BLOD & BLOD & 1.2 & 0.2 & 172.1 & 33.0 \\
\hline UZ-14-1 & 16.2 & 86 & 23.9 & 1.0 & BLOD & BLOD & 1.1 & 0.2 & 125.2 & 15.2 \\
\hline UZ-14-2 & 9.3 & 30 & 11.3 & 0.5 & BLOD & BLOD & 1.0 & 0.2 & 153.3 & 29.4 \\
\hline UZ-14-3 & 4.8 & 38 & 4.9 & 0.3 & BLOD & BLOD & 1.1 & 0.2 & 179.6 & 31.4 \\
\hline UZ-14-4 & 8.3 & 35 & 9.9 & 1.5 & BLOD & BLOD & 0.9 & 0.2 & 155.2 & 35.7 \\
\hline UZ-14-5 & 5.2 & 28 & 9.3 & 0.5 & BLOD & BLOD & 1.2 & 0.3 & 104.3 & 20.7 \\
\hline UZ-14-6 & 13.4 & 53 & 21.3 & 1.1 & BLOD & BLOD & 1.1 & 0.5 & 116.5 & 17.7 \\
\hline UZ-14-7 & 11.6 & 67 & 17.1 & 0.8 & BLOD & BLOD & 0.9 & 0.2 & 125.9 & 17.1 \\
\hline UZ-14-8 & 16.5 & 77 & 14.6 & 0.6 & BLOD & BLOD & 0.9 & 0.2 & 209.3 & 26.4 \\
\hline UZ-14-9 & 26.2 & 111 & 42.7 & 1.5 & BLOD & BLOD & 1.0 & 0.2 & 113.6 & 12.3 \\
\hline UZ-14-10 & 3.1 & 11 & 6.8 & 0.3 & BLOD & BLOD & 0.8 & 0.2 & 85.4 & 26.2 \\
\hline UZ-14-11 & 9.3 & 32 & 12.3 & 0.6 & BLOD & BLOD & 1.0 & 0.2 & 140.2 & 26.2 \\
\hline UZ-14-12 & 13.1 & 51 & 25.8 & 1.3 & BLOD & BLOD & 1.1 & 0.1 & 93.7 & 14.4 \\
\hline UZ-14-13 & 13.4 & 62 & 21.7 & 1.2 & BLOD & BLOD & 1.0 & 0.3 & 114.4 & 16.4 \\
\hline UZ-14-14 & 5.2 & 35 & 11.6 & 0.5 & BLOD & BLOD & 1.4 & 0.2 & 82.1 & 14.7 \\
\hline UZ-14-15 & 10.9 & 48 & 16.1 & 0.7 & BLOD & BLOD & 1.1 & 0.2 & 125.1 & 19.4 \\
\hline UZ-14-16 & 14.5 & 43 & 20.0 & 1.1 & 1230 & 400 & 1.0 & 0.2 & 134.0 & 22.3 \\
\hline UZ-14-17 & 11.5 & 48 & 27.0 & 1.2 & 1520 & 630 & 1.0 & 0.2 & 78.6 & 12.2 \\
\hline UZ-14-18 & 17.4 & 55 & 24.2 & 0.9 & 1650 & 620 & 1.0 & 0.4 & 133.0 & 19.3 \\
\hline
\end{tabular}




\begin{tabular}{|c|c|c|c|c|c|c|c|c|c|c|}
\hline UZ-14-19 & 11.3 & 32 & 11.7 & 0.5 & 10700 & 820 & 1.0 & 0.2 & 177.6 & 33.0 \\
\hline UZ-14-20 & 7.6 & 28 & 10.6 & 0.8 & 9400 & 1400 & 1.1 & 0.2 & 131.3 & 27.0 \\
\hline UZ-14-21 & 11.2 & 42 & 10.9 & 0.6 & 960 & 450 & 1.0 & 0.2 & 188.9 & 32.0 \\
\hline UZ-14-22 & 4.5 & 20 & 7.2 & 0.5 & 1020 & 570 & 0.8 & 0.1 & 116.1 & 27.6 \\
\hline UZ-14-23 & 8.9 & 37 & 8.5 & 0.4 & BLOD & BLOD & 1.5 & 0.3 & 194.2 & 33.7 \\
\hline UZ-14-24 & 8.4 & 50 & 11.2 & 0.5 & BLOD & BLOD & 0.8 & 0.2 & 139.0 & 21.2 \\
\hline UZ-14-25 & 9.8 & 40 & 9.3 & 0.5 & 3900 & 1100 & 1.1 & 0.2 & 195.3 & 33.3 \\
\hline UZ-14-26 & 14.7 & 56 & 22.1 & 1.3 & BLOD & BLOD & 1.0 & 0.3 & 123.2 & 18.6 \\
\hline UZ-14-27 & 17.7 & 84 & 17.3 & 0.9 & BLOD & BLOD & 0.9 & 0.2 & 189.9 & 23.9 \\
\hline UZ-14-28 & 12.8 & 65 & 17.9 & 1.0 & BLOD & BLOD & 1.4 & 0.4 & 132.3 & 18.5 \\
\hline UZ-14-29 & 15.0 & 60 & 26.2 & 1.0 & BLOD & BLOD & 1.1 & 0.1 & 105.9 & 14.8 \\
\hline UZ-14-30 & 16.2 & 63 & 16.4 & 0.7 & BLOD & BLOD & 0.9 & 0.2 & 181.9 & 25.3 \\
\hline UZ-14-31 & 10.0 & 45 & 16.1 & 0.8 & BLOD & BLOD & 1.0 & 0.3 & 115.6 & 18.7 \\
\hline UZ-14-32 & 8.5 & 28 & 15.4 & 0.8 & BLOD & BLOD & 1.0 & 0.2 & 101.9 & 20.3 \\
\hline UZ-15-1 & 4.0 & 37 & 5.6 & 0.3 & BLOD & BLOD & 1.5 & 0.4 & 131.0 & 23.0 \\
\hline UZ-15-2 & 15.9 & 62 & 28.4 & 1.9 & BLOD & BLOD & 1.6 & 0.7 & 103.8 & 15.4 \\
\hline UZ-15-3 & 7.5 & 43 & 6.5 & 0.4 & BLOD & BLOD & 1.5 & 0.4 & 212.8 & 35.4 \\
\hline UZ-15-4 & 11.1 & 34 & 14.5 & 0.7 & BLOD & BLOD & 3.3 & 0.0 & 141.6 & 25.8 \\
\hline UZ-15-5 & 10.4 & 37 & 8.6 & 0.5 & BLOD & BLOD & 1.6 & 0.4 & 223.5 & 39.9 \\
\hline UZ-15-6 & 6.2 & 24 & 8.9 & 0.5 & BLOD & BLOD & 1.2 & 0.4 & 127.9 & 27.4 \\
\hline UZ-15-7 & 3.7 & 10 & 7.1 & 0.3 & BLOD & BLOD & 1.8 & 0.2 & 97.6 & 31.3 \\
\hline UZ-15-8 & 15.5 & 49 & 17.7 & 0.9 & BLOD & BLOD & 1.7 & 0.2 & 162.3 & 25.3 \\
\hline UZ-15-9 & 18.3 & 66 & 35.3 & 1.9 & BLOD & BLOD & 1.7 & 0.4 & 95.9 & 13.4 \\
\hline UZ-15-10 & 16.4 & 50 & 26.1 & 1.1 & BLOD & BLOD & 1.2 & 0.6 & 116.4 & 17.7 \\
\hline UZ-15-11 & 10.5 & 26 & 15.2 & 0.6 & BLOD & BLOD & 1.0 & 0.4 & 127.8 & 26.1 \\
\hline UZ-15-12 & 5.1 & 13 & 7.1 & 0.4 & BLOD & BLOD & 1.1 & 0.2 & 134.3 & 38.4 \\
\hline UZ-15-13 & 8.3 & 32 & 7.7 & 0.5 & BLOD & BLOD & 1.6 & 0.6 & 200.5 & 38.4 \\
\hline UZ-15-14 & 17.2 & 53 & 23.8 & 1.4 & BLOD & BLOD & 1.7 & 0.4 & 134.0 & 20.7 \\
\hline UZ-15-15 & 4.8 & 41 & 7.4 & 0.4 & BLOD & BLOD & 1.4 & 0.2 & 121.6 & 20.5 \\
\hline UZ-15-16 & 8.9 & 39 & 7.3 & 0.6 & BLOD & BLOD & 1.4 & 0.5 & 224.9 & 40.7 \\
\hline UZ-15-17 & 9.3 & 55 & 5.5 & 0.3 & BLOD & BLOD & 1.6 & 0.4 & 313.5 & 46.9 \\
\hline
\end{tabular}




\begin{tabular}{|c|c|c|c|c|c|c|c|c|c|c|}
\hline UZ-15-18 & 6.8 & 32 & 9.1 & 0.5 & BLOD & BLOD & 1.6 & 0.3 & 137.3 & 25.9 \\
\hline UZ-15-19 & 4.8 & 18 & 8.8 & 0.5 & BLOD & BLOD & 1.6 & 0.3 & 102.2 & 25.0 \\
\hline UZ-15-20 & 3.9 & 17 & 6.1 & 0.5 & BLOD & BLOD & 1.9 & 0.4 & 118.2 & 30.3 \\
\hline UZ-15-21 & 8.7 & 36 & 13.1 & 0.8 & BLOD & BLOD & 1.5 & 0.1 & 122.2 & 22.1 \\
\hline UZ-15-22 & 3.9 & 23 & 7.5 & 0.5 & 2600 & 1100 & 1.2 & 0.2 & 96.1 & 21.2 \\
\hline UZ-15-23 & 17.1 & 48 & 32.6 & 1.6 & BLOD & BLOD & 0.9 & 0.4 & 97.2 & 15.3 \\
\hline UZ-15-24 & 9.4 & 46 & 7.7 & 0.4 & 16500 & 2700 & 1.3 & 0.2 & 224.1 & 35.6 \\
\hline UZ-15-25 & 6.0 & 32 & 10.3 & 0.5 & BLOD & BLOD & 1.2 & 0.7 & 108.6 & 20.3 \\
\hline UZ-15-26 & 4.8 & 20 & 5.9 & 0.3 & BLOD & BLOD & 1.6 & 0.3 & 151.4 & 35.1 \\
\hline UZ-15-27 & 4.4 & 13 & 4.3 & 0.3 & BLOD & BLOD & 1.6 & 0.2 & 191.2 & 55.1 \\
\hline UZ-15-28 & 6.0 & 28 & 8.6 & 0.4 & 690 & 390 & 1.5 & 0.2 & 129.9 & 25.8 \\
\hline UZ-15-29 & 10.3 & 24 & 13.5 & 0.7 & BLOD & BLOD & 1.4 & 0.1 & 141.5 & 30.3 \\
\hline UZ-15-30 & 16.1 & 36 & 16.0 & 0.7 & BLOD & BLOD & 2.1 & 0.7 & 186.4 & 32.9 \\
\hline UZ-15-31 & 6.9 & 35 & 7.2 & 0.3 & BLOD & BLOD & 1.4 & 0.4 & 179.1 & 31.8 \\
\hline UZ-15-32 & 15.6 & 62 & 29.3 & 1.4 & BLOD & BLOD & 1.7 & 0.2 & 98.2 & 13.8 \\
\hline UZ-15-33 & 5.4 & 24 & 6.5 & 0.4 & BLOD & BLOD & NA & 0.0 & 154.2 & 33.2 \\
\hline UZ-15-34 & 9.7 & 52 & 9.8 & 0.5 & BLOD & BLOD & 1.6 & 0.2 & 183.0 & 27.9 \\
\hline UZ-15-35 & 5.2 & 23 & 8.2 & 0.5 & BLOD & BLOD & 0.8 & 0.0 & 116.6 & 25.5 \\
\hline UZ-15-36 & 5.6 & 21 & 7.6 & 0.4 & BLOD & BLOD & 1.5 & 0.1 & 135.6 & 31.0 \\
\hline UZ-15-37 & 12.5 & 52 & 24.3 & 1.1 & BLOD & BLOD & 1.4 & 0.1 & 95.5 & 14.4 \\
\hline UZ-15-38 & 12.3 & 35 & 14.9 & 0.8 & BLOD & BLOD & 1.6 & 0.4 & 152.5 & 27.7 \\
\hline UZ-15-39 & 3.6 & 11 & 6.3 & 0.4 & BLOD & BLOD & NA & 0.0 & 105.4 & 32.6 \\
\hline UZ-15-40 & 7.9 & 35 & 13.8 & 0.6 & BLOD & BLOD & 1.6 & 0.2 & 105.2 & 18.8 \\
\hline UZ-16a-1 & 20.5 & 54 & 17.8 & 0.9 & 650 & 220 & 1.4 & 0.3 & 246.8 & 37.1 \\
\hline UZ-16a-2 & 34.8 & 47 & 43.6 & 1.9 & BLOD & BLOD & 1.2 & 0.2 & 170.4 & 26.7 \\
\hline UZ-16a-3 & 32.3 & 37 & 127.0 & 7.8 & BLOD & BLOD & 0.9 & 0.3 & 54.3 & 9.7 \\
\hline UZ-16a-4 & 6.7 & 9 & 6.5 & 0.3 & BLOD & BLOD & 0.9 & 0.2 & 219.1 & 74.4 \\
\hline UZ-16a-5 & 44.5 & 76 & 120.6 & 6.1 & BLOD & BLOD & 1.1 & 0.4 & 78.8 & 10.3 \\
\hline UZ-16a-6 & 36.5 & 83 & 27.8 & 1.2 & BLOD & BLOD & 1.3 & 0.2 & 280.5 & 34.7 \\
\hline UZ-16a-7 & 45.4 & 53 & 60.2 & 2.7 & BLOD & BLOD & 1.4 & 0.4 & 161.1 & 24.0 \\
\hline UZ-16a-8 & 10.1 & 25 & 24.5 & 3.1 & 21400 & 4600 & 0.9 & 0.2 & 87.7 & 21.0 \\
\hline
\end{tabular}




\begin{tabular}{|c|c|c|c|c|c|c|c|c|c|c|}
\hline UZ-16a-9 & 16.1 & 44 & 23.2 & 1.1 & BLOD & BLOD & 1.2 & 0.2 & 148.5 & 24.1 \\
\hline UZ-16a-10 & 32.4 & 70 & 44.5 & 2.5 & BLOD & BLOD & 1.1 & 0.4 & 155.5 & 21.3 \\
\hline UZ-16a-11 & 18.6 & 40 & 33.8 & 2.0 & BLOD & BLOD & 1.5 & 0.4 & 117.8 & 20.4 \\
\hline UZ-16a-12 & 38.6 & 72 & 64.6 & 4.3 & BLOD & BLOD & 1.7 & 0.3 & 127.6 & 17.9 \\
\hline UZ-16a-13 & 28.4 & 37 & 47.3 & 1.7 & BLOD & BLOD & 1.1 & 0.2 & 128.2 & 22.1 \\
\hline UZ-16a-14 & 30.2 & 72 & 37.0 & 1.7 & BLOD & BLOD & 1.3 & 0.3 & 174.4 & 23.0 \\
\hline UZ-16a-15 & 46.6 & 47 & 33.1 & 1.8 & BLOD & BLOD & 1.4 & 0.3 & 301.0 & 48.2 \\
\hline UZ-16a-16 & 17.3 & 24 & 21.6 & 1.6 & 3040 & 350 & 2.6 & 0.1 & 171.6 & 37.8 \\
\hline UZ-16a-17 & 25.3 & 13 & 59.2 & 5.6 & 660 & 280 & 1.5 & 0.4 & 91.5 & 27.0 \\
\hline UZ-16a-18 & 19.2 & 16 & 58.1 & 2.8 & BLOD & BLOD & 1.1 & 0.2 & 70.6 & 18.2 \\
\hline UZ-16a-19 & 32.6 & 63 & 45.7 & 2.6 & BLOD & BLOD & 1.2 & 0.3 & 152.3 & 21.8 \\
\hline UZ-16a-20 & 22.7 & 49 & 32.0 & 1.2 & BLOD & BLOD & 1.6 & 0.1 & 151.6 & 23.1 \\
\hline UZ-16a-21 & 39.5 & 47 & 59.9 & 3.2 & BLOD & BLOD & 1.4 & 0.5 & 140.8 & 22.5 \\
\hline UZ-16a-22 & 15.9 & 45 & 17.3 & 1.0 & 1380 & 220 & 1.5 & 0.2 & 196.4 & 32.2 \\
\hline UZ-16a-23 & 10.1 & 26 & 15.3 & 0.8 & 6400 & 2500 & 0.8 & 0.0 & 141.5 & 29.2 \\
\hline UZ-16a-24 & 39.6 & 50 & 46.6 & 4.2 & BLOD & BLOD & 1.1 & 0.2 & 181.8 & 31.2 \\
\hline UZ-16a-25 & 39.4 & 96 & 22.4 & 1.2 & BLOD & BLOD & 1.2 & 0.3 & 375.9 & 45.6 \\
\hline UZ-16a-26 & 40.4 & 124 & 40.6 & 2.1 & 600 & 220 & 1.2 & 0.2 & 212.5 & 23.4 \\
\hline UZ-16a-27 & 5.8 & 15 & 4.9 & 0.2 & BLOD & BLOD & 0.7 & 0.2 & 252.0 & 66.9 \\
\hline UZ-16a-28 & 28.2 & 63 & 56.0 & 2.5 & 620 & 250 & 1.1 & 0.4 & 107.7 & 15.0 \\
\hline UZ-16a-29 & 11.0 & 21 & 18.4 & 1.0 & BLOD & BLOD & 1.2 & 0.3 & 127.9 & 29.1 \\
\hline UZ-16a-30 & 13.6 & 54 & 3.5 & 0.4 & 1580 & 500 & 1.4 & 0.3 & 828.4 & 150.1 \\
\hline UZ-16a-31 & 13.1 & 22 & 36.3 & 1.8 & BLOD & BLOD & 1.3 & 0.3 & 76.9 & 17.1 \\
\hline UZ-16a-32 & 44.4 & 98 & 57.7 & 2.9 & BLOD & BLOD & 1.1 & 0.3 & 164.4 & 19.5 \\
\hline UZ-16a-33 & 14.8 & 32 & 23.8 & 1.1 & BLOD & BLOD & 1.0 & 0.2 & 132.5 & 24.7 \\
\hline UZ-16a-34 & 26.4 & 58 & 49.7 & 3.3 & 3300 & 1400 & 1.2 & 0.2 & 113.5 & 17.2 \\
\hline UZ-16a-35 & 4.4 & 16 & 5.1 & 0.2 & BLOD & BLOD & 1.6 & 0.7 & 185.2 & 47.4 \\
\hline UZ-16a-36 & 5.5 & 23 & 5.8 & 0.3 & 1320 & 410 & 1.4 & 0.3 & 203.0 & 43.9 \\
\hline UZ-16a-37 & 17.9 & 45 & 20.2 & 1.1 & 2430 & 450 & 1.7 & 0.3 & 189.9 & 31.0 \\
\hline UZ-16a-38 & 46.5 & 69 & 72.4 & 5.5 & BLOD & BLOD & 1.4 & 0.4 & 137.4 & 20.2 \\
\hline UZ-16a-39 & 25.4 & 67 & 33.6 & 2.1 & BLOD & BLOD & 1.3 & 0.4 & 161.5 & 23.0 \\
\hline
\end{tabular}




\begin{tabular}{|c|c|c|c|c|c|c|c|c|c|c|}
\hline UZ-16a-40 & 9.3 & 44 & 17.8 & 0.9 & BLOD & BLOD & 0.8 & 0.2 & 111.6 & 18.2 \\
\hline UZ-16a-41 & 40.2 & 59 & 40.4 & 2.3 & BLOD & BLOD & 1.4 & 0.4 & 212.9 & 31.3 \\
\hline UZ-18-1 & 32.9 & 67 & 41.2 & 2.1 & 1050 & 250 & 1.4 & 0.5 & 170.5 & 23.4 \\
\hline UZ-18-2 & 10.6 & 21 & 14.1 & 0.8 & 1590 & 340 & 1.1 & 0.2 & 161.6 & 36.8 \\
\hline UZ-18-3 & 12.8 & 22 & 25.1 & 1.2 & BLOD & BLOD & 1.0 & 0.2 & 109.0 & 24.2 \\
\hline UZ-18-4 & 9.5 & 19 & 14.5 & 0.5 & BLOD & BLOD & 1.2 & 0.3 & 139.7 & 32.8 \\
\hline UZ-18-5 & 38.9 & 76 & 51.9 & 2.6 & 17800 & 3900 & 1.2 & 0.3 & 160.1 & 20.9 \\
\hline UZ-19-1 & 15.5 & 20 & 21.9 & 0.9 & 1610 & 300 & 1.8 & 0.7 & 151.2 & 34.9 \\
\hline UZ-19-2 & 35.6 & 92 & 53.3 & 2.6 & 3210 & 440 & 1.7 & 0.2 & 142.7 & 17.3 \\
\hline UZ-19-3 & 55.2 & 69 & 56.8 & 4.9 & 3860 & 510 & 1.9 & 0.4 & 207.6 & 31.7 \\
\hline UZ-19-4 & 36.4 & 87 & 29.5 & 1.6 & 4170 & 530 & 1.7 & 0.4 & 264.0 & 33.2 \\
\hline UZ-19-5 & 21.0 & 61 & 26.8 & 1.1 & 3420 & 430 & 1.7 & 0.2 & 167.6 & 23.4 \\
\hline UZ-19-6 & 37.3 & 65 & 36.5 & 2.1 & 4070 & 440 & 1.7 & 0.3 & 218.2 & 30.9 \\
\hline UZ-19-7 & 51.1 & 85 & 62.1 & 2.1 & 3390 & 400 & 1.7 & 0.3 & 175.8 & 21.0 \\
\hline UZ-19-8 & 37.9 & 77 & 31.8 & 1.4 & 2940 & 320 & 1.2 & 0.2 & 254.9 & 32.6 \\
\hline UZ-19-9 & 35.7 & 123 & 44.7 & 1.8 & 3160 & 360 & 1.9 & 0.4 & 170.5 & 18.0 \\
\hline UZ-19-10 & 36.2 & 75 & 33.1 & 1.1 & 2330 & 450 & 1.6 & 0.3 & 233.6 & 29.4 \\
\hline UZ-19-11 & 43.0 & 121 & 43.4 & 2.5 & 19900 & 1100 & 1.9 & 0.6 & 211.6 & 24.1 \\
\hline UZ-19-12 & 63.2 & 64 & 50.8 & 2.4 & 2760 & 390 & 1.3 & 0.4 & 265.9 & 36.9 \\
\hline UZ-19-13 & 32.4 & 44 & 41.6 & 2.0 & 3160 & 430 & 1.8 & 0.9 & 166.4 & 27.1 \\
\hline UZ-19-14 & 48.4 & 118 & 41.0 & 1.8 & 2710 & 420 & 1.7 & 0.4 & 252.4 & 27.4 \\
\hline UZ-19-15 & 51.6 & 65 & 53.4 & 2.2 & 2350 & 390 & 1.6 & 1.3 & 206.7 & 28.1 \\
\hline UZ-19-16 & 31.2 & 37 & 20.3 & 2.5 & 2490 & 520 & 2.2 & 1.0 & 328.9 & 68.7 \\
\hline UZ-19-17 & 8.1 & 16 & 5.2 & 0.3 & 860 & 340 & 1.6 & 0.4 & 333.5 & 86.1 \\
\hline UZ-19-18 & 30.3 & 39 & 34.9 & 1.9 & 4310 & 550 & 1.6 & 0.4 & 185.7 & 32.2 \\
\hline UZ-19-19 & 46.1 & 41 & 36.5 & 1.8 & 2450 & 350 & 1.6 & 0.2 & 270.1 & 45.4 \\
\hline UZ-19-20 & 72.1 & 57 & 35.6 & 1.5 & 2260 & 400 & 1.4 & 0.3 & 433.2 & 62.3 \\
\hline UZ-19-21 & 48.8 & 61 & 51.6 & 2.1 & 2470 & 340 & 1.6 & 0.2 & 202.1 & 28.2 \\
\hline UZ-19-22 & 32.7 & 58 & 30.2 & 1.2 & 2980 & 300 & 1.7 & 0.6 & 231.3 & 32.9 \\
\hline UZ-19-23 & 23.5 & 43 & 21.9 & 1.3 & 1850 & 340 & 1.6 & 0.5 & 229.2 & 38.5 \\
\hline UZ-19-24 & 48.4 & 90 & 41.3 & 1.7 & 2650 & 310 & 1.7 & 0.4 & 250.4 & 29.8 \\
\hline
\end{tabular}




\begin{tabular}{|c|c|c|c|c|c|c|c|c|c|c|}
\hline UZ-19-25 & 58.8 & 83 & 77.6 & 3.0 & 2370 & 230 & 1.9 & 0.4 & 161.9 & 19.8 \\
\hline UZ-19-26 & 44.0 & 84 & 41.9 & 2.6 & 2310 & 350 & 1.7 & 0.3 & 224.4 & 29.4 \\
\hline UZ-19-27 & 22.9 & 61 & 28.1 & 1.5 & 1910 & 350 & 1.6 & 0.3 & 174.3 & 25.0 \\
\hline UZ-19-28 & 45.9 & 52 & 33.7 & 1.6 & 2260 & 310 & 1.7 & 0.3 & 290.9 & 44.0 \\
\hline UZ-19-29 & 55.2 & 84 & 37.5 & 1.9 & 1790 & 310 & 1.6 & 0.4 & 314.8 & 39.6 \\
\hline UZ-19-30 & 46.0 & 70 & 35.6 & 1.1 & 2490 & 250 & 1.6 & 0.7 & 276.0 & 35.6 \\
\hline UZ-19-31 & 36.9 & 50 & 26.4 & 0.9 & 2280 & 280 & 1.4 & 0.5 & 298.1 & 44.7 \\
\hline UZ-20-1 & 11.7 & 23 & 22.9 & 1.2 & BLOD & BLOD & 1.8 & 0.3 & 94.7 & 20.7 \\
\hline UZ-20-2 & 22.0 & 74 & 26.9 & 1.4 & BLOD & BLOD & 1.8 & 0.4 & 150.9 & 20.1 \\
\hline UZ-20-3 & 11.8 & 58 & 13.6 & 0.6 & 1120 & 330 & 2.3 & 0.8 & 160.9 & 23.0 \\
\hline UZ-20-4 & 16.8 & 79 & 31.0 & 1.5 & BLOD & BLOD & 1.6 & 0.4 & 100.5 & 12.9 \\
\hline UZ-20-5 & 8.4 & 14 & 14.5 & 0.7 & BLOD & BLOD & 1.5 & 0.4 & 107.3 & 29.5 \\
\hline UZ-20-6 & 14.8 & 67 & 17.2 & 0.7 & BLOD & BLOD & 2.1 & 0.6 & 159.6 & 21.3 \\
\hline UZ-20-7 & 13.3 & 25 & 11.2 & 0.7 & BLOD & BLOD & 2.2 & 0.3 & 219.8 & 46.5 \\
\hline UZ-20-8 & 38.5 & 76 & 82.7 & 4.5 & BLOD & BLOD & 1.9 & 0.5 & 86.2 & 11.4 \\
\hline UZ-20-9 & 17.6 & 46 & 28.9 & 2.4 & BLOD & BLOD & 1.6 & 0.5 & 112.9 & 19.6 \\
\hline UZ-20-10 & 26.3 & 74 & 38.7 & 2.1 & BLOD & BLOD & 1.8 & 0.7 & 125.5 & 16.8 \\
\hline UZ-20-11 & 15.9 & 69 & 14.2 & 0.8 & BLOD & BLOD & 1.9 & 0.3 & 207.8 & 28.9 \\
\hline UZ-20-12 & 24.0 & 76 & 26.9 & 1.6 & BLOD & BLOD & 2.0 & 0.4 & 165.0 & 22.2 \\
\hline UZ-20-13 & 9.0 & 25 & 19.3 & 1.1 & BLOD & BLOD & 1.4 & 0.7 & 86.3 & 18.2 \\
\hline UZ-20-14 & 15.2 & 52 & 26.7 & 1.5 & BLOD & BLOD & 1.8 & 0.4 & 105.3 & 16.3 \\
\hline UZ-20-15 & 23.6 & 99 & 31.0 & 2.1 & BLOD & BLOD & 2.1 & 0.5 & 141.1 & 17.9 \\
\hline UZ-20-16 & 10.4 & 26 & 17.0 & 1.1 & BLOD & BLOD & 2.2 & 0.2 & 113.3 & 23.8 \\
\hline UZ-20-17 & 10.6 & 37 & 10.9 & 0.6 & BLOD & BLOD & 2.8 & 0.3 & 179.1 & 31.6 \\
\hline UZ-20-18 & 10.1 & 36 & 24.0 & 1.1 & BLOD & BLOD & 2.8 & 0.3 & 77.6 & 13.7 \\
\hline UZ-20-19 & 18.2 & 57 & 24.1 & 1.4 & BLOD & BLOD & 2.5 & 0.6 & 139.4 & 20.8 \\
\hline UZ-20-20 & 11.2 & 41 & 13.6 & 0.7 & BLOD & BLOD & 2.3 & 0.8 & 152.4 & 25.7 \\
\hline UZ-20-21 & 26.6 & 75 & 47.7 & 2.6 & 1170 & 460 & 2.4 & 0.7 & 103.2 & 13.7 \\
\hline UZ-20-22 & 11.8 & 29 & 11.1 & 0.7 & BLOD & BLOD & 2.0 & 0.5 & 195.8 & 39.1 \\
\hline UZ-20-23 & 9.8 & 50 & 16.6 & 0.8 & BLOD & BLOD & 1.2 & 0.2 & 109.6 & 17.0 \\
\hline UZ-20-24 & 25.7 & 84 & 55.7 & 2.6 & 1020 & 430 & 0.9 & 0.2 & 85.5 & 10.6 \\
\hline
\end{tabular}




\begin{tabular}{|c|c|c|c|c|c|c|c|c|c|c|}
\hline UZ-20-25 & 34.6 & 120 & 52.6 & 3.1 & 930 & 460 & 1.4 & 0.6 & 121.7 & 14.0 \\
\hline UZ-20-26 & 10.2 & 38 & 17.6 & 0.9 & BLOD & BLOD & 1.3 & 0.6 & 107.0 & 18.7 \\
\hline UZ-20-27 & 18.3 & 44 & 26.3 & 1.6 & BLOD & BLOD & 1.9 & 0.3 & 128.6 & 21.5 \\
\hline UZ-20-28 & 17.3 & 57 & 15.5 & 1.0 & BLOD & BLOD & 1.4 & 0.5 & 206.9 & 31.3 \\
\hline UZ-20-29 & 27.0 & 50 & 44.9 & 2.5 & BLOD & BLOD & 1.6 & 0.3 & 111.2 & 17.4 \\
\hline UZ-21-1 & 23.7 & 113 & 28.5 & 1.1 & BLOD & BLOD & 2.1 & 0.4 & 154.0 & 16.7 \\
\hline UZ-21-2 & 22.7 & 64 & 34.6 & 1.6 & BLOD & BLOD & 1.6 & 0.6 & 121.1 & 16.8 \\
\hline UZ-21-3 & 44.8 & 183 & 76.6 & 3.9 & BLOD & BLOD & 2.0 & 0.4 & 108.3 & 10.6 \\
\hline UZ-21-4 & 21.0 & 97 & 31.8 & 1.6 & BLOD & BLOD & 1.8 & 0.3 & 122.0 & 14.6 \\
\hline UZ-21-5 & 25.1 & 102 & 35.3 & 1.4 & BLOD & BLOD & 1.6 & 0.4 & 131.6 & 14.9 \\
\hline UZ-21-6 & 30.7 & 85 & 37.1 & 1.4 & BLOD & BLOD & 1.8 & 0.8 & 152.8 & 18.5 \\
\hline UZ-21-7 & 29.5 & 161 & 35.5 & 1.2 & BLOD & BLOD & 2.0 & 0.4 & 153.9 & 14.4 \\
\hline UZ-21-8 & 16.8 & 70 & 25.8 & 1.5 & 1920 & 730 & 2.1 & 0.4 & 120.6 & 16.7 \\
\hline UZ-21-9 & 20.2 & 44 & 33.2 & 1.6 & BLOD & BLOD & 1.3 & 0.5 & 112.4 & 18.3 \\
\hline UZ-21-10 & 23.8 & 68 & 34.0 & 1.4 & BLOD & BLOD & 1.9 & 0.7 & 129.6 & 17.3 \\
\hline UZ-21-11 & 25.9 & 85 & 46.2 & 1.6 & BLOD & BLOD & 1.5 & 0.5 & 103.5 & 12.4 \\
\hline UZ-21-12 & 22.6 & 97 & 30.4 & 1.3 & BLOD & BLOD & 1.7 & 0.7 & 137.8 & 16.1 \\
\hline UZ-21-13 & 23.4 & 102 & 23.3 & 1.2 & BLOD & BLOD & 2.0 & 0.8 & 185.5 & 21.9 \\
\hline UZ-21-14 & 31.6 & 118 & 52.9 & 2.5 & BLOD & BLOD & 2.1 & 0.6 & 110.5 & 12.2 \\
\hline UZ-21-15 & 26.4 & 98 & 33.7 & 1.4 & 700 & 460 & 2.3 & 0.5 & 145.0 & 16.8 \\
\hline UZ-21-16 & 25.4 & 100 & 37.2 & 2.3 & BLOD & BLOD & 2.1 & 0.7 & 126.4 & 15.6 \\
\hline UZ-21-17 & 24.4 & 162 & 35.7 & 1.3 & BLOD & BLOD & 2.1 & 1.2 & 126.3 & 11.9 \\
\hline UZ-21-18 & 26.6 & 121 & 30.0 & 1.8 & 3400 & 1000 & 1.8 & 0.4 & 164.1 & 18.9 \\
\hline UZ-21-19 & 30.4 & 100 & 51.8 & 2.3 & 870 & 400 & 2.0 & 0.6 & 108.5 & 12.6 \\
\hline UZ-21-20 & 45.7 & 120 & 84.8 & 2.8 & BLOD & BLOD & 1.5 & 0.5 & 99.8 & 10.4 \\
\hline UZ-21-21 & 24.3 & 110 & 38.5 & 1.8 & BLOD & BLOD & 2.0 & 1.0 & 116.9 & 13.2 \\
\hline UZ-21-22 & 42.9 & 105 & 71.9 & 4.8 & BLOD & BLOD & 1.8 & 0.7 & 110.3 & 13.7 \\
\hline UZ-21-23 & 30.2 & 73 & 34.7 & 1.7 & BLOD & BLOD & 1.7 & 0.4 & 160.7 & 21.3 \\
\hline UZ-21-24 & 25.7 & 119 & 36.4 & 1.6 & 720 & 370 & 1.7 & 0.3 & 130.6 & 14.2 \\
\hline UZ-21-25 & 29.2 & 168 & 54.3 & 2.7 & BLOD & BLOD & 2.0 & 0.5 & 99.6 & 9.9 \\
\hline UZ-21-26 & 25.1 & 103 & 31.2 & 1.5 & BLOD & BLOD & 1.8 & 0.9 & 148.7 & 17.3 \\
\hline
\end{tabular}




\begin{tabular}{|c|c|c|c|c|c|c|c|c|c|c|}
\hline UZ-21-27 & 30.1 & 110 & 34.3 & 1.5 & BLOD & BLOD & 1.1 & 0.3 & 162.5 & 18.1 \\
\hline UZ-21-28 & 21.1 & 75 & 25.4 & 0.9 & BLOD & BLOD & 1.4 & 0.5 & 153.2 & 19.3 \\
\hline UZ-21-29 & 24.6 & 68 & 34.6 & 1.6 & BLOD & BLOD & 1.2 & 0.4 & 131.6 & 17.8 \\
\hline UZ-21-30 & 23.9 & 71 & 32.7 & 1.4 & BLOD & BLOD & 1.2 & 0.5 & 135.0 & 17.8 \\
\hline UZ-21-31 & 21.8 & 61 & 33.9 & 1.5 & BLOD & BLOD & 1.9 & 0.3 & 119.0 & 16.7 \\
\hline UZ-21-32 & 24.1 & 89 & 31.9 & 1.7 & BLOD & BLOD & 1.6 & 0.7 & 139.8 & 17.4 \\
\hline UZ-21-33 & 20.4 & 100 & 31.2 & 1.5 & 690 & 370 & 2.2 & 0.5 & 120.9 & 14.2 \\
\hline UZ-21-34 & 25.2 & 95 & 32.6 & 1.6 & BLOD & BLOD & 2.1 & 0.5 & 143.0 & 17.2 \\
\hline UZ-21-35 & 26.3 & 86 & 42.6 & 1.9 & BLOD & BLOD & 2.1 & 0.6 & 114.2 & 14.0 \\
\hline UZ-21-36 & 30.5 & 92 & 36.6 & 2.5 & BLOD & BLOD & 2.1 & 0.3 & 154.1 & 20.1 \\
\hline UZ-22-1 & 5.1 & 33 & 3.6 & 0.2 & 780 & 380 & 1.5 & 0.3 & 265.3 & 50.0 \\
\hline UZ-22-2 & 7.2 & 22 & 8.5 & 0.5 & BLOD & BLOD & 0.6 & 0.0 & 157.1 & 35.4 \\
\hline UZ-22-3 & 8.3 & 39 & 6.2 & 0.3 & 740 & 290 & 1.5 & 0.3 & 250.2 & 43.3 \\
\hline UZ-22-4 & 4.6 & 18 & 6.5 & 0.4 & 990 & 420 & 2.2 & 0.2 & 130.5 & 32.1 \\
\hline UZ-22-5 & 5.7 & 24 & 6.8 & 0.3 & 1010 & 390 & 1.8 & 0.3 & 156.2 & 33.0 \\
\hline UZ-22-6 & 3.6 & 16 & 3.9 & 0.2 & 1030 & 370 & 1.6 & 0.3 & 168.7 & 43.9 \\
\hline UZ-22-7 & 3.7 & 13 & 4.3 & 0.2 & BLOD & BLOD & 2.3 & 0.5 & 159.7 & 45.3 \\
\hline UZ-22-8 & 6.2 & 24 & 5.4 & 0.4 & 1370 & 480 & 2.5 & 0.3 & 212.1 & 46.4 \\
\hline UZ-22-9 & 6.3 & 27 & 7.3 & 0.6 & 1090 & 450 & 2.0 & 0.1 & 160.5 & 34.0 \\
\hline UZ-22-10 & 5.2 & 19 & 3.9 & 0.3 & 1080 & 490 & 1.9 & 0.5 & 242.2 & 58.9 \\
\hline UZ-22-11 & 7.8 & 27 & 5.2 & 0.3 & BLOD & BLOD & 1.6 & 0.3 & 279.5 & 57.8 \\
\hline UZ-22-12 & 5.7 & 32 & 5.3 & 0.3 & 2150 & 520 & 2.1 & 0.2 & 201.2 & 38.5 \\
\hline UZ-22-13 & 4.5 & 13 & 4.8 & 0.3 & BLOD & BLOD & 1.3 & 0.4 & 176.7 & 50.6 \\
\hline UZ-22-14 & 7.2 & 34 & 6.4 & 0.3 & BLOD & BLOD & 1.7 & 0.3 & 206.8 & 37.6 \\
\hline UZ-22-15 & 5.1 & 17 & 5.2 & 0.3 & 990 & 440 & 1.6 & 0.2 & 182.8 & 46.0 \\
\hline UZ-22-16 & 7.6 & 25 & 6.2 & 0.3 & 890 & 420 & 2.3 & 0.7 & 229.3 & 48.0 \\
\hline UZ-22-17 & 5.0 & 22 & 4.0 & 0.3 & BLOD & BLOD & 1.0 & 0.2 & 232.0 & 52.5 \\
\hline UZ-22-18 & 3.8 & 22 & 3.9 & 0.2 & 1770 & 490 & 2.2 & 0.8 & 178.7 & 40.0 \\
\hline UZ-22-19 & 6.8 & 40 & 5.7 & 0.4 & 1290 & 500 & 2.0 & 0.5 & 219.6 & 38.7 \\
\hline UZ-22-20 & 6.0 & 36 & 4.4 & 0.3 & BLOD & BLOD & 1.9 & 0.3 & 249.1 & 44.8 \\
\hline UZ-22-21 & 8.6 & 34 & 6.2 & 0.3 & BLOD & BLOD & 1.8 & 0.2 & 256.1 & 47.0 \\
\hline
\end{tabular}




\begin{tabular}{|c|c|c|c|c|c|c|c|c|c|c|}
\hline UZ-22-22 & 11.3 & 35 & 10.1 & 0.7 & 1130 & 600 & 2.5 & 0.3 & 208.5 & 38.7 \\
\hline UZ-22-23 & 6.6 & 25 & 4.6 & 0.3 & 1780 & 500 & 2.1 & 0.3 & 267.0 & 56.3 \\
\hline UZ-22-24 & 5.3 & 27 & 5.2 & 0.4 & 990 & 400 & 2.0 & 0.4 & 188.2 & 39.4 \\
\hline UZ-22-25 & 5.3 & 28 & 4.8 & 0.2 & 1140 & 410 & 1.4 & 0.5 & 203.0 & 39.9 \\
\hline UZ-22-26 & 4.3 & 21 & 5.3 & 0.2 & BLOD & BLOD & 1.5 & 0.3 & 148.4 & 33.4 \\
\hline UZ-22-27 & 6.0 & 39 & 7.1 & 0.5 & BLOD & BLOD & 1.5 & 0.2 & 157.5 & 28.0 \\
\hline UZ-22-28 & 3.2 & 29 & 3.5 & 0.2 & 1710 & 370 & 1.5 & 0.4 & 169.2 & 33.5 \\
\hline UZ-22-29 & 6.9 & 29 & 6.1 & 0.3 & BLOD & BLOD & 2.1 & 0.9 & 211.6 & 41.1 \\
\hline UZ-22-30 & 7.8 & 23 & 4.3 & 0.2 & BLOD & BLOD & 1.8 & 0.2 & 338.1 & 73.9 \\
\hline UZ-22-31 & 9.6 & 31 & 6.9 & 0.3 & 1100 & 370 & 1.8 & 0.2 & 257.6 & 48.8 \\
\hline UZ-22-32 & 11.7 & 46 & 9.8 & 0.6 & 1110 & 450 & 1.5 & 0.4 & 220.2 & 36.0 \\
\hline UZ-22-33 & 7.5 & 47 & 6.9 & 0.3 & 1110 & 410 & 1.5 & 1.0 & 200.3 & 31.6 \\
\hline UZ-22-34 & 9.6 & 43 & 5.3 & 0.3 & BLOD & BLOD & 1.4 & 0.9 & 337.1 & 57.0 \\
\hline UZ-22-35 & 3.5 & 25 & 5.0 & 0.4 & 1290 & 500 & 1.7 & 0.1 & 131.0 & 28.2 \\
\hline UZ-22-36 & 8.3 & 27 & 4.4 & 0.3 & BLOD & BLOD & 1.5 & 0.4 & 349.0 & 71.3 \\
\hline UZ-22-37 & 6.5 & 21 & 6.2 & 0.4 & BLOD & BLOD & 1.9 & 0.4 & 194.4 & 44.6 \\
\hline UZ-22-38 & 3.2 & 18 & 3.4 & 0.3 & 106000 & 18000 & 2.4 & 0.3 & 174.7 & 44.5 \\
\hline UZ-22-39 & 4.2 & 20 & 4.6 & 0.2 & 860 & 430 & 1.9 & 0.3 & 171.1 & 39.7 \\
\hline UZ-22-40 & 4.4 & 27 & 3.6 & 0.3 & 1170 & 370 & 1.1 & 0.3 & 225.5 & 47.1 \\
\hline UZ-23-1 & 5.3 & 37 & 4.2 & 0.2 & 2510 & 440 & 1.9 & 0.3 & 233.0 & 40.9 \\
\hline UZ-23-2 & 7.3 & 25 & 7.4 & 0.4 & 2220 & 460 & 2.0 & 0.3 & 183.2 & 38.3 \\
\hline UZ-23-3 & 3.5 & 21 & 4.1 & 0.2 & 1820 & 500 & 1.7 & 0.3 & 157.9 & 36.2 \\
\hline UZ-23-4 & 7.4 & 49 & 4.7 & 0.3 & 2540 & 450 & 1.9 & 0.4 & 288.2 & 45.4 \\
\hline UZ-23-5 & 7.7 & 33 & 5.6 & 0.4 & 1750 & 450 & 1.9 & 1.1 & 254.3 & 48.3 \\
\hline UZ-23-6 & 9.1 & 38 & 6.4 & 0.3 & 1680 & 460 & 1.7 & 0.2 & 264.7 & 46.1 \\
\hline UZ-23-7 & 5.2 & 34 & 3.7 & 0.2 & 2200 & 460 & 1.6 & 0.3 & 263.7 & 49.4 \\
\hline UZ-23-8 & 6.9 & 38 & 5.1 & 0.3 & 3070 & 560 & 1.7 & 0.4 & 254.1 & 45.1 \\
\hline UZ-23-9 & 8.1 & 28 & 6.5 & 0.4 & 1370 & 460 & 1.8 & 0.4 & 229.6 & 46.0 \\
\hline UZ-23-10 & 8.4 & 40 & 4.4 & 0.2 & 2280 & 480 & 1.8 & 0.2 & 351.8 & 60.3 \\
\hline UZ-23-11 & 3.4 & 16 & 4.0 & 0.3 & 2830 & 690 & 1.9 & 0.3 & 157.8 & 41.2 \\
\hline UZ-23-12 & 5.5 & 20 & 4.9 & 0.3 & 1850 & 420 & 1.8 & 0.2 & 211.2 & 49.4 \\
\hline
\end{tabular}




\begin{tabular}{|c|c|c|c|c|c|c|c|c|c|c|}
\hline UZ-23-13 & 5.1 & 21 & 3.9 & 0.2 & 1730 & 460 & 1.9 & 0.3 & 242.5 & 55.6 \\
\hline UZ-23-14 & 7.5 & 29 & 5.9 & 0.3 & 1750 & 470 & 2.1 & 0.5 & 237.5 & 46.5 \\
\hline UZ-23-15 & 7.3 & 30 & 4.4 & 0.3 & 2240 & 430 & 2.2 & 0.3 & 305.5 & 59.9 \\
\hline UZ-23-16 & 6.0 & 35 & 3.7 & 0.2 & 1920 & 510 & 2.0 & 0.4 & 299.0 & 54.7 \\
\hline UZ-23-17 & 5.3 & 21 & 4.8 & 0.4 & 2020 & 460 & 1.7 & 0.3 & 205.1 & 48.1 \\
\hline UZ-23-18 & 4.4 & 20 & 4.0 & 0.2 & 2060 & 400 & 2.2 & 0.2 & 207.7 & 48.5 \\
\hline UZ-23-19 & 5.8 & 30 & 4.6 & 0.3 & 2590 & 450 & 2.4 & 0.7 & 233.6 & 45.4 \\
\hline UZ-23-20 & 5.2 & 17 & 5.4 & 0.3 & 2250 & 490 & 2.3 & 0.3 & 180.2 & 45.3 \\
\hline UZ-23-21 & 3.5 & 29 & 4.4 & 0.3 & 2060 & 380 & 1.5 & 0.2 & 143.9 & 28.7 \\
\hline UZ-23-22 & 7.3 & 44 & 3.8 & 0.2 & 2380 & 530 & 2.0 & 0.4 & 354.0 & 58.1 \\
\hline UZ-23-23 & 6.5 & 33 & 4.4 & 0.2 & 1870 & 440 & 2.1 & 0.2 & 276.1 & 51.1 \\
\hline UZ-23-24 & 3.3 & 19 & 4.7 & 0.5 & 2060 & 480 & 2.3 & 0.2 & 128.6 & 33.2 \\
\hline UZ-23-25 & 3.0 & 17 & 5.1 & 0.3 & 2340 & 440 & 2.6 & 0.2 & 109.7 & 27.8 \\
\hline UZ-23-26 & 3.6 & 21 & 4.0 & 0.2 & 2120 & 430 & 2.4 & 0.3 & 167.4 & 37.8 \\
\hline UZ-23-27 & 11.0 & 66 & 10.2 & 0.6 & 2330 & 430 & 1.9 & 0.5 & 200.0 & 28.0 \\
\hline UZ-23-28 & 11.1 & 42 & 5.3 & 0.3 & 2420 & 430 & 1.8 & 0.6 & 388.2 & 66.3 \\
\hline UZ-23-29 & 4.3 & 18 & 3.5 & 0.2 & 2010 & 410 & 2.2 & 0.3 & 226.4 & 55.6 \\
\hline UZ-23-30 & 5.3 & 28 & 3.4 & 0.2 & 2150 & 500 & 2.1 & 0.2 & 292.4 & 58.3 \\
\hline UZ-23-31 & 6.6 & 43 & 4.8 & 0.3 & 2280 & 450 & 1.9 & 0.3 & 253.8 & 42.2 \\
\hline UZ-23-32 & 2.7 & 18 & 3.1 & 0.2 & 2020 & 560 & 2.1 & 0.3 & 163.4 & 40.0 \\
\hline UZ-23-33 & 5.1 & 33 & 6.0 & 0.4 & 2360 & 500 & 1.8 & 0.3 & 160.0 & 30.2 \\
\hline UZ-23-34 & 4.0 & 25 & 3.5 & 0.2 & 2370 & 430 & 1.2 & 0.3 & 213.3 & 45.3 \\
\hline UZ-23-35 & 4.1 & 25 & 4.0 & 0.2 & 2210 & 400 & 2.0 & 0.3 & 188.8 & 39.4 \\
\hline UZ-23-36 & 7.7 & 23 & 6.3 & 0.3 & 2280 & 470 & 1.6 & 0.3 & 227.5 & 49.5 \\
\hline UZ-23-37 & 6.2 & 31 & 6.3 & 0.4 & 2090 & 500 & 1.3 & 0.2 & 183.1 & 35.6 \\
\hline UZ-23-38 & 9.3 & 40 & 9.0 & 0.4 & 2260 & 500 & 1.6 & 0.2 & 190.5 & 32.1 \\
\hline UZ-23-39 & 5.7 & 33 & 4.1 & 0.3 & 1820 & 470 & 1.8 & 0.2 & 254.9 & 48.2 \\
\hline UZ-23-40 & 7.0 & 38 & 3.8 & 0.2 & 1930 & 490 & 1.3 & 0.4 & 338.2 & 59.9 \\
\hline UZ-24-1 & 2.5 & 11 & 11.4 & 0.5 & BLOD & BLOD & 1.3 & 0.2 & 47.5 & 14.6 \\
\hline UZ-24-2 & 8.2 & 35 & 12.3 & 0.5 & BLOD & BLOD & 1.4 & 0.2 & 142.8 & 25.5 \\
\hline UZ-24-3 & 9.0 & 12 & 17.5 & 1.1 & BLOD & BLOD & 1.3 & 0.1 & 110.3 & 32.9 \\
\hline
\end{tabular}




\begin{tabular}{|c|c|c|c|c|c|c|c|c|c|c|}
\hline UZ-24-4 & 7.4 & 26 & 13.3 & 0.6 & 3900 & 1700 & 1.0 & 0.2 & 118.9 & 24.3 \\
\hline UZ-24-5 & 11.2 & 20 & 20.0 & 1.0 & BLOD & BLOD & 1.7 & 0.2 & 119.9 & 27.8 \\
\hline UZ-24-6 & 10.4 & 23 & 24.6 & 1.5 & 780 & 360 & 1.6 & 0.6 & 90.5 & 19.9 \\
\hline UZ-24-7 & 5.8 & 22 & 14.7 & 0.7 & BLOD & BLOD & 2.0 & 0.3 & 84.3 & 18.6 \\
\hline UZ-24-8 & 8.2 & 11 & 23.1 & 1.0 & BLOD & BLOD & 1.9 & 0.4 & 75.8 & 23.3 \\
\hline UZ-24-9 & 10.4 & 36 & 14.7 & 0.8 & BLOD & BLOD & 1.9 & 0.3 & 150.4 & 26.8 \\
\hline UZ-24-10 & 12.4 & 34 & 44.2 & 1.9 & BLOD & BLOD & 2.3 & 0.3 & 59.8 & 10.8 \\
\hline UZ-24-11 & 9.9 & 19 & 19.4 & 0.8 & BLOD & BLOD & 2.5 & 0.2 & 108.9 & 25.7 \\
\hline UZ-24-12 & 20.6 & 74 & 60.6 & 2.2 & 610 & 290 & 2.3 & 0.4 & 72.7 & 9.3 \\
\hline UZ-24-13 & 2.7 & 5 & 7.9 & 0.4 & BLOD & BLOD & 2.1 & 0.2 & 73.1 & 33.0 \\
\hline UZ-24-14 & 7.3 & 15 & 22.7 & 1.2 & BLOD & BLOD & 2.4 & 0.3 & 68.6 & 18.3 \\
\hline UZ-24-15 & 5.1 & 12 & 9.6 & 0.4 & BLOD & BLOD & 1.9 & 0.4 & 113.8 & 33.4 \\
\hline UZ-24-16 & 7.0 & 8 & 11.5 & 0.5 & BLOD & BLOD & 2.1 & 0.3 & 129.7 & 46.5 \\
\hline UZ-24-17 & 6.9 & 14 & 18.3 & 0.9 & BLOD & BLOD & 2.2 & 0.2 & 81.1 & 22.2 \\
\hline UZ-24-18 & 4.7 & 6 & 13.6 & 0.5 & BLOD & BLOD & 1.5 & 0.2 & 74.1 & 30.5 \\
\hline UZ-24-19 & 8.2 & 37 & 14.4 & 0.7 & BLOD & BLOD & 2.4 & 0.4 & 120.8 & 21.3 \\
\hline UZ-24-20 & 11.5 & 15 & 41.4 & 3.6 & BLOD & BLOD & 2.0 & 0.6 & 59.2 & 16.3 \\
\hline UZ-24-21 & 16.2 & 51 & 43.8 & 7.7 & BLOD & BLOD & 2.0 & 0.4 & 79.0 & 18.0 \\
\hline UZ-24-22 & 9.7 & 32 & 21.0 & 1.2 & BLOD & BLOD & 2.3 & 0.2 & 98.6 & 18.7 \\
\hline UZ-24-23 & 11.8 & 23 & 27.2 & 1.4 & BLOD & BLOD & 2.4 & 0.4 & 92.4 & 20.2 \\
\hline UZ-24-24 & 10.2 & 46 & 24.9 & 1.0 & BLOD & BLOD & 2.8 & 0.3 & 87.3 & 13.7 \\
\hline UZ-24-25 & 15.0 & 60 & 33.4 & 1.6 & BLOD & BLOD & 2.3 & 0.4 & 95.9 & 13.7 \\
\hline UZ-24-26 & 9.9 & 52 & 28.7 & 1.6 & BLOD & BLOD & 2.3 & 0.4 & 73.7 & 11.4 \\
\hline UZ-24-27 & 10.5 & 36 & 16.4 & 0.6 & BLOD & BLOD & 2.4 & 0.6 & 137.1 & 24.0 \\
\hline UZ-24-28 & 3.4 & 12 & 8.4 & 0.5 & 630 & 280 & 2.2 & 0.2 & 86.2 & 25.6 \\
\hline UZ-24-29 & 7.1 & 15 & 16.2 & 0.6 & BLOD & BLOD & 1.9 & 0.2 & 94.1 & 24.8 \\
\hline UZ-24-30 & 3.7 & 8 & 9.7 & 0.5 & BLOD & BLOD & 1.9 & 0.7 & 81.9 & 29.5 \\
\hline UZ-24-31 & 8.9 & 56 & 30.1 & 2.0 & 630 & 330 & 1.3 & 0.2 & 63.0 & 9.7 \\
\hline UZ-24-32 & 12.7 & 38 & 26.7 & 1.3 & BLOD & BLOD & 1.4 & 0.2 & 101.8 & 17.7 \\
\hline UZ-24-33 & 4.7 & 15 & 5.4 & 0.3 & BLOD & BLOD & 1.1 & 0.2 & 186.6 & 49.6 \\
\hline UZ-24-34 & 25.4 & 113 & 82.6 & 4.5 & BLOD & BLOD & 1.4 & 0.4 & 65.8 & 7.6 \\
\hline
\end{tabular}




\begin{tabular}{|c|c|c|c|c|c|c|c|c|c|c|}
\hline UZ-24-35 & 3.0 & 8 & 5.5 & 0.3 & BLOD & BLOD & 1.3 & 0.2 & 118.4 & 42.5 \\
\hline UZ-25-1 & 9.7 & 12 & 21.5 & 1.0 & BLOD & BLOD & 0.9 & 0.1 & 93.6 & 27.6 \\
\hline UZ-25-2 & 10.7 & 27 & 23.9 & 1.3 & BLOD & BLOD & 1.2 & 0.5 & 92.4 & 18.9 \\
\hline UZ-25-3 & 6.6 & 24 & 5.9 & 0.3 & BLOD & BLOD & 1.0 & 0.2 & 231.1 & 49.1 \\
\hline UZ-25-4 & 13.6 & 29 & 21.4 & 0.8 & 490 & 210 & 0.9 & 0.2 & 131.1 & 25.4 \\
\hline UZ-25-5 & 8.0 & 21 & 18.8 & 1.5 & BLOD & BLOD & 0.8 & 0.1 & 88.1 & 20.8 \\
\hline UZ-25-6 & 4.2 & 9 & 18.4 & 0.8 & BLOD & BLOD & 0.6 & 0.1 & 46.8 & 15.9 \\
\hline UZ-25-7 & 12.1 & 28 & 24.0 & 1.0 & BLOD & BLOD & 0.9 & 0.1 & 104.5 & 20.7 \\
\hline UZ-25-8 & 9.7 & 32 & 15.6 & 0.8 & 420 & 190 & 1.3 & 0.5 & 128.3 & 24.3 \\
\hline UZ-25-9 & 16.2 & 47 & 32.7 & 1.5 & BLOD & BLOD & 1.4 & 0.4 & 102.4 & 16.2 \\
\hline UZ-25-10 & 7.9 & 24 & 15.3 & 0.8 & 620 & 380 & 0.8 & 0.2 & 107.3 & 23.0 \\
\hline UZ-25-11 & 3.2 & 5 & 9.2 & 0.5 & 810 & 190 & 1.6 & 0.2 & 73.4 & 33.2 \\
\hline UZ-25-12 & 7.7 & 21 & 21.3 & 1.2 & 510 & 220 & 1.4 & 0.2 & 75.2 & 17.2 \\
\hline UZ-25-13 & 2.9 & 8 & 4.3 & 0.2 & BLOD & BLOD & 1.0 & 0.2 & 138.3 & 49.7 \\
\hline UZ-25-14 & 9.6 & 25 & 23.4 & 1.0 & BLOD & BLOD & 0.9 & 0.2 & 84.4 & 17.6 \\
\hline UZ-25-15 & 2.9 & 7 & 11.3 & 0.5 & BLOD & BLOD & 0.9 & 0.1 & 53.5 & 20.5 \\
\hline UZ-25-16 & 16.0 & 58 & 34.0 & 1.6 & BLOD & BLOD & 1.0 & 0.3 & 97.5 & 14.2 \\
\hline UZ-25-17 & 12.0 & 55 & 26.7 & 1.1 & BLOD & BLOD & 1.1 & 0.3 & 93.2 & 13.7 \\
\hline UZ-25-18 & 15.7 & 50 & 35.2 & 1.7 & BLOD & BLOD & 1.3 & 0.2 & 92.4 & 14.3 \\
\hline UZ-25-19 & 12.2 & 48 & 25.9 & 0.9 & BLOD & BLOD & 1.0 & 0.3 & 97.5 & 15.0 \\
\hline UZ-25-20 & 13.4 & 39 & 29.6 & 1.1 & BLOD & BLOD & 1.0 & 0.1 & 93.7 & 15.9 \\
\hline UZ-25-21 & 26.1 & 107 & 50.6 & 2.1 & BLOD & BLOD & 1.1 & 0.2 & 106.6 & 12.1 \\
\hline UZ-25-22 & 17.7 & 69 & 39.7 & 1.9 & BLOD & BLOD & 0.9 & 0.2 & 91.9 & 12.5 \\
\hline UZ-25-23 & 28.0 & 68 & 47.2 & 1.6 & 570 & 210 & 1.0 & 0.2 & 122.8 & 16.3 \\
\hline UZ-25-24 & 12.0 & 57 & 31.3 & 1.2 & BLOD & BLOD & 1.0 & 0.2 & 78.9 & 11.4 \\
\hline UZ-25-25 & 15.1 & 47 & 36.7 & 1.8 & BLOD & BLOD & 0.9 & 0.2 & 84.9 & 13.5 \\
\hline UZ-25-26 & 9.9 & 40 & 17.0 & 0.8 & BLOD & BLOD & 1.1 & 0.2 & 120.5 & 20.5 \\
\hline UZ-25-27 & 14.4 & 77 & 25.3 & 1.1 & BLOD & BLOD & 0.9 & 0.2 & 117.9 & 15.2 \\
\hline UZ-25-28 & 9.2 & 44 & 37.0 & 3.2 & BLOD & BLOD & 1.0 & 0.2 & 51.5 & 9.2 \\
\hline UZ-25-29 & 8.8 & 36 & 18.9 & 0.9 & 390 & 200 & 0.8 & 0.2 & 96.2 & 17.2 \\
\hline UZ-25-30 & 4.1 & 17 & 13.0 & 1.0 & BLOD & BLOD & 0.7 & 0.2 & 65.8 & 16.9 \\
\hline
\end{tabular}




\begin{tabular}{|c|c|c|c|c|c|c|c|c|c|c|}
\hline UZ-25-31 & 12.3 & 40 & 14.7 & 1.0 & BLOD & BLOD & 1.1 & 0.6 & 172.7 & 30.6 \\
\hline UZ-25-32 & 13.9 & 74 & 37.0 & 1.5 & BLOD & BLOD & 0.8 & 0.1 & 77.8 & 10.1 \\
\hline UZ-25-33 & 17.2 & 40 & 58.4 & 3.0 & BLOD & BLOD & 1.1 & 0.2 & 60.7 & 10.4 \\
\hline UZ-25-34 & 8.5 & 23 & 26.4 & 1.9 & BLOD & BLOD & 1.5 & 0.3 & 66.3 & 14.9 \\
\hline UZ-25-35 & 8.6 & 29 & 16.6 & 0.7 & BLOD & BLOD & 0.8 & 0.1 & 107.9 & 21.0 \\
\hline UZ-25-36 & 24.0 & 100 & 75.3 & 4.7 & 310 & 180 & 1.0 & 0.4 & 65.8 & 8.2 \\
\hline UZ-25-37 & 18.3 & 61 & 29.1 & 1.3 & BLOD & BLOD & 1.2 & 0.3 & 130.3 & 18.5 \\
\hline UZ-25-38 & 30.2 & 103 & 63.2 & 3.1 & BLOD & BLOD & 1.3 & 0.3 & 98.9 & 11.6 \\
\hline UZ-25-39 & 10.2 & 32 & 29.9 & 1.6 & 530 & 190 & 0.9 & 0.2 & 70.6 & 13.4 \\
\hline UZ-25-40 & 8.5 & 24 & 22.9 & 1.0 & 460 & 210 & 0.9 & 0.2 & 76.2 & 16.2 \\
\hline UZ-26-1 & 41.0 & 16.61 & 13.7 & 0.7 & BLOD & BLOD & 1.2 & 0.3 & 238.7 & 39.3 \\
\hline UZ-26-2 & 61.0 & 11.44 & 14.0 & 1.0 & BLOD & BLOD & 1.4 & 0.4 & 162.2 & 23.6 \\
\hline UZ-26-3 & 37.0 & 12.13 & 9.1 & 0.5 & BLOD & BLOD & 1.3 & 0.3 & 261.6 & 45.7 \\
\hline UZ-26-4 & 82.0 & 50 & 13.4 & 1.1 & BLOD & BLOD & 1.4 & 0.3 & 257.1 & 50.8 \\
\hline UZ-26-5 & 49.0 & 18.23 & 13.4 & 0.9 & BLOD & BLOD & 1.3 & 0.4 & 283.9 & 40.3 \\
\hline UZ-26-6 & 50.0 & 15.35 & 37.0 & 4.4 & BLOD & BLOD & 1.3 & 0.4 & 98.0 & 18.2 \\
\hline UZ-26-7 & 169.0 & 50.34 & 15.1 & 2.1 & BLOD & BLOD & 1.3 & 0.4 & 200.5 & 39.8 \\
\hline UZ-26-8 & 34.0 & 8.661 & 44.8 & 4.0 & BLOD & BLOD & 1.3 & 0.5 & 221.3 & 26.1 \\
\hline UZ-26-9 & 98.0 & 28.7 & 12.2 & 1.0 & BLOD & BLOD & 1.4 & 0.3 & 140.7 & 26.7 \\
\hline UZ-26-10 & 75.0 & 13.06 & 15.4 & 1.2 & 63900 & 7400 & 1.3 & 0.3 & 164.2 & 26.3 \\
\hline UZ-26-11 & 22.0 & 8.116 & 15.0 & 0.9 & 22600 & 3600 & 1.2 & 0.2 & 172.1 & 22.3 \\
\hline UZ-26-12 & 51.0 & 17.75 & 10.4 & 0.9 & 10700 & 1900 & 1.1 & 0.2 & 154.5 & 35.3 \\
\hline UZ-26-13 & 37.0 & 9.623 & 21.7 & 2.8 & 10800 & 1700 & 1.5 & 0.6 & 161.9 & 30.8 \\
\hline UZ-26-14 & 40.0 & 24.53 & 15.0 & 1.2 & 6980 & 580 & 1.1 & 0.3 & 127.3 & 23.3 \\
\hline UZ-26-15 & 45.0 & 19.04 & 17.8 & 2.0 & 6510 & 990 & 1.2 & 0.4 & 270.5 & 52.5 \\
\hline UZ-26-16 & 69.0 & 22.46 & 28.5 & 2.8 & 3840 & 610 & 1.2 & 0.4 & 132.5 & 23.7 \\
\hline UZ-26-17 & 16.0 & 8.692 & 19.6 & 2.4 & 1550 & 320 & 1.5 & 0.5 & 225.6 & 38.7 \\
\hline UZ-26-18 & 40.0 & 8.935 & 13.3 & 1.0 & 2070 & 310 & 1.1 & 0.3 & 129.8 & 33.8 \\
\hline UZ-26-19 & 12.0 & 7.158 & 17.5 & 1.4 & 1380 & 230 & 1.0 & 0.3 & 101.5 & 18.0 \\
\hline UZ-26-20 & 39.0 & 14.85 & 9.9 & 0.6 & 1200 & 250 & 1.2 & 0.4 & 142.8 & 42.1 \\
\hline UZ-26-21 & 49.0 & 26.52 & 19.3 & 1.5 & 940 & 150 & 1.3 & 0.5 & 152.4 & 27.1 \\
\hline
\end{tabular}




\begin{tabular}{|c|c|c|c|c|c|c|c|c|c|c|}
\hline UZ-26-22 & 22.0 & 9.731 & 17.5 & 1.3 & 660 & 230 & 0.5 & 0.2 & 296.6 & 47.8 \\
\hline UZ-26-23 & 29.0 & 19.1 & 12.8 & 0.7 & 820 & 170 & 1.2 & 0.2 & 150.7 & 33.1 \\
\hline UZ-26-24 & 83.0 & 33.63 & 28.0 & 2.0 & 550 & 180 & 1.5 & 0.3 & 135.3 & 26.9 \\
\hline UZ-26-25 & 28.0 & 26.11 & 42.6 & 2.6 & BLOD & BLOD & 1.1 & 0.3 & 156.3 & 19.6 \\
\hline UZ-26-26 & 59.0 & 14.08 & 16.2 & 1.1 & 960 & 130 & 1.5 & 0.4 & 171.9 & 25.2 \\
\hline UZ-26-27 & 55.0 & 29.31 & 14.3 & 0.9 & 700 & 160 & 1.2 & 0.3 & 284.2 & 49.1 \\
\hline UZ-28-1 & 138.0 & 34.15 & 72.0 & 8.0 & BLOD & BLOD & 1.1 & 0.3 & 71.6 & 10.0 \\
\hline UZ-28-2 & 83.0 & 21.68 & 34.1 & 1.5 & BLOD & BLOD & 1.2 & 0.2 & 126.1 & 14.9 \\
\hline UZ-28-3 & 32.0 & 14.67 & 61.8 & 4.8 & BLOD & BLOD & 1.3 & 0.4 & 47.4 & 9.1 \\
\hline UZ-28-4 & 12.0 & 1.999 & 8.1 & 0.5 & BLOD & BLOD & 1.2 & 0.1 & 73.5 & 21.7 \\
\hline UZ-28-5 & 38.0 & 9.19 & 15.5 & 1.4 & BLOD & BLOD & 1.1 & 0.3 & 117.7 & 21.9 \\
\hline UZ-28-6 & 34.0 & 11.52 & 17.4 & 1.3 & BLOD & BLOD & 1.2 & 0.2 & 131.3 & 24.6 \\
\hline UZ-28-7 & 14.0 & 4.844 & 19.8 & 3.0 & 10700 & 1900 & 1.2 & 0.2 & 48.8 & 15.0 \\
\hline UZ-28-8 & 37.0 & 10.44 & 28.9 & 1.8 & 10800 & 1700 & 1.2 & 0.4 & 72.0 & 12.7 \\
\hline UZ-28-9 & 54.0 & 16.61 & 28.3 & 2.1 & 6980 & 580 & 1.2 & 0.2 & 116.5 & 18.1 \\
\hline UZ-28-10 & 65.0 & 17.41 & 37.1 & 2.8 & 3840 & 610 & 1.4 & 0.3 & 93.4 & 13.6 \\
\hline UZ-28-11 & 85.0 & 17.96 & 22.3 & 2.0 & 1550 & 320 & 1.2 & 0.2 & 159.4 & 22.4 \\
\hline UZ-28-12 & 92.0 & 14.4 & 15.5 & 0.9 & 940 & 150 & 1.3 & 0.2 & 183.2 & 22.1 \\
\hline UZ-28-13 & 14.0 & 3.821 & 12.5 & 0.9 & 820 & 170 & 1.1 & 0.3 & 39.0 & 10.8 \\
\hline UZ-29a-1 & 18.2 & 61 & 17.2 & 0.7 & 630 & 210 & 3.4 & 1.1 & 218.4 & 30.8 \\
\hline UZ-29a-2 & 22.3 & 27 & 45.3 & 2.6 & 670 & 240 & 3.5 & 1.0 & 101.8 & 20.9 \\
\hline UZ-29a-3 & 23.7 & 69 & 47.7 & 3.2 & 540 & 220 & 3.2 & 1.8 & 102.8 & 14.8 \\
\hline UZ-29a-4 & 16.4 & 28 & 20.1 & 1.6 & 690 & 220 & 3.7 & 1.5 & 168.7 & 35.3 \\
\hline UZ-29a-5 & 1.6 & 4 & 3.4 & 0.2 & 540 & 190 & 0.6 & 0.1 & 99.2 & 50.1 \\
\hline UZ-29a-6 & 33.2 & 60 & 42.8 & 1.9 & 590 & 200 & 3.2 & 3.1 & 160.4 & 22.9 \\
\hline UZ-29a-7 & 21.8 & 37 & 46.8 & 2.6 & BLOD & BLOD & 3.9 & 0.5 & 96.3 & 17.2 \\
\hline UZ-29a-8 & 13.0 & 28 & 24.2 & 1.3 & BLOD & BLOD & 4.3 & 1.4 & 111.1 & 22.3 \\
\hline UZ-29a-9 & 20.8 & 50 & 41.2 & 1.9 & 490 & 260 & 3.8 & 0.9 & 104.6 & 16.1 \\
\hline UZ-29a-10 & 29.2 & 72 & 43.1 & 2.1 & 450 & 250 & 3.1 & 1.2 & 140.2 & 18.8 \\
\hline UZ-29a-11 & 9.2 & 28 & 17.1 & 0.8 & BLOD & BLOD & 1.6 & 0.2 & 111.6 & 22.2 \\
\hline UZ-29a-12 & 23.6 & 45 & 37.0 & 1.9 & 1420 & 290 & 5.2 & 1.7 & 131.8 & 21.5 \\
\hline
\end{tabular}




\begin{tabular}{|c|c|c|c|c|c|c|c|c|c|c|}
\hline UZ-29a-13 & 3.0 & 9 & 7.0 & 0.4 & BLOD & BLOD & 1.5 & 0.2 & 90.2 & 30.7 \\
\hline UZ-29a-14 & 26.0 & 80 & 48.6 & 2.5 & 1220 & 280 & 3.7 & 0.4 & 110.6 & 14.4 \\
\hline UZ-29a-15 & 19.5 & 52 & 44.8 & 2.9 & BLOD & BLOD & 4.2 & 1.8 & 90.1 & 14.3 \\
\hline UZ-29a-16 & 22.7 & 54 & 50.1 & 4.0 & 10800 & 2000 & 2.2 & 0.4 & 93.7 & 15.3 \\
\hline UZ-29a-17 & 36.2 & 125 & 67.2 & 3.9 & 1340 & 280 & 3.2 & 1.1 & 111.3 & 12.7 \\
\hline UZ-29a-18 & 30.4 & 141 & 21.2 & 1.0 & BLOD & BLOD & 3.2 & 0.5 & 296.0 & 31.1 \\
\hline UZ-29a-19 & 13.2 & 24 & 23.0 & 1.7 & 820 & 310 & 3.0 & 0.4 & 119.0 & 26.3 \\
\hline UZ-29a-20 & 21.4 & 77 & 42.4 & 2.2 & BLOD & BLOD & 2.7 & 1.4 & 104.3 & 13.7 \\
\hline UZ-29a-21 & 29.0 & 72 & 48.6 & 2.9 & BLOD & BLOD & 2.0 & 0.7 & 123.4 & 17.1 \\
\hline UZ-29a-22 & 22.3 & 44 & 42.5 & 2.3 & 1470 & 500 & 3.2 & 1.8 & 108.6 & 18.0 \\
\hline UZ-29a-23 & 22.4 & 88 & 40.6 & 2.1 & 880 & 320 & 4.4 & 1.5 & 113.8 & 14.3 \\
\hline UZ-29a-24 & 23.2 & 56 & 40.1 & 1.6 & BLOD & BLOD & 5.6 & 1.2 & 119.5 & 17.4 \\
\hline UZ-29a-25 & 24.3 & 78 & 37.7 & 1.8 & BLOD & BLOD & 3.7 & 1.9 & 133.3 & 17.3 \\
\hline UZ-29a-26 & 20.0 & 38 & 40.7 & 3.4 & BLOD & BLOD & 3.9 & 0.6 & 101.5 & 19.0 \\
\hline UZ-29a-27 & 23.7 & 93 & 38.2 & 2.0 & 660 & 310 & 4.3 & 1.3 & 128.2 & 15.8 \\
\hline UZ-29a-28 & 21.4 & 41 & 40.7 & 2.4 & BLOD & BLOD & 2.2 & 0.5 & 108.6 & 18.7 \\
\hline UZ-29a-29 & 23.9 & 95 & 36.9 & 1.6 & 950 & 320 & 3.9 & 0.8 & 133.6 & 15.9 \\
\hline UZ-29a-30 & 23.5 & 46 & 38.5 & 2.1 & BLOD & BLOD & 3.1 & 0.9 & 126.1 & 20.5 \\
\hline UZ-29a-31 & 31.2 & 71 & 34.6 & 1.7 & BLOD & BLOD & 1.1 & 0.2 & 186.3 & 25.1 \\
\hline UZ-29a-32 & 26.7 & 70 & 39.8 & 2.0 & 1270 & 430 & 1.8 & 0.6 & 138.5 & 18.9 \\
\hline UZ-29a-33 & 25.4 & 83 & 44.7 & 2.0 & BLOD & BLOD & 2.8 & 0.5 & 117.7 & 14.8 \\
\hline UZ-29a-34 & 21.6 & 41 & 36.3 & 1.7 & 1130 & 460 & 3.2 & 1.0 & 123.0 & 20.7 \\
\hline UZ-29a-35 & 20.8 & 97 & 32.2 & 1.5 & 1120 & 400 & 3.8 & 1.0 & 133.7 & 15.9 \\
\hline UZ-29a-36 & 26.1 & 81 & 44.9 & 2.6 & BLOD & BLOD & 3.6 & 0.8 & 120.3 & 15.9 \\
\hline UZ-29a-37 & 27.1 & 62 & 34.2 & 1.9 & 3630 & 900 & 3.8 & 0.7 & 163.8 & 23.7 \\
\hline UZ-29b-1 & 5.1 & 18 & 4.7 & 0.2 & 750 & 330 & 1.3 & 0.3 & 224.2 & 54.8 \\
\hline UZ-29b-2 & 28.1 & 43 & 40.2 & 2.3 & 6800 & 1800 & 1.2 & 0.2 & 144.5 & 24.3 \\
\hline UZ-29b-3 & 32.5 & 165 & 37.6 & 1.7 & 1430 & 340 & 1.8 & 0.5 & 178.8 & 17.7 \\
\hline UZ-29b-4 & 20.9 & 35 & 37.7 & 1.5 & BLOD & BLOD & 2.0 & 0.6 & 114.6 & 20.5 \\
\hline UZ-29b-5 & 32.5 & 52 & 39.9 & 1.8 & 690 & 310 & 2.1 & 0.2 & 168.4 & 25.5 \\
\hline UZ-29b-6 & 27.9 & 99 & 60.9 & 3.2 & BLOD & BLOD & 1.8 & 0.4 & 94.8 & 11.4 \\
\hline
\end{tabular}




\begin{tabular}{|c|c|c|c|c|c|c|c|c|c|c|}
\hline UZ-29b-7 & 26.7 & 62 & 40.8 & 2.3 & BLOD & BLOD & 1.9 & 0.4 & 135.4 & 19.6 \\
\hline UZ-29b-8 & 32.4 & 106 & 39.6 & 2.1 & BLOD & BLOD & 1.6 & 0.3 & 169.2 & 20.0 \\
\hline UZ-29b-9 & 27.0 & 72 & 38.0 & 2.1 & 1470 & 340 & 2.1 & 0.7 & 147.1 & 20.1 \\
\hline UZ-29b-10 & 28.0 & 46 & 38.4 & 2.0 & 1210 & 330 & 2.3 & 0.2 & 150.8 & 24.4 \\
\hline UZ-29b-11 & 23.3 & 63 & 38.1 & 1.5 & BLOD & BLOD & 1.7 & 0.4 & 126.7 & 17.5 \\
\hline UZ-29b-12 & 22.3 & 59 & 36.7 & 1.5 & BLOD & BLOD & 1.9 & 0.5 & 125.6 & 17.9 \\
\hline UZ-29b-13 & 32.8 & 99 & 50.0 & 2.4 & 810 & 340 & 1.5 & 0.4 & 135.8 & 16.1 \\
\hline UZ-29b-14 & 27.0 & 60 & 38.3 & 1.9 & 1240 & 280 & 1.2 & 0.3 & 145.5 & 21.0 \\
\hline UZ-29b-15 & 38.6 & 91 & 40.7 & 1.7 & 930 & 270 & 1.4 & 0.2 & 196.1 & 23.6 \\
\hline UZ-29b-16 & 23.2 & 38 & 35.3 & 1.5 & BLOD & BLOD & 1.4 & 0.4 & 135.7 & 23.4 \\
\hline UZ-29b-17 & 40.1 & 133 & 33.0 & 1.8 & 940 & 310 & 1.3 & 0.3 & 251.0 & 27.7 \\
\hline UZ-29b-18 & 18.9 & 39 & 30.2 & 1.5 & BLOD & BLOD & 1.5 & 0.4 & 129.6 & 22.4 \\
\hline UZ-29b-19 & 26.8 & 78 & 41.0 & 2.6 & 1270 & 320 & 1.5 & 0.2 & 135.1 & 18.4 \\
\hline UZ-29b-20 & 26.8 & 78 & 38.2 & 2.1 & BLOD & BLOD & 1.6 & 0.4 & 145.3 & 19.2 \\
\hline UZ-29b-21 & 34.3 & 110 & 38.6 & 2.5 & BLOD & BLOD & 1.4 & 0.5 & 183.6 & 22.5 \\
\hline UZ-29b-22 & 39.8 & 99 & 48.2 & 2.2 & 1100 & 410 & 2.1 & 0.8 & 170.6 & 20.1 \\
\hline UZ-29b-23 & 36.1 & 123 & 50.1 & 3.3 & BLOD & BLOD & 1.6 & 0.4 & 149.0 & 17.7 \\
\hline UZ-29b-24 & 25.0 & 64 & 29.6 & 1.4 & BLOD & BLOD & 2.2 & 0.2 & 174.8 & 24.5 \\
\hline UZ-29b-25 & 28.9 & 57 & 40.5 & 2.3 & 4320 & 920 & 1.6 & 0.3 & 147.6 & 22.1 \\
\hline UZ-29b-26 & 30.6 & 45 & 37.7 & 1.7 & BLOD & BLOD & 2.4 & 0.6 & 167.8 & 27.0 \\
\hline UZ-29b-27 & 32.9 & 92 & 46.4 & 3.0 & 990 & 330 & 2.7 & 0.5 & 146.8 & 19.0 \\
\hline UZ-29b-28 & 27.6 & 70 & 43.7 & 2.7 & 1120 & 270 & 2.7 & 0.3 & 130.6 & 18.4 \\
\hline UZ-29b-29 & 30.2 & 89 & 43.3 & 1.9 & BLOD & BLOD & 2.3 & 0.4 & 144.0 & 17.6 \\
\hline UZ-29b-30 & 34.5 & 86 & 39.7 & 2.6 & 1070 & 350 & 2.2 & 0.4 & 179.7 & 23.9 \\
\hline UZ-29b-31 & 24.5 & 88 & 22.6 & 1.3 & BLOD & BLOD & 2.2 & 0.5 & 224.1 & 28.7 \\
\hline UZ-29b-32 & 29.3 & 68 & 48.6 & 2.2 & BLOD & BLOD & 1.8 & 0.4 & 124.4 & 16.9 \\
\hline UZ-29b-33 & 28.5 & 87 & 34.4 & 1.5 & 1680 & 330 & 2.1 & 0.4 & 171.5 & 21.1 \\
\hline UZ-29b-34 & 28.2 & 82 & 38.3 & 1.8 & BLOD & BLOD & 1.9 & 0.4 & 152.0 & 19.3 \\
\hline UZ-29b-35 & 28.6 & 87 & 44.1 & 2.1 & 1200 & 280 & 2.2 & 0.5 & 134.2 & 16.7 \\
\hline UZ-29b-36 & 32.9 & 138 & 38.8 & 1.7 & 1760 & 320 & 2.1 & 0.7 & 175.5 & 18.3 \\
\hline UZ-29b-37 & 23.1 & 78 & 38.9 & 2.4 & BLOD & BLOD & 1.3 & 0.3 & 122.9 & 16.6 \\
\hline
\end{tabular}




\begin{tabular}{|c|c|c|c|c|c|c|c|c|c|c|}
\hline UZ-29b-38 & 28.7 & 63 & 39.4 & 1.9 & BLOD & BLOD & 1.3 & 0.4 & 150.7 & 21.3 \\
\hline UZ-29b-39 & 19.3 & 41 & 40.4 & 2.2 & BLOD & BLOD & 1.6 & 0.6 & 98.9 & 16.9 \\
\hline UZ-30-1 & 24.3 & 68 & 36.8 & 1.7 & BLOD & BLOD & 2.0 & 0.4 & 136.7 & 18.6 \\
\hline UZ-30-2 & 18.5 & 40 & 36.3 & 3.0 & 1020 & 520 & 1.7 & 0.4 & 105.3 & 19.3 \\
\hline UZ-30-3 & 28.2 & 53 & 41.2 & 2.4 & BLOD & BLOD & 1.8 & 0.3 & 141.6 & 21.9 \\
\hline UZ-30-4 & 25.2 & 78 & 35.9 & 1.8 & 540 & 230 & 1.9 & 0.5 & 144.9 & 18.9 \\
\hline UZ-30-5 & 19.4 & 21 & 37.9 & 2.0 & BLOD & BLOD & 1.2 & 0.4 & 105.6 & 24.1 \\
\hline UZ-30-6 & 24.7 & 56 & 50.9 & 2.8 & BLOD & BLOD & 1.5 & 0.5 & 100.3 & 15.1 \\
\hline UZ-30-7 & 32.7 & 60 & 46.0 & 2.2 & BLOD & BLOD & 1.5 & 0.2 & 146.8 & 21.1 \\
\hline UZ-30-8 & 24.4 & 76 & 36.7 & 1.6 & BLOD & BLOD & 1.5 & 0.3 & 137.2 & 17.8 \\
\hline UZ-30-9 & 7.4 & 22 & 10.0 & 0.5 & BLOD & BLOD & 1.2 & 0.2 & 153.1 & 34.2 \\
\hline UZ-30-10 & 28.3 & 60 & 38.1 & 1.7 & BLOD & BLOD & 1.6 & 0.3 & 153.5 & 21.9 \\
\hline UZ-30-11 & 24.0 & 70 & 37.3 & 2.4 & BLOD & BLOD & 1.5 & 0.3 & 133.0 & 18.9 \\
\hline UZ-30-12 & 28.5 & 62 & 39.8 & 2.1 & 650 & 270 & 1.5 & 0.2 & 148.2 & 21.3 \\
\hline UZ-30-13 & 30.2 & 110 & 38.1 & 1.7 & BLOD & BLOD & 1.5 & 0.3 & 164.1 & 18.6 \\
\hline UZ-30-14 & 20.7 & 40 & 33.8 & 1.8 & 600 & 260 & 1.7 & 0.3 & 126.6 & 21.8 \\
\hline UZ-30-15 & 32.2 & 78 & 46.4 & 2.0 & BLOD & BLOD & 1.4 & 0.4 & 143.3 & 18.4 \\
\hline UZ-30-16 & 21.9 & 45 & 20.9 & 1.1 & BLOD & BLOD & 1.4 & 0.2 & 216.6 & 35.4 \\
\hline UZ-30-17 & 29.8 & 94 & 40.6 & 1.7 & BLOD & BLOD & 1.8 & 0.3 & 151.8 & 18.0 \\
\hline UZ-30-18 & 28.1 & 70 & 24.1 & 1.1 & BLOD & BLOD & 2.0 & 0.4 & 240.6 & 32.4 \\
\hline UZ-30-19 & 4.1 & 8 & 7.6 & 0.5 & BLOD & BLOD & 1.5 & 0.5 & 110.8 & 40.2 \\
\hline UZ-30-20 & 20.2 & 48 & 33.2 & 1.8 & 660 & 300 & 1.5 & 0.5 & 126.0 & 20.1 \\
\hline UZ-30-21 & 32.0 & 87 & 34.5 & 2.0 & 18500 & 4200 & 1.7 & 0.4 & 191.8 & 24.7 \\
\hline UZ-30-22 & 32.0 & 99 & 33.5 & 1.6 & BLOD & BLOD & 1.6 & 0.3 & 197.2 & 23.4 \\
\hline UZ-30-23 & 27.3 & 70 & 55.9 & 3.4 & BLOD & BLOD & 1.6 & 0.3 & 100.8 & 14.1 \\
\hline UZ-30-24 & 23.2 & 71 & 37.1 & 1.9 & BLOD & BLOD & 2.1 & 0.6 & 129.5 & 17.6 \\
\hline UZ-30-25 & 28.6 & 62 & 41.3 & 3.6 & 3400 & 1100 & 1.9 & 0.4 & 143.1 & 22.8 \\
\hline UZ-30-26 & 2.6 & 18 & 3.9 & 0.2 & 1460 & 410 & 1.4 & 0.6 & 141.1 & 34.7 \\
\hline UZ-30-27 & 26.0 & 98 & 40.1 & 2.7 & 1340 & 650 & 1.5 & 0.4 & 134.0 & 17.2 \\
\hline UZ-30-28 & 25.4 & 116 & 37.1 & 1.6 & BLOD & BLOD & 1.4 & 0.5 & 141.4 & 15.6 \\
\hline UZ-30-29 & 14.9 & 39 & 35.5 & 1.7 & BLOD & BLOD & 1.2 & 0.2 & 87.0 & 15.0 \\
\hline
\end{tabular}




\begin{tabular}{|c|c|c|c|c|c|c|c|c|c|c|}
\hline UZ-30-30 & 20.5 & 92 & 34.5 & 1.4 & 1040 & 390 & 1.6 & 0.5 & 122.7 & 14.6 \\
\hline UZ-30-31 & 32.7 & 110 & 59.8 & 2.6 & BLOD & BLOD & 1.5 & 0.3 & 113.0 & 12.7 \\
\hline UZ-30-32 & 23.3 & 67 & 40.4 & 2.0 & BLOD & BLOD & 1.5 & 0.6 & 119.0 & 16.4 \\
\hline UZ-30-33 & 29.1 & 81 & 44.3 & 1.7 & 1080 & 490 & 2.0 & 0.4 & 135.7 & 16.9 \\
\hline UZ-30-34 & 28.3 & 57 & 54.1 & 3.1 & 870 & 460 & 2.5 & 0.4 & 108.2 & 16.2 \\
\hline UZ-30-35 & 28.9 & 50 & 37.2 & 2.6 & BLOD & BLOD & 1.9 & 0.3 & 160.6 & 26.2 \\
\hline UZ-30-36 & 31.4 & 73 & 44.2 & 3.1 & 4400 & 1400 & 1.7 & 0.5 & 146.9 & 20.9 \\
\hline UZ-30-37 & 25.3 & 56 & 34.7 & 1.5 & 1070 & 560 & 1.5 & 0.3 & 150.9 & 22.1 \\
\hline UZ-30-38 & 30.4 & 46 & 40.2 & 1.7 & BLOD & BLOD & 1.6 & 0.3 & 156.1 & 24.8 \\
\hline UZ-30-39 & 19.9 & 37 & 36.3 & 2.0 & BLOD & BLOD & 1.5 & 0.3 & 113.1 & 20.2 \\
\hline UZ-30-40 & 28.9 & 85 & 37.7 & 1.9 & BLOD & BLOD & 1.3 & 0.3 & 158.3 & 20.0 \\
\hline UZ-31-1 & 12.0 & 31 & 9.3 & 0.6 & BLOD & BLOD & 1.3 & 0.2 & 267.7 & 51.9 \\
\hline UZ-31-2 & 23.3 & 25 & 41.5 & 1.8 & 1050 & 320 & 1.5 & 0.4 & 116.2 & 24.3 \\
\hline UZ-31-3 & 12.8 & 18 & 21.5 & 1.0 & 710 & 300 & 1.4 & 0.2 & 123.4 & 30.1 \\
\hline UZ-31-4 & 16.3 & 56 & 21.1 & 1.0 & 640 & 300 & 1.3 & 0.2 & 160.0 & 23.6 \\
\hline UZ-31-5 & 11.7 & 28 & 7.5 & 0.5 & BLOD & BLOD & 1.1 & 0.2 & 323.3 & 65.5 \\
\hline UZ-31-6 & 2.8 & 6 & 4.4 & 0.2 & BLOD & BLOD & 1.1 & 0.2 & 129.6 & 53.6 \\
\hline UZ-31-7 & 17.3 & 29 & 29.0 & 1.7 & 600 & 340 & 1.3 & 0.2 & 123.5 & 24.6 \\
\hline UZ-31-8 & 15.4 & 27 & 21.1 & 1.0 & 590 & 310 & 1.6 & 0.4 & 151.3 & 30.6 \\
\hline UZ-31-9 & 12.3 & 36 & 15.6 & 1.1 & 4100 & 1700 & 1.3 & 0.3 & 163.3 & 30.3 \\
\hline UZ-31-10 & 2.5 & 3 & 4.4 & 0.2 & 730 & 320 & 1.3 & 0.2 & 118.8 & 69.0 \\
\hline UZ-31-11 & 6.0 & 17 & 8.0 & 0.4 & 500 & 260 & 1.5 & 0.2 & 156.3 & 39.3 \\
\hline UZ-31-12 & 19.9 & 53 & 32.3 & 6.0 & 1140 & 540 & 1.3 & 0.3 & 127.4 & 29.9 \\
\hline UZ-31-13 & 22.0 & 43 & 37.7 & 2.3 & 1190 & 430 & 1.6 & 0.3 & 120.4 & 20.4 \\
\hline UZ-31-14 & 9.5 & 11 & 18.3 & 1.0 & 630 & 240 & 1.4 & 0.3 & 107.4 & 33.2 \\
\hline UZ-31-15 & 21.1 & 47 & 30.0 & 1.1 & BLOD & BLOD & 1.2 & 0.3 & 145.1 & 22.6 \\
\hline UZ-31-16 & 14.0 & 42 & 14.0 & 0.6 & 900 & 240 & 1.1 & 0.3 & 206.3 & 34.0 \\
\hline UZ-31-17 & 11.7 & 32 & 8.8 & 0.6 & BLOD & BLOD & 1.0 & 0.2 & 275.4 & 53.0 \\
\hline UZ-31-18 & 21.1 & 96 & 17.9 & 0.9 & 2660 & 350 & 1.8 & 0.2 & 244.2 & 29.7 \\
\hline UZ-31-19 & 4.0 & 14 & 4.4 & 0.3 & 630 & 310 & 1.0 & 0.2 & 189.4 & 52.7 \\
\hline UZ-31-20 & 23.2 & 60 & 22.2 & 1.3 & 600 & 280 & 1.4 & 0.2 & 216.2 & 31.9 \\
\hline
\end{tabular}




\begin{tabular}{|c|c|c|c|c|c|c|c|c|c|c|}
\hline UZ-31-21 & 17.8 & 35 & 24.2 & 1.4 & BLOD & BLOD & 1.0 & 0.3 & 152.4 & 28.0 \\
\hline UZ-31-22 & 6.8 & 8 & 12.7 & 0.9 & 770 & 230 & 1.2 & 0.2 & 111.8 & 40.5 \\
\hline UZ-31-23 & 21.4 & 71 & 20.7 & 1.3 & BLOD & BLOD & 1.2 & 0.3 & 213.3 & 30.0 \\
\hline UZ-31-24 & 31.1 & 102 & 68.8 & 2.8 & BLOD & BLOD & 1.4 & 0.3 & 93.4 & 10.7 \\
\hline UZ-31-25 & 10.6 & 50 & 17.2 & 0.7 & BLOD & BLOD & 1.0 & 0.2 & 126.9 & 19.5 \\
\hline UZ-31-26 & 12.4 & 44 & 12.9 & 0.7 & 590 & 230 & 1.2 & 0.3 & 198.4 & 32.7 \\
\hline UZ-31-27 & 30.2 & 80 & 31.0 & 2.5 & 1650 & 980 & 1.0 & 0.3 & 201.1 & 28.9 \\
\hline UZ-31-28 & 3.4 & 6 & 4.8 & 0.3 & 450 & 220 & 1.6 & 0.2 & 148.6 & 61.8 \\
\hline UZ-31-29 & 9.6 & 20 & 9.3 & 0.5 & 740 & 270 & 1.0 & 0.2 & 211.7 & 49.6 \\
\hline UZ-31-30 & 6.3 & 28 & 8.2 & 0.5 & BLOD & BLOD & 1.2 & 0.3 & 159.1 & 32.1 \\
\hline UZ-31-31 & 7.1 & 11 & 13.1 & 0.9 & BLOD & BLOD & 1.0 & 0.3 & 111.4 & 34.8 \\
\hline UZ-31-32 & 1.8 & 9 & 4.1 & 0.3 & BLOD & BLOD & 1.5 & 0.2 & 91.4 & 31.2 \\
\hline UZ-31-33 & 9.6 & 36 & 11.0 & 0.6 & BLOD & BLOD & 0.9 & 0.2 & 179.9 & 32.4 \\
\hline UZ-31-34 & 12.4 & 44 & 10.8 & 0.7 & BLOD & BLOD & 1.2 & 0.2 & 235.5 & 39.8 \\
\hline UZ-31-35 & 11.8 & 15 & 20.8 & 1.4 & BLOD & BLOD & 1.1 & 0.2 & 116.8 & 31.5 \\
\hline UZ-31-36 & 17.5 & 42 & 22.2 & 2.1 & BLOD & BLOD & 1.3 & 0.3 & 162.7 & 30.2 \\
\hline UZ-31-37 & 12.3 & 28 & 18.0 & 0.8 & BLOD & BLOD & 1.2 & 0.2 & 140.8 & 28.0 \\
\hline UZ-31-38 & 8.7 & 10 & 5.8 & 0.4 & 300 & 140 & 1.7 & 0.2 & 306.3 & 99.5 \\
\hline UZ-31-39 & 11.9 & 45 & 22.4 & 1.2 & 460 & 220 & 1.4 & 0.2 & 109.7 & 18.0 \\
\hline UZ-32-1 & 6.8 & 17 & 5.9 & 0.3 & BLOD & BLOD & 1.1 & 0.5 & 237.9 & 59.9 \\
\hline UZ-32-2 & 7.5 & 12 & 9.2 & 0.7 & 1110 & 280 & 2.1 & 0.2 & 170.1 & 51.3 \\
\hline UZ-32-3 & 8.5 & 10 & 11.0 & 0.7 & BLOD & BLOD & 1.9 & 0.8 & 159.5 & 52.0 \\
\hline UZ-32-4 & 14.9 & 12 & 17.8 & 1.0 & BLOD & BLOD & 1.4 & 0.8 & 172.7 & 51.3 \\
\hline UZ-32-5 & 12.0 & 16 & 12.0 & 0.6 & BLOD & BLOD & 2.3 & 0.4 & 207.8 & 53.7 \\
\hline UZ-32-6 & 7.6 & 22 & 9.0 & 0.4 & BLOD & BLOD & 1.1 & 0.3 & 174.5 & 38.7 \\
\hline UZ-32-7 & 10.2 & 10 & 12.9 & 1.0 & BLOD & BLOD & 1.8 & 0.2 & 163.4 & 53.6 \\
\hline UZ-32-8 & 9.4 & 19 & 9.6 & 0.5 & BLOD & BLOD & 1.7 & 0.3 & 201.2 & 48.2 \\
\hline UZ-32-9 & 7.5 & 20 & 12.3 & 0.7 & BLOD & BLOD & 2.4 & 0.1 & 125.6 & 29.4 \\
\hline UZ-32-10 & 6.4 & 13 & 11.5 & 0.7 & BLOD & BLOD & 2.1 & 0.1 & 115.4 & 33.0 \\
\hline UZ-32-11 & 3.9 & 5 & 9.2 & 0.4 & BLOD & BLOD & 2.2 & 0.3 & 88.2 & 39.8 \\
\hline UZ-32-12 & 18.8 & 35 & 15.1 & 0.9 & BLOD & BLOD & 1.5 & 0.4 & 258.3 & 47.5 \\
\hline
\end{tabular}




\begin{tabular}{|c|c|c|c|c|c|c|c|c|c|c|}
\hline UZ-32-13 & 11.2 & 20 & 14.4 & 0.6 & BLOD & BLOD & 2.0 & 0.6 & 161.6 & 37.4 \\
\hline UZ-32-14 & 18.6 & 15 & 16.5 & 0.9 & 680 & 240 & 1.8 & 0.1 & 232.7 & 62.1 \\
\hline UZ-32-15 & 14.9 & 51 & 16.5 & 0.8 & BLOD & BLOD & 1.7 & 0.3 & 187.4 & 28.8 \\
\hline UZ-32-16 & 8.8 & 35 & 6.8 & 0.4 & 2480 & 350 & 1.6 & 0.3 & 269.1 & 50.0 \\
\hline UZ-32-17 & 20.3 & 38 & 25.2 & 1.3 & BLOD & BLOD & 2.0 & 0.3 & 166.1 & 29.1 \\
\hline UZ-32-18 & 14.8 & 30 & 13.9 & 0.6 & 2250 & 340 & 2.7 & 0.3 & 219.7 & 42.1 \\
\hline UZ-32-19 & 29.2 & 42 & 19.5 & 1.0 & BLOD & BLOD & 1.9 & 0.3 & 310.0 & 52.0 \\
\hline UZ-32-20 & 11.5 & 13 & 15.9 & 0.9 & BLOD & BLOD & 1.6 & 0.4 & 148.7 & 42.5 \\
\hline UZ-32-21 & 7.7 & 11 & 10.0 & 0.6 & 21200 & 4900 & 1.4 & 0.6 & 160.9 & 49.9 \\
\hline UZ-32-22 & 13.1 & 16 & 23.6 & 2.9 & BLOD & BLOD & 1.6 & 0.5 & 115.1 & 32.4 \\
\hline UZ-32-23 & 9.0 & 19 & 22.0 & 1.3 & BLOD & BLOD & 1.9 & 0.5 & 84.4 & 20.3 \\
\hline UZ-32-24 & 17.0 & 48 & 28.1 & 1.4 & BLOD & BLOD & 1.5 & 0.4 & 124.7 & 19.7 \\
\hline UZ-32-25 & 7.6 & 11 & 8.0 & 0.5 & BLOD & BLOD & 1.6 & 0.9 & 198.1 & 61.4 \\
\hline UZ-32-26 & 9.1 & 12 & 14.7 & 1.0 & BLOD & BLOD & 1.3 & 0.0 & 127.4 & 38.2 \\
\hline UZ-32-27 & 6.5 & 11 & 10.5 & 0.5 & BLOD & BLOD & 1.6 & 0.3 & 128.8 & 39.6 \\
\hline UZ-32-28 & 9.5 & 13 & 9.3 & 0.5 & BLOD & BLOD & 2.0 & 0.2 & 212.7 & 60.9 \\
\hline UZ-32-29 & 8.5 & 18 & 6.8 & 0.3 & BLOD & BLOD & 2.2 & 0.1 & 255.9 & 62.5 \\
\hline UZ-32-30 & 9.8 & 10 & 7.5 & 0.4 & BLOD & BLOD & 1.0 & 0.2 & 268.9 & 87.0 \\
\hline UZ-32-31 & 10.7 & 11 & 14.0 & 0.7 & BLOD & BLOD & 1.4 & 0.3 & 158.2 & 48.9 \\
\hline UZ-35-1 & 17.1 & 42 & 12.9 & 0.8 & BLOD & BLOD & 1.1 & 0.3 & 300.0 & 51.9 \\
\hline UZ-35-2 & 12.2 & 18 & 9.9 & 0.9 & BLOD & BLOD & 1.4 & 0.3 & 278.6 & 71.8 \\
\hline UZ-35-3 & 16.2 & 35 & 16.4 & 0.6 & BLOD & BLOD & 1.4 & 0.5 & 223.3 & 40.2 \\
\hline UZ-35-4 & 6.0 & 16 & 7.0 & 0.4 & 660 & 280 & 1.5 & 0.6 & 193.2 & 50.7 \\
\hline UZ-35-5 & 8.8 & 9 & 9.3 & 0.6 & BLOD & BLOD & 1.3 & 0.2 & 214.7 & 73.7 \\
\hline UZ-35-6 & 6.7 & 16 & 10.2 & 0.5 & 500 & 310 & 1.2 & 0.3 & 150.5 & 39.2 \\
\hline UZ-35-7 & 5.8 & 16 & 6.1 & 0.3 & 610 & 220 & 1.1 & 0.1 & 216.3 & 56.4 \\
\hline UZ-35-8 & 11.5 & 32 & 10.4 & 0.5 & 780 & 270 & 1.1 & 0.2 & 251.3 & 47.8 \\
\hline UZ-35-9 & 5.1 & 5 & 3.7 & 0.3 & 1100 & 320 & 1.2 & 0.0 & 315.4 & 143.5 \\
\hline UZ-35-10 & 3.6 & 7 & 8.6 & 0.5 & 700 & 350 & 0.9 & 0.3 & 94.1 & 36.3 \\
\hline UZ-35-11 & 9.2 & 20 & 9.3 & 0.6 & BLOD & BLOD & 1.1 & 0.2 & 223.1 & 53.1 \\
\hline UZ-35-12 & 13.6 & 24 & 24.3 & 1.1 & BLOD & BLOD & 1.0 & 0.2 & 126.5 & 27.2 \\
\hline
\end{tabular}




\begin{tabular}{|c|c|c|c|c|c|c|c|c|c|c|}
\hline UZ-35-13 & 10.7 & 20 & 10.2 & 0.5 & 790 & 320 & 0.6 & 0.1 & 239.1 & 56.0 \\
\hline UZ-35-14 & 5.7 & 17 & 9.6 & 0.5 & BLOD & BLOD & 0.8 & 0.2 & 136.1 & 34.4 \\
\hline UZ-35-15 & 6.5 & 14 & 11.4 & 0.6 & BLOD & BLOD & 0.9 & 0.2 & 128.5 & 35.6 \\
\hline UZ-35-16 & 5.0 & 12 & 7.1 & 0.5 & BLOD & BLOD & 1.2 & 0.7 & 160.7 & 48.2 \\
\hline UZ-35-17 & 8.2 & 27 & 8.4 & 0.5 & BLOD & BLOD & 1.2 & 0.5 & 223.4 & 46.2 \\
\hline UZ-35-18 & 13.1 & 42 & 21.9 & 0.9 & BLOD & BLOD & 1.0 & 0.2 & 135.0 & 22.5 \\
\hline UZ-35-19 & 2.7 & 9 & 6.3 & 0.5 & BLOD & BLOD & 0.9 & 0.3 & 97.0 & 33.6 \\
\hline UZ-35-20 & 10.5 & 43 & 27.0 & 1.5 & 890 & 450 & 1.0 & 0.2 & 88.3 & 15.0 \\
\hline UZ-35-21 & 9.4 & 29 & 14.3 & 0.7 & BLOD & BLOD & 1.2 & 0.2 & 149.9 & 29.8 \\
\hline UZ-35-22 & 7.6 & 33 & 8.9 & 0.5 & BLOD & BLOD & 1.0 & 0.2 & 191.7 & 36.4 \\
\hline UZ-35-23 & 7.4 & 16 & 7.1 & 0.4 & 1760 & 600 & 1.0 & 0.2 & 235.7 & 61.2 \\
\hline UZ-35-24 & 5.1 & 8 & 6.6 & 0.4 & BLOD & BLOD & 1.3 & 0.2 & 176.9 & 64.1 \\
\hline UZ-35-25 & 18.0 & 49 & 22.5 & 1.1 & BLOD & BLOD & 1.3 & 0.3 & 181.5 & 28.8 \\
\hline UZ-35-26 & 9.2 & 26 & 8.9 & 0.4 & BLOD & BLOD & 1.3 & 0.3 & 235.5 & 49.0 \\
\hline UZ-35-27 & 8.4 & 38 & 15.5 & 1.0 & BLOD & BLOD & 1.2 & 0.1 & 123.2 & 22.3 \\
\hline UZ-35-28 & 5.8 & 17 & 10.6 & 0.4 & BLOD & BLOD & 1.1 & 0.3 & 123.4 & 30.9 \\
\hline UZ-35-29 & 14.2 & 38 & 9.3 & 0.5 & 8130 & 860 & 1.0 & 0.3 & 343.8 & 60.7 \\
\hline UZ-35-30 & 15.8 & 24 & 15.2 & 1.3 & BLOD & BLOD & 1.0 & 0.3 & 235.6 & 53.4 \\
\hline UZ-35-31 & 12.9 & 39 & 8.6 & 0.4 & BLOD & BLOD & 1.1 & 0.2 & 337.3 & 59.0 \\
\hline UZ-35-32 & 8.5 & 23 & 18.1 & 0.9 & BLOD & BLOD & 1.8 & 0.4 & 107.2 & 23.5 \\
\hline UZ-35-33 & 16.2 & 46 & 16.8 & 1.1 & BLOD & BLOD & 1.2 & 0.2 & 218.3 & 36.8 \\
\hline UZ-35-34 & 11.5 & 31 & 25.7 & 1.5 & BLOD & BLOD & 1.3 & 0.1 & 101.3 & 19.8 \\
\hline UZ-35-35 & 8.0 & 22 & 13.0 & 0.6 & BLOD & BLOD & 1.3 & 0.2 & 138.5 & 31.0 \\
\hline UZ-35-36 & 5.3 & 13 & 11.8 & 0.6 & BLOD & BLOD & 1.3 & 0.3 & 100.7 & 28.8 \\
\hline UZ-36-1 & 6.2 & 22 & 5.9 & 0.3 & BLOD & BLOD & 1.2 & 0.2 & 230.9 & 51.3 \\
\hline UZ-36-2 & 4.5 & 18 & 5.1 & 0.3 & BLOD & BLOD & 1.1 & 0.2 & 198.0 & 48.3 \\
\hline UZ-36-3 & 3.6 & 17 & 4.7 & 0.3 & 660 & 320 & 1.2 & 0.3 & 168.0 & 43.0 \\
\hline UZ-36-4 & 5.4 & 18 & 11.4 & 0.8 & 98000 & 15000 & 1.5 & 0.1 & 104.2 & 25.8 \\
\hline UZ-36-5 & 4.7 & 23 & 6.9 & 0.4 & 810 & 310 & 1.0 & 0.2 & 151.2 & 33.2 \\
\hline UZ-36-6 & 3.3 & 14 & 4.5 & 0.2 & 850 & 410 & 1.2 & 0.2 & 159.4 & 43.6 \\
\hline UZ-36-7 & 5.0 & 23 & 5.2 & 0.3 & BLOD & BLOD & 1.0 & 0.2 & 213.8 & 46.5 \\
\hline
\end{tabular}




\begin{tabular}{|c|c|c|c|c|c|c|c|c|c|c|}
\hline UZ-36-8 & 4.4 & 15 & 6.6 & 0.4 & BLOD & BLOD & 0.7 & 0.2 & 146.3 & 39.0 \\
\hline UZ-36-9 & 4.4 & 16 & 12.5 & 1.0 & BLOD & BLOD & 1.2 & 0.2 & 78.4 & 20.8 \\
\hline UZ-36-10 & 6.3 & 19 & 15.6 & 0.8 & BLOD & BLOD & 1.2 & 0.2 & 89.1 & 21.2 \\
\hline UZ-36-11 & 14.7 & 51 & 15.6 & 0.8 & BLOD & BLOD & 1.5 & 0.6 & 208.1 & 32.0 \\
\hline UZ-36-12 & 7.7 & 35 & 7.6 & 0.3 & BLOD & BLOD & 1.4 & 0.2 & 223.9 & 39.7 \\
\hline UZ-36-13 & 4.3 & 19 & 8.5 & 0.3 & BLOD & BLOD & 1.2 & 0.3 & 113.0 & 26.7 \\
\hline UZ-36-14 & 7.5 & 21 & 4.4 & 0.2 & BLOD & BLOD & 1.3 & 0.4 & 375.2 & 85.6 \\
\hline UZ-36-15 & 7.7 & 28 & 15.5 & 1.2 & BLOD & BLOD & 1.3 & 0.2 & 109.2 & 22.7 \\
\hline UZ-36-16 & 7.0 & 26 & 5.7 & 0.4 & 670 & 280 & 1.2 & 0.2 & 272.5 & 58.0 \\
\hline UZ-36-17 & 12.6 & 44 & 28.4 & 1.5 & BLOD & BLOD & 1.5 & 0.2 & 97.8 & 16.1 \\
\hline UZ-36-18 & 4.3 & 18 & 6.0 & 0.3 & BLOD & BLOD & 1.4 & 0.3 & 157.6 & 38.2 \\
\hline UZ-36-19 & 12.2 & 39 & 10.4 & 0.6 & BLOD & BLOD & 1.4 & 0.3 & 257.8 & 44.8 \\
\hline UZ-36-20 & 19.0 & 80 & 34.7 & 1.5 & BLOD & BLOD & 1.3 & 0.1 & 120.9 & 15.2 \\
\hline UZ-36-21 & 11.9 & 45 & 26.5 & 1.2 & BLOD & BLOD & 1.2 & 0.3 & 99.5 & 16.0 \\
\hline UZ-36-22 & 10.2 & 32 & 22.7 & 1.2 & BLOD & BLOD & 1.5 & 0.7 & 99.2 & 18.7 \\
\hline UZ-36-23 & 15.1 & 44 & 32.8 & 1.5 & 590 & 240 & 1.3 & 0.4 & 101.9 & 16.5 \\
\hline UZ-36-24 & 5.4 & 23 & 5.0 & 0.2 & 3470 & 800 & 1.2 & 0.2 & 242.6 & 52.8 \\
\hline UZ-36-25 & 4.2 & 26 & 6.7 & 0.4 & 1690 & 610 & 1.2 & 0.3 & 138.3 & 28.7 \\
\hline UZ-36-26 & 5.0 & 18 & 5.0 & 0.3 & 590 & 170 & 1.2 & 0.4 & 220.8 & 54.1 \\
\hline UZ-36-27 & 3.8 & 19 & 6.1 & 0.3 & 420 & 190 & 1.1 & 0.3 & 136.9 & 32.3 \\
\hline UZ-36-28 & 3.2 & 11 & 7.9 & 0.6 & 8300 & 1700 & 1.5 & 0.3 & 88.4 & 27.6 \\
\hline UZ-36-29 & 8.0 & 30 & 9.3 & 0.7 & BLOD & BLOD & 1.1 & 0.3 & 190.7 & 38.0 \\
\hline UZ-36-30 & 5.8 & 25 & 6.1 & 0.4 & 400 & 190 & 1.2 & 0.3 & 209.1 & 44.2 \\
\hline UZ-36-31 & 6.4 & 25 & 7.3 & 0.4 & BLOD & BLOD & 1.1 & 0.2 & 191.7 & 40.2 \\
\hline UZ-36-32 & 4.0 & 19 & 5.7 & 0.3 & 390 & 180 & 1.2 & 0.3 & 155.4 & 36.9 \\
\hline UZ-36-33 & 11.2 & 62 & 7.2 & 0.4 & BLOD & BLOD & 1.2 & 0.2 & 341.9 & 48.6 \\
\hline UZ-36-34 & 1.2 & 7 & 3.2 & 0.2 & 410 & 170 & 1.5 & 0.3 & 80.4 & 30.9 \\
\hline UZ-36-35 & 5.5 & 25 & 6.1 & 0.4 & 350 & 210 & 1.3 & 0.2 & 198.7 & 42.0 \\
\hline UZ-36-36 & 3.1 & 12 & 5.0 & 0.3 & 370 & 170 & 1.2 & 0.2 & 139.0 & 41.3 \\
\hline UZ-36-37 & 5.1 & 14 & 7.1 & 0.4 & 460 & 190 & 1.1 & 0.2 & 158.8 & 43.7 \\
\hline
\end{tabular}




\begin{tabular}{|c|c|c|c|c|c|c|c|c|c|c|}
\hline UZ-36-38 & 6.5 & 16 & 6.1 & 0.3 & BLOD & BLOD & 1.1 & 0.2 & 235.0 & 60.6 \\
\hline UZ-37-1 & 28.0 & 74 & 47.6 & 2.2 & 2680 & 640 & 1.2 & 0.2 & 130.1 & 17.0 \\
\hline UZ-37-2 & 16.2 & 34 & 27.5 & 1.1 & 880 & 270 & 1.2 & 0.2 & 130.5 & 23.5 \\
\hline UZ-37-3 & 21.7 & 43 & 29.4 & 1.4 & 930 & 230 & 1.3 & 0.3 & 163.2 & 26.8 \\
\hline UZ-37-4 & 28.4 & 42 & 58.0 & 7.3 & 3000 & 1600 & 1.3 & 0.3 & 108.1 & 21.9 \\
\hline UZ-37-5 & 26.5 & 43 & 29.6 & 1.3 & 1430 & 260 & 1.3 & 0.3 & 197.9 & 32.3 \\
\hline UZ-37-6 & 15.8 & 60 & 24.7 & 1.5 & 1280 & 240 & 1.2 & 0.2 & 141.7 & 20.9 \\
\hline UZ-37-7 & 14.1 & 46 & 24.7 & 1.5 & 1080 & 300 & 1.3 & 0.2 & 126.6 & 20.8 \\
\hline UZ-37-8 & 23.4 & 81 & 32.2 & 1.8 & 850 & 330 & 1.3 & 0.2 & 160.8 & 20.9 \\
\hline UZ-37-9 & 14.1 & 25 & 21.3 & 0.8 & BLOD & BLOD & 1.1 & 0.2 & 146.2 & 30.3 \\
\hline UZ-37-10 & 27.0 & 71 & 59.4 & 2.5 & 1200 & 450 & 1.4 & 0.2 & 100.3 & 13.2 \\
\hline UZ-37-11 & 20.7 & 57 & 36.0 & 1.6 & 620 & 330 & 1.6 & 0.4 & 127.4 & 18.5 \\
\hline UZ-37-12 & 25.0 & 40 & 44.1 & 1.5 & 1070 & 330 & 1.3 & 0.3 & 125.2 & 20.8 \\
\hline UZ-37-13 & 20.8 & 29 & 17.7 & 0.8 & 1320 & 290 & 1.3 & 0.3 & 258.6 & 50.4 \\
\hline UZ-37-14 & 37.9 & 57 & 52.0 & 3.3 & 810 & 300 & 1.4 & 0.3 & 161.3 & 24.5 \\
\hline UZ-37-15 & 33.2 & 28 & 48.5 & 2.3 & 1170 & 250 & 1.5 & 0.3 & 151.5 & 30.1 \\
\hline UZ-37-16 & 43.2 & 53 & 80.2 & 4.9 & 38000 & 15000 & 1.3 & 0.4 & 119.2 & 18.5 \\
\hline UZ-37-17 & 19.9 & 33 & 23.4 & 1.3 & 730 & 240 & 1.3 & 0.3 & 188.3 & 35.2 \\
\hline UZ-37-18 & 11.5 & 16 & 23.8 & 1.5 & 1150 & 290 & 1.4 & 0.2 & 106.6 & 27.8 \\
\hline UZ-37-19 & 17.1 & 27 & 62.5 & 3.4 & 780 & 310 & 1.2 & 0.2 & 60.6 & 12.3 \\
\hline UZ-37-20 & 16.2 & 48 & 14.5 & 1.0 & 1060 & 240 & 1.1 & 0.2 & 247.7 & 40.4 \\
\hline UZ-37-21 & 24.3 & 46 & 22.9 & 1.0 & 1070 & 260 & 1.5 & 0.2 & 235.1 & 37.2 \\
\hline UZ-37-22 & 26.2 & 59 & 42.9 & 6.3 & 14000 & 10000 & 1.2 & 0.3 & 135.2 & 27.0 \\
\hline UZ-37-23 & 6.3 & 20 & 10.6 & 0.6 & 1830 & 260 & 1.2 & 0.2 & 131.9 & 30.8 \\
\hline UZ-37-24 & 33.2 & 57 & 88.6 & 4.1 & 1300 & 310 & 1.2 & 0.2 & 82.8 & 12.0 \\
\hline UZ-37-25 & 19.9 & 13 & 30.2 & 1.2 & 850 & 300 & 1.2 & 0.4 & 145.8 & 41.2 \\
\hline UZ-37-26 & 13.9 & 20 & 20.4 & 1.2 & 1170 & 350 & 1.4 & 0.2 & 150.7 & 35.3 \\
\hline UZ-37-27 & 28.4 & 40 & 53.6 & 2.5 & 1260 & 350 & 1.3 & 0.4 & 117.2 & 19.8 \\
\hline UZ-37-28 & 15.5 & 30 & 30.9 & 1.5 & 1580 & 270 & 1.5 & 0.6 & 111.1 & 21.4 \\
\hline UZ-37-29 & 16.8 & 25 & 34.3 & 1.7 & 1240 & 310 & 1.3 & 0.2 & 108.3 & 22.7 \\
\hline UZ-37-30 & 26.3 & 22 & 41.6 & 2.4 & 1120 & 260 & 1.3 & 0.2 & 139.6 & 31.3 \\
\hline
\end{tabular}




\begin{tabular}{|c|c|c|c|c|c|c|c|c|c|c|}
\hline UZ-37-31 & 22.5 & 31 & 80.0 & 41.0 & 1040000 & 290000 & 1.2 & 0.3 & 62.0 & 33.8 \\
\hline UZ-37-32 & 20.5 & 38 & 36.6 & 2.7 & 22300 & 3700 & 1.3 & 0.2 & 123.8 & 22.6 \\
\hline UZ-38-1 & 4.6 & 27 & 6.0 & 0.3 & BLOD & BLOD & 1.0 & 0.2 & 172.0 & 35.0 \\
\hline UZ-38-2 & 3.8 & 12 & 10.8 & 0.5 & BLOD & BLOD & 1.3 & 0.5 & 78.3 & 23.1 \\
\hline UZ-38-3 & 4.7 & 13 & 6.0 & 0.2 & BLOD & BLOD & 1.0 & 0.1 & 172.4 & 48.7 \\
\hline UZ-38-4 & 9.1 & 46 & 11.0 & 0.8 & BLOD & BLOD & 1.2 & 0.2 & 181.7 & 30.4 \\
\hline UZ-38-5 & 7.5 & 17 & 14.0 & 0.9 & BLOD & BLOD & 1.3 & 0.1 & 118.3 & 29.9 \\
\hline UZ-38-6 & 1.2 & 8 & 2.8 & 0.2 & BLOD & BLOD & 1.1 & 0.3 & 96.6 & 34.8 \\
\hline UZ-38-7 & 8.4 & 34 & 13.7 & 0.7 & BLOD & BLOD & 1.3 & 0.3 & 135.6 & 24.7 \\
\hline UZ-38-8 & 6.9 & 24 & 15.0 & 0.7 & BLOD & BLOD & 0.9 & 0.2 & 102.1 & 21.7 \\
\hline UZ-38-9 & 12.1 & 27 & 24.6 & 1.0 & BLOD & BLOD & 1.0 & 0.2 & 108.4 & 21.7 \\
\hline UZ-38-10 & 12.6 & 61 & 18.8 & 1.6 & BLOD & BLOD & 1.3 & 0.4 & 147.8 & 23.4 \\
\hline UZ-38-11 & 9.9 & 21 & 8.2 & 0.5 & BLOD & BLOD & 1.8 & 0.4 & 266.2 & 61.2 \\
\hline UZ-38-12 & 6.5 & 15 & 4.7 & 0.3 & BLOD & BLOD & 0.8 & 0.1 & 305.3 & 81.5 \\
\hline UZ-38-13 & 38.0 & 45 & 98.6 & 4.8 & 1180 & 430 & 1.0 & 0.2 & 85.1 & 13.7 \\
\hline UZ-38-14 & 4.8 & 9 & 8.1 & 0.6 & BLOD & BLOD & 1.3 & 0.3 & 129.6 & 44.5 \\
\hline UZ-38-15 & 8.3 & 32 & 11.6 & 0.4 & BLOD & BLOD & 0.9 & 0.2 & 158.0 & 29.1 \\
\hline UZ-38-16 & 1.0 & 2 & 1.8 & 0.2 & BLOD & BLOD & 1.6 & 0.1 & 126.3 & 90.1 \\
\hline UZ-38-17 & 5.2 & 8 & 12.7 & 0.9 & BLOD & BLOD & 0.8 & 0.2 & 90.3 & 32.8 \\
\hline UZ-38-18 & 1.5 & 5 & 2.8 & 0.2 & BLOD & BLOD & 1.8 & 1.8 & 122.2 & 55.5 \\
\hline UZ-38-19 & 1.9 & 5 & 4.7 & 0.3 & BLOD & BLOD & 1.0 & 0.3 & 88.8 & 40.3 \\
\hline UZ-38-20 & 23.2 & 54 & 43.8 & 2.1 & BLOD & BLOD & 1.1 & 0.2 & 117.0 & 17.5 \\
\hline UZ-38-21 & 2.7 & 8 & 3.0 & 0.2 & BLOD & BLOD & 1.2 & 0.4 & 200.8 & 72.5 \\
\hline UZ-38-22 & 2.2 & 3 & 6.8 & 0.3 & BLOD & BLOD & 0.8 & 0.2 & 71.2 & 41.3 \\
\hline UZ-38-23 & 6.8 & 25 & 11.6 & 0.6 & BLOD & BLOD & 1.0 & 0.2 & 129.9 & 27.3 \\
\hline UZ-38-24 & 17.1 & 40 & 16.8 & 0.8 & BLOD & BLOD & 1.3 & 0.2 & 225.1 & 38.1 \\
\hline UZ-38-25 & 2.3 & 3 & 13.5 & 0.8 & BLOD & BLOD & 1.2 & 0.3 & 37.7 & 21.9 \\
\hline UZ-38-26 & 2.5 & 3 & 2.7 & 0.2 & 1310 & 430 & 0.7 & 0.3 & 207.2 & 120.6 \\
\hline UZ-38-27 & 28.0 & 74 & 51.6 & 3.0 & 1010 & 370 & 1.2 & 0.3 & 119.8 & 16.2 \\
\hline UZ-38-28 & 2.7 & 8 & 4.1 & 0.3 & 690 & 350 & 1.2 & 0.4 & 141.9 & 51.3 \\
\hline UZ-38-29 & 7.7 & 19 & 16.6 & 0.8 & BLOD & BLOD & 1.0 & 0.2 & 102.7 & 24.4 \\
\hline
\end{tabular}




\begin{tabular}{|c|c|c|c|c|c|c|c|c|c|c|}
\hline UZ-38-30 & 1.7 & 4 & 3.2 & 0.2 & BLOD & BLOD & 0.9 & 0.0 & 119.0 & 60.3 \\
\hline UZ-38-31 & 12.7 & 14 & 19.4 & 0.9 & BLOD & BLOD & 0.7 & 0.1 & 144.2 & 39.5 \\
\hline UZ-38-32 & 6.5 & 15 & 4.8 & 0.3 & BLOD & BLOD & 0.8 & 0.4 & 300.9 & 80.9 \\
\hline UZ-38-33 & 4.7 & 9 & 6.0 & 0.3 & BLOD & BLOD & 0.9 & 0.1 & 170.8 & 58.0 \\
\hline UZ-38-34 & 2.5 & 10 & 2.0 & 0.2 & BLOD & BLOD & 1.0 & 0.2 & 270.8 & 91.6 \\
\hline UZ-38-35 & 13.4 & 32 & 33.1 & 2.1 & BLOD & BLOD & 0.9 & 0.3 & 89.4 & 17.1 \\
\hline UZ-39-1 & 26.4 & 75 & 40.6 & 2.5 & BLOD & BLOD & 1.3 & 0.2 & 143.8 & 19.6 \\
\hline UZ-39-2 & 2.3 & 11 & 5.1 & 0.3 & BLOD & BLOD & 1.2 & 0.6 & 99.8 & 30.8 \\
\hline UZ-39-3 & 37.2 & 117 & 94.4 & 5.1 & BLOD & BLOD & 1.5 & 0.3 & 87.2 & 9.9 \\
\hline UZ-39-4 & 18.9 & 76 & 44.4 & 2.3 & BLOD & BLOD & 1.5 & 0.3 & 94.2 & 12.4 \\
\hline UZ-39-5 & 20.9 & 75 & 34.4 & 1.4 & BLOD & BLOD & 1.5 & 0.2 & 134.2 & 17.2 \\
\hline UZ-39-6 & 34.1 & 126 & 53.0 & 2.9 & 1030 & 380 & 1.6 & 0.5 & 142.2 & 15.8 \\
\hline UZ-39-7 & 41.5 & 143 & 79.3 & 3.3 & BLOD & BLOD & 1.6 & 0.3 & 115.8 & 11.7 \\
\hline UZ-39-8 & 47.4 & 109 & 141.6 & 4.9 & BLOD & BLOD & 1.5 & 0.2 & 74.0 & 8.1 \\
\hline UZ-39-9 & 11.0 & 48 & 22.9 & 1.1 & BLOD & BLOD & 1.4 & 0.2 & 106.0 & 16.6 \\
\hline UZ-39-10 & 17.3 & 43 & 36.3 & 1.7 & BLOD & BLOD & 1.4 & 0.4 & 105.4 & 17.3 \\
\hline UZ-39-11 & 37.6 & 89 & 72.7 & 2.3 & BLOD & BLOD & 1.5 & 0.4 & 114.4 & 13.4 \\
\hline UZ-39-12 & 18.8 & 50 & 101.4 & 3.5 & 830 & 350 & 1.5 & 0.2 & 40.9 & 6.2 \\
\hline UZ-39-13 & 23.2 & 75 & 99.0 & 6.9 & 19500 & 6600 & 1.8 & 0.2 & 51.8 & 7.3 \\
\hline UZ-39-14 & 15.4 & 66 & 34.2 & 1.9 & BLOD & BLOD & 1.6 & 0.2 & 99.7 & 14.0 \\
\hline UZ-39-15 & 34.3 & 99 & 87.7 & 3.1 & BLOD & BLOD & 1.7 & 0.3 & 86.5 & 9.8 \\
\hline UZ-39-16 & 14.7 & 75 & 27.1 & 1.7 & BLOD & BLOD & 1.6 & 0.2 & 120.0 & 16.4 \\
\hline UZ-39-17 & 26.2 & 91 & 51.2 & 2.7 & BLOD & BLOD & 1.1 & 0.2 & 113.3 & 14.0 \\
\hline UZ-39-18 & 31.5 & 102 & 31.9 & 1.8 & BLOD & BLOD & 1.4 & 0.3 & 218.0 & 26.2 \\
\hline UZ-39-19 & 17.0 & 89 & 39.6 & 2.0 & 660 & 390 & 1.8 & 0.2 & 95.0 & 11.7 \\
\hline UZ-39-20 & 11.2 & 28 & 35.3 & 1.8 & BLOD & BLOD & 1.4 & 0.3 & 69.9 & 13.9 \\
\hline UZ-39-21 & 23.8 & 81 & 56.2 & 4.4 & BLOD & BLOD & 1.1 & 0.2 & 93.4 & 13.2 \\
\hline UZ-39-22 & 2.8 & 10 & 72.5 & 3.3 & BLOD & BLOD & 1.0 & 0.3 & 8.6 & 2.8 \\
\hline UZ-39-23 & 7.3 & 36 & 65.7 & 2.4 & 760 & 290 & 1.2 & 0.2 & 24.4 & 4.3 \\
\hline UZ-39-24 & 5.3 & 33 & 12.9 & 0.6 & BLOD & BLOD & 1.1 & 0.2 & 90.7 & 16.8 \\
\hline UZ-39-25 & 34.5 & 134 & 152.8 & 7.2 & 800 & 330 & 1.4 & 0.3 & 50.0 & 5.3 \\
\hline
\end{tabular}




\begin{tabular}{|c|c|c|c|c|c|c|c|c|c|c|}
\hline UZ-39-26 & 24.1 & 142 & 91.8 & 4.3 & BLOD & BLOD & 1.3 & 0.2 & 58.1 & 6.0 \\
\hline UZ-39-27 & 34.4 & 121 & 53.1 & 3.6 & 660 & 340 & 1.3 & 0.3 & 143.1 & 17.1 \\
\hline UZ-39-28 & 27.8 & 136 & 34.3 & 1.6 & BLOD & BLOD & 1.6 & 0.6 & 178.9 & 18.8 \\
\hline UZ-39-29 & 12.2 & 61 & 126.1 & 8.0 & BLOD & BLOD & 1.5 & 0.3 & 21.3 & 3.2 \\
\hline UZ-39-30 & 14.9 & 49 & 32.9 & 1.5 & BLOD & BLOD & 1.4 & 0.3 & 100.1 & 15.5 \\
\hline UZ-39-31 & 6.5 & 36 & 16.0 & 0.7 & BLOD & BLOD & 1.1 & 0.3 & 90.2 & 15.9 \\
\hline UZ-39-32 & 48.4 & 261 & 158.7 & 7.4 & BLOD & BLOD & 1.5 & 0.4 & 67.4 & 5.8 \\
\hline UZ-39-33 & 20.8 & 74 & 44.7 & 2.0 & 850 & 350 & 1.6 & 0.5 & 102.8 & 13.4 \\
\hline UZ-39-34 & 17.3 & 66 & 35.0 & 1.4 & 980 & 350 & 1.3 & 0.2 & 109.5 & 14.8 \\
\hline UZ-39-35 & 42.3 & 174 & 85.3 & 3.8 & BLOD & BLOD & 1.5 & 0.3 & 109.7 & 10.5 \\
\hline UZ-39-36 & 31.0 & 182 & 62.0 & 2.6 & BLOD & BLOD & 1.3 & 0.4 & 110.5 & 10.3 \\
\hline UZ-39-37 & 15.7 & 78 & 25.6 & 1.2 & BLOD & BLOD & 1.3 & 0.2 & 135.5 & 17.4 \\
\hline UZ-39-38 & 27.1 & 113 & 57.0 & 2.6 & BLOD & BLOD & 1.4 & 0.2 & 105.2 & 11.7 \\
\hline UZ-40-1 & 12.2 & 45 & 39.3 & 2.0 & BLOD & BLOD & 1.3 & 0.3 & 68.6 & 11.1 \\
\hline UZ-40-2 & 14.3 & 15 & 13.9 & 1.1 & 1230 & 360 & 1.4 & 0.9 & 227.0 & 61.9 \\
\hline UZ-40-3 & 12.4 & 36 & 24.0 & 1.8 & BLOD & BLOD & 1.2 & 0.2 & 114.0 & 21.3 \\
\hline UZ-40-4 & 7.4 & 8 & 9.4 & 0.5 & 4700 & 1100 & 1.3 & 0.2 & 172.8 & 62.3 \\
\hline UZ-40-5 & 8.0 & 14 & 9.6 & 0.5 & BLOD & BLOD & 1.2 & 0.1 & 182.8 & 50.3 \\
\hline UZ-40-6 & 4.2 & 6 & 8.8 & 0.5 & BLOD & BLOD & 1.3 & 0.2 & 105.1 & 43.4 \\
\hline UZ-40-7 & 9.5 & 15 & 28.9 & 1.3 & 730 & 310 & 1.2 & 0.5 & 72.7 & 19.3 \\
\hline UZ-40-8 & 14.0 & 27 & 28.6 & 1.7 & BLOD & BLOD & 1.5 & 0.3 & 107.8 & 22.1 \\
\hline UZ-40-9 & 8.2 & 26 & 10.2 & 0.4 & 810 & 300 & 1.2 & 0.2 & 177.1 & 36.2 \\
\hline UZ-40-10 & 7.2 & 25 & 10.8 & 0.6 & BLOD & BLOD & 1.4 & 0.3 & 148.1 & 31.1 \\
\hline UZ-40-11 & 12.6 & 27 & 24.9 & 1.1 & 800 & 240 & 1.5 & 0.6 & 111.8 & 22.5 \\
\hline UZ-40-12 & 8.7 & 21 & 20.2 & 1.2 & BLOD & BLOD & 1.5 & 0.9 & 95.5 & 21.9 \\
\hline UZ-40-13 & 5.5 & 14 & 14.5 & 0.7 & 670 & 210 & 1.3 & 0.2 & 83.1 & 22.8 \\
\hline UZ-40-14 & 7.6 & 21 & 14.5 & 0.7 & BLOD & BLOD & 1.2 & 0.2 & 116.6 & 26.5 \\
\hline UZ-40-15 & 12.1 & 24 & 26.7 & 1.4 & 510 & 200 & 1.3 & 0.3 & 100.0 & 21.4 \\
\hline UZ-40-16 & 15.3 & 57 & 29.9 & 1.7 & BLOD & BLOD & 1.5 & 0.4 & 113.4 & 16.9 \\
\hline UZ-40-17 & 2.8 & 9 & 2.9 & 0.2 & BLOD & BLOD & 1.3 & 0.2 & 216.2 & 73.7 \\
\hline UZ-40-18 & 8.3 & 22 & 12.3 & 0.7 & BLOD & BLOD & 1.6 & 0.3 & 148.3 & 33.1 \\
\hline
\end{tabular}




\begin{tabular}{|c|c|c|c|c|c|c|c|c|c|c|}
\hline UZ-40-19 & 13.3 & 39 & 34.0 & 2.3 & 420 & 230 & 1.1 & 0.1 & 86.2 & 15.3 \\
\hline UZ-40-20 & 11.4 & 37 & 24.0 & 1.2 & 450 & 230 & 1.4 & 0.5 & 105.0 & 18.5 \\
\hline UZ-40-21 & 12.0 & 33 & 23.0 & 1.2 & 430 & 220 & 1.3 & 0.4 & 115.2 & 21.4 \\
\hline UZ-40-22 & 7.0 & 27 & 10.6 & 0.8 & BLOD & BLOD & 1.4 & 0.2 & 147.3 & 31.1 \\
\hline UZ-40-23 & 10.6 & 41 & 25.9 & 1.2 & 430 & 220 & 1.4 & 0.3 & 90.4 & 15.1 \\
\hline UZ-40-24 & 8.2 & 24 & 21.3 & 1.2 & BLOD & BLOD & 1.4 & 0.2 & 84.6 & 18.2 \\
\hline UZ-40-25 & 3.6 & 23 & 15.1 & 0.7 & 810 & 210 & 1.2 & 0.3 & 52.0 & 11.3 \\
\hline UZ-40-26 & 10.7 & 28 & 20.8 & 0.9 & 540 & 230 & 1.4 & 0.2 & 113.8 & 22.5 \\
\hline UZ-40-27 & 6.0 & 11 & 12.1 & 1.0 & BLOD & BLOD & 1.1 & 0.1 & 110.3 & 34.7 \\
\hline UZ-40-28 & 4.1 & 26 & 6.8 & 0.3 & BLOD & BLOD & 1.4 & 1.0 & 135.4 & 27.9 \\
\hline UZ-40-29 & 6.8 & 26 & 14.6 & 0.8 & 430 & 190 & 1.0 & 0.3 & 102.7 & 21.2 \\
\hline UZ-40-30 & 12.0 & 26 & 23.0 & 1.1 & BLOD & BLOD & 1.1 & 0.2 & 115.4 & 23.7 \\
\hline UZ-40-31 & 10.1 & 28 & 19.2 & 1.0 & 400 & 180 & 1.3 & 0.2 & 116.3 & 23.2 \\
\hline UZ-40-32 & 7.4 & 32 & 14.6 & 0.7 & 360 & 170 & 1.1 & 0.3 & 112.7 & 21.1 \\
\hline UZ-40-33 & 4.3 & 8 & 7.1 & 0.4 & BLOD & BLOD & 1.3 & 0.2 & 132.2 & 47.5 \\
\hline UZ-40-34 & 7.7 & 22 & 21.6 & 1.0 & BLOD & BLOD & 1.0 & 0.1 & 78.6 & 17.4 \\
\hline UZ-40-35 & 20.2 & 40 & 61.6 & 2.1 & BLOD & BLOD & 1.2 & 0.2 & 72.6 & 12.1 \\
\hline UZ-40-36 & 8.6 & 36 & 12.0 & 0.5 & BLOD & BLOD & 1.0 & 0.2 & 158.8 & 28.1 \\
\hline UZ-40-37 & 3.7 & 6 & 11.0 & 0.7 & BLOD & BLOD & 1.2 & 0.1 & 74.6 & 30.9 \\
\hline UZ-40-38 & 7.5 & 12 & 14.1 & 0.9 & BLOD & BLOD & NA & 0.0 & 118.1 & 35.3 \\
\hline UZ-40-39 & 7.2 & 20 & 15.4 & 0.6 & BLOD & BLOD & 1.3 & 0.2 & 103.7 & 23.9 \\
\hline UZ-41-1 & 17.1 & 68 & 22.0 & 1.4 & 1150 & 290 & 1.6 & 0.3 & 171.5 & 24.4 \\
\hline UZ-41-2 & 13.9 & 43 & 32.8 & 2.2 & 1050 & 270 & 2.0 & 0.6 & 93.8 & 16.0 \\
\hline UZ-41-3 & 15.9 & 59 & 29.1 & 1.4 & 1300 & 350 & 1.3 & 0.2 & 120.4 & 17.3 \\
\hline UZ-41-4 & 21.6 & 42 & 29.6 & 1.6 & 750 & 250 & 1.5 & 0.3 & 161.6 & 27.1 \\
\hline UZ-41-5 & 19.3 & 46 & 33.8 & 1.7 & 1340 & 250 & 1.6 & 0.4 & 125.9 & 20.2 \\
\hline UZ-41-6 & 24.9 & 51 & 44.4 & 1.9 & 1060 & 240 & 1.5 & 0.3 & 124.1 & 18.8 \\
\hline UZ-41-7 & 18.8 & 74 & 34.0 & 1.6 & 1110 & 220 & 1.7 & 0.3 & 122.1 & 16.0 \\
\hline UZ-41-8 & 10.8 & 14 & 23.9 & 1.2 & 1440 & 270 & 1.5 & 0.3 & 99.6 & 27.4 \\
\hline UZ-41-9 & 9.5 & 11 & 20.9 & 0.9 & 1060 & 250 & 1.8 & 0.1 & 100.2 & 30.7 \\
\hline UZ-41-10 & 18.6 & 50 & 17.1 & 1.0 & 970 & 270 & 1.5 & 0.3 & 240.6 & 38.0 \\
\hline
\end{tabular}




\begin{tabular}{|c|c|c|c|c|c|c|c|c|c|c|}
\hline UZ-41-11 & 11.4 & 45 & 18.0 & 1.2 & 940 & 270 & 1.6 & 0.5 & 139.9 & 23.5 \\
\hline UZ-41-12 & 15.5 & 31 & 33.4 & 2.2 & 1070 & 250 & 1.3 & 0.3 & 102.5 & 20.0 \\
\hline UZ-41-13 & 12.9 & 35 & 25.2 & 1.3 & 1270 & 250 & 1.6 & 0.2 & 113.2 & 20.5 \\
\hline UZ-41-14 & 9.6 & 15 & 22.1 & 1.0 & 1080 & 190 & 1.6 & 0.3 & 96.1 & 25.4 \\
\hline UZ-41-15 & 17.5 & 26 & 33.7 & 1.5 & 1060 & 230 & 1.4 & 0.3 & 114.6 & 23.5 \\
\hline UZ-41-16 & 18.1 & 26 & 47.4 & 3.4 & 13700 & 3200 & 1.4 & 0.2 & 84.5 & 17.9 \\
\hline UZ-41-17 & 12.8 & 21 & 27.2 & 1.2 & 740 & 210 & 1.5 & 0.4 & 103.7 & 23.4 \\
\hline UZ-41-18 & 23.6 & 63 & 29.3 & 1.8 & 1070 & 270 & 1.3 & 0.2 & 177.7 & 25.8 \\
\hline UZ-41-19 & 10.2 & 30 & 16.9 & 0.9 & 1320 & 300 & 1.4 & 0.3 & 133.5 & 25.9 \\
\hline UZ-41-20 & 20.6 & 41 & 35.5 & 1.8 & 1390 & 250 & 1.6 & 0.6 & 128.4 & 21.6 \\
\hline UZ-41-21 & 21.9 & 34 & 30.5 & 1.1 & 1350 & 220 & 1.6 & 0.2 & 158.9 & 28.5 \\
\hline UZ-41-22 & 11.7 & 31 & 30.5 & 3.1 & 3600 & 1300 & 1.6 & 0.5 & 84.9 & 17.8 \\
\hline UZ-41-23 & 17.9 & 40 & 31.4 & 1.6 & 1050 & 270 & 1.5 & 0.3 & 126.0 & 21.5 \\
\hline UZ-41-24 & 14.9 & 39 & 11.4 & 0.5 & 1630 & 280 & 1.7 & 0.5 & 289.8 & 49.2 \\
\hline UZ-41-25 & 20.2 & 44 & 35.5 & 1.4 & 1740 & 250 & 1.6 & 0.3 & 125.9 & 20.2 \\
\hline UZ-41-26 & 16.7 & 23 & 32.6 & 1.3 & 1130 & 250 & 1.6 & 0.4 & 113.3 & 24.4 \\
\hline UZ-41-27 & 15.7 & 22 & 27.1 & 1.4 & 1190 & 230 & 1.6 & 0.3 & 127.7 & 28.4 \\
\hline UZ-41-28 & 21.1 & 44 & 53.2 & 2.9 & 800 & 260 & 1.7 & 0.2 & 87.9 & 14.5 \\
\hline UZ-41-29 & 13.9 & 33 & 19.9 & 1.7 & 1410 & 310 & 1.4 & 0.3 & 154.1 & 30.5 \\
\hline UZ-41-30 & 11.0 & 25 & 14.7 & 0.6 & 1030 & 240 & 1.6 & 0.3 & 165.6 & 34.5 \\
\hline UZ-41-31 & 18.9 & 58 & 33.5 & 1.6 & 1000 & 210 & 1.3 & 0.3 & 124.9 & 18.1 \\
\hline UZ-41-32 & 11.4 & 26 & 24.6 & 1.2 & 890 & 250 & 1.2 & 0.3 & 102.2 & 21.0 \\
\hline UZ-41-33 & 15.1 & 48 & 23.3 & 1.2 & 1260 & 220 & 1.9 & 0.3 & 143.5 & 22.7 \\
\hline UZ-41-34 & 16.4 & 41 & 15.7 & 0.9 & 1010 & 210 & 1.6 & 0.5 & 230.5 & 39.2 \\
\hline UZ-41-35 & 27.4 & 45 & 29.6 & 1.1 & 1370 & 230 & 1.4 & 0.3 & 204.3 & 32.4 \\
\hline UZ-41-36 & 17.8 & 41 & 26.1 & 1.1 & 800 & 220 & 1.4 & 0.2 & 150.8 & 25.1 \\
\hline UZ-41-37 & 9.1 & 21 & 9.3 & 0.8 & 1380 & 250 & 0.8 & 0.2 & 215.3 & 50.8 \\
\hline UZ-41-38 & 14.7 & 42 & 19.7 & 1.1 & 1130 & 210 & 1.5 & 0.3 & 164.6 & 27.7 \\
\hline UZ-41-39 & 15.3 & 21 & 38.2 & 1.9 & 930 & 230 & 1.6 & 0.3 & 88.6 & 20.1 \\
\hline UZ-41-40 & 16.7 & 39 & 33.4 & 1.8 & 1020 & 190 & 1.5 & 0.2 & 110.3 & 19.1 \\
\hline UZ-41-41 & 17.4 & 31 & 36.0 & 1.4 & 690 & 210 & 1.4 & 0.2 & 107.0 & 20.1 \\
\hline
\end{tabular}




\begin{tabular}{|c|c|c|c|c|c|c|c|c|c|c|}
\hline UZ-41-42 & 17.9 & 41 & 26.0 & 1.7 & 41600 & 9300 & 1.4 & 0.3 & 151.9 & 26.4 \\
\hline UZ-41-43 & 9.6 & 24 & 19.9 & 4.0 & 20000 & 15000 & 1.3 & 0.3 & 107.1 & 31.0 \\
\hline UZ-42-1 & 4.6 & 11 & 5.3 & 0.3 & BLOD & BLOD & 0.5 & 0.2 & 191.7 & 59.0 \\
\hline UZ-42-2 & 1.9 & 2 & 8.4 & 0.5 & BLOD & BLOD & 1.1 & 0.4 & 51.0 & 36.3 \\
\hline UZ-42-3 & 6.8 & 8 & 6.5 & 0.4 & 640 & 190 & 1.3 & 0.3 & 229.5 & 82.9 \\
\hline UZ-42-4 & 6.1 & 14 & 7.1 & 0.5 & BLOD & BLOD & 1.2 & 0.1 & 190.4 & 53.1 \\
\hline UZ-42-5 & 4.0 & 4 & 7.5 & 0.5 & BLOD & BLOD & 1.5 & 0.2 & 119.2 & 60.3 \\
\hline UZ-42-6 & 4.4 & 16 & 11.2 & 0.6 & BLOD & BLOD & 0.9 & 0.2 & 87.7 & 22.7 \\
\hline UZ-42-7 & 3.9 & 7 & 14.4 & 0.8 & BLOD & BLOD & 1.0 & 0.1 & 60.5 & 23.2 \\
\hline UZ-42-8 & 8.1 & 33 & 26.6 & 1.3 & BLOD & BLOD & 1.0 & 0.2 & 67.5 & 12.5 \\
\hline UZ-42-9 & 10.5 & 33 & 21.1 & 0.9 & BLOD & BLOD & 1.2 & 0.2 & 109.8 & 20.1 \\
\hline UZ-42-10 & 4.4 & 11 & 9.8 & 0.6 & BLOD & BLOD & 1.0 & 0.1 & 99.2 & 30.7 \\
\hline UZ-42-11 & 3.5 & 16 & 5.7 & 0.4 & BLOD & BLOD & 1.0 & 0.1 & 135.2 & 35.2 \\
\hline UZ-42-12 & 8.1 & 16 & 6.7 & 0.3 & 1430 & 530 & 1.1 & 0.2 & 269.5 & 69.5 \\
\hline UZ-42-13 & 2.6 & 5 & 3.5 & 0.2 & BLOD & BLOD & 1.0 & 0.1 & 163.2 & 73.6 \\
\hline UZ-42-14 & 5.7 & 26 & 10.0 & 0.4 & BLOD & BLOD & 1.3 & 0.4 & 127.3 & 26.0 \\
\hline UZ-42-15 & 5.8 & 19 & 9.3 & 0.5 & BLOD & BLOD & 0.7 & 0.2 & 137.3 & 32.6 \\
\hline UZ-42-16 & 2.4 & 9 & 4.7 & 0.3 & BLOD & BLOD & 0.6 & 0.1 & 114.3 & 38.9 \\
\hline UZ-42-17 & 6.6 & 16 & 8.6 & 0.4 & BLOD & BLOD & 1.1 & 0.2 & 169.7 & 43.8 \\
\hline UZ-42-18 & 4.5 & 14 & 9.4 & 0.4 & BLOD & BLOD & 1.1 & 0.2 & 107.0 & 29.2 \\
\hline UZ-42-19 & 6.7 & 31 & 11.4 & 0.7 & BLOD & BLOD & 1.1 & 0.2 & 130.2 & 25.2 \\
\hline UZ-42-20 & 9.3 & 21 & 9.7 & 0.7 & BLOD & BLOD & 1.2 & 0.2 & 212.3 & 49.8 \\
\hline UZ-42-21 & 8.4 & 19 & 18.6 & 1.4 & BLOD & BLOD & 1.5 & 0.2 & 99.5 & 24.3 \\
\hline UZ-42-22 & 14.6 & 34 & 19.3 & 0.8 & BLOD & BLOD & 1.1 & 0.5 & 167.1 & 30.2 \\
\hline UZ- $42-23$ & 5.5 & 23 & 10.5 & 0.6 & BLOD & BLOD & 1.0 & 0.3 & 115.8 & 25.4 \\
\hline UZ-42-24 & 3.1 & 5 & 5.4 & 0.3 & BLOD & BLOD & 1.0 & 0.6 & 128.5 & 58.1 \\
\hline UZ-42-25 & 7.2 & 14 & 8.3 & 0.5 & BLOD & BLOD & 1.3 & 0.2 & 192.0 & 53.0 \\
\hline UZ-42-26 & 3.5 & 10 & 4.4 & 0.3 & BLOD & BLOD & 1.2 & 0.2 & 178.2 & 57.8 \\
\hline UZ-42-27 & 11.0 & 26 & 18.5 & 1.0 & BLOD & BLOD & 0.8 & 0.2 & 131.0 & 27.1 \\
\hline UZ-42-28 & 5.7 & 17 & 7.3 & 0.3 & BLOD & BLOD & 1.0 & 0.3 & 172.5 & 43.1 \\
\hline UZ-42-29 & 6.2 & 8 & 8.9 & 0.5 & BLOD & BLOD & 1.0 & 0.5 & 152.1 & 54.7 \\
\hline
\end{tabular}




\begin{tabular}{|c|c|c|c|c|c|c|c|c|c|c|}
\hline UZ-42-30 & 7.4 & 13 & 9.0 & 0.6 & BLOD & BLOD & 1.2 & 0.1 & 182.6 & 52.4 \\
\hline UZ-42-31 & 14.1 & 37 & 21.6 & 1.0 & BLOD & BLOD & 0.9 & 0.3 & 144.1 & 25.2 \\
\hline UZ-42-32 & 4.3 & 9 & 5.4 & 0.3 & 400 & 210 & 1.4 & 0.2 & 175.9 & 60.0 \\
\hline UZ-42-33 & 7.2 & 15 & 5.8 & 0.3 & BLOD & BLOD & 1.3 & 0.3 & 276.7 & 73.4 \\
\hline UZ-42-34 & 7.7 & 9 & 10.3 & 0.5 & BLOD & BLOD & 0.8 & 0.1 & 165.4 & 56.1 \\
\hline UZ-42-35 & 3.1 & 5 & 10.9 & 0.5 & BLOD & BLOD & 1.2 & 0.3 & 62.3 & 28.1 \\
\hline UZ-42-36 & 5.9 & 7 & 6.0 & 0.3 & BLOD & BLOD & 1.4 & 0.3 & 218.2 & 83.8 \\
\hline UZ-43-1 & 4.6 & 21 & 9.9 & 0.5 & BLOD & BLOD & 0.6 & 0.1 & 85.9 & 19.6 \\
\hline UZ-43-2 & 10.5 & 35 & 16.6 & 0.8 & BLOD & BLOD & 1.0 & 0.3 & 116.2 & 20.9 \\
\hline UZ-43-3 & 8.5 & 24 & 21.2 & 1.1 & BLOD & BLOD & 0.7 & 0.1 & 74.2 & 15.9 \\
\hline UZ-43-4 & 3.5 & 17 & 3.5 & 0.3 & BLOD & BLOD & 1.6 & 0.2 & 185.7 & 47.6 \\
\hline UZ-43-5 & 23.4 & 45 & 25.2 & 1.7 & 18600 & 5400 & 1.3 & 0.4 & 171.8 & 28.9 \\
\hline UZ-43-6 & 10.2 & 31 & 14.5 & 0.6 & BLOD & BLOD & 0.7 & 0.1 & 130.2 & 24.6 \\
\hline UZ-43-7 & 18.9 & 55 & 51.6 & 2.9 & BLOD & BLOD & 1.1 & 0.3 & 67.9 & 10.2 \\
\hline UZ-43-8 & 8.5 & 33 & 15.1 & 1.0 & 970 & 390 & 1.1 & 0.3 & 104.7 & 19.9 \\
\hline UZ-43-9 & 27.1 & 58 & 58.6 & 2.7 & BLOD & BLOD & 1.2 & 0.3 & 85.7 & 12.4 \\
\hline UZ-43-10 & 7.5 & 15 & 13.8 & 0.7 & BLOD & BLOD & 0.8 & 0.2 & 100.8 & 26.8 \\
\hline UZ-43-11 & 7.4 & 32 & 13.0 & 0.7 & BLOD & BLOD & 1.1 & 0.2 & 104.7 & 19.7 \\
\hline UZ-43-12 & 3.1 & 11 & 3.3 & 0.2 & BLOD & BLOD & 1.0 & 0.2 & 172.9 & 53.6 \\
\hline UZ-43-13 & 14.6 & 28 & 25.0 & 2.0 & 720 & 400 & 1.1 & 0.2 & 107.7 & 22.5 \\
\hline UZ-43-14 & 8.9 & 48 & 22.1 & 1.1 & BLOD & BLOD & 1.0 & 0.2 & 74.5 & 11.7 \\
\hline UZ-43-15 & 14.6 & 48 & 19.6 & 1.1 & BLOD & BLOD & 0.8 & 0.2 & 137.5 & 21.9 \\
\hline UZ-43-16 & 6.8 & 19 & 10.8 & 0.8 & 34200 & 6700 & 1.4 & 0.3 & 116.8 & 28.5 \\
\hline UZ-43-17 & 3.0 & 13 & 7.6 & 0.5 & BLOD & BLOD & 0.8 & 0.2 & 74.2 & 21.2 \\
\hline UZ-43-18 & 9.8 & 20 & 14.1 & 1.6 & BLOD & BLOD & 1.0 & 0.3 & 128.3 & 32.5 \\
\hline UZ-43-19 & 3.3 & 7 & 9.0 & 0.5 & BLOD & BLOD & 1.5 & 0.9 & 67.3 & 25.9 \\
\hline UZ-43-20 & 8.0 & 27 & 14.1 & 0.7 & BLOD & BLOD & 1.2 & 0.2 & 104.6 & 21.1 \\
\hline UZ-43-21 & 5.9 & 17 & 8.5 & 0.5 & BLOD & BLOD & 1.1 & 0.1 & 127.2 & 32.1 \\
\hline UZ-43-22 & 5.3 & 23 & 13.2 & 0.7 & BLOD & BLOD & 1.3 & 0.2 & 74.8 & 16.3 \\
\hline UZ-43-23 & 7.5 & 17 & 10.5 & 0.7 & BLOD & BLOD & 0.8 & 0.2 & 132.2 & 33.5 \\
\hline UZ-43-24 & 13.7 & 32 & 21.6 & 1.0 & BLOD & BLOD & 1.0 & 0.2 & 116.9 & 21.8 \\
\hline
\end{tabular}




\begin{tabular}{|c|c|c|c|c|c|c|c|c|c|c|}
\hline UZ-43-25 & 3.9 & 11 & 8.7 & 0.5 & BLOD & BLOD & 1.5 & 0.2 & 82.8 & 25.6 \\
\hline UZ-43-26 & 6.5 & 22 & 10.2 & 0.5 & BLOD & BLOD & 1.1 & 0.1 & 116.7 & 25.9 \\
\hline UZ- $43-27$ & 8.1 & 45 & 12.8 & 0.7 & BLOD & BLOD & 1.5 & 0.4 & 117.6 & 19.3 \\
\hline UZ-43-28 & 7.7 & 46 & 14.0 & 0.7 & BLOD & BLOD & 1.4 & 0.2 & 101.0 & 16.2 \\
\hline UZ-43-29 & 6.7 & 27 & 14.9 & 0.8 & 1090 & 500 & 0.9 & 0.2 & 82.8 & 16.8 \\
\hline UZ-43-30 & 20.0 & 80 & 30.1 & 1.3 & BLOD & BLOD & 1.3 & 0.2 & 122.7 & 15.4 \\
\hline UZ-43-31 & 5.6 & 13 & 8.2 & 0.4 & 6900 & 1600 & 1.2 & 0.2 & 125.3 & 35.7 \\
\hline UZ-43-32 & 4.8 & 17 & 14.3 & 0.9 & BLOD & BLOD & 1.1 & 0.2 & 61.8 & 15.6 \\
\hline UZ-43-33 & 3.5 & 16 & 4.8 & 0.5 & BLOD & BLOD & 1.1 & 0.2 & 135.5 & 36.5 \\
\hline UZ-43-34 & 6.2 & 30 & 10.9 & 0.6 & BLOD & BLOD & 1.4 & 0.3 & 105.9 & 20.6 \\
\hline UZ-43-35 & 7.8 & 29 & 10.9 & 0.8 & BLOD & BLOD & 1.4 & 0.1 & 132.8 & 27.0 \\
\hline UZ-43-36 & 30.7 & 60 & 47.7 & 2.5 & BLOD & BLOD & 1.4 & 0.2 & 119.2 & 17.2 \\
\hline UZ-43-37 & 14.2 & 37 & 15.7 & 0.8 & BLOD & BLOD & 1.3 & 0.2 & 166.6 & 29.4 \\
\hline UZ-44-1 & 14.9 & 40 & 24.4 & 1.1 & BLOD & BLOD & 0.9 & 0.2 & 138.5 & 23.8 \\
\hline UZ-44-2 & 25.1 & 42 & 50.4 & 2.0 & 770 & 340 & 1.2 & 0.2 & 112.8 & 18.8 \\
\hline UZ-44-3 & 1.5 & 6 & 1.4 & 0.2 & 2900 & 1200 & 1.5 & 0.3 & 246.8 & 107.8 \\
\hline UZ-44-4 & 8.3 & 18 & 16.7 & 0.7 & BLOD & BLOD & 1.1 & 0.3 & 112.4 & 27.5 \\
\hline UZ-44-5 & 13.1 & 33 & 18.1 & 0.8 & BLOD & BLOD & 0.9 & 0.2 & 163.1 & 30.3 \\
\hline UZ-44-6 & 27.1 & 34 & 28.0 & 1.8 & BLOD & BLOD & 1.3 & 0.3 & 219.5 & 41.6 \\
\hline UZ-44-7 & 12.6 & 31 & 12.0 & 0.6 & BLOD & BLOD & 1.0 & 0.2 & 238.9 & 46.2 \\
\hline UZ-44-8 & 9.8 & 40 & 36.6 & 1.9 & BLOD & BLOD & 1.3 & 0.7 & 60.5 & 10.5 \\
\hline UZ-44-9 & 5.2 & 21 & 10.3 & 0.6 & BLOD & BLOD & 1.3 & 0.2 & 113.1 & 26.1 \\
\hline UZ-44-10 & 18.8 & 65 & 18.3 & 1.3 & BLOD & BLOD & 1.4 & 0.3 & 232.6 & 35.1 \\
\hline UZ-44-11 & 66.3 & 113 & 137.5 & 6.5 & BLOD & BLOD & 1.2 & 0.3 & 109.3 & 12.7 \\
\hline UZ-44-12 & 3.7 & 10 & 7.6 & 0.5 & 1010 & 800 & 1.2 & 0.1 & 109.6 & 35.9 \\
\hline UZ-44-13 & 17.4 & 37 & 46.9 & 1.9 & BLOD & BLOD & 1.1 & 0.2 & 84.0 & 14.8 \\
\hline UZ-44-14 & 14.9 & 55 & 10.9 & 0.8 & BLOD & BLOD & 1.2 & 0.2 & 307.6 & 49.5 \\
\hline UZ-44-15 & 9.9 & 38 & 12.6 & 0.6 & BLOD & BLOD & 1.3 & 0.2 & 176.7 & 30.9 \\
\hline UZ-44-16 & 9.6 & 38 & 15.0 & 0.7 & BLOD & BLOD & 1.1 & 0.1 & 145.0 & 25.6 \\
\hline UZ-44-17 & 12.0 & 50 & 17.6 & 0.9 & BLOD & BLOD & 1.0 & 0.3 & 154.9 & 24.4 \\
\hline UZ-44-18 & 37.4 & 92 & 74.9 & 3.0 & BLOD & BLOD & 1.3 & 0.3 & 113.2 & 13.8 \\
\hline
\end{tabular}




\begin{tabular}{|c|c|c|c|c|c|c|c|c|c|c|}
\hline UZ-44-19 & 15.3 & 30 & 21.1 & 1.3 & BLOD & BLOD & 1.1 & 0.5 & 164.5 & 32.7 \\
\hline UZ-44-20 & 18.7 & 55 & 23.2 & 1.1 & BLOD & BLOD & 1.2 & 0.2 & 182.9 & 27.6 \\
\hline UZ-44-21 & 12.6 & 53 & 11.7 & 0.6 & BLOD & BLOD & 1.1 & 0.2 & 242.5 & 37.4 \\
\hline UZ-44-22 & 14.6 & 45 & 26.0 & 1.1 & BLOD & BLOD & 1.0 & 0.3 & 127.3 & 20.7 \\
\hline UZ-44-23 & 63.4 & 147 & 122.9 & 5.1 & BLOD & BLOD & 1.3 & 0.3 & 116.8 & 12.2 \\
\hline UZ-44-24 & 10.1 & 29 & 14.8 & 0.8 & BLOD & BLOD & 1.0 & 0.2 & 154.1 & 30.8 \\
\hline UZ-44-25 & 15.3 & 64 & 23.7 & 1.6 & BLOD & BLOD & 1.4 & 0.4 & 146.3 & 22.0 \\
\hline UZ-44-26 & 18.7 & 60 & 45.6 & 2.0 & 9000 & 750 & 1.1 & 0.3 & 93.0 & 13.5 \\
\hline UZ-44-27 & 17.9 & 66 & 23.6 & 1.3 & BLOD & BLOD & 1.2 & 0.3 & 172.2 & 24.7 \\
\hline UZ-44-28 & 7.4 & 24 & 33.0 & 70.0 & 2400000 & 2100000 & 0.8 & 0.2 & 50.7 & 108.1 \\
\hline UZ-44-29 & 19.6 & 40 & 24.7 & 1.2 & BLOD & BLOD & 1.2 & 0.2 & 180.2 & 31.1 \\
\hline UZ-44-30 & 45.1 & 73 & 93.0 & 3.6 & BLOD & BLOD & 1.3 & 0.2 & 110.0 & 14.6 \\
\hline UZ-44-31 & 15.8 & 43 & 21.6 & 1.3 & 620 & 340 & 1.4 & 0.2 & 166.0 & 28.4 \\
\hline UZ-44-32 & 9.9 & 32 & 16.4 & 1.1 & BLOD & BLOD & 1.4 & 0.2 & 136.8 & 26.7 \\
\hline UZ-44-33 & 9.3 & 35 & 9.3 & 0.5 & BLOD & BLOD & 1.5 & 0.2 & 226.4 & 41.7 \\
\hline UZ-44-34 & 8.7 & 25 & 12.9 & 0.6 & 800 & 270 & 1.3 & 0.2 & 154.0 & 32.5 \\
\hline UZ-44-35 & 8.4 & 23 & 20.9 & 0.9 & 600 & 290 & 1.6 & 0.2 & 91.3 & 20.0 \\
\hline UZ-44-36 & 10.2 & 55 & 16.8 & 0.8 & BLOD & BLOD & 1.3 & 0.3 & 137.4 & 20.8 \\
\hline UZ-44-37 & 10.9 & 35 & 9.4 & 0.7 & 720 & 320 & 1.1 & 0.2 & 262.7 & 49.9 \\
\hline UZ-44-38 & 17.2 & 42 & 15.1 & 0.9 & BLOD & BLOD & 1.3 & 0.3 & 257.7 & 44.6 \\
\hline UZ-44-39 & 13.3 & 58 & 17.4 & 0.8 & BLOD & BLOD & 1.2 & 0.1 & 173.5 & 25.7 \\
\hline UZ-44-40 & 10.5 & 30 & 9.9 & 0.6 & BLOD & BLOD & 1.1 & 0.2 & 239.2 & 47.4 \\
\hline UZ-44-41 & 7.9 & 25 & 13.0 & 0.8 & BLOD & BLOD & 1.2 & 0.3 & 137.5 & 29.7 \\
\hline UZ-44-42 & 5.5 & 22 & 8.4 & 0.5 & BLOD & BLOD & 0.9 & 0.2 & 149.5 & 33.8 \\
\hline UZ-45-1 & 9.8 & 28 & 14.8 & 0.8 & BLOD & BLOD & 0.9 & 0.2 & 150.1 & 30.3 \\
\hline UZ-45-2 & 22.6 & 29 & 27.3 & 1.9 & BLOD & BLOD & 1.1 & 0.3 & 187.3 & 38.3 \\
\hline UZ-45-3 & 6.1 & 11 & 10.3 & 0.7 & BLOD & BLOD & 1.0 & 0.2 & 133.5 & 41.7 \\
\hline UZ-45-4 & 3.2 & 12 & 6.2 & 0.3 & BLOD & BLOD & 0.9 & 0.1 & 116.4 & 34.6 \\
\hline UZ-45-5 & 11.2 & 22 & 21.4 & 0.8 & BLOD & BLOD & 1.4 & 0.2 & 119.2 & 26.4 \\
\hline UZ-45-6 & 10.4 & 35 & 13.4 & 0.7 & BLOD & BLOD & 1.0 & 0.2 & 174.8 & 32.0 \\
\hline UZ-45-7 & 3.8 & 9 & 9.5 & 0.8 & BLOD & BLOD & 1.1 & 0.1 & 90.2 & 31.2 \\
\hline
\end{tabular}




\begin{tabular}{|c|c|c|c|c|c|c|c|c|c|c|}
\hline UZ-45-8 & 18.3 & 64 & 20.2 & 1.2 & BLOD & BLOD & 1.1 & 0.3 & 205.2 & 30.1 \\
\hline UZ-45-9 & 5.5 & 16 & 9.4 & 0.6 & BLOD & BLOD & 0.7 & 0.3 & 131.7 & 34.4 \\
\hline UZ-45-10 & 5.7 & 14 & 8.1 & 0.4 & BLOD & BLOD & 0.9 & 0.3 & 159.9 & 44.2 \\
\hline UZ-45-11 & 10.1 & 40 & 12.1 & 0.6 & BLOD & BLOD & 1.1 & 0.2 & 188.3 & 32.7 \\
\hline UZ-45-12 & 3.7 & 11 & 8.9 & 0.5 & BLOD & BLOD & 0.6 & 0.2 & 94.3 & 29.2 \\
\hline UZ-45-13 & 7.6 & 28 & 6.3 & 0.4 & BLOD & BLOD & 1.2 & 0.3 & 275.5 & 56.2 \\
\hline UZ-45-14 & 4.5 & 11 & 12.9 & 0.8 & BLOD & BLOD & 0.5 & 0.1 & 79.4 & 24.7 \\
\hline UZ-45-15 & 5.0 & 22 & 9.3 & 0.4 & BLOD & BLOD & 1.1 & 0.1 & 122.0 & 27.3 \\
\hline UZ-45-16 & 16.1 & 44 & 31.1 & 1.4 & BLOD & BLOD & 1.1 & 0.2 & 117.0 & 19.3 \\
\hline UZ-45-17 & 9.3 & 46 & 16.5 & 0.8 & BLOD & BLOD & 1.0 & 0.3 & 128.1 & 21.0 \\
\hline UZ-45-18 & 8.7 & 34 & 9.6 & 0.6 & BLOD & BLOD & 1.0 & 0.2 & 204.7 & 38.9 \\
\hline UZ-45-19 & 8.0 & 29 & 12.1 & 0.8 & BLOD & BLOD & 0.9 & 0.1 & 149.8 & 30.3 \\
\hline UZ-45-20 & 10.9 & 24 & 15.9 & 0.9 & BLOD & BLOD & 1.1 & 0.5 & 155.5 & 33.7 \\
\hline UZ-45-21 & 7.0 & 29 & 9.4 & 0.6 & BLOD & BLOD & 1.0 & 0.3 & 169.1 & 34.0 \\
\hline UZ-45-22 & 5.2 & 22 & 5.6 & 0.3 & BLOD & BLOD & 1.3 & 0.1 & 209.1 & 46.8 \\
\hline UZ-45-23 & 4.1 & 14 & 5.3 & 0.3 & BLOD & BLOD & 1.0 & 0.1 & 174.8 & 48.3 \\
\hline UZ-45-24 & 10.9 & 33 & 10.3 & 0.6 & BLOD & BLOD & 1.1 & 0.2 & 239.8 & 45.7 \\
\hline UZ-45-25 & 8.7 & 28 & 10.2 & 0.5 & BLOD & BLOD & 1.3 & 0.3 & 193.7 & 38.9 \\
\hline UZ-45-26 & 4.0 & 16 & 7.7 & 0.4 & BLOD & BLOD & 1.1 & 0.3 & 116.5 & 30.3 \\
\hline UZ-45-27 & 6.4 & 22 & 7.7 & 0.4 & BLOD & BLOD & 0.8 & 0.2 & 190.1 & 42.6 \\
\hline UZ-45-28 & 3.7 & 21 & 8.4 & 0.4 & BLOD & BLOD & 1.6 & 0.3 & 100.0 & 22.8 \\
\hline UZ-45-29 & 8.1 & 31 & 12.2 & 0.6 & BLOD & BLOD & 1.1 & 0.3 & 151.7 & 29.3 \\
\hline UZ-45-30 & 10.1 & 35 & 15.4 & 0.8 & BLOD & BLOD & 1.0 & 0.2 & 148.1 & 27.2 \\
\hline UZ-45-31 & 9.4 & 20 & 9.0 & 0.7 & BLOD & BLOD & 1.0 & 0.3 & 237.6 & 57.8 \\
\hline UZ-45-32 & 6.9 & 29 & 9.7 & 0.5 & BLOD & BLOD & 1.6 & 0.2 & 162.1 & 32.4 \\
\hline UZ-45-33 & 4.0 & 18 & 7.0 & 0.4 & BLOD & BLOD & 1.0 & 0.1 & 128.1 & 31.8 \\
\hline UZ-45-34 & 6.7 & 22 & 9.0 & 0.5 & BLOD & BLOD & 0.7 & 0.2 & 166.9 & 37.7 \\
\hline UZ-45-35 & 10.6 & 34 & 14.4 & 0.8 & BLOD & BLOD & 1.0 & 0.2 & 167.7 & 31.2 \\
\hline UZ-45-36 & 2.8 & 13 & 5.3 & 0.3 & BLOD & BLOD & 1.1 & 0.1 & 117.1 & 33.5 \\
\hline UZ-45-37 & 16.6 & 70 & 54.8 & 2.5 & BLOD & BLOD & 1.3 & 0.2 & 68.4 & 9.4 \\
\hline UZ-45-38 & 6.9 & 17 & 8.5 & 0.4 & BLOD & BLOD & 1.5 & 0.2 & 183.9 & 46.3 \\
\hline
\end{tabular}




\begin{tabular}{|c|c|c|c|c|c|c|c|c|c|c|}
\hline UZ-45-39 & 8.8 & 36 & 9.6 & 0.6 & BLOD & BLOD & 0.6 & 0.1 & 207.5 & 38.1 \\
\hline UZ-45-40 & 2.4 & 8 & 4.9 & 0.3 & BLOD & BLOD & 0.9 & 0.1 & 112.2 & 40.5 \\
\hline UZ-45-41 & 3.8 & 15 & 7.6 & 0.4 & BLOD & BLOD & 1.1 & 0.2 & 113.2 & 30.3 \\
\hline UZ-45-42 & 9.8 & 28 & 14.8 & 0.8 & BLOD & BLOD & 0.9 & 0.2 & 150.1 & 30.3 \\
\hline UZ-48-1 & 2.9 & 5 & 4.3 & 0.3 & 19800 & 3200 & 1.8 & 0.5 & 113.9 & 51.8 \\
\hline UZ-48-2 & 6.4 & 11 & 5.6 & 0.4 & 20900 & 5200 & 1.6 & 0.5 & 197.9 & 61.6 \\
\hline UZ-48-3 & 5.6 & 11 & 4.3 & 0.3 & 17400 & 4600 & 2.1 & 0.2 & 226.8 & 70.3 \\
\hline UZ-48-4 & 4.0 & 7 & 6.0 & 0.5 & 4700 & 1700 & 1.1 & 0.4 & 115.0 & 44.6 \\
\hline UZ-48-5 & 16.3 & 47 & 11.6 & 0.4 & BLOD & BLOD & 1.7 & 0.3 & 241.5 & 37.5 \\
\hline UZ-48-6 & 4.2 & 6 & 6.2 & 0.5 & 38400 & 8900 & 3.1 & 0.6 & 116.6 & 48.8 \\
\hline UZ-48-7 & 0.7 & 1 & 4.4 & 0.4 & 3700 & 2200 & 2.3 & 0.5 & 25.6 & 25.7 \\
\hline UZ-48-8 & 4.0 & 7 & 4.9 & 0.2 & 1460 & 400 & 3.3 & 1.1 & 138.0 & 52.8 \\
\hline UZ-48-9 & 3.2 & 6 & 7.2 & 0.4 & 3410 & 550 & 1.4 & 0.4 & 76.1 & 31.5 \\
\hline UZ-48-10 & 5.3 & 7 & 6.9 & 0.4 & 1230 & 220 & 1.2 & 0.3 & 130.6 & 50.2 \\
\hline UZ-48-11 & 3.2 & 4 & 6.5 & 0.3 & 1200 & 210 & 1.3 & 0.3 & 83.3 & 41.9 \\
\hline UZ-48-12 & 26.5 & 49 & 36.6 & 1.5 & 550 & 190 & 2.0 & 0.5 & 124.8 & 19.2 \\
\hline UZ-48-13 & 7.1 & 14 & 7.5 & 0.4 & BLOD & BLOD & 1.3 & 0.8 & 163.8 & 45.1 \\
\hline UZ-48-14 & 6.3 & 10 & 6.3 & 0.3 & 1000 & 220 & 2.7 & 1.1 & 172.3 & 55.5 \\
\hline UZ-48-15 & 1.0 & 2 & 6.0 & 0.3 & 2540 & 400 & 1.5 & 0.5 & 28.9 & 20.5 \\
\hline UZ-48-16 & 4.0 & 18 & 7.1 & 0.3 & 1330 & 240 & 1.4 & 0.1 & 96.4 & 23.5 \\
\hline UZ-48-17 & 2.4 & 5 & 6.0 & 0.3 & 1010 & 200 & 1.3 & 0.3 & 69.1 & 31.2 \\
\hline UZ-48-18 & 3.0 & 4 & 5.9 & 0.3 & 1270 & 230 & 1.5 & 0.3 & 88.0 & 44.3 \\
\hline UZ-48-19 & 3.1 & 6 & 6.4 & 0.3 & 1130 & 240 & 1.2 & 0.1 & 82.8 & 34.2 \\
\hline UZ-48-20 & 2.5 & 3 & 5.3 & 0.3 & 1190 & 240 & 1.3 & 0.2 & 80.9 & 47.0 \\
\hline UZ-48-21 & 35.4 & 89 & 48.8 & 2.2 & BLOD & BLOD & 1.5 & 0.6 & 124.9 & 15.3 \\
\hline UZ-48-22 & 30.1 & 62 & 31.7 & 1.3 & 3940 & 390 & 1.6 & 0.5 & 163.5 & 22.8 \\
\hline UZ-48-23 & 4.4 & 9 & 5.9 & 0.4 & 18700 & 4800 & 1.4 & 0.3 & 127.1 & 43.5 \\
\hline UZ-48-24 & 3.7 & 13 & 6.7 & 0.3 & 1300 & 260 & 1.2 & 0.3 & 93.8 & 26.6 \\
\hline UZ-48-25 & 2.8 & 7 & 3.8 & 0.2 & 1660 & 510 & 1.1 & 0.1 & 126.7 & 48.8 \\
\hline UZ-48-26 & 7.6 & 32 & 5.7 & 0.2 & 2110 & 300 & 1.5 & 0.2 & 229.3 & 42.6 \\
\hline UZ-48-27 & 5.8 & 16 & 4.6 & 0.3 & 1360 & 310 & 1.4 & 0.3 & 216.5 & 56.5 \\
\hline
\end{tabular}




\begin{tabular}{|c|c|c|c|c|c|c|c|c|c|c|}
\hline UZ-48-28 & 3.8 & 10 & 5.5 & 0.3 & 1410 & 320 & 1.5 & 0.1 & 117.6 & 38.0 \\
\hline UZ-48-29 & 1.9 & 3 & 5.1 & 0.3 & 1570 & 320 & 1.5 & 0.3 & 63.9 & 37.2 \\
\hline UZ-48-30 & 2.9 & 7 & 6.3 & 0.4 & 1320 & 360 & 1.6 & 0.1 & 80.0 & 30.8 \\
\hline UZ-48-31 & 2.2 & 4 & 3.1 & 0.2 & 1440 & 260 & 1.1 & 0.1 & 118.9 & 60.0 \\
\hline UZ-48-32 & 1.5 & 3 & 3.7 & 0.3 & 6100 & 2300 & 1.1 & 0.2 & 68.5 & 39.9 \\
\hline UZ-48-33 & 1.7 & 5 & 3.4 & 0.2 & 2000 & 430 & 1.0 & 0.1 & 85.6 & 38.8 \\
\hline UZ-48-34 & 5.1 & 12 & 3.9 & 0.2 & 2060 & 610 & 1.4 & 0.1 & 220.9 & 65.4 \\
\hline UZ-49-1 & 47.0 & 130 & 80.3 & 3.5 & BLOD & BLOD & 1.4 & 0.2 & 128.2 & 13.9 \\
\hline UZ-49-2 & 16.7 & 22 & 32.1 & 1.5 & BLOD & BLOD & 1.2 & 0.2 & 113.8 & 25.4 \\
\hline UZ-49-3 & 22.4 & 49 & 48.7 & 2.9 & BLOD & BLOD & 0.9 & 0.4 & 100.5 & 16.3 \\
\hline UZ-49-4 & 37.5 & 91 & 60.3 & 2.8 & BLOD & BLOD & 1.4 & 0.3 & 136.0 & 16.8 \\
\hline UZ-49-5 & 18.6 & 35 & 36.6 & 2.3 & 1350 & 460 & 1.1 & 0.3 & 111.3 & 20.7 \\
\hline UZ-49-6 & 51.6 & 125 & 80.3 & 4.7 & 5600 & 2300 & 1.5 & 0.5 & 140.7 & 16.4 \\
\hline UZ-49-7 & 41.9 & 152 & 81.4 & 3.6 & BLOD & BLOD & 1.4 & 0.5 & 112.7 & 11.7 \\
\hline UZ-49-8 & 13.0 & 33 & 25.4 & 1.1 & BLOD & BLOD & 1.1 & 0.3 & 111.6 & 20.7 \\
\hline UZ-49-9 & 38.8 & 137 & 88.8 & 7.2 & BLOD & BLOD & 1.6 & 0.5 & 95.6 & 12.1 \\
\hline UZ-49-10 & 39.3 & 110 & 63.1 & 4.8 & BLOD & BLOD & 1.5 & 0.3 & 136.3 & 17.8 \\
\hline UZ-49-11 & 23.6 & 72 & 53.2 & 2.5 & BLOD & BLOD & 1.2 & 0.4 & 97.3 & 13.1 \\
\hline UZ-49-12 & 43.8 & 158 & 74.5 & 3.8 & 700 & 320 & 1.5 & 0.4 & 128.6 & 13.6 \\
\hline UZ-49-13 & 22.8 & 56 & 21.0 & 1.1 & BLOD & BLOD & 1.4 & 0.5 & 237.1 & 35.8 \\
\hline UZ-49-14 & 16.6 & 26 & 33.2 & 1.4 & 1030 & 440 & 1.2 & 0.2 & 109.7 & 22.6 \\
\hline UZ-49-15 & 39.0 & 118 & 65.5 & 3.1 & BLOD & BLOD & 1.2 & 0.4 & 130.2 & 14.8 \\
\hline UZ-49-16 & 12.2 & 35 & 20.9 & 1.4 & BLOD & BLOD & 1.2 & 0.4 & 127.5 & 23.9 \\
\hline UZ-49-17 & 46.1 & 114 & 69.3 & 7.1 & 7900 & 1900 & 1.2 & 0.3 & 145.4 & 21.3 \\
\hline UZ-49-18 & 29.7 & 121 & 47.8 & 1.4 & BLOD & BLOD & 1.3 & 0.3 & 136.0 & 14.5 \\
\hline UZ-49-19 & 47.9 & 119 & 78.7 & 4.5 & 710 & 280 & 1.3 & 0.3 & 133.1 & 15.7 \\
\hline UZ-49-20 & 23.2 & 83 & 32.5 & 1.5 & BLOD & BLOD & 1.3 & 0.3 & 156.2 & 20.0 \\
\hline UZ-49-21 & 30.0 & 76 & 46.8 & 3.3 & BLOD & BLOD & 1.3 & 0.3 & 140.1 & 20.0 \\
\hline UZ-49-22 & 36.3 & 117 & 91.1 & 6.1 & BLOD & BLOD & 1.3 & 0.4 & 87.3 & 10.8 \\
\hline UZ-49-23 & 44.6 & 177 & 52.8 & 2.7 & BLOD & BLOD & 1.4 & 0.4 & 184.9 & 18.9 \\
\hline UZ-49-24 & 27.8 & 91 & 30.5 & 1.6 & BLOD & BLOD & 1.2 & 0.2 & 199.4 & 25.1 \\
\hline
\end{tabular}




\begin{tabular}{|c|c|c|c|c|c|c|c|c|c|c|}
\hline UZ-49-25 & 30.4 & 121 & 56.6 & 3.9 & BLOD & BLOD & 1.4 & 0.4 & 117.5 & 14.5 \\
\hline UZ-49-26 & 18.0 & 30 & 31.0 & 1.7 & BLOD & BLOD & 1.3 & 0.2 & 127.2 & 25.0 \\
\hline UZ-49-27 & 21.4 & 56 & 42.2 & 2.1 & BLOD & BLOD & 1.3 & 0.4 & 110.9 & 16.6 \\
\hline UZ-49-28 & 50.5 & 151 & 71.5 & 5.8 & 700 & 330 & 1.3 & 0.3 & 154.5 & 19.2 \\
\hline UZ-49-29 & 25.1 & 48 & 37.7 & 1.8 & BLOD & BLOD & 1.3 & 0.2 & 145.8 & 23.2 \\
\hline UZ-49-30 & 31.9 & 71 & 56.3 & 3.1 & BLOD & BLOD & 1.6 & 0.5 & 124.1 & 17.2 \\
\hline UZ-49-31 & 39.6 & 87 & 83.5 & 3.5 & BLOD & BLOD & 1.5 & 0.5 & 103.9 & 12.9 \\
\hline UZ-49-32 & 23.6 & 67 & 34.4 & 1.5 & 1470 & 510 & 1.6 & 0.3 & 150.0 & 20.7 \\
\hline UZ-49-33 & 38.3 & 97 & 63.4 & 2.3 & 660 & 320 & 1.3 & 0.2 & 132.1 & 15.5 \\
\hline UZ-49-34 & 20.9 & 69 & 29.7 & 1.2 & BLOD & BLOD & 1.3 & 0.4 & 154.0 & 20.8 \\
\hline UZ-49-35 & 58.0 & 112 & 107.1 & 5.7 & BLOD & BLOD & 1.3 & 0.3 & 118.5 & 14.0 \\
\hline UZ-49-36 & 36.5 & 70 & 66.2 & 4.5 & BLOD & BLOD & 1.3 & 0.2 & 120.8 & 17.5 \\
\hline UZ-50-1 & 26.2 & 125 & 45.8 & 2.0 & 930 & 290 & 1.6 & 0.5 & 125.1 & 13.7 \\
\hline UZ-50-2 & 46.6 & 145 & 69.9 & 3.0 & 2790 & 370 & 1.8 & 0.5 & 145.9 & 15.2 \\
\hline UZ-50-3 & 40.1 & 207 & 62.3 & 2.5 & 1010 & 260 & 1.5 & 0.3 & 140.7 & 13.1 \\
\hline UZ-50-4 & 31.8 & 99 & 39.2 & 1.4 & 1890 & 350 & 1.6 & 0.4 & 177.4 & 20.7 \\
\hline UZ-50-5 & 20.0 & 69 & 451.0 & 26.0 & 2540 & 690 & 1.7 & 0.3 & 9.7 & 1.4 \\
\hline UZ-50-6 & 12.8 & 37 & 12.7 & 1.1 & 700 & 430 & 1.1 & 0.3 & 220.6 & 42.3 \\
\hline UZ-50-7 & 26.3 & 119 & 32.5 & 1.5 & 1290 & 360 & 1.6 & 0.4 & 177.2 & 20.0 \\
\hline UZ-50-8 & 24.8 & 62 & 35.3 & 1.6 & 2300 & 360 & 1.7 & 0.5 & 153.9 & 22.0 \\
\hline UZ-50-9 & 22.9 & 90 & 27.3 & 1.7 & 1120 & 360 & 1.5 & 0.3 & 183.3 & 24.0 \\
\hline UZ-50-10 & 33.2 & 63 & 56.4 & 2.3 & 1040 & 390 & 1.6 & 0.4 & 128.9 & 18.1 \\
\hline UZ-50-11 & 37.2 & 172 & 70.8 & 5.7 & 1600 & 400 & 1.6 & 0.3 & 115.0 & 13.8 \\
\hline UZ-50-12 & 40.2 & 109 & 53.1 & 3.9 & 2600 & 420 & 1.6 & 0.4 & 165.7 & 21.4 \\
\hline UZ-50-13 & 34.1 & 64 & 76.9 & 2.9 & 1620 & 350 & 1.9 & 0.6 & 97.1 & 13.5 \\
\hline UZ-50-14 & 24.1 & 105 & 55.8 & 3.1 & 1170 & 420 & 1.4 & 0.2 & 94.5 & 11.5 \\
\hline UZ-50-15 & 25.3 & 124 & 38.5 & 1.3 & 1100 & 270 & 1.7 & 0.3 & 143.7 & 15.3 \\
\hline UZ-50-16 & 66.9 & 191 & 136.7 & 5.5 & 1030 & 300 & 1.7 & 0.5 & 107.1 & 10.2 \\
\hline UZ-50-17 & 39.1 & 102 & 52.2 & 3.0 & 2750 & 460 & 1.6 & 0.3 & 164.1 & 20.3 \\
\hline UZ-50-18 & 52.6 & 141 & 62.9 & 3.1 & 2700 & 470 & 1.6 & 0.4 & 183.1 & 19.8 \\
\hline UZ-50-19 & 35.5 & 144 & 75.7 & 3.1 & 760 & 270 & 1.8 & 0.5 & 102.6 & 10.7 \\
\hline
\end{tabular}




\begin{tabular}{|c|c|c|c|c|c|c|c|c|c|c|} 
UZ-50-20 & 29.5 & 72 & 37.9 & 1.6 & 2230 & 320 & 1.4 & 0.2 & 170.5 & 22.8 \\
UZ-50-21 & 25.5 & 55 & 118.0 & 11.0 & 2990 & 580 & 1.6 & 0.4 & 47.3 & 8.1 \\
UZ-50-22 & 36.0 & 73 & 58.1 & 3.6 & 2210 & 460 & 1.5 & 0.2 & 135.7 & 19.1 \\
UZ-50-23 & 35.2 & 73 & 73.4 & 2.9 & 1260 & 520 & 1.8 & 0.5 & 104.8 & 13.8 \\
UZ-50-24 & 52.8 & 164 & 73.6 & 3.0 & 2240 & 400 & 1.6 & 0.4 & 156.9 & 15.6 \\
UZ-50-25 & 45.4 & 108 & 110.1 & 4.1 & 1610 & 420 & 1.7 & 0.4 & 90.2 & 10.2 \\
UZ-50-26 & 45.3 & 101 & 88.9 & 5.1 & 1060 & 310 & 1.5 & 0.4 & 111.6 & 13.8 \\
UZ-50-27 & 28.1 & 97 & 34.0 & 1.8 & 670 & 330 & 1.6 & 0.3 & 181.0 & 22.4 \\
UZ-50-28 & 57.7 & 166 & 72.2 & 3.7 & 720 & 290 & 1.6 & 0.4 & 174.9 & 18.2 \\
UZ-50-29 & 32.7 & 110 & 36.0 & 1.9 & 2110 & 420 & 1.9 & 0.7 & 198.8 & 23.6 \\
\hline
\end{tabular}




\subsection{Supplementary File 2}

1 Single grain apatite fission track data for samples taken from the Kyzylkum-Nurata segment plotted using Vermeesch (2009). Single grain ages are coloured according to their respective uranium 238 (U) measurements.

\section{Bukantau Radial Plots}
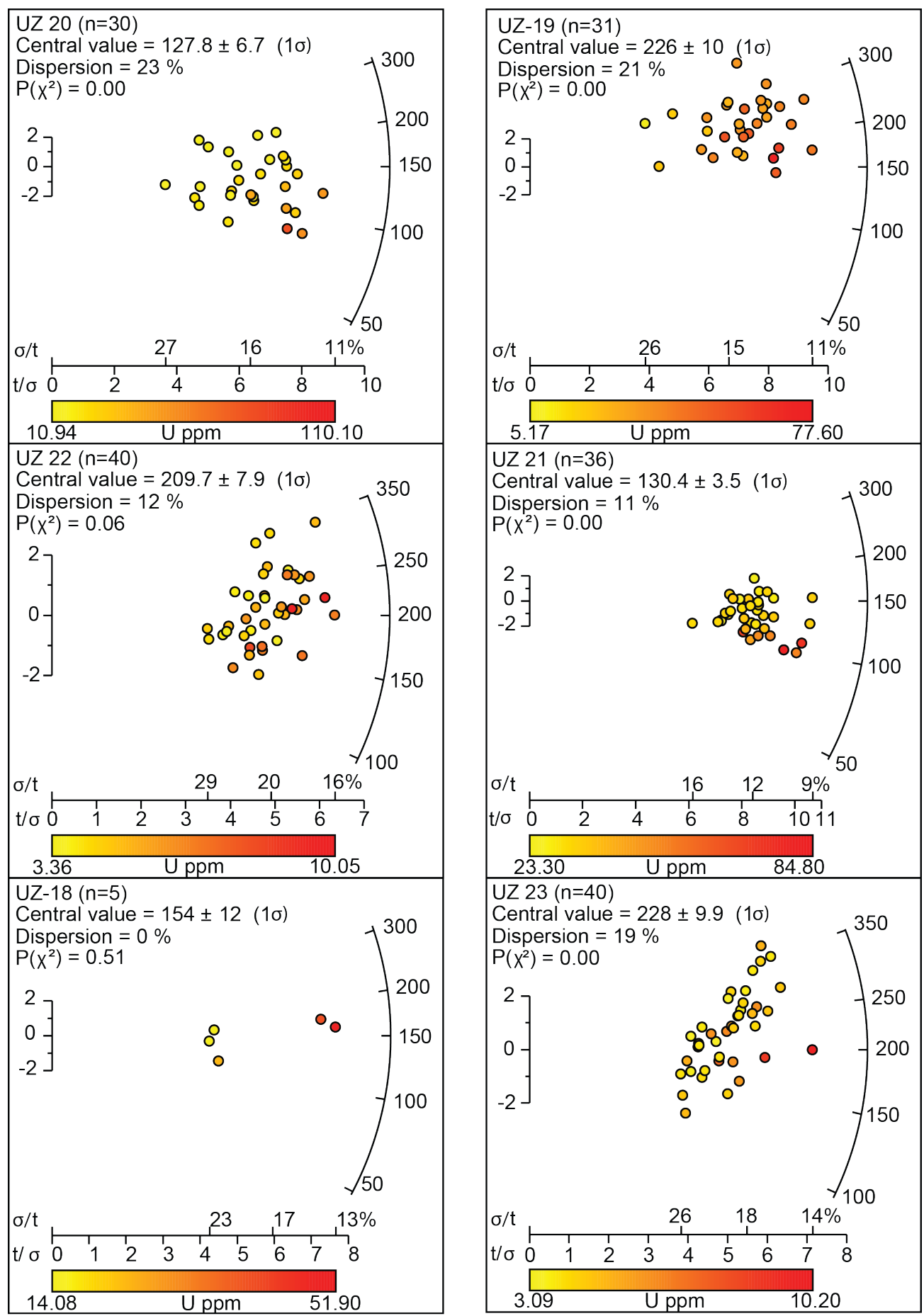
Kuldjuktau Radial Plots_1
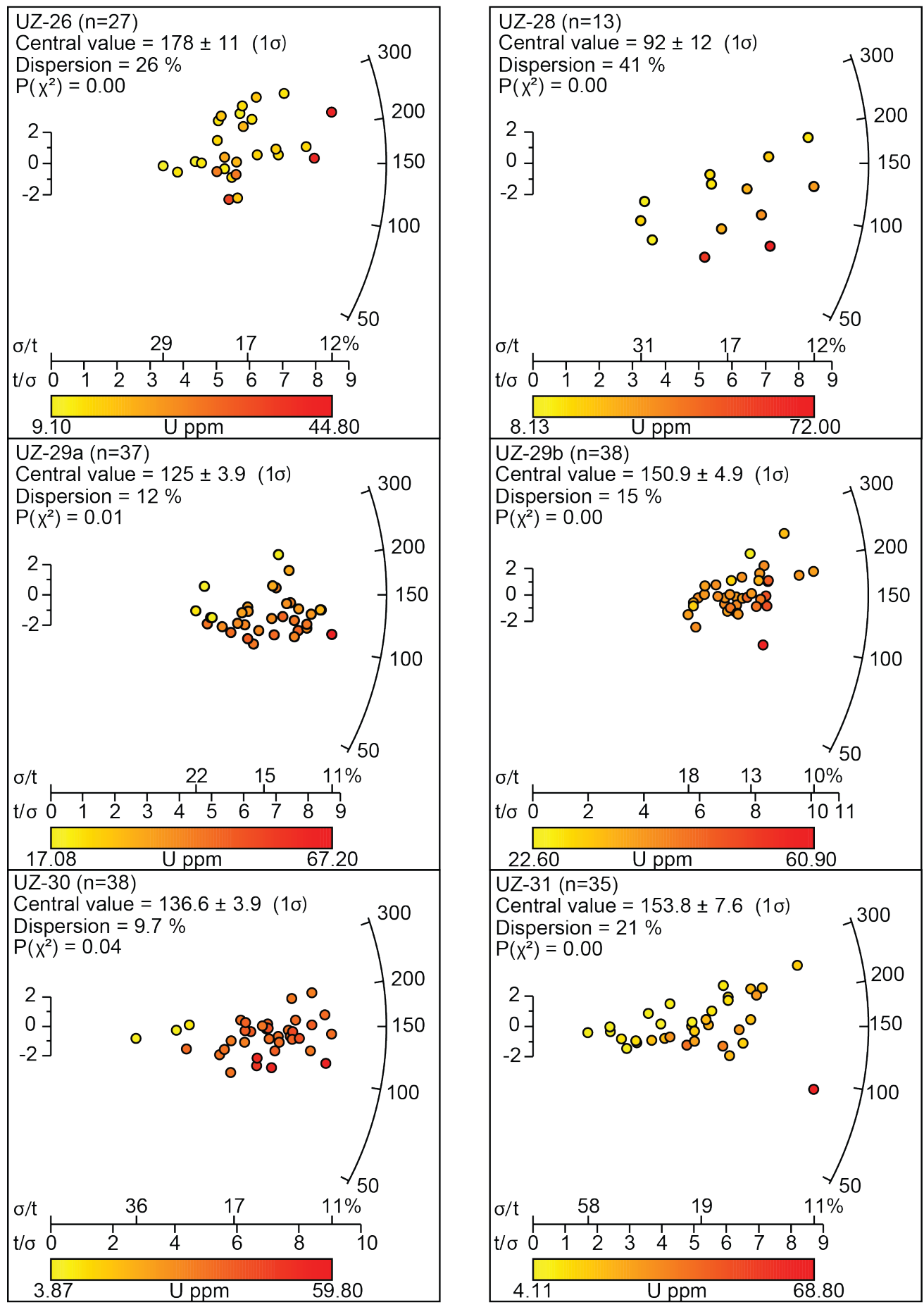
Kuldjuktau Radial Plot_2

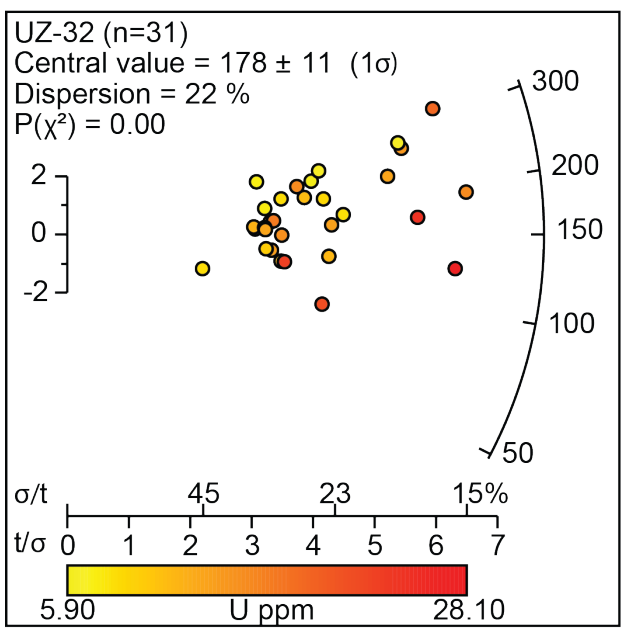


Northern Nurata Radial Plots_1
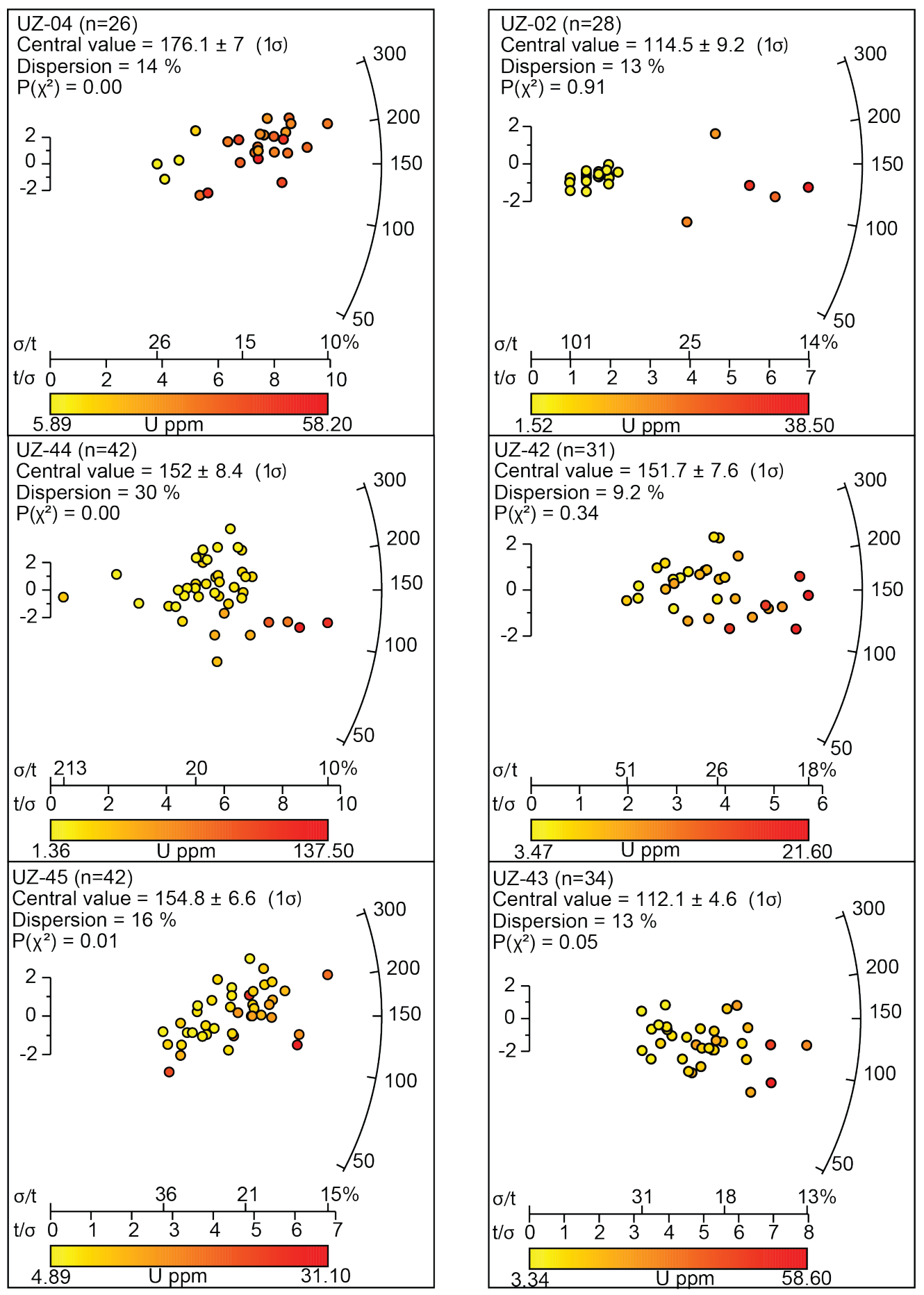
South Nurata Range
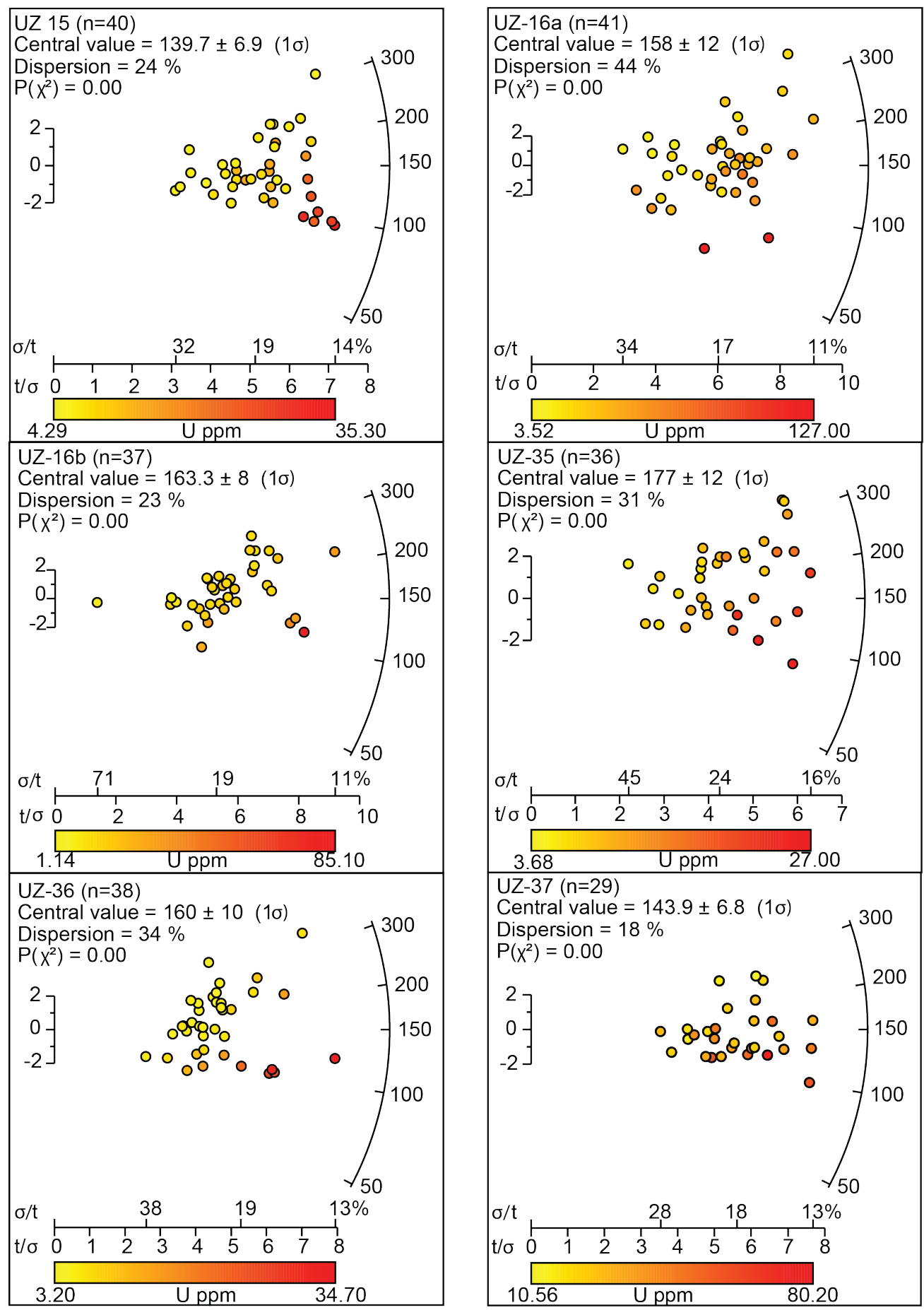
South Nurata Range_2

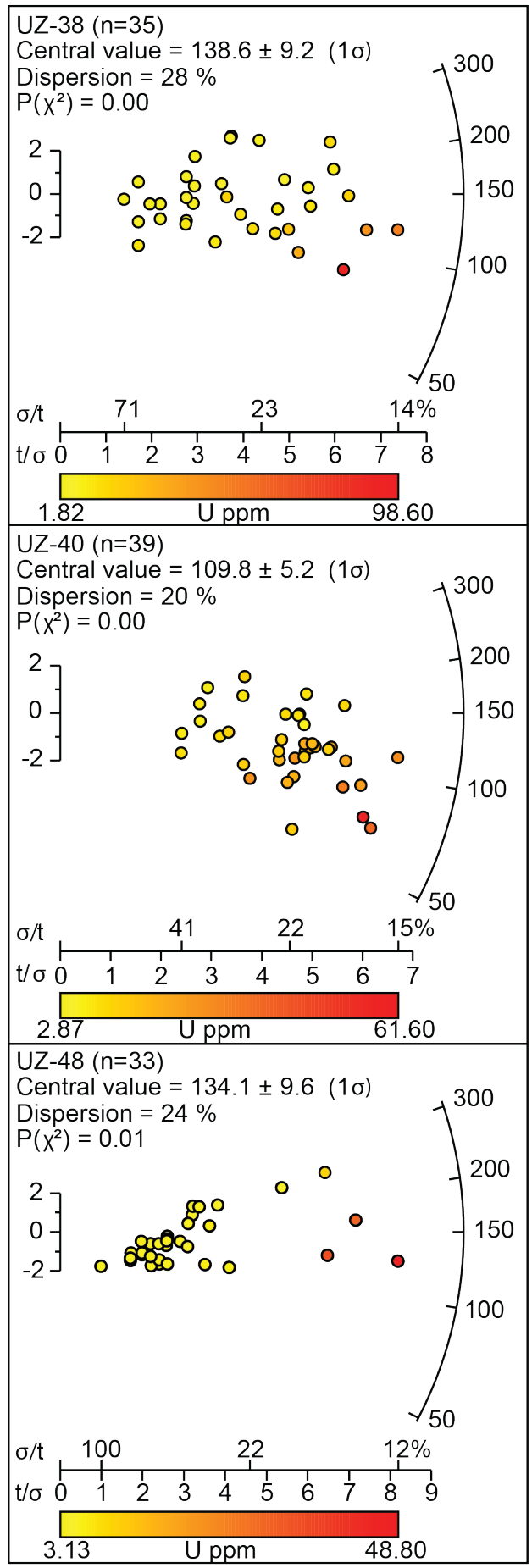

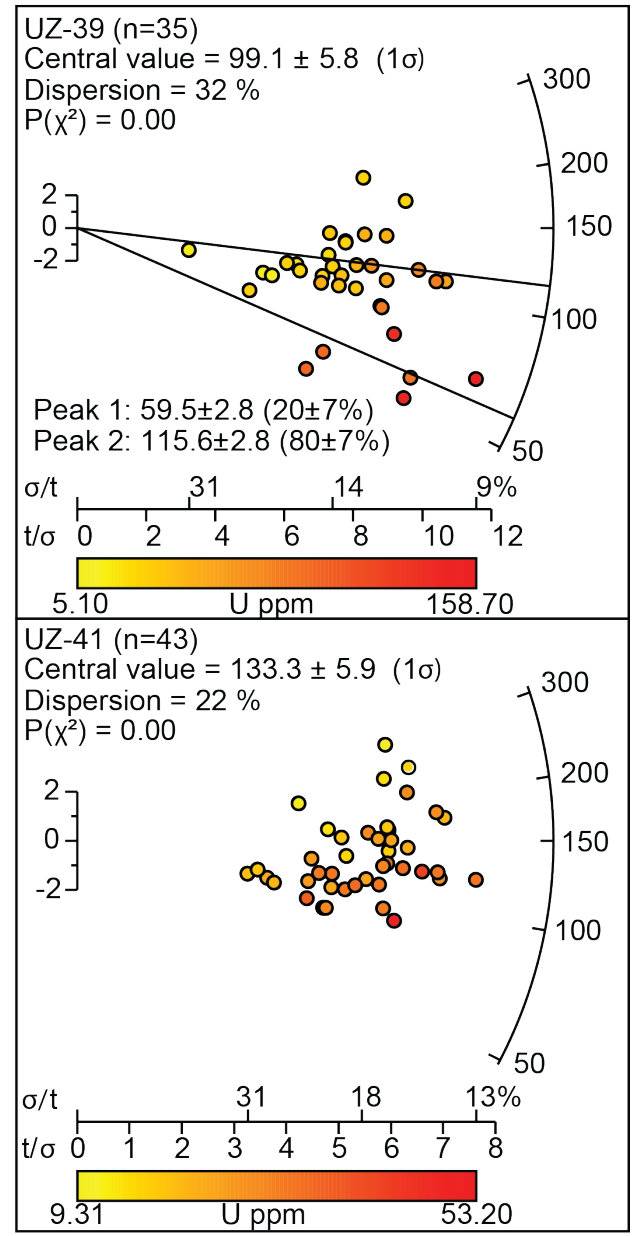


Karatyube Massif Radial Plots_1

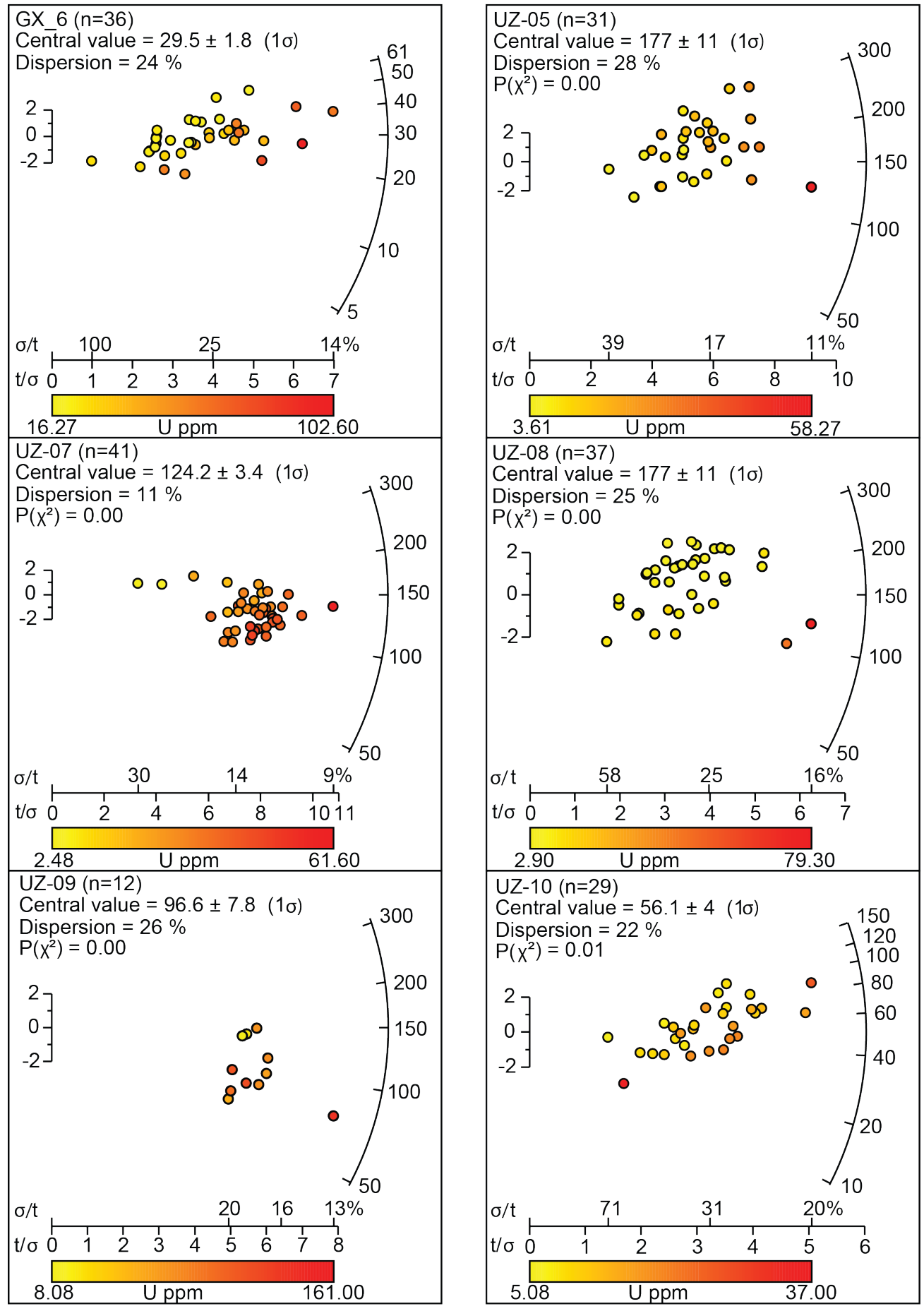


8

Karatyube Massif Radial Plots_2

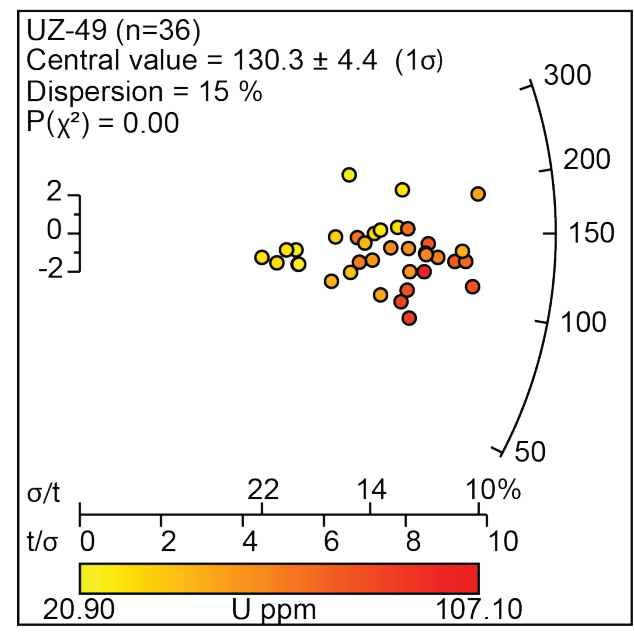




\section{Ziadin Mountains Radial Plots}
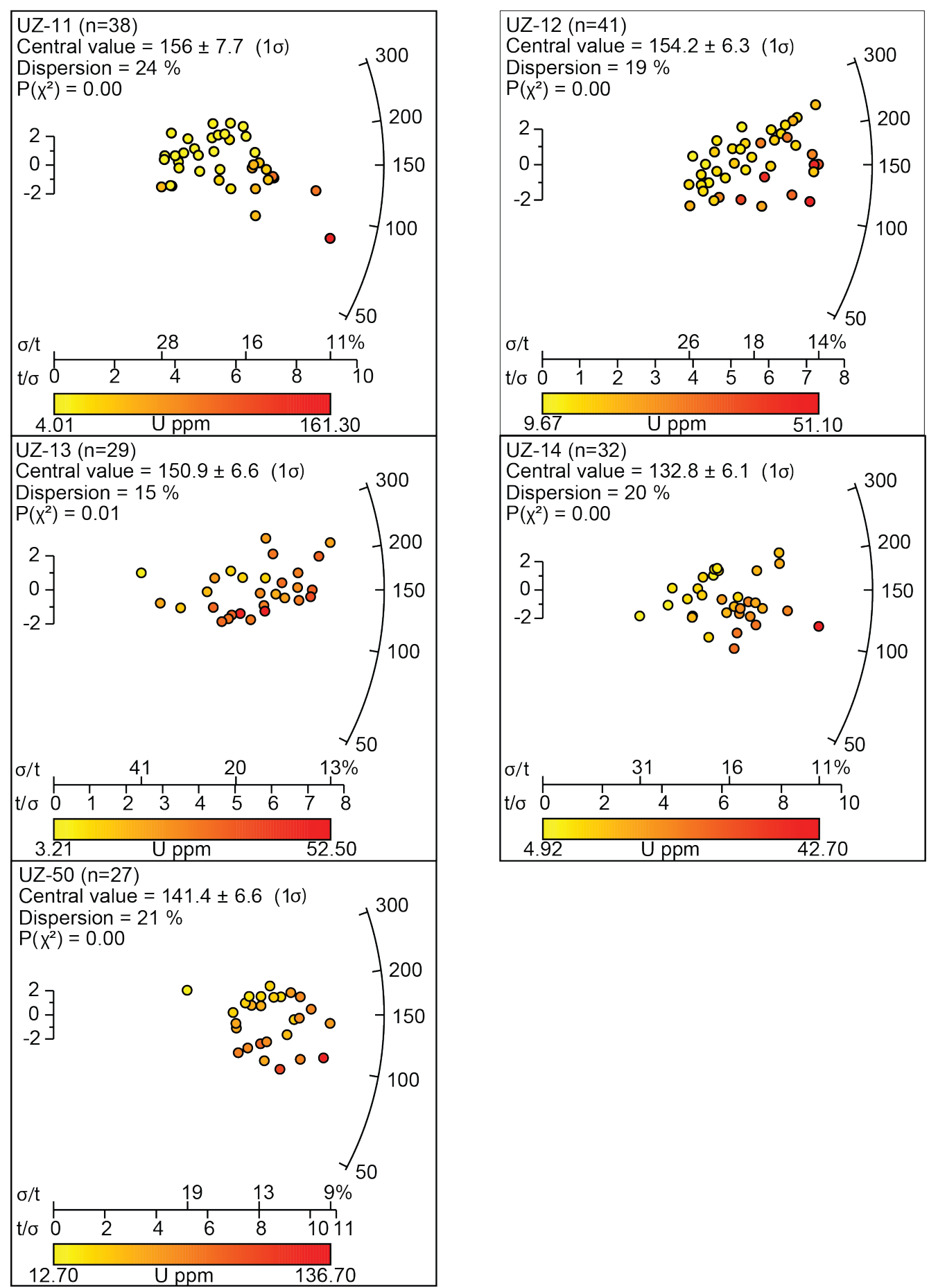


\section{Aydar Radial Plots}
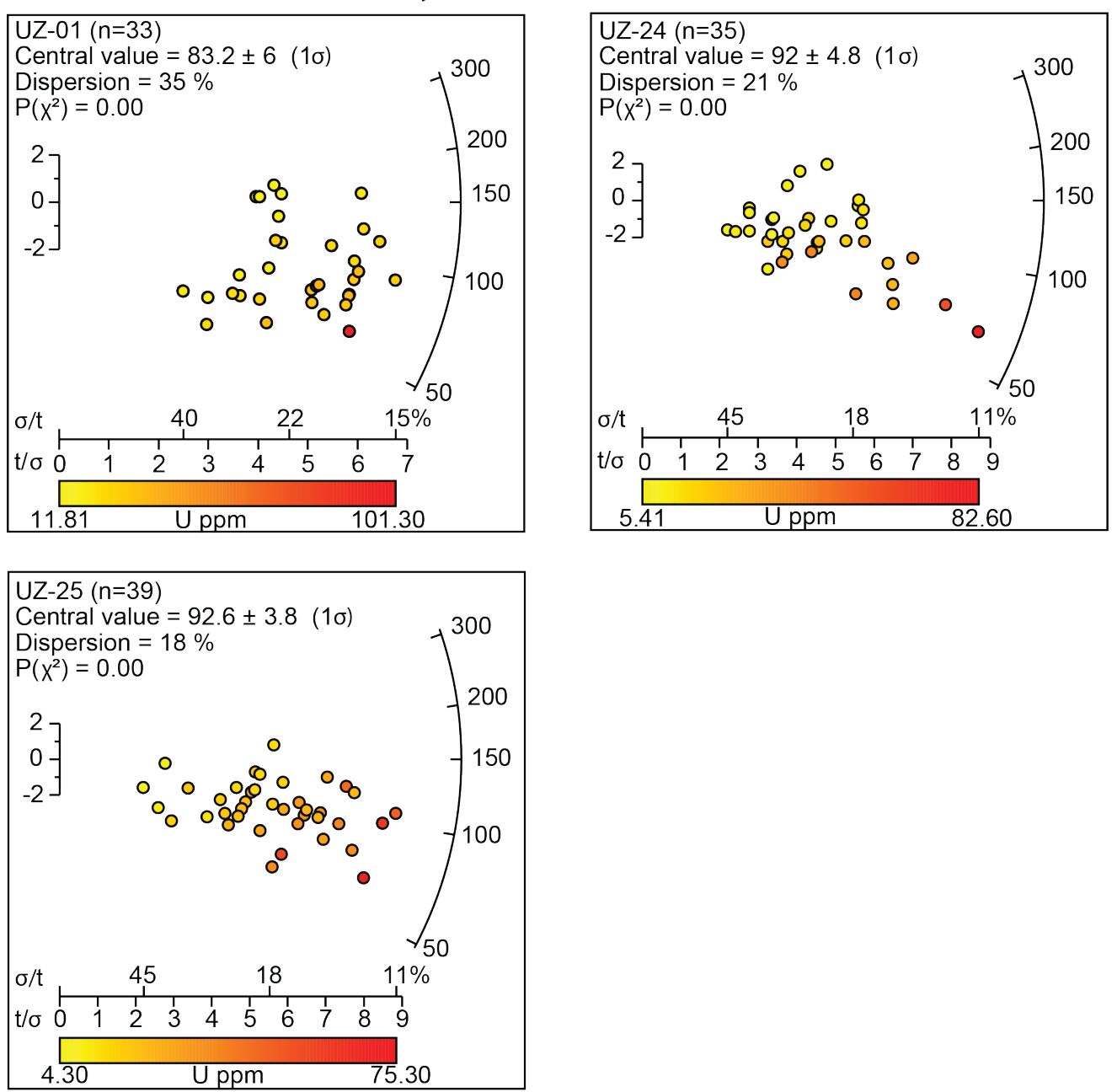


\subsection{Supplementary File 3}

1 Individual time-temperature plots for each sample modelled using Gallagher (2012). For modelling parameters see Supplementary File 5

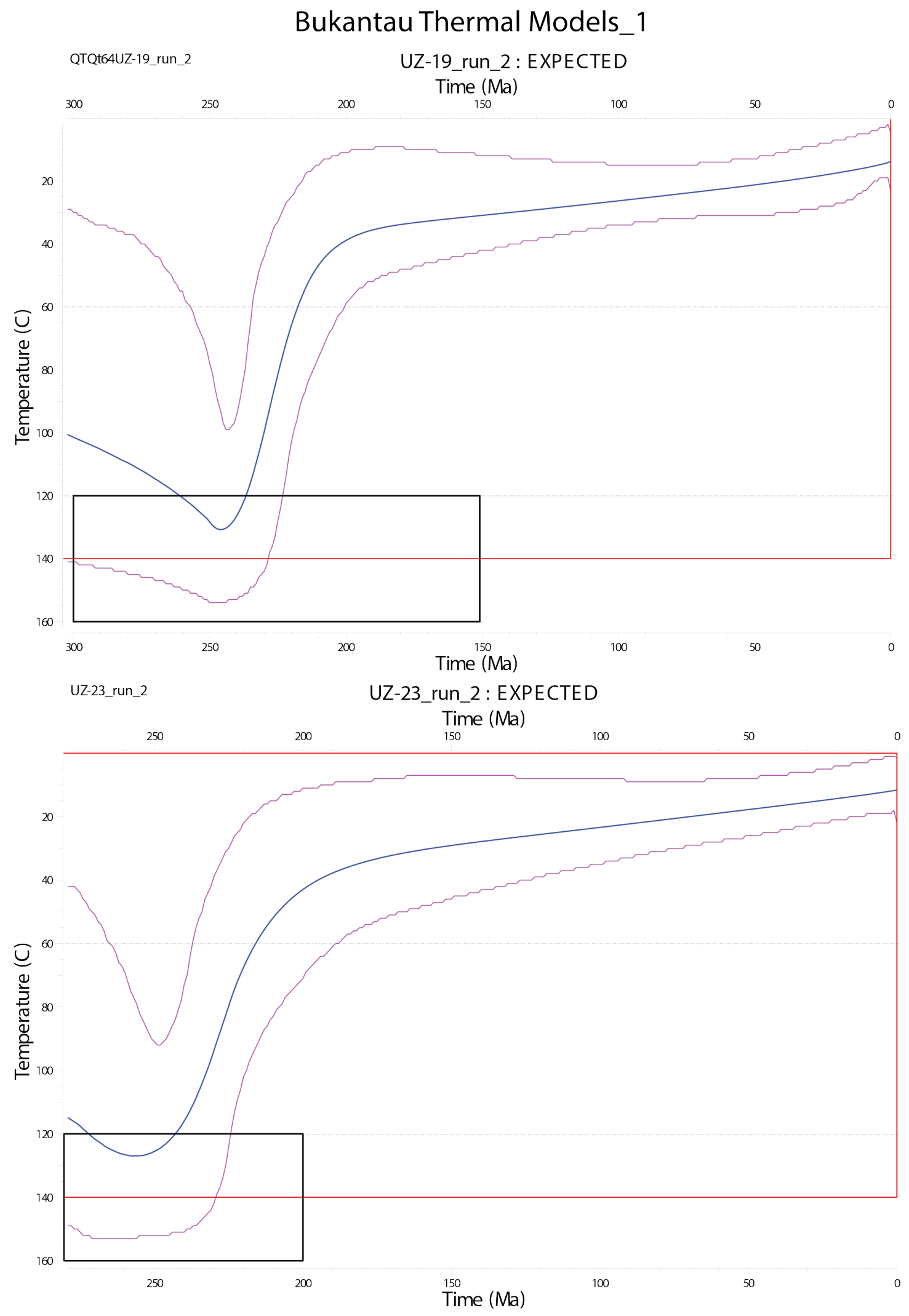



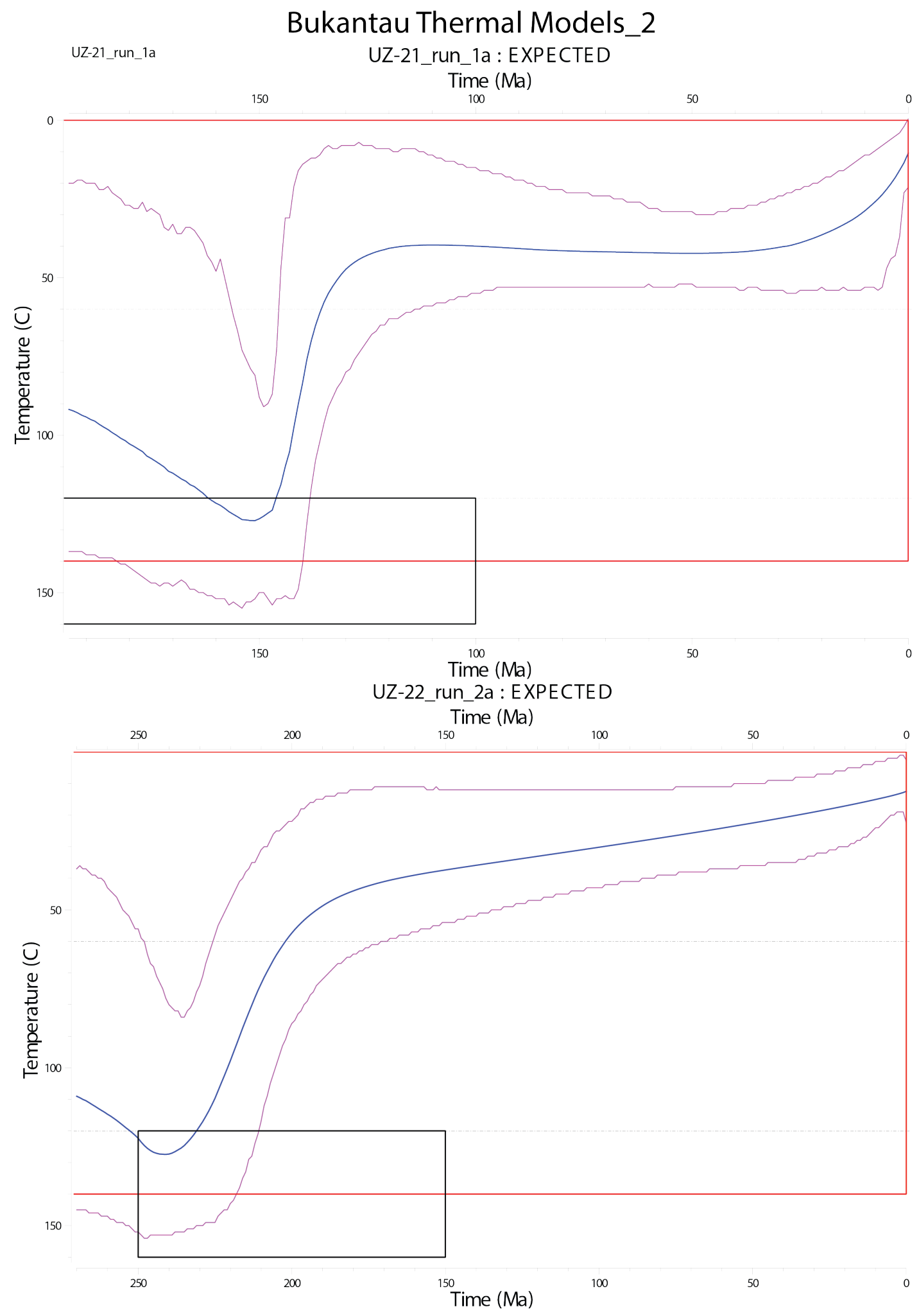
3

\section{Bukantau Thermal Models-3}

\section{UZ-20_run_2a : EXPECTED}

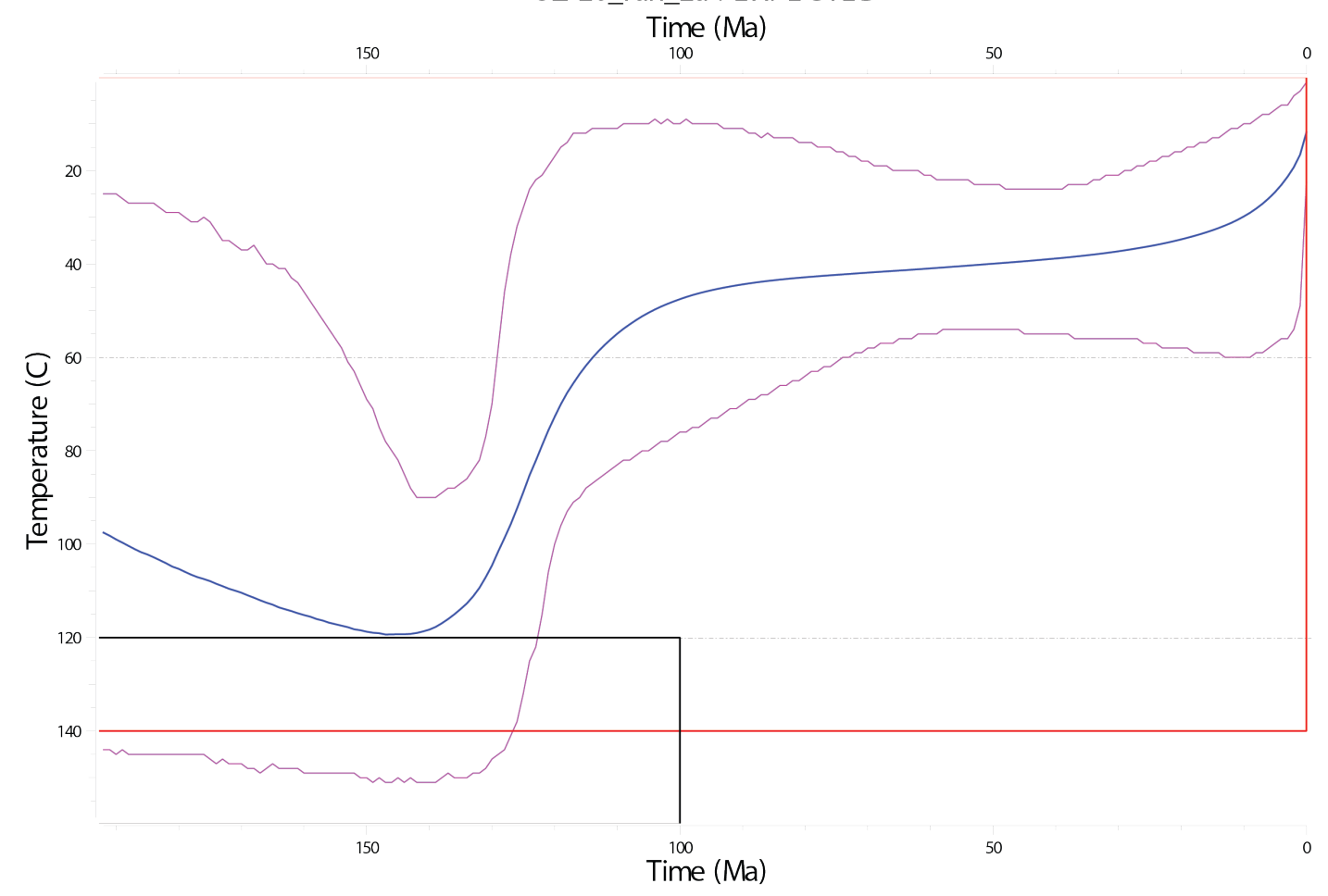




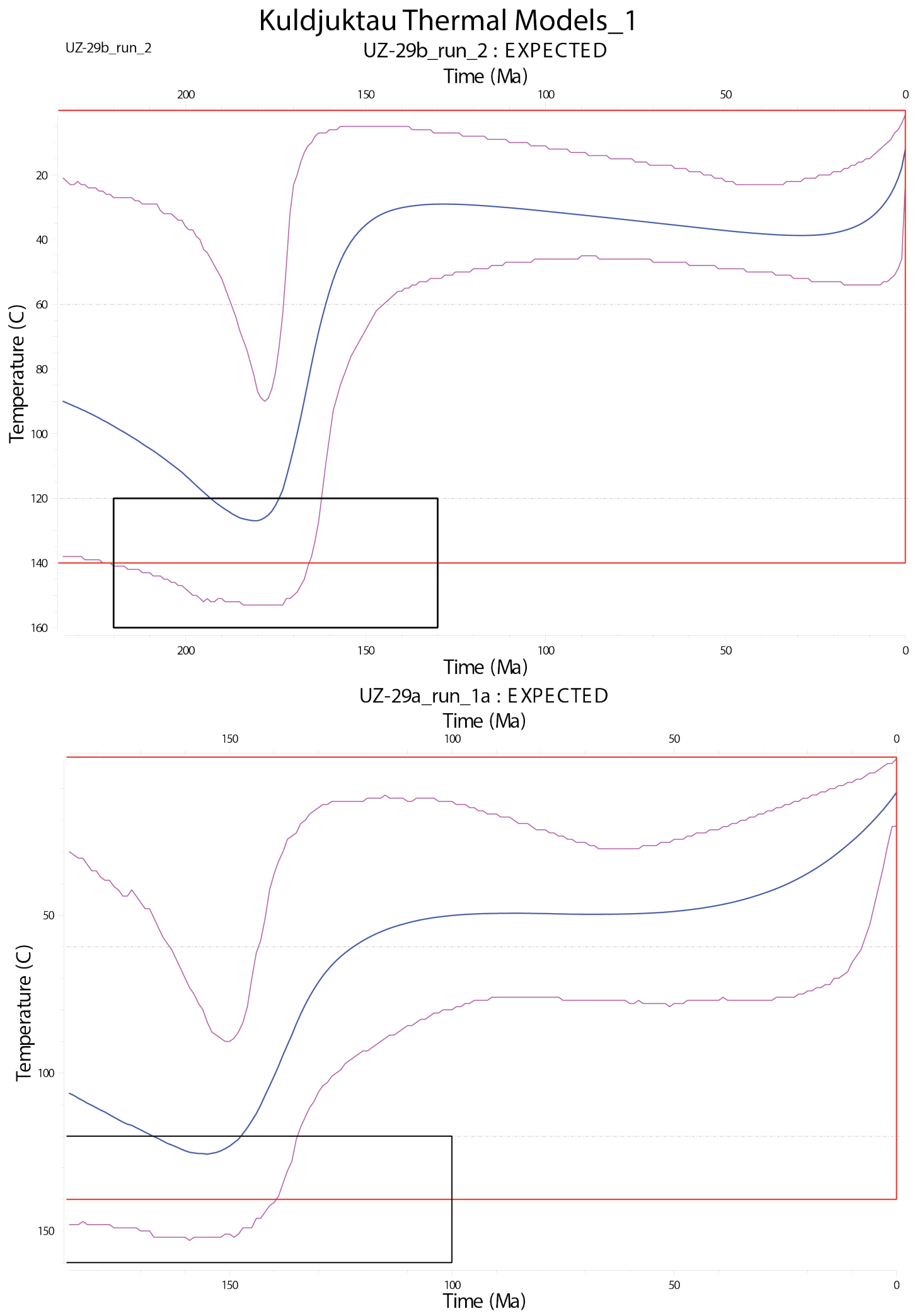


Kuldjuktau Thermal Models_2
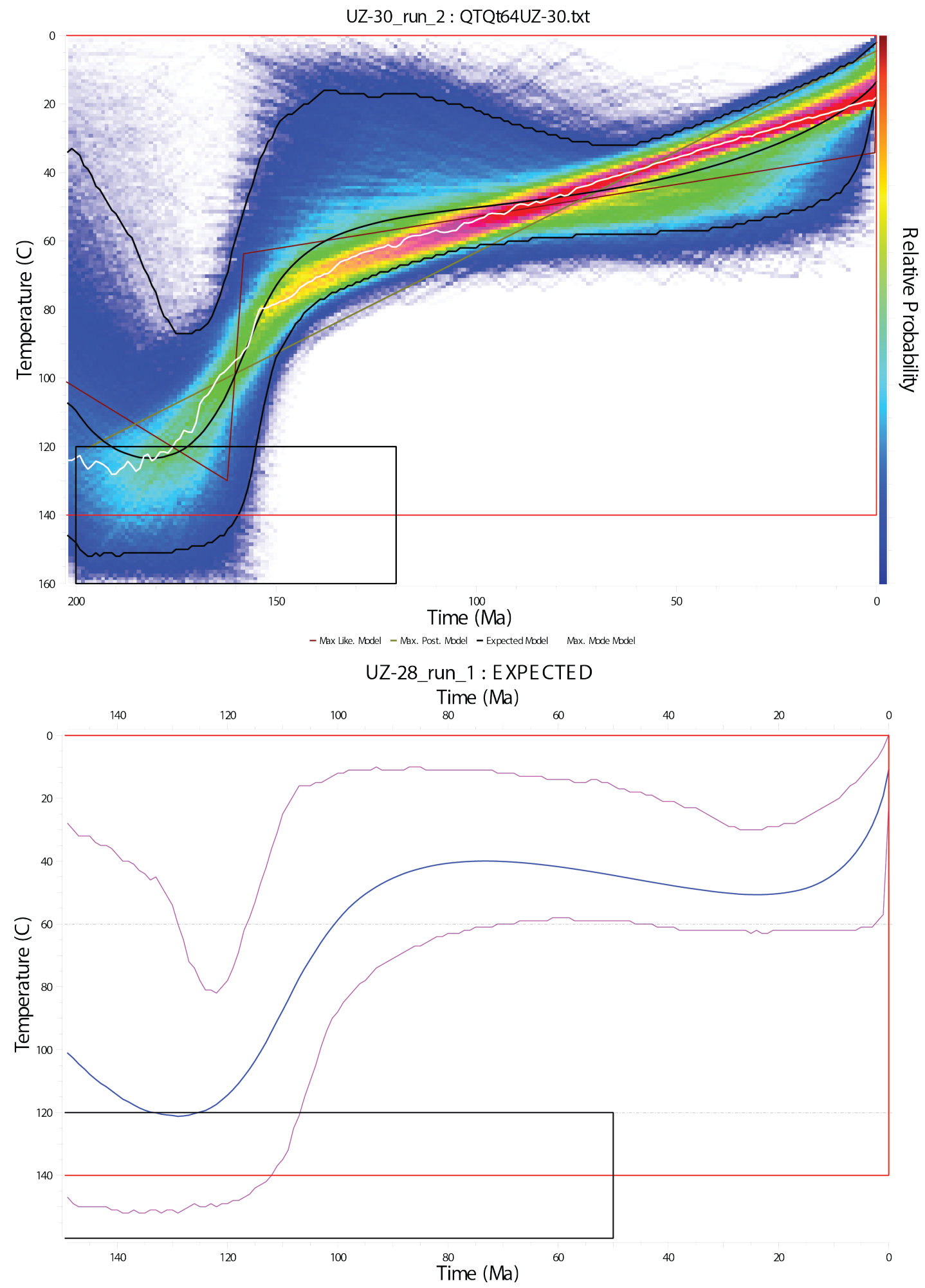


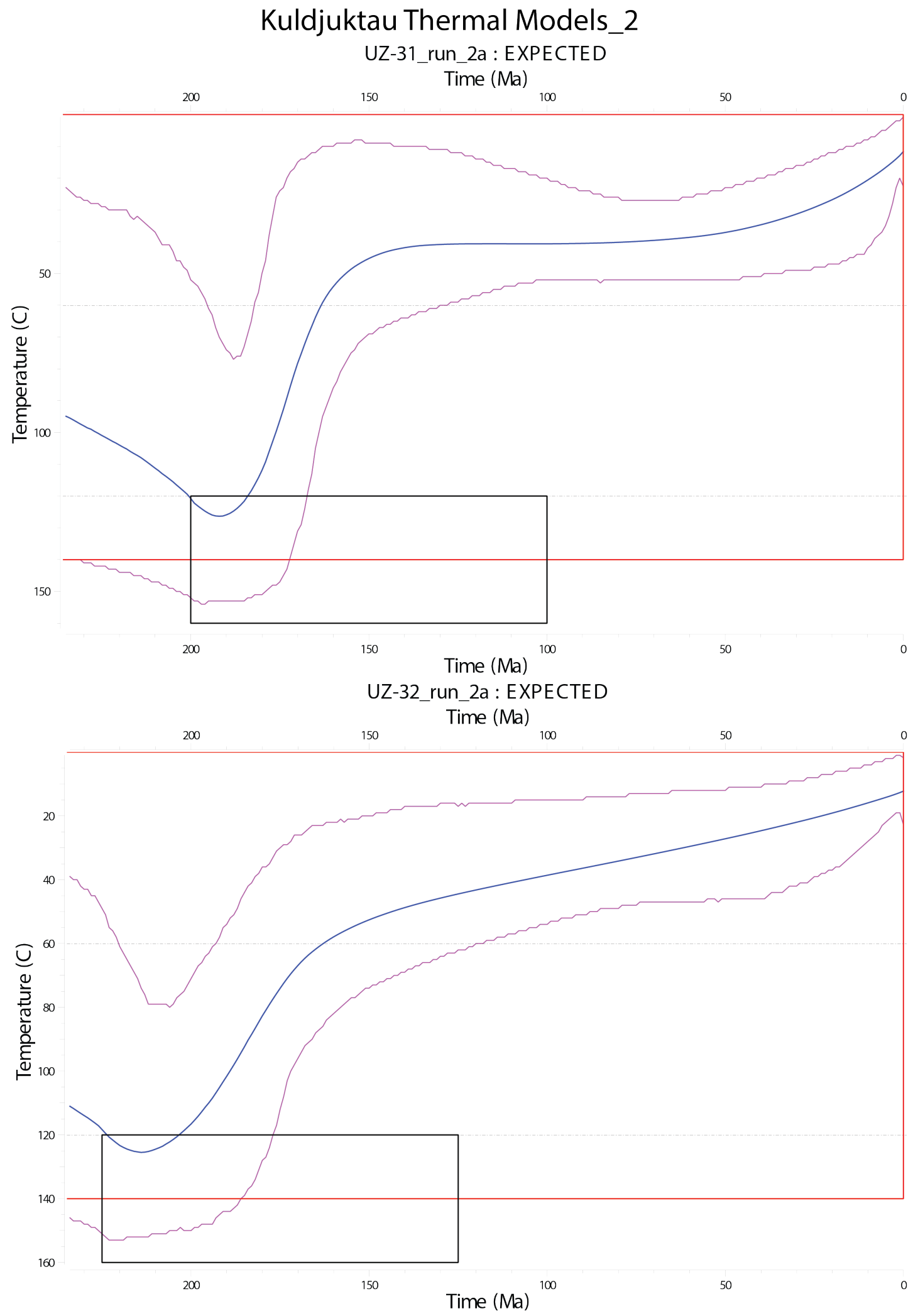




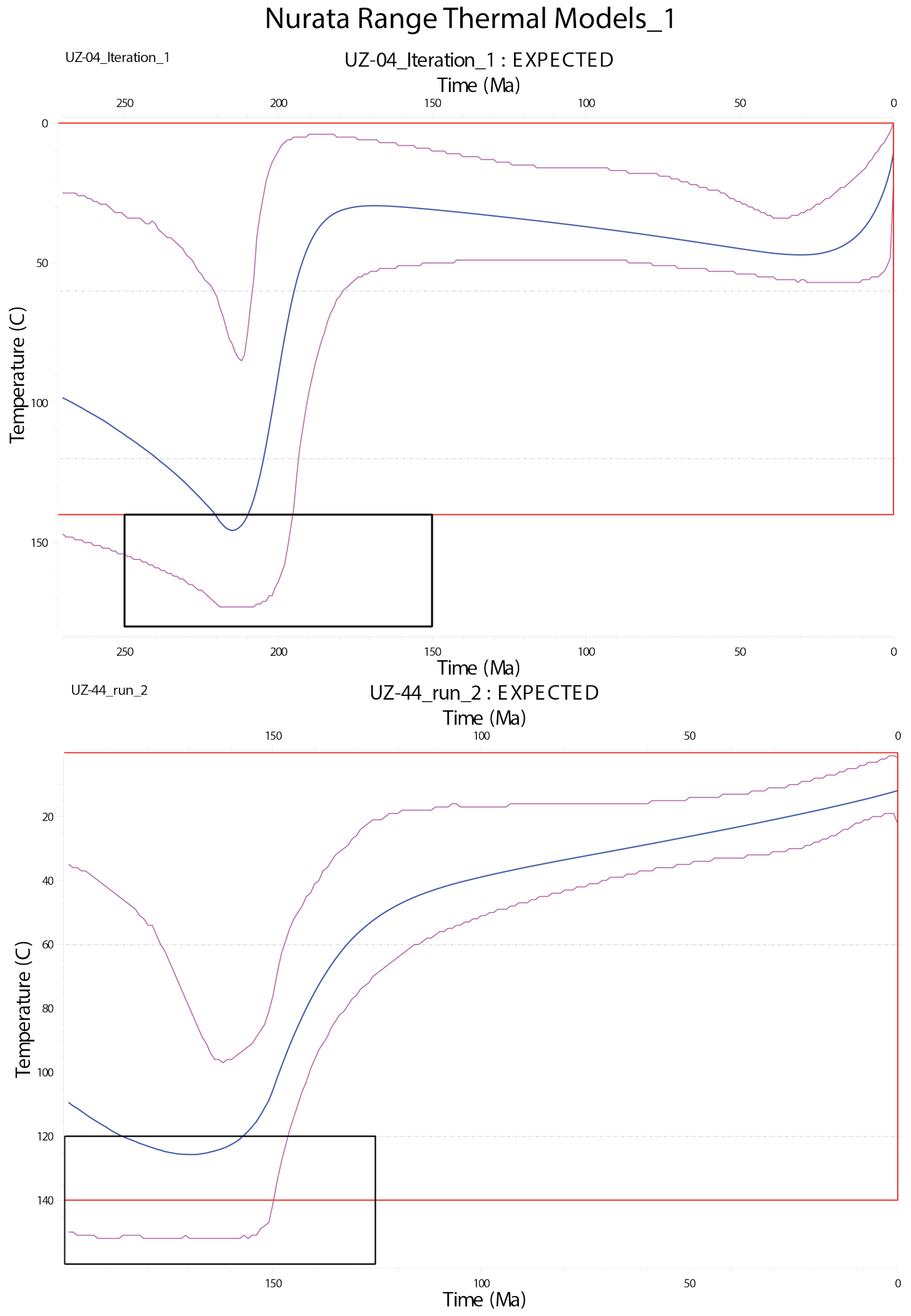



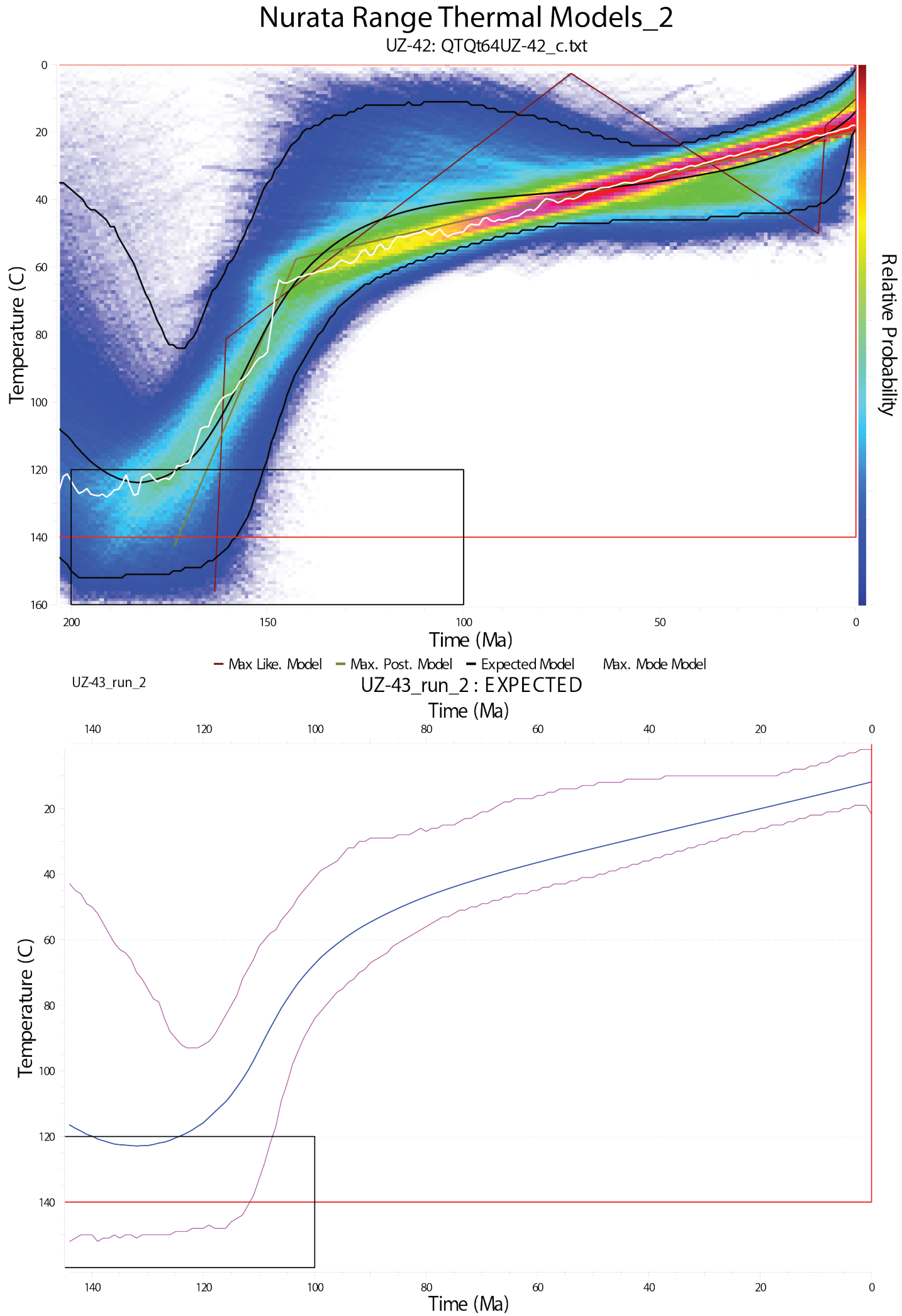
UZ-02_run_2

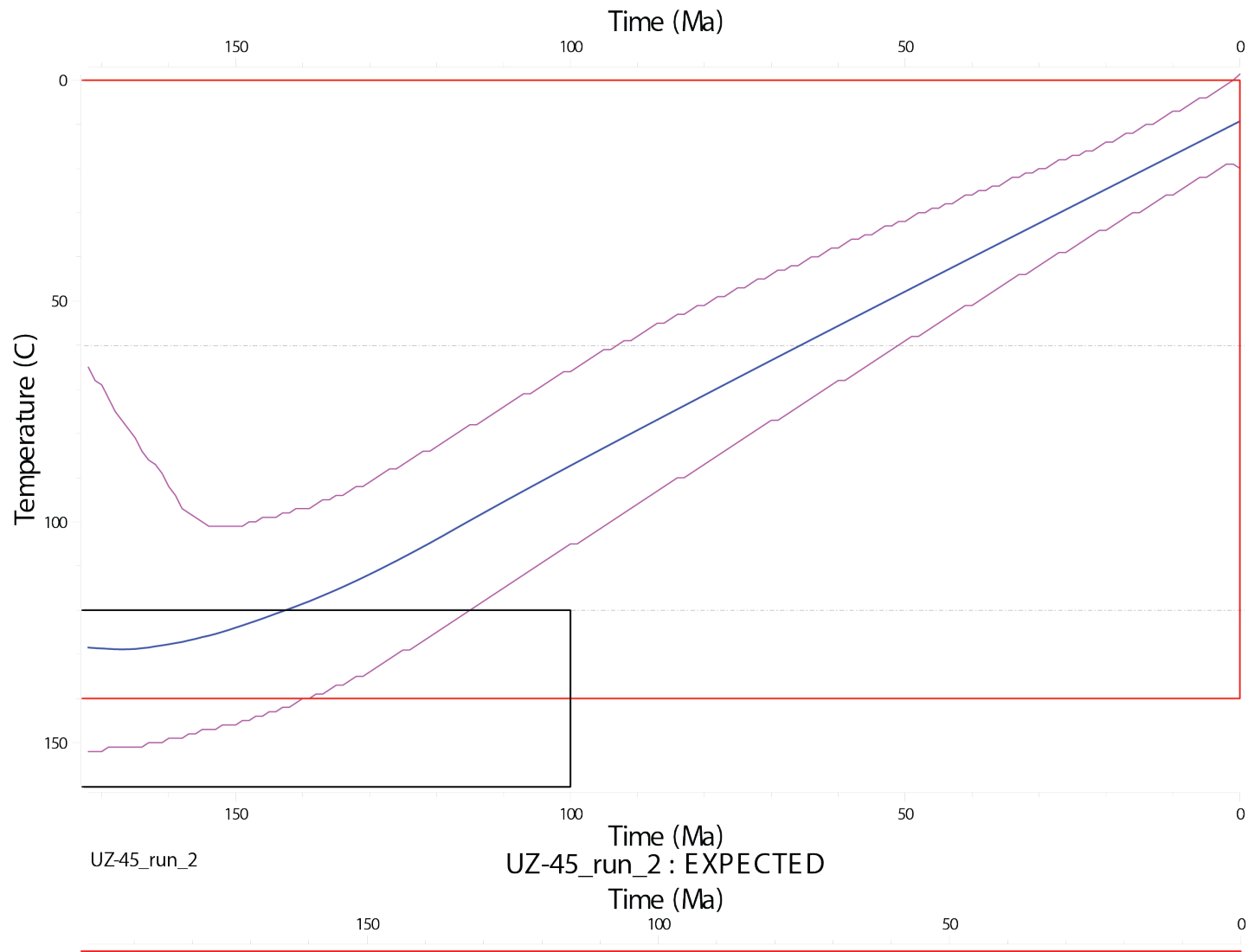

UZ-02_run_2: EXPECTED

Time (Ma)

Nurata Range Thermal Models_3

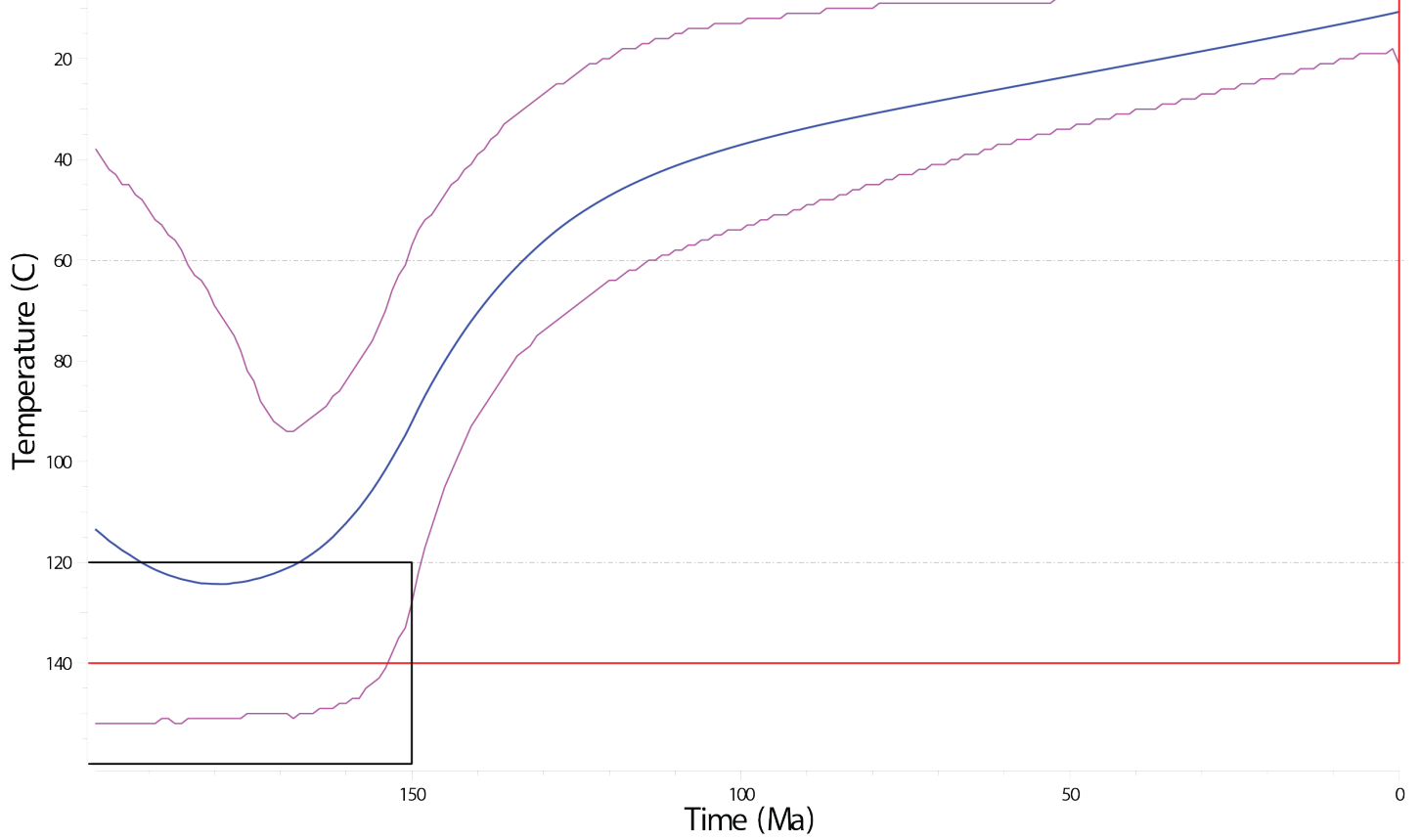




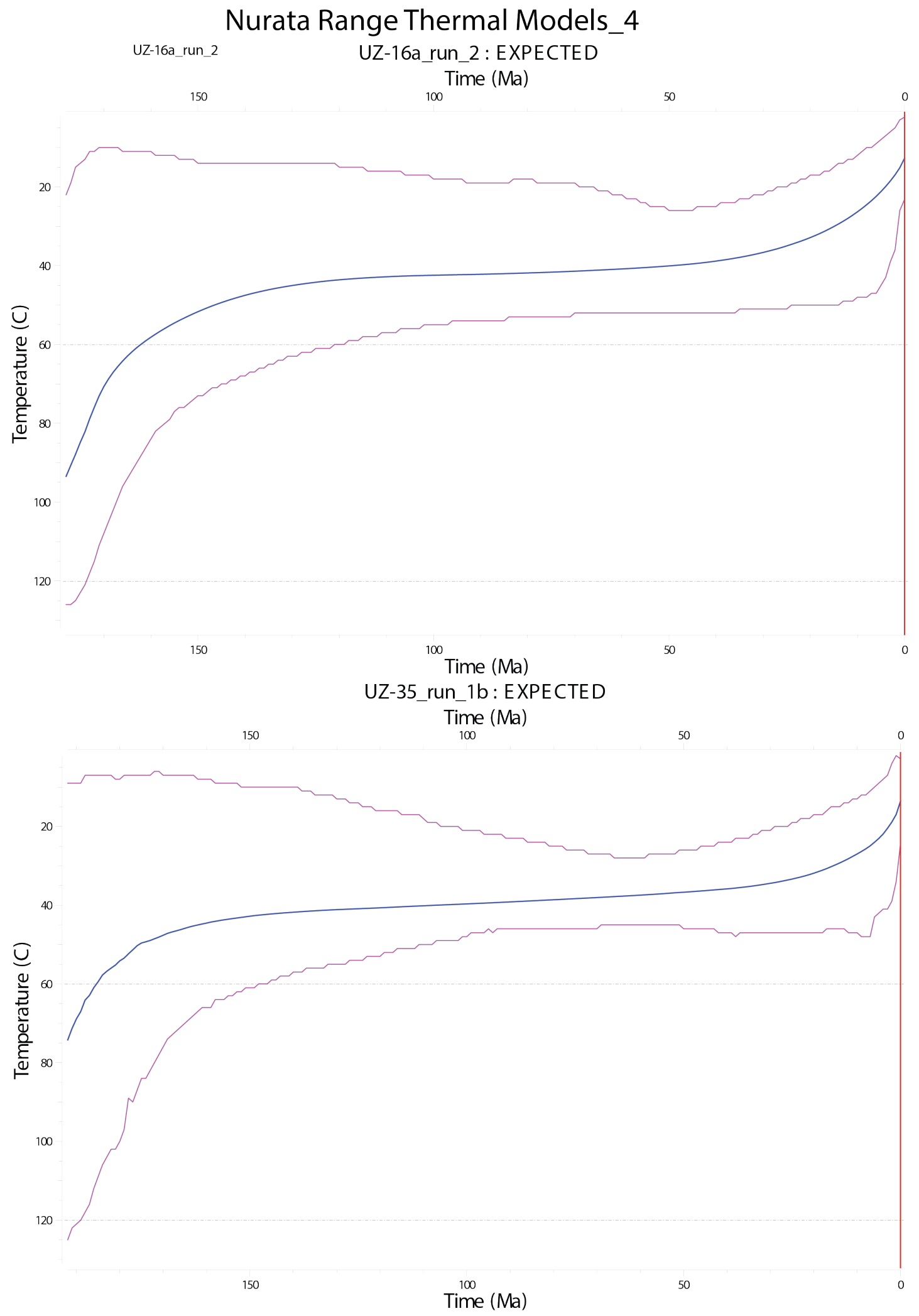


11

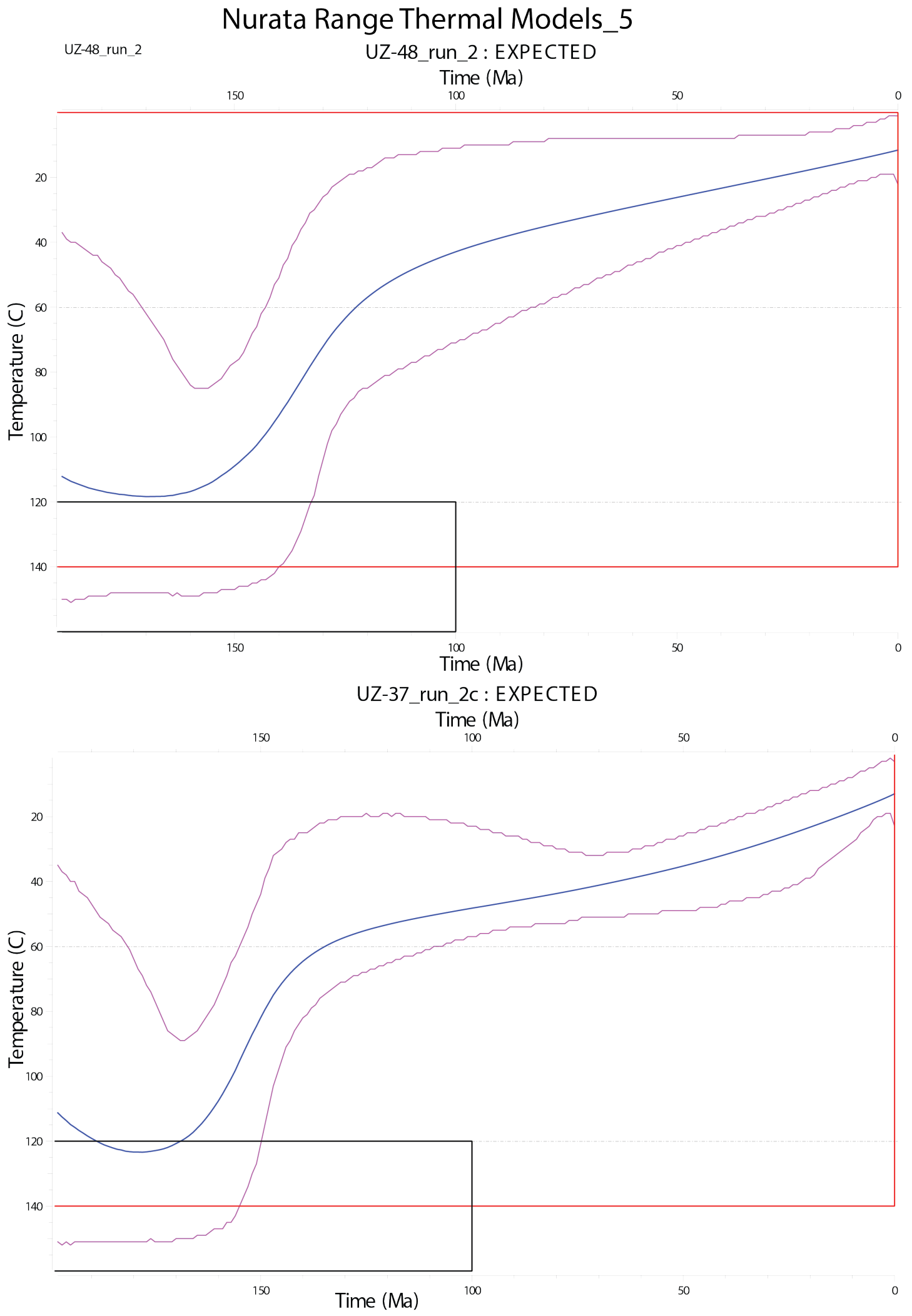




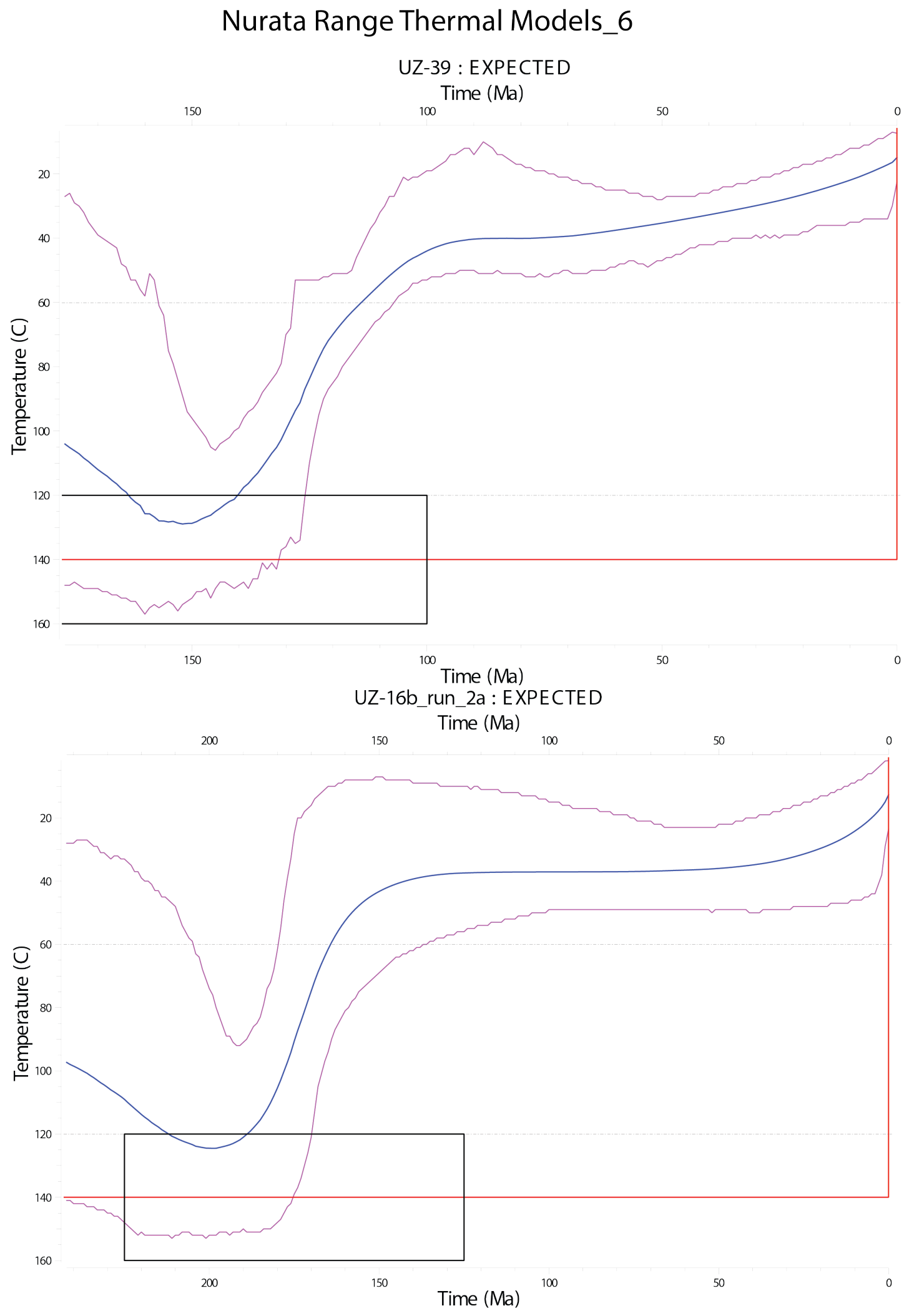




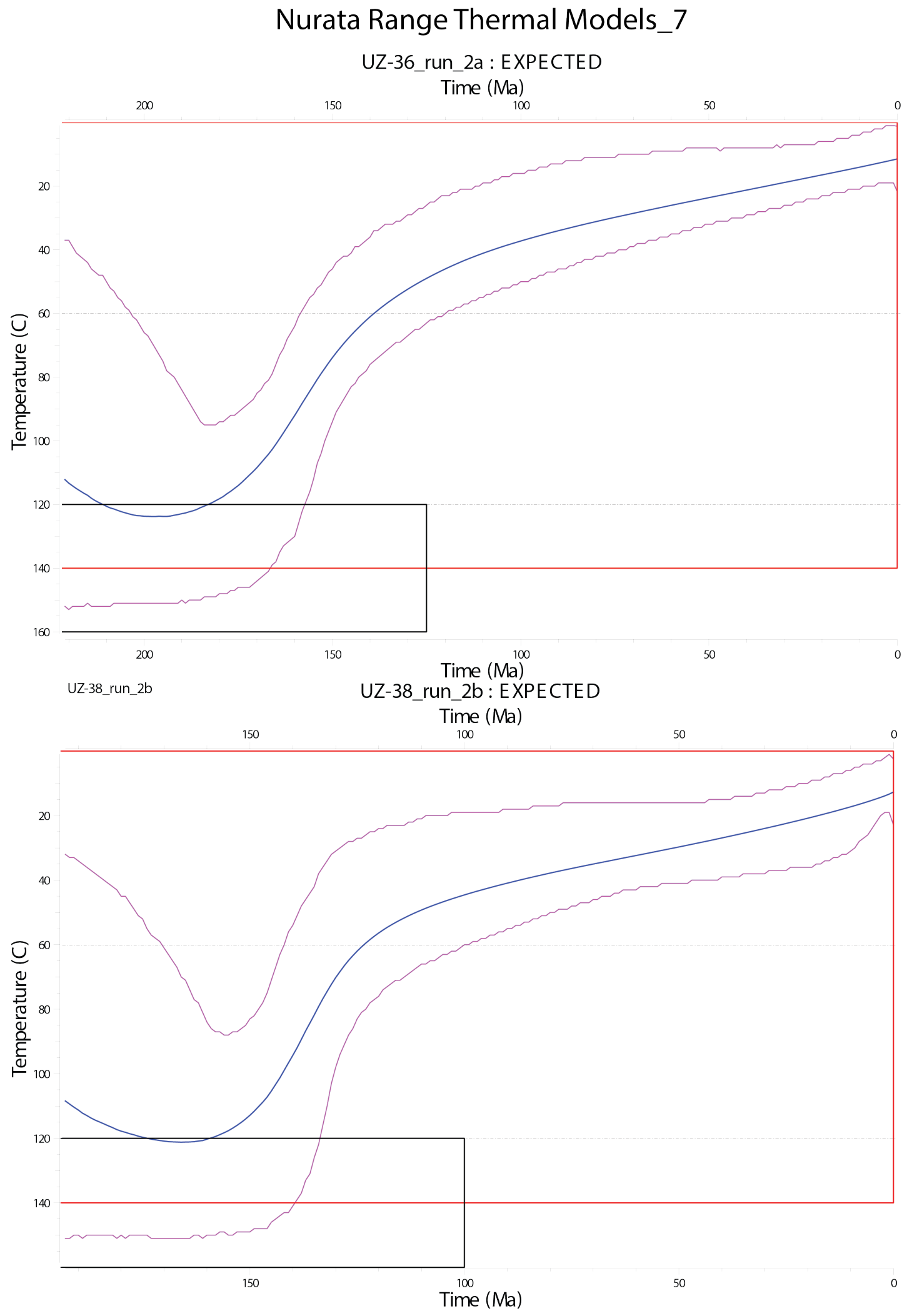




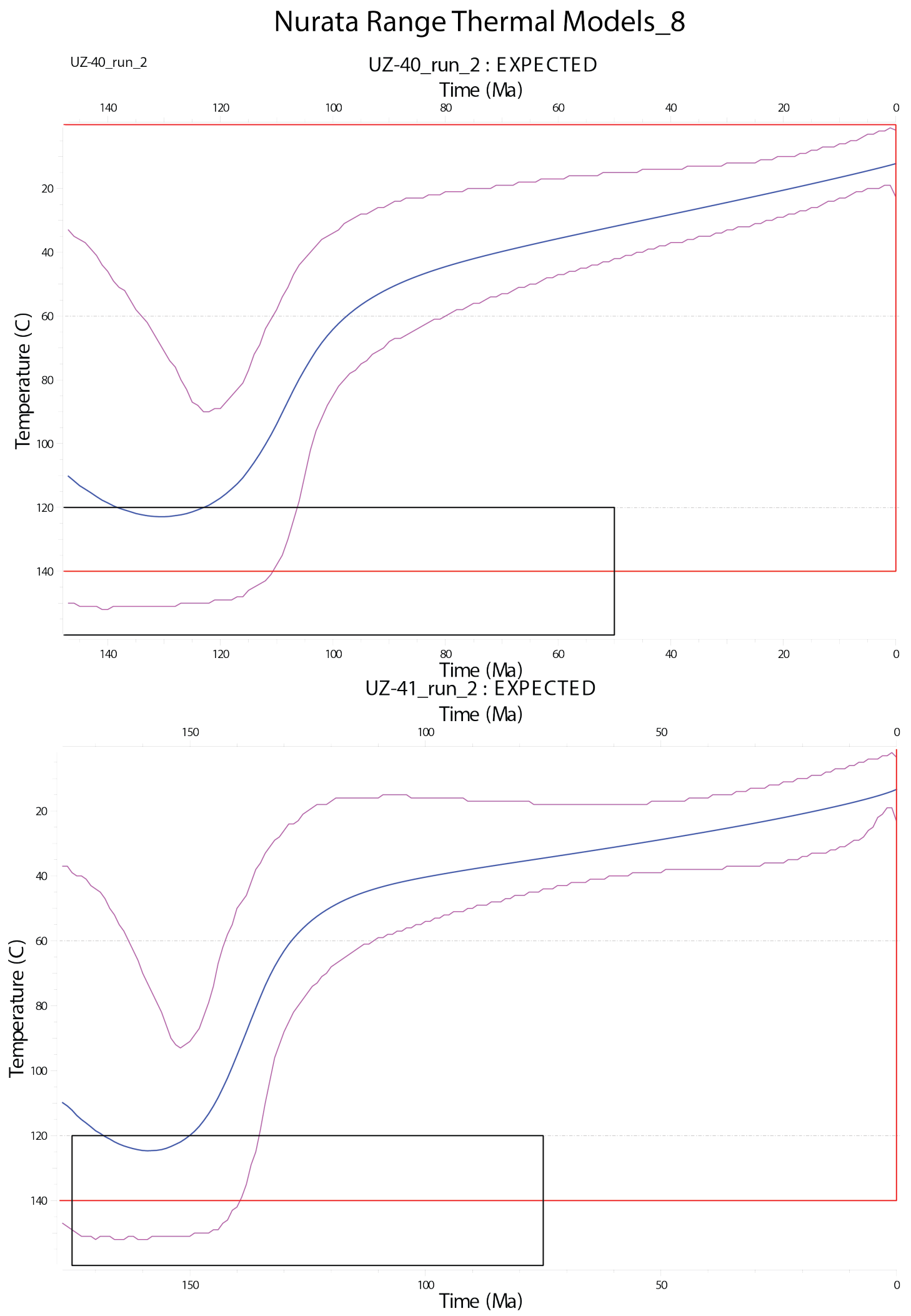


Nurata Range Thermal Models_9

UZ-15_run_2a : EXPECTED Time (Ma)

$100 \quad 50$

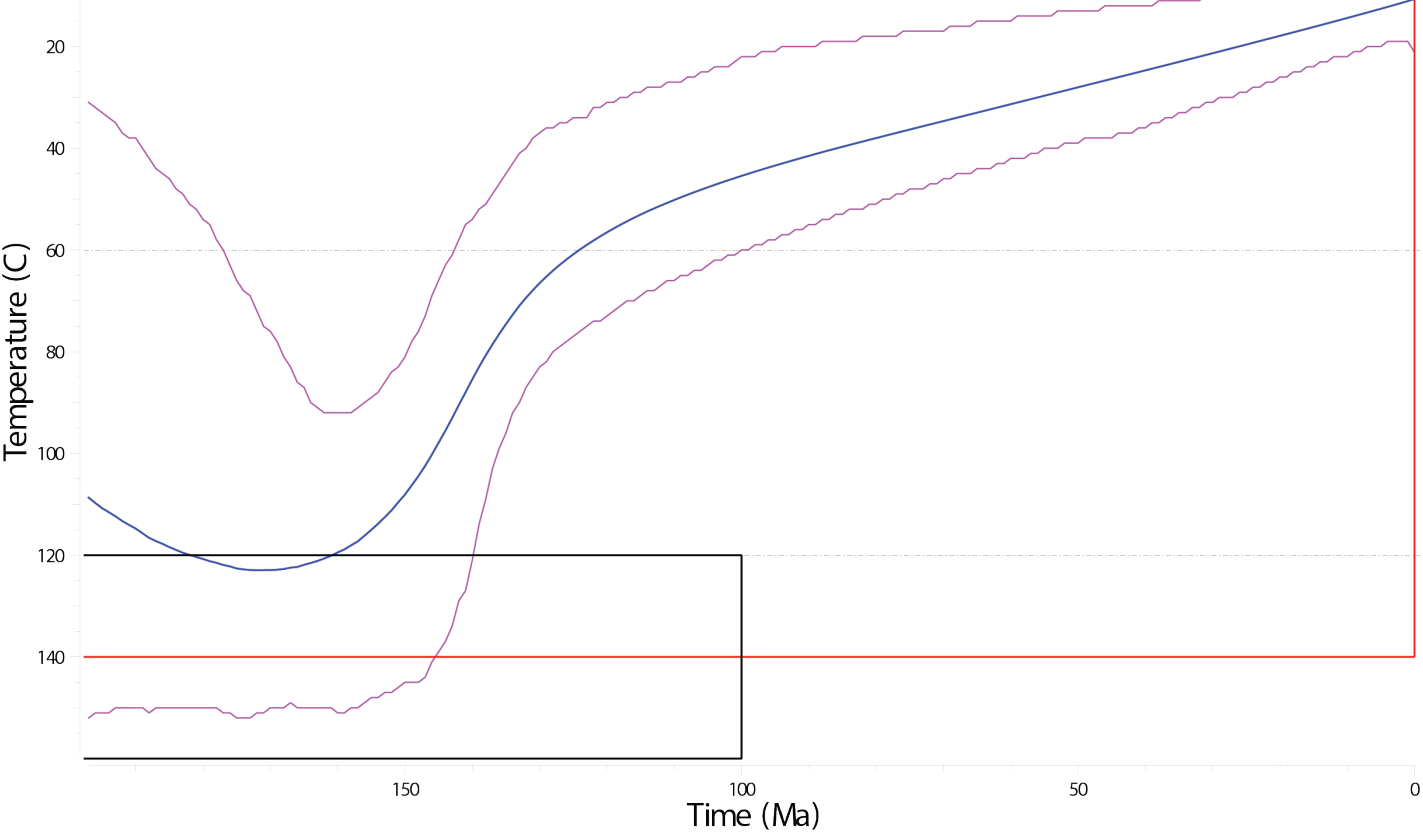




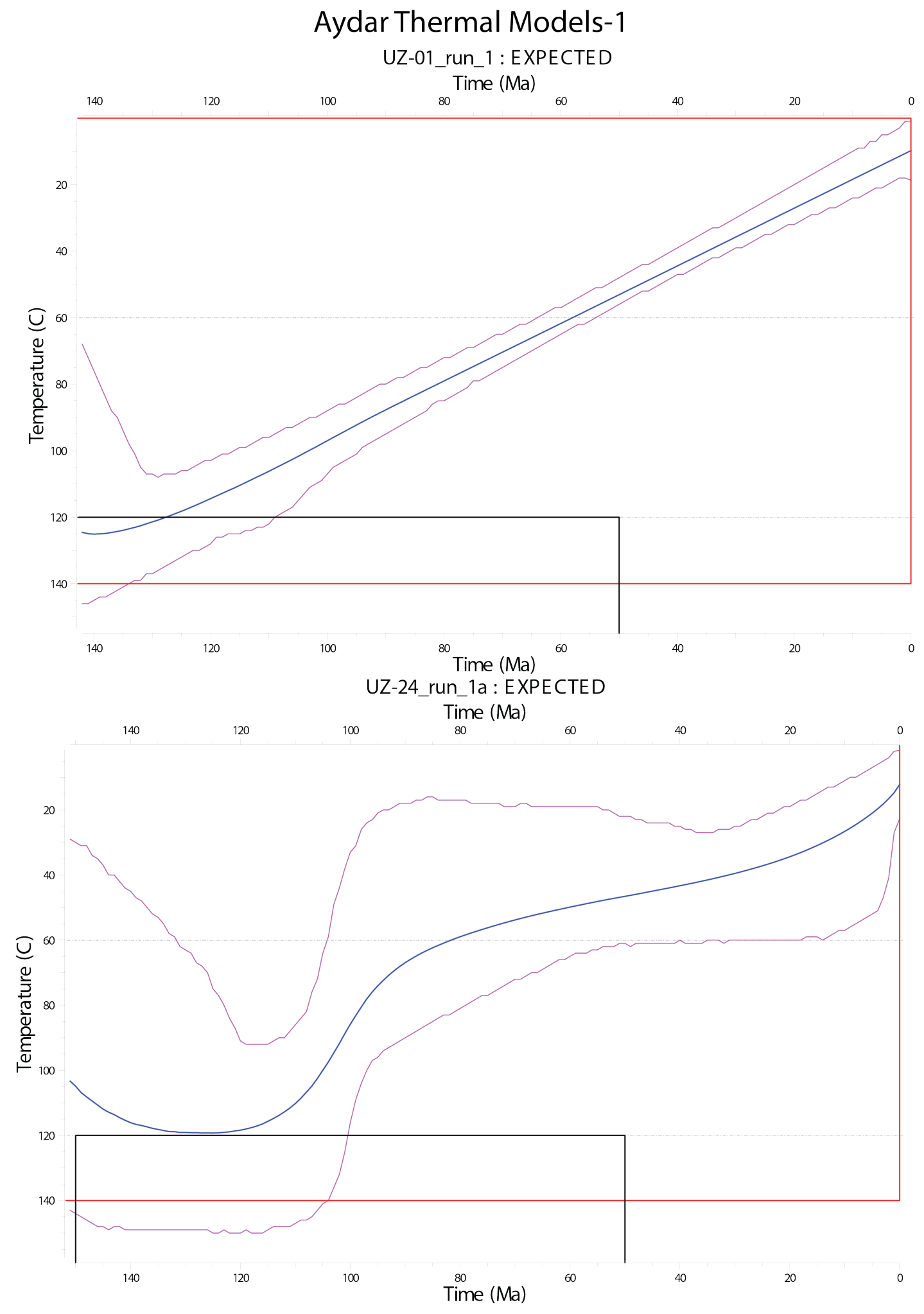




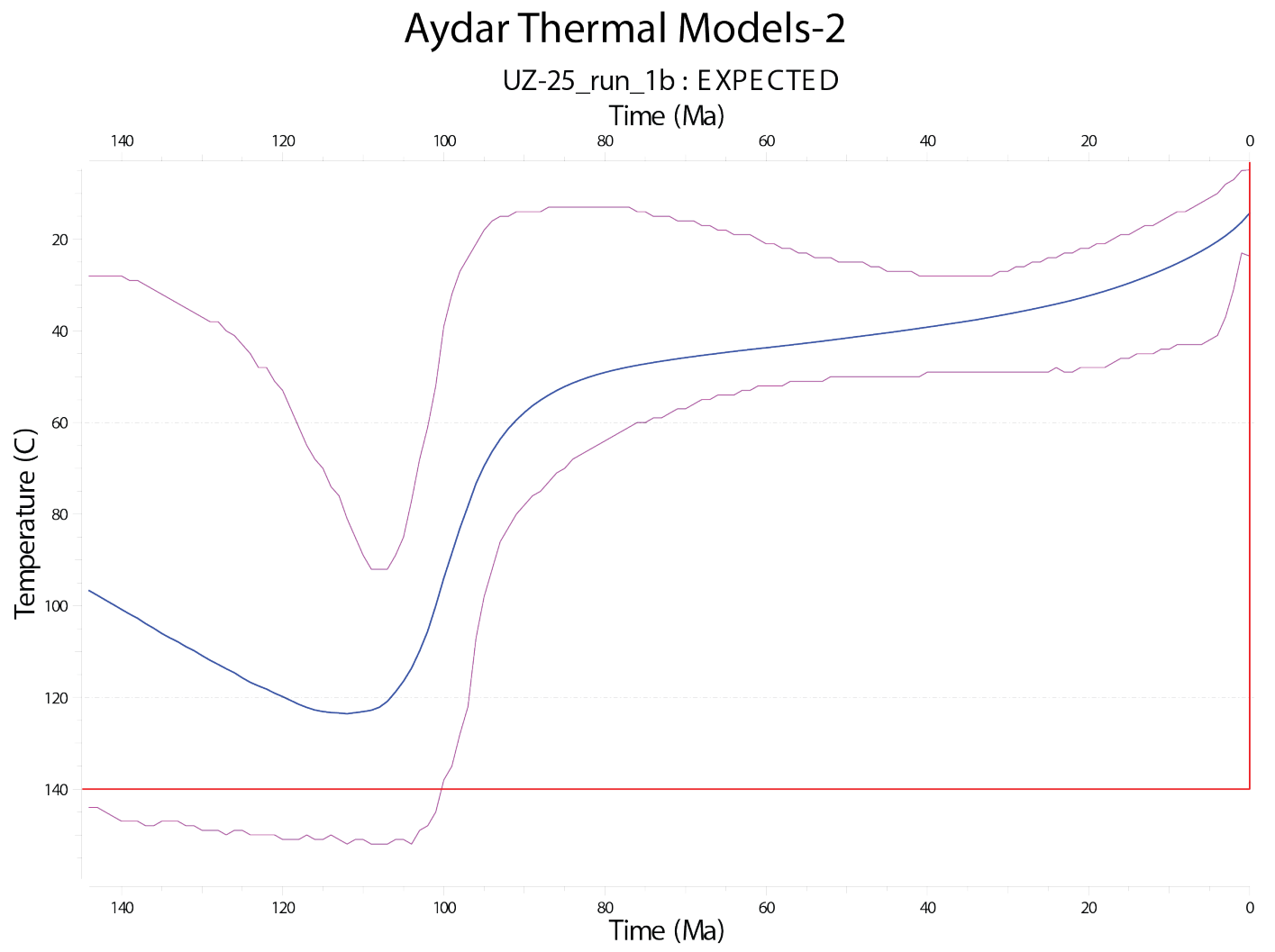



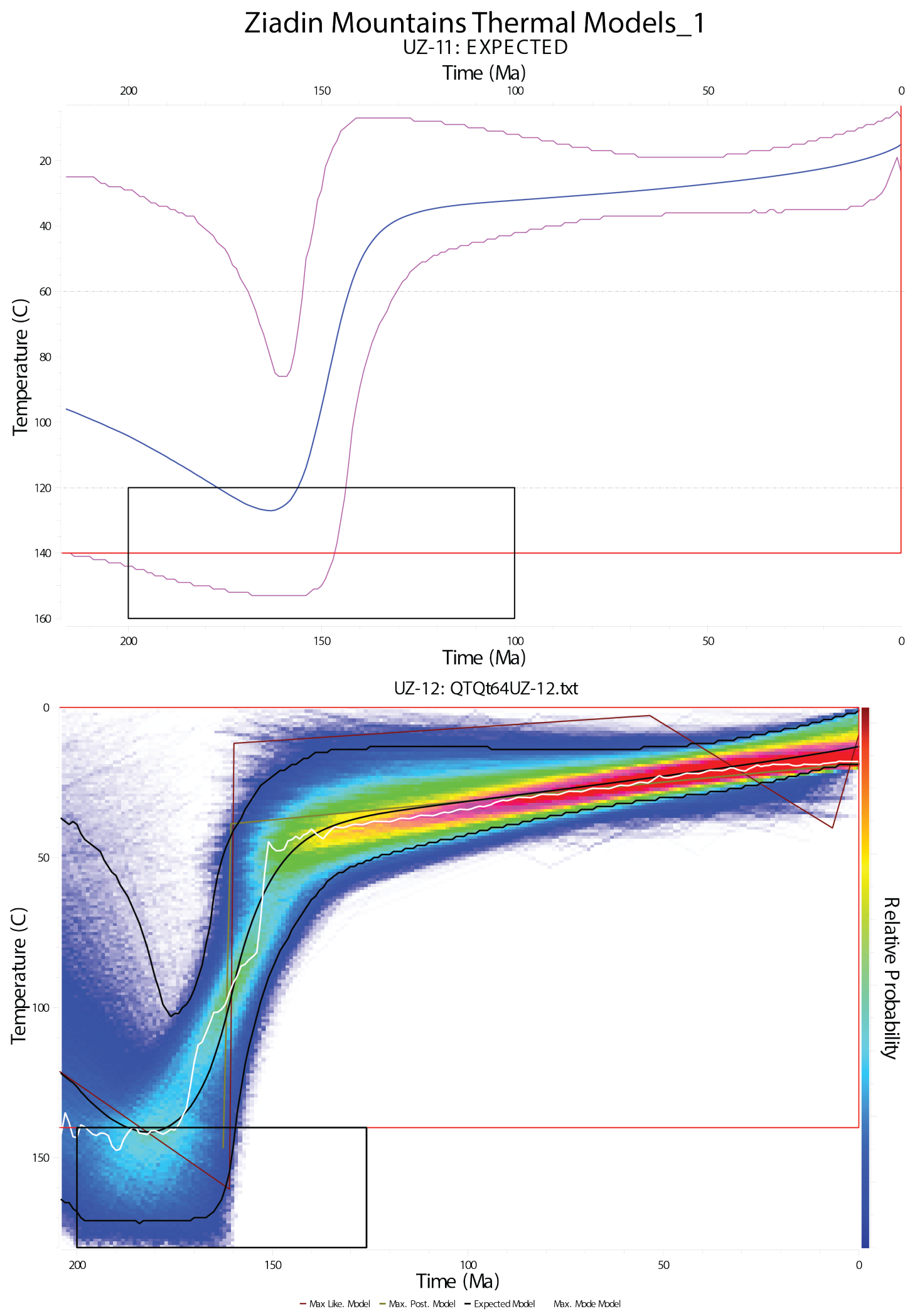


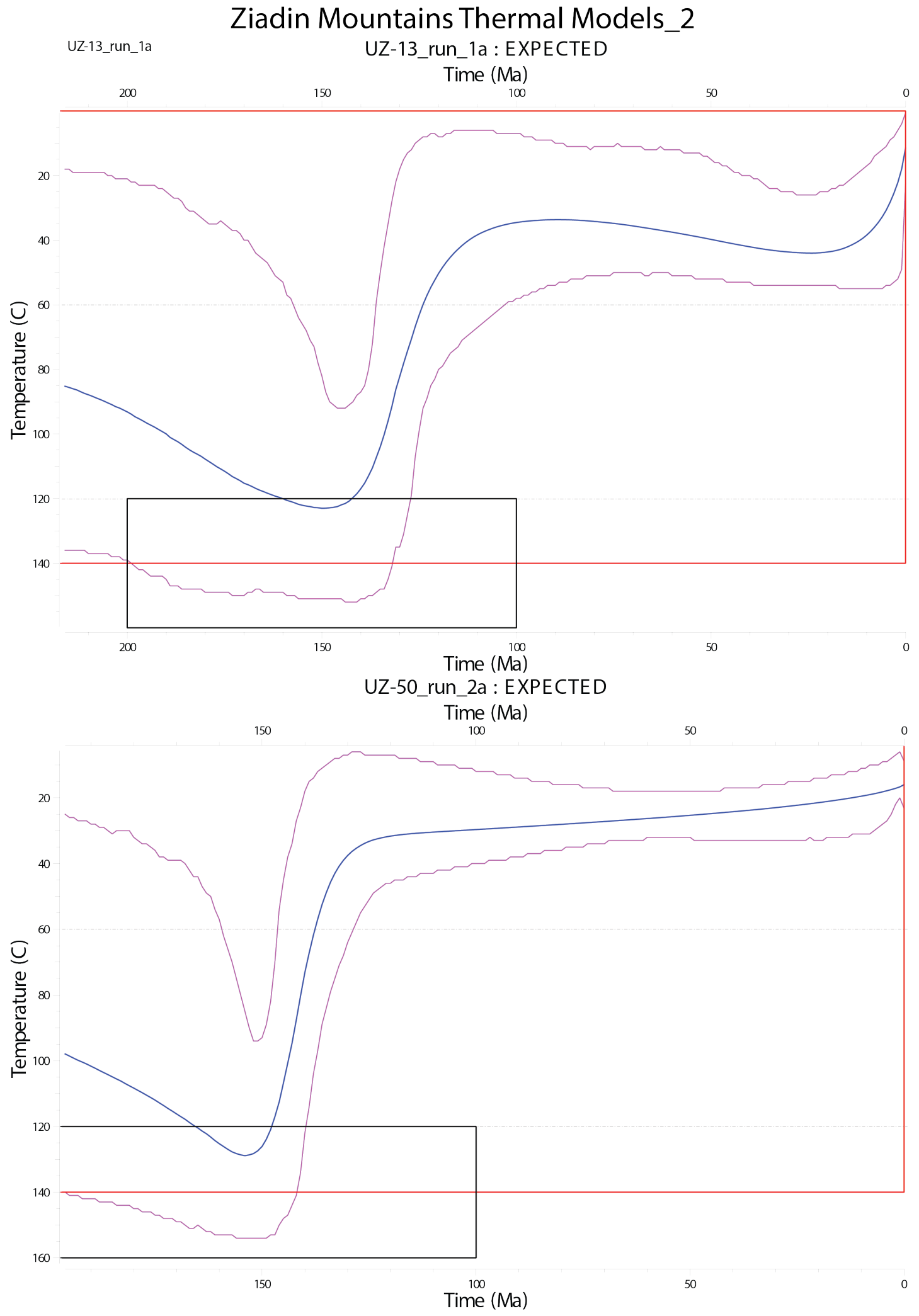




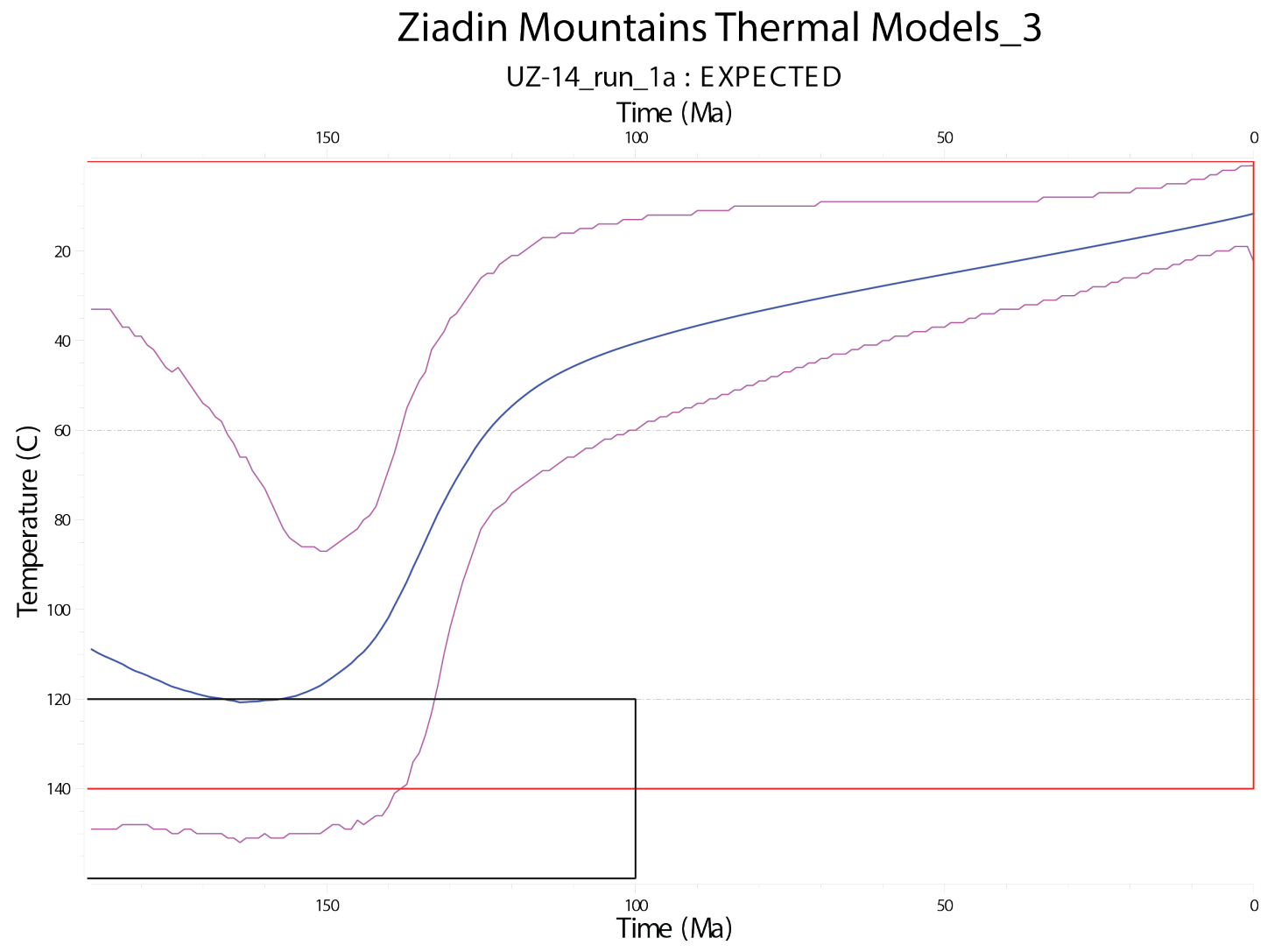




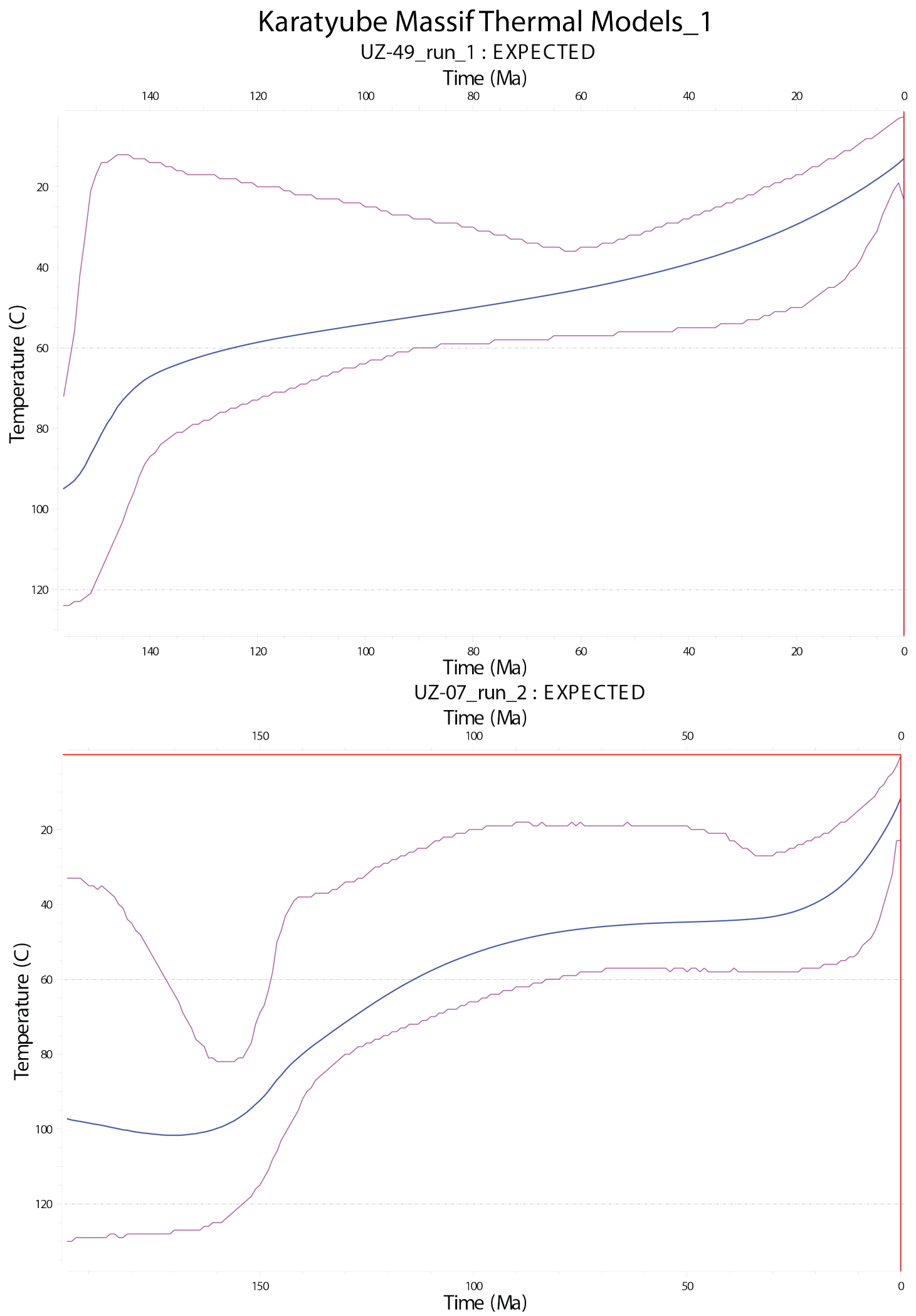




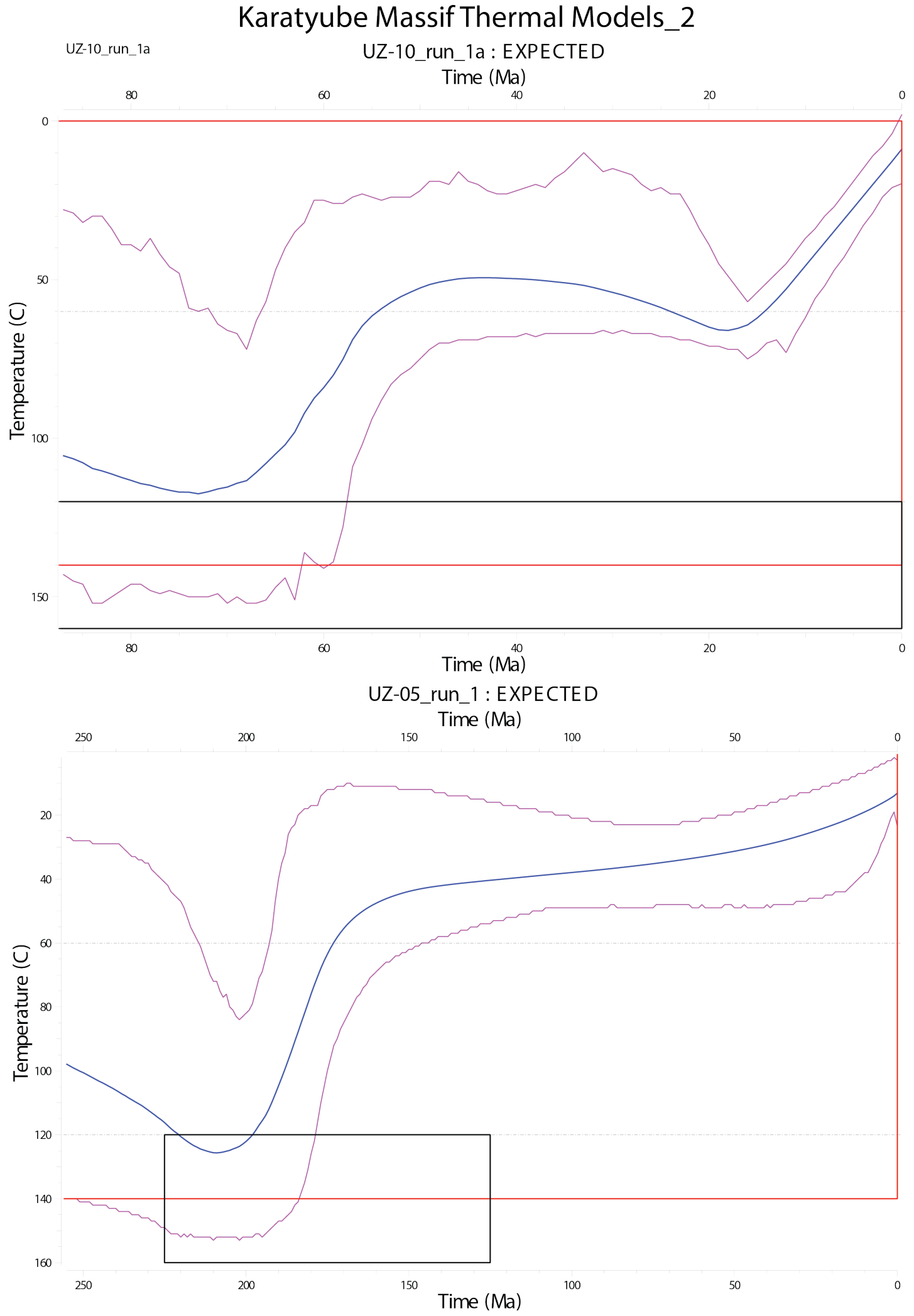



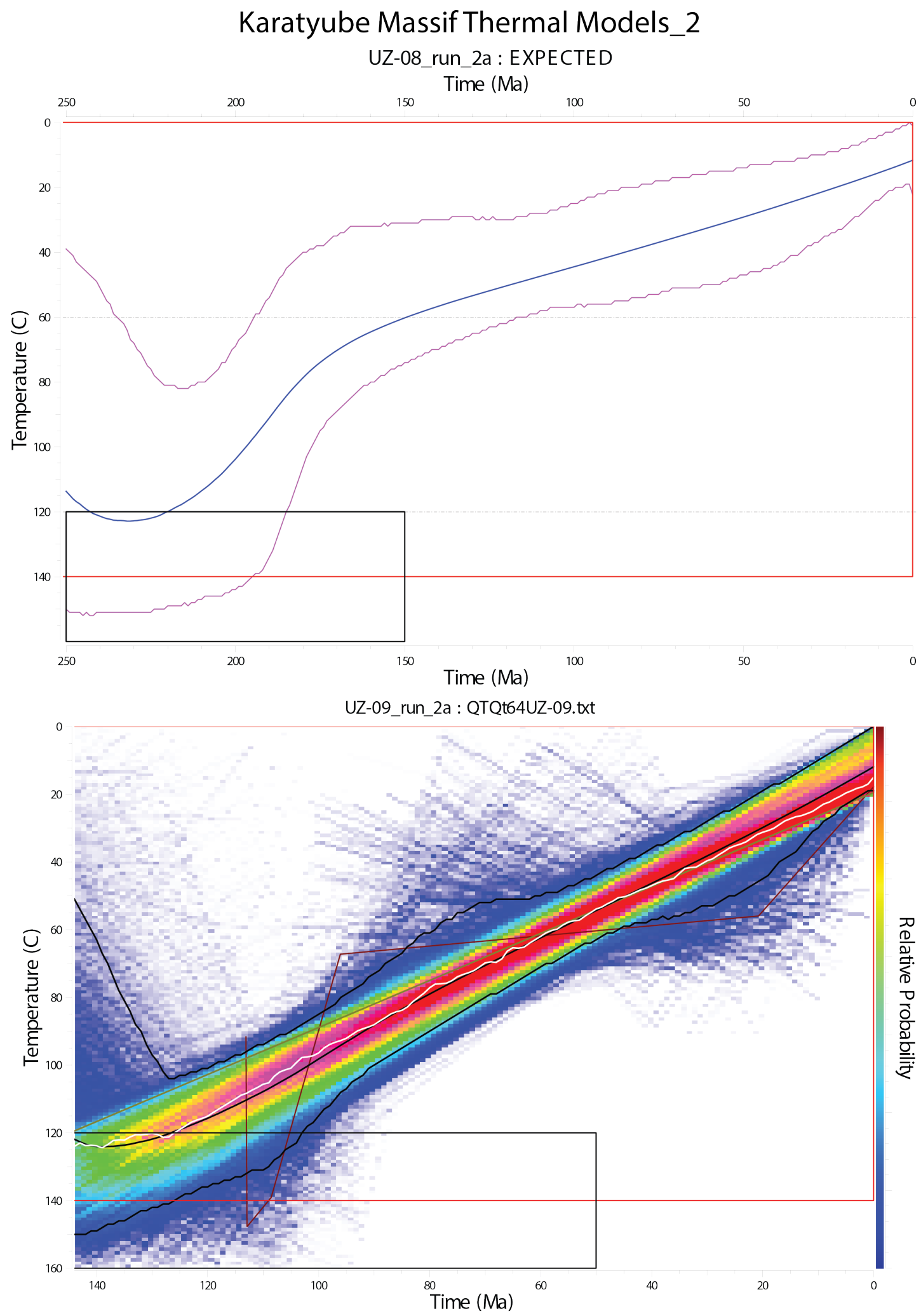

\subsection{Supplementary File 4}

Thermal history modelling parameters following Flowers et al. (2015). 
Supplementary File 5: Thermal history model input table for simulations of the Kyzylkum-Nurata Segment, Uzbekistan and Tajikistan, based on framework established by Flowers et al. (2015)

1. Thermochronologic Data

Samples and data used in simulations

\begin{tabular}{lcccc}
\hline \multicolumn{2}{c}{ Simulation inputs } & \multicolumn{1}{c}{ Data Source } & All data \\
\hline Sample Region & AHe & AFT & & \\
\hline Bukantau & & & & yes \\
UZ-19 & & $\times$ & Supplementary File 1 and 4 & yes \\
UZ-20 & $\times$ & Supplementary File 1 and 4 & yes \\
UZ-21 & $\times$ & $\times$ & Table 2 and Supplementary File 1 and 4 & yes \\
UZ-22 & & $\times$ & Supplementary File 1 and 4 & yes \\
UZ-23 & & $\times$ & Supplementary File 1 and 4
\end{tabular}

Kuldjuktau

UZ-28

UZ-29a

$U Z-29 b$

UZ-30

UZ-31

UZ-32

$\times \quad$ Supplementary File 1 and $4 \quad$ yes

$\times \quad$ Supplementary File 1 and $4 \quad$ yes

$\times \quad$ Supplementary File 1 and $4 \quad$ yes

$\times \quad$ Supplementary File 1 and $4 \quad$ yes

$x \quad$ Supplementary File 1 and $4 \quad$ yes

$\times \quad$ Supplementary File 1 and $4 \quad$ yes

\section{Nurata Range}

UZ-02

UZ-04

UZ-15

UZ-42

UZ-43

UZ-44

UZ-16a

$U Z-16 b$

UZ-35

UZ-36

UZ-37

UZ-38

UZ-39

$\times$

UZ-40

UZ-41

UZ-48

$x$

Tymski

UZ-11

UZ-12

UZ-13

UZ-14

UZ-50

$\times \quad$ Supplementary File 1 and $4 \quad$ yes

$\times \quad$ Supplementary File 1 and 4 yes

$\times \quad$ Supplementary File 1 and 4 yes

$\times \quad$ Supplementary File 1 and 4 yes

$\times \quad$ Supplementary File 1 and 4 yes

$\times \quad$ Supplementary File 1 and 4 yes

$\times \quad$ Supplementary File 1 and 4 yes

$\times \quad$ Supplementary File 1 and 4 yes

$\times \quad$ Supplementary File 1 and 4 yes

$\times \quad$ Supplementary File 1 and 4 yes

$\times \quad$ Supplementary File 1 and 4 yes

$\times \quad$ Supplementary File 1 and 4 yes

$\times \quad$ Table 2 and Supplementary File 1 and 4 yes

$\times \quad$ Supplementary File 1 and 4 yes

$\times \quad$ Supplementary File 1 and 4 yes

$\times \quad$ Supplementary File 1 and 4 yes

Syr Darya

UZ-01

Table 2 and Supplementary File 1 and 4

yes

UZ-24

$\times \quad$ Supplementary File 1 and 4 
Gissar

UZ-05

UZ-07

UZ-08

UZ-10

UZ-49

$\times$

$\times \quad$ Supplementary File 1 and 4 yes

$\times \quad$ Supplementary File 1 and 4 yes

$\times \quad$ Supplementary File 1 and 4 yes

$\times \quad$ Table 2 and Supplementary File 1 and 4 yes

$\times \quad$ Supplementary File 1 and 4 yes

\section{Data treatment, uncertainties, and other relevant constraints}

AHe Data

He dates (Ma): Single grain AHe ages were from Supplementary File 2 modelled individually

Error (Ma) applied in modeling: error of $1 \sigma$ was used from Supplementary file 1

$r(\mu \mathrm{m})$ : Equivalent spherical radius of each grain

AFT data

$\mathrm{Cl}$ wt\%: From Supplementary file 1

Lengths: Length data for all samples is available in Supplementary File 4

Initial mean track length: $16.3 \mu \mathrm{m}$

Track length reduction standard: 0.893

\section{Additional geological information}

Assumption Explaination and data source

As all the samples were granitoid and there was no evidence for re-heating. Samples we assumed to have come from $>120^{\circ} \mathrm{C}$ through the APAZ

3. System- and model-specific parameters

He radiation damage model : Flowers et al. 2009

FT annealing model : Ketcham et al. 2007

FT c-axis projection : Not used

Modeling code : QTQt 5.6.0 PC

Statistical fitting criteria : Default QTQt values

MCMC Parameters : Burn-in $=200,000$, Post-burn-in $=200,000$ 